\title{
5 MODELAGEM BIM DE INFRAESTRUTURA URBANA A PARTIR DE iau usp LEVANTAMENTOS AÉREOS COM DRONE
}

JÚLIO CÉSAR FRANCO JÚNIOR

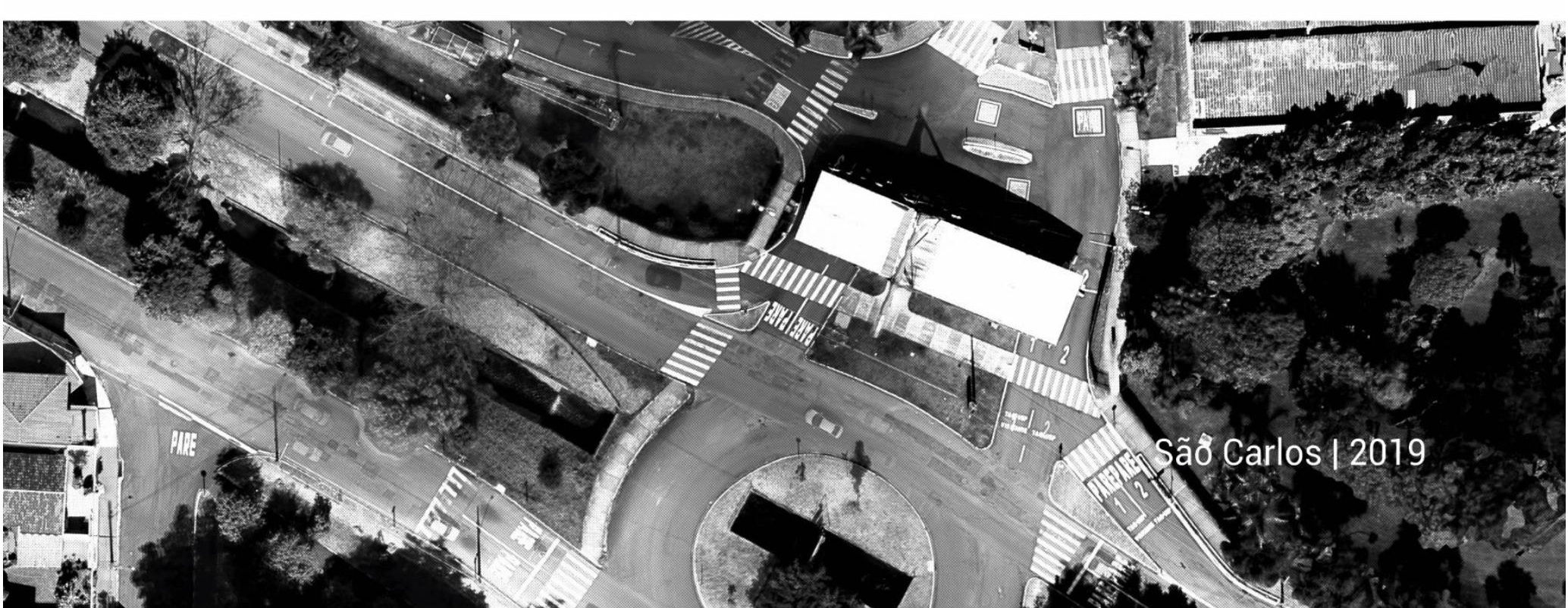



JÚLIO CÉSAR FRANCO JÚNIOR

\section{MODELAGEM BIM DE INFRAESTRUTURA URBANA A PARTIR DE LEVANTAMENTOS AÉREOS COM DRONE}

Dissertação apresentada ao Instituto de Arquitetura e Urbanismo da Universidade de São Paulo, como parte dos requisitos para obtenção do título de Mestre em Ciências.

Área de concentração

Arquitetura, Urbanismo e Tecnologia

Orientador

Prof. Dr. Márcio Minto Fabrício

O presente trabalho foi realizado com apoio da Coordenação de Aperfeiçoamento de Pessoal de Nível Superior - Brasil (CAPES) - Código de Financiamento 1760514 e Fundação de Amparo à Pesquisa do Estado de São Paulo - FAPESP. Processo $n^{\circ}$ 2017/24896-4.

Versão Corrigida 


\section{AUTORIZO A REPRODUCAO TOTAL OU PARCIAL DESTE TRABALHO, POR QUALQUER MEIO CONVENCIONAL OU ELETRONICO, PARA FINS DE ESTUDO E PESQUISA, DESDE QUE CITADA A FONTE}

Ficha catalográfica elaborada pela Biblioteca do Instituto de Arquitetura e Urbanismo com os dados fornecidos pelo(a) autor(a)

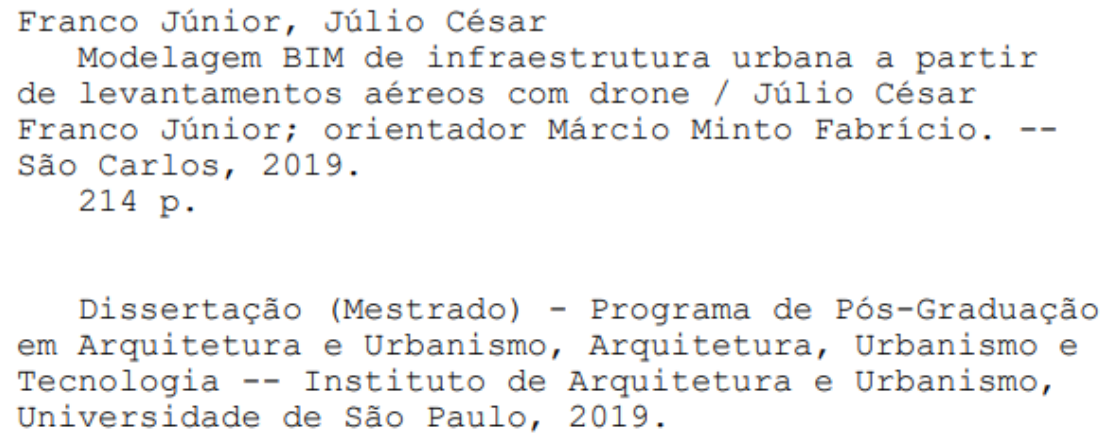

1. BIM. 2. Infraestrutura urbana. 3. Aerofotogrametria. 4. Aeronaves remotamente pilotadas. 5. Aeronaves não tripuladas. I. Minto Fabrício, Márcio, orient. II. Título. 
FRANCO JÚNIOR, J. C. MODELAGEM BIM DE INFRAESTRUTURA URBANA A PARTIR DE LEVANTAMENTOS AÉREOS COM DRONE. 214 p. Dissertação (Mestrado em Arquitetura e Urbanismo) - Instituto de Arquitetura e Urbanismo, Universidade de São Paulo, São Carlos, 2019 .

Data da defesa: 04 de dezembro de 2019

Orientador: Prof. Dr. Márcio Minto Fabrício

Ata de defesa

Ata de defesa de Dissertação do(a) Senhor(a) Júlio César Franco Júnior no Programa: Arquitetura e Urbanismo, do(a) Instituto de Arquitetura e Urbanismo da Universidade de São Paulo.

Aos 04 dias do mês de dezembro de 2019, no(a) Sala de Pós-Graduação 2, do IA realizou-se a Defesa da Dissertação do(a) Senhor(a) Júlio César Franco Júnior, apresentada para a obtenção do título de Mestre intitulada:

"Modelagem BIM de infraestrutura urbana a partir de levantamentos aéreos com drone"

Após declarada aberta a sessão, o(a) Sr(a) Presidente passa a palavra ao candidato para exposição e a seguir aos examinadores para as devidas arguições que se desenvolvem nos termos regimentais. Em seguida, a Comissão Julgadora proclama o resultado:

\begin{tabular}{|c|c|c|c|}
\hline Nome dos Participantes da Banca & Função & Sigla da CPG & Resultado \\
\hline Márcio Minto Fabricio & Presidente & IAU - USP & Não Votante \\
\hline Arivaldo Leão de Amorim & Titular & UFBA - Externo & AFROVADS \\
\hline Marcel Fantin & Titular & IAU - USP & \\
\hline Eloisa Dezen-kempter & Suplente & UNICAMP - Externo & Giado \\
\hline
\end{tabular}

Resultado Final: Hprovacho

Parecer da Comissão Julgadora *

Eu, Ana Paula Sampaio Fregona Ana vaule amfoie os(as) Senhores(as). São Carlos, aos 04 dias do mês de dezembro de 2019.

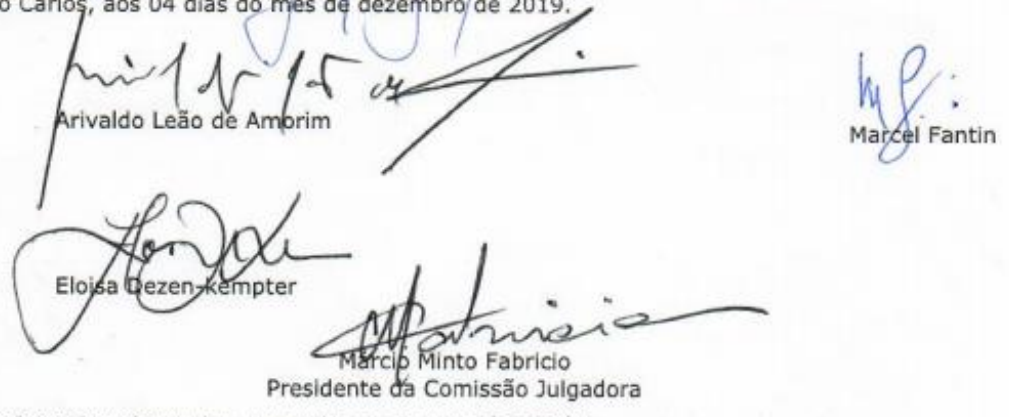

- Obs: Se o candidato for reprovado por algum dos membros, o preenchimento do parecer é obrigatónio.

A defesa foi homologada pela Comissão de Pós-Graduação em $11 / 12 / 19$ e, portanto, o(a) aluno(a) _ ao título de Mestre em Ciências obtido no Programa Arquitetura e Urbanismo - Área de concentração: Arquitetura Urbanismo e $^{-}$ Tecnologia.

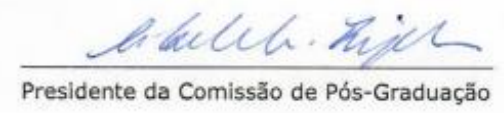





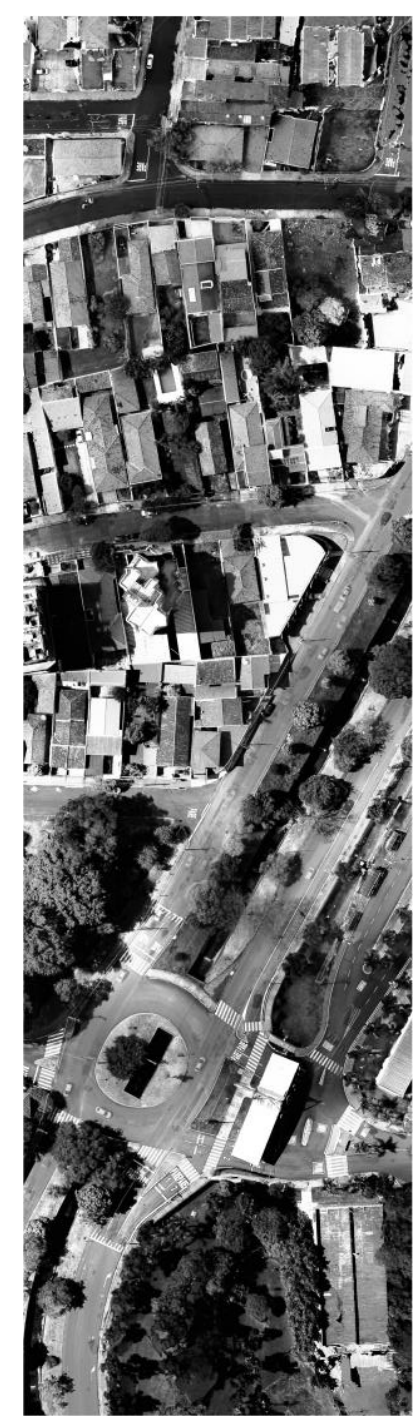

Ilustração 1 (Capa) Cidade Jardim Fonte: Autor (2019). 



\section{AGRADECIMENTOS}

À Coordenação de Aperfeiçoamento de Pessoal de Nível Superior - Brasil (CAPES) - Código de Financiamento 1760514.

Ao financiamento da Fundação de Amparo à Pesquisa do Estado de São Paulo FAPESP. Processo n² 2017/24896-4.

Ao professor Márcio, meu orientador, pela confiança, amizade e orientação nesse e em outros trabalhos, e por contribuir imensamente na minha formação como engenheiro e pesquisador.

Ao Grupo de pesquisa ArquiTec, pela acolhida e apoio em discussões e aconselhamento sobre minha pesquisa. E à Marta, pela competência e disposição em ajudar no que for preciso.

Aos funcionários do IAU, especialmente ao Valmir, Mara, Flávia, Dibo, Evandro e Everton pela simpatia e solicitude.

Aos professores do IAU, Anja, Marcel, Simone, pela contribuição que indiretamente deram a esse trabalho.

Aos professores do STT, Irineu, Segantine e Ana Larocca por possibilitarem a utilização de equipamentos de topografia. Ao técnico Carlos pela disposição e energia em ajudar nos levantamentos de campo. E aos colegas Diego e Sérgio pelo auxílio no processamento de dados.

À revisão atenta e competente de Camila, Lucas e Michele.

Aos amigos do IAU, em especial a Michele, Lucas, Lorena, Heliara, Vinícius, Louise, Márcio e Beatriz, por compartilharem comigo alegrias e inquietações.

A Camila, parceira de todas as horas e aventuras.

À minha família por todo apoio, incentivo, amor incondicional e peitos sempre abertos.

E a todos que, mesmo não citados, contribuíram nessa jornada.

Muito obrigado! 



\section{RESUMO}

FRANCO JÚNIOR, J. C. MODELAGEM BIM DE INFRAESTRUTURA URBANA A PARTIR DE LEVANTAMENTOS AÉREOS COM DRONE. 214 p. Dissertação (Mestrado em Arquitetura e Urbanismo) - Instituto de Arquitetura e Urbanismo, Universidade de São Paulo, São Carlos, 2019.

O desenvolvimento da infraestrutura urbana, bem como sua manutenção, requer documentação técnica estruturada para eficiência de gestão e acesso a informações necessárias a intervenções e emergências. A problemática envolve informações existentes não devidamente atualizadas, intervenções sem registro consistente e integrado, dados obsoletos e lacunas de informação que geram perdas sistemáticas de informações ao longo do ciclo de vida da infraestrutura urbana. Este trabalho se propõe a estudar o uso de RPAS/drones e BIM para levantamentos e documentação de infraestrutura urbana. Para tanto, investiga a geração de mapas e modelos geométricos (3D), estudando técnicas de levantamento aéreo, de fotogrametria digital, e de modelagem BIM para integração de dados e documentação de obras de infraestrutura do Campus 2 da USP São Carlos. Os métodos e abordagens de pesquisa incluem (i) Pesquisa bibliográfica, com foco em fotogrametria aérea digital, modelagem da informação da construção e infraestrutura urbana; (ii) Aprendizagem de ferramentas para o levantamento aéreo, processamento de imagens e nuvens de pontos, e modelagem BIM; e (iii) Pesquisa experimental de levantamento aéreo com o DJI Mavic Pro, processamento de imagens por Structure from Motion (SfM) via PIX4D, Agisoft Photoscan e Autodesk Recap e modelagem BIM com a suíte Autodesk. Os resultados envolvem análises do uso de aerofotogrametria e BIM para infraestrutura urbana, por meio da aquisição de fotos aéreas, mapas e desenvolvimento de ortofotos e modelos geométricos. Os resultados demonstram a combinação efetiva das tecnologias de levantamento e modelagem BIM para aplicações em infraestrutura urbana. Os produtos gerados adicionam à uma base digital de informações de ativos que pode servir para melhorar a integração de dados técnicos de documentação. O conhecimento proveniente deste trabalho contribui para clarificar, de modo prático, o uso de técnicas de levantamento e modelagem da infraestrutura urbana, as quais representam potenciais oportunidades de melhoria para documentação e gestão de sistemas de infraestrutura urbana.

Palavras-chave: BIM. Fotogrametria. RPAS. Drone. Infraestrutura urbana. 



\begin{abstract}
FRANCO JÚNIOR, J. C. BIM modeling of urban infrastructure using drone aerial surveys. 214 p. Master's Thesis (Master of Science in Architecture and Urbanism) - Institute of Architecture and Urbanism, University of São Paulo, São Carlos, 2019.

The development of urban infrastructure, as well as its maintenance, require structured technical documentation for management efficiency and access to essential information for interventions and emergencies. The problematic involves existing outdated information, interventions with inconsistent and unintegrated records, obsolete data, and gaps of information that generate systematic losses of information throughout the lifecycle of urban infrastructure. This work proposes the study of UAVs/drones and BIM for surveying and documenting urban infrastructure. Therefore, it includes the investigation and development of maps and 3D models, comprising the study of aerial survey techniques, digital photogrammetry, and BIM modeling for data integration and documentation of infrastructure works at Campus 2, USP São Carlos. Methods and research approach include (i) bibliographic research, focusing on digital aerial photogrammetry, building information modeling, and urban infrastructure; (ii) exploring tools for aerial surveying, image and point cloud processing, and BIM modeling; and (iii) experimental research applying aerial survey with DJI Mavic Pro, image processing using Structure from Motion (SfM) via PIX4D, Agisoft Photoscan, and Autodesk Recap, and BIM modeling with Autodesk suit. Results encompass analyses of the use of aerial photogrammetry and BIM for urban infrastructure by means of aerial photo acquisition, 2D maps, and the development of orthophotos and 3D models. Results demonstrate the effective combination of survey and modeling technologies for application in urban infrastructure. The generated products add to a digital asset information base that can enhance the integration of documentation technical data. The knowledge derived from this work helps to clarify, in practice, the use of techniques for surveying and modeling of urban infrastructure, what represent potential improvement opportunities for the documentation and management of urban infrastructure systems.
\end{abstract}

Keywords: BIM. Photogrammetry. UAV. Urban infrastructure. 



\section{SUMÁRIO}

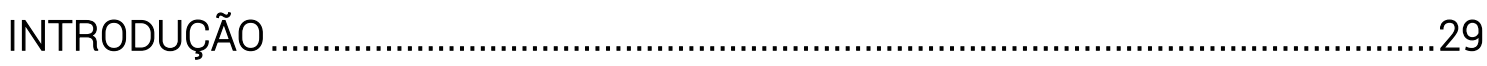

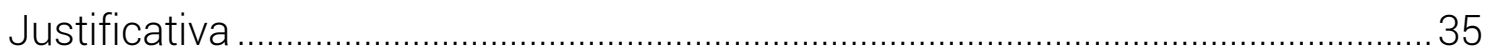

Objetivos

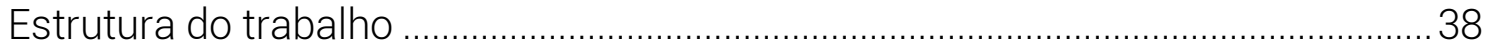

Organização da dissertação...................................................................................... 40

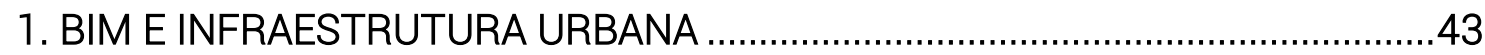

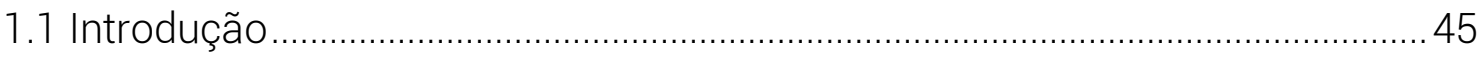

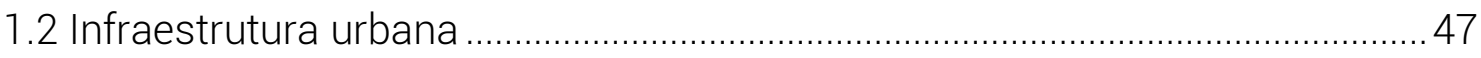

1.2.1 Sistemas de Infraestrutura Urbana (SIU) .................................................... 47

1.2.2 Infraestrutura urbana e desenvolvimento econômico ........................................ 49

1.2.3 Projeto integrado de infraestrutura ................................................................. 50

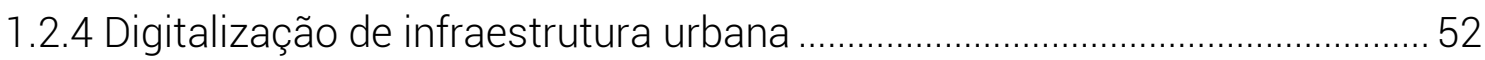

1.3 Modelagem da informação da construção ......................................................... 54

1.3.1 Termos e definições gerais ............................................................................ 55

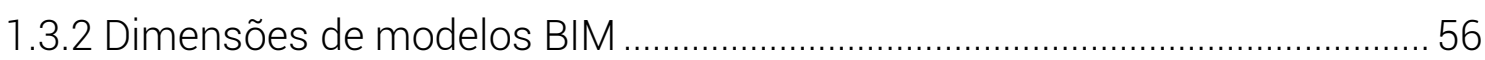

1.3.3 Nível de Desenvolvimento - ND (LOD) ………………...................................57

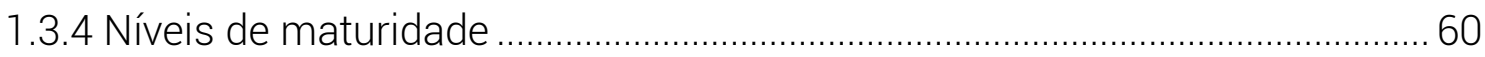

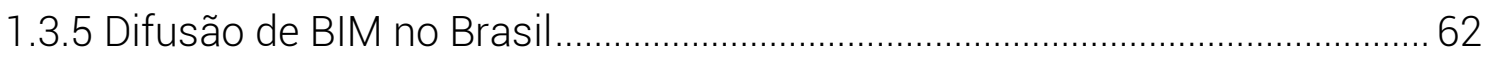

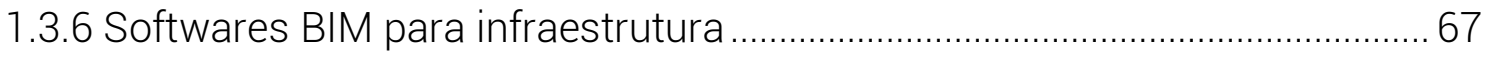

1.3.7 BIM e documentação de infraestrutura ..........................................................

1.3.8 BIM e informações geográficas ....................................................................73

2. LEVANTAMENTOS AÉREOS EM INFRAESTRUTURA URBANA …………….......77

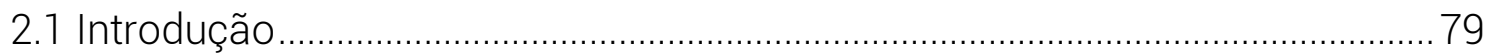

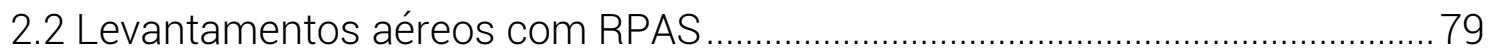

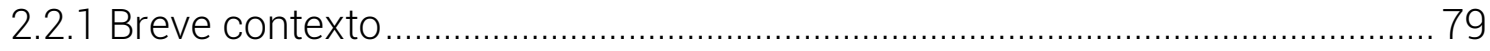


2.2.2 Regulamentações brasileiras para RPAS

2.2.3 Aplicações de RPAS em levantamentos ..........................................................87

2.3 Da imagem aérea à modelagem fotogramétrica ...............................................90

2.3.1 Princípios básicos de fotogrametria digital .....................................................90

2.4 Definições de Sistemas de Aeronaves Remotamente Pilotadas .................... 106

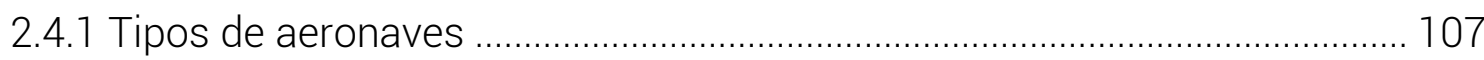

2.4.2 Sistemas de controle de voo ......................................................................... 115

2.4.3 Câmeras e sensores embarcados ................................................................... 118

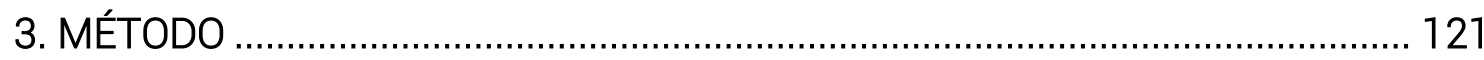

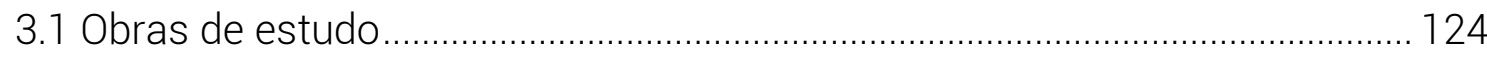

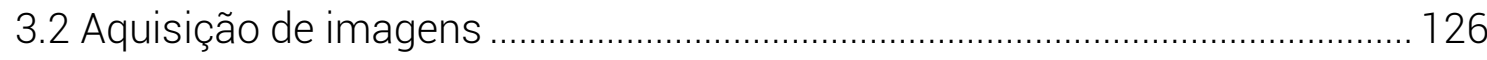

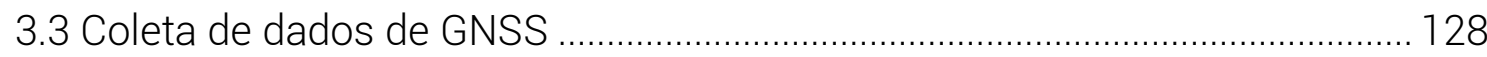

3.4 Processsamento de imagens e Geração de produtos fotogramétricos....... 129

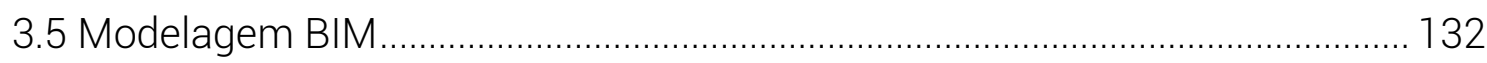

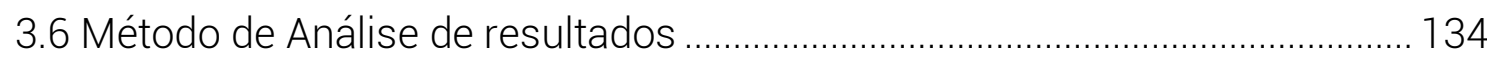

3.7Esquema geral do método 135

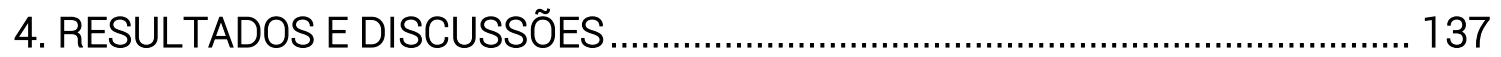

4.1 Fase 1- Testes de validação .............................................................................. 139

4.1.1 Rua 11 / Acesso à Biblioteca ..................................................................... 139

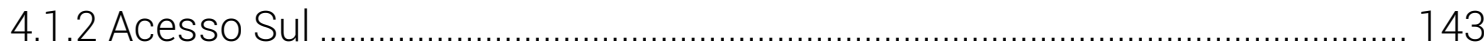

4.1.3 Análise de resultados | Fase 1 .................................................................... 148

4.2 Fase 2 - Levantamentos georreferenciados com GCPs ................................ 150

4.2.1 Pontos de controle coletados por GNSS ..................................................... 150

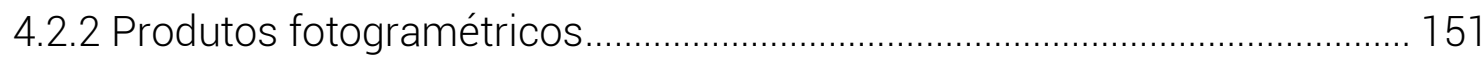

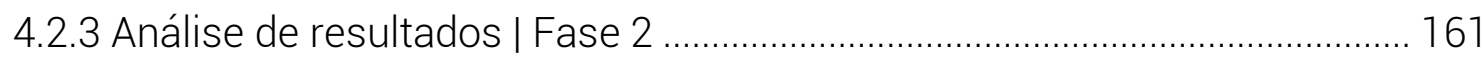




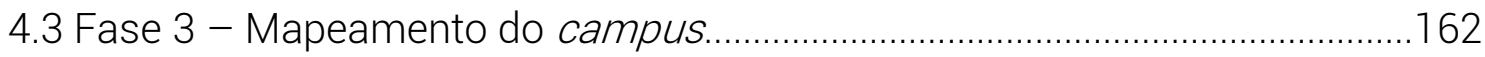

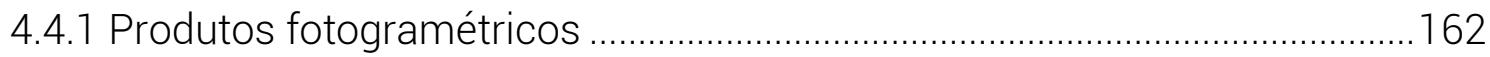

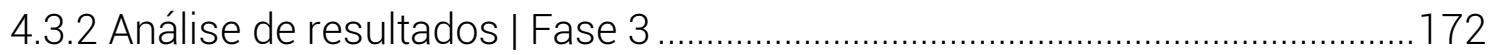

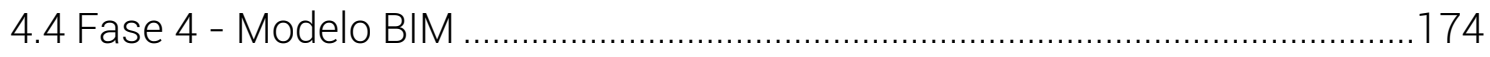

4.4.1 Criação do modelo e importação de dados ...................................................174

4.4.2 Modelagem do terreno e volumetrias de edificações ....................................179

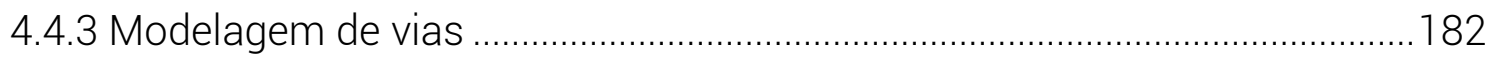

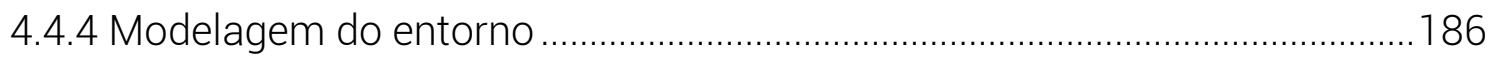

4.4.5 Importação de modelos BIM existentes ........................................................ 187

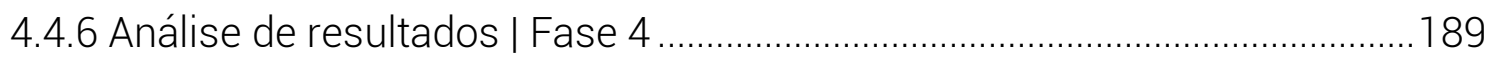

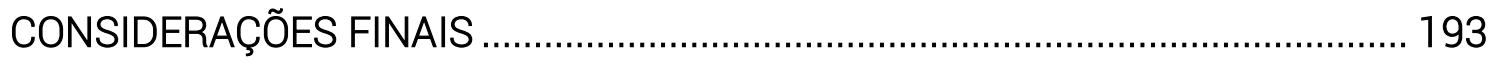

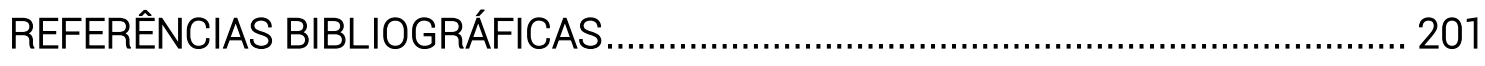

ANEXO I - Checklist de voo............................................................................. 215 



\section{LISTA DE FIGURAS}

Figura 1 - Nível de estresse por recursos de 2600 cidades ......................................46

Figura 2 - Níveis de desenvolvimento de modelos BIM ........................................... 58

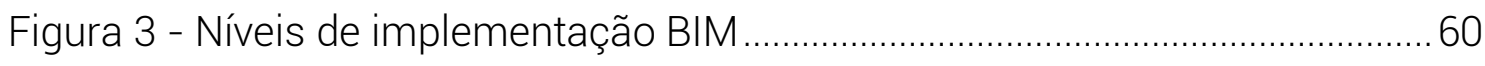

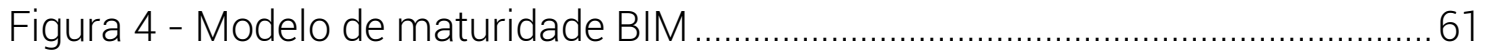

Figura 5 - Tempo de implementação de BIM por empresas (por região/país) .... 63

Figura 6 - Porcentagem de Contratantes que utilizam BIM por tipologias de projeto (por país)

Figura 7 - Fundamentos de BIM.

65

Figura 8 - Conceito de Integração entre dados por meio do Autodesk InfraWorks

Figura 9 - Curva de MacLeamy: comparativo entre processos tradicionais baseados em CAD e processos BIM .71

Figura 10 - Tecnologias de levantamento: cobertura x nível de detalhes 88

Figura 11 - Vista estereoscópica de sobreposição de duas imagens mostrando o mesmo objeto por diferentes ângulos. A impressão da terceira dimensão aparece no espaço formando um modelo estereoscópico.

Figura 12 - Projeção de pontos de ligação e de controle das imagens para reconstrução 3D da superfície do solo 93

Figura 13 - Trajetória de voo e sobreposição de áreas capturadas pelas imagens

Figura 14 - Visualização de plano de voo no software Pix4Capture e uma das imagens capturadas 96

Figura 15 - Diagrama de exposição e o triângulo ISO, abertura e velocidade do obturador

Figura 16 - Fluxo geral do processamento por fotogrametria 100

Figura 17 - Fluxo de trabalho no Pix4D - da captura à análise de resultados ....102

Figura 18 - Interface web Pix4D. 102

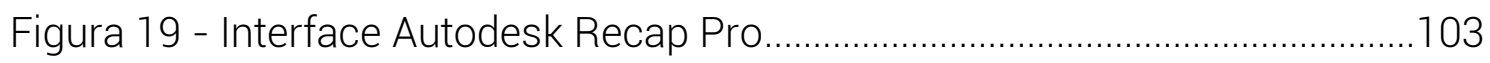

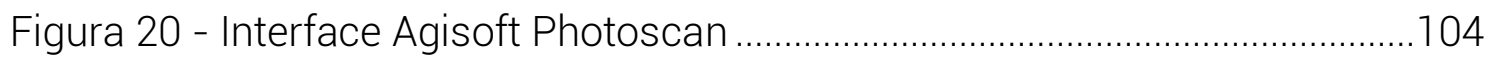

Figura 21 - Processamento fotogramétrico por SfM via Agisoft Photoscan......105 
Figura 22 - Base operacional de RPAS

Figura 23 - RPAS híbridos Skydrone-Quantix e Wingtra em transição para voo horizontal. 114

Figura 24 - (a) RPAS Carbonix-Volanti e (b)RPAS Google-Wing. 114 Figura 25 - Esquema de funcionamento dos sistemas de correção RTK e PPK 116

Figura 26 - Exemplos de GCP: levantamento de coordenadas geográficas de quina de calçada utilizada como GCP naturais e alvo artificial disposto em solo ........117 Figura 27 - Espectro da luz visível em micrometros de comprimento de onda. Bandas: Azul (0.4-0.5 mm), Verde (0.5-0.6), e vermelho (0.6-0.7), UltravioletaPróximo 0.3-0.4, Infravermelho-Próximo 0.7-1.5. 118 Figura 28 - Representação de faixas captadas por câmeras multiespectrais (imagem sem escala). 120

Figura 29 - Representação de faixas captadas por câmeras hiperespectrais (imagem sem escala) 120

Figura 30 - Localização da Rua 11 e do Acesso Sul do Campus 2 - USP São Carlos 125

Figura 31 - Planta esquemática da Rua 11 do Campus 2 - USP São Carlos ..... 125 Figura 32 - Planta esquemática de intervenções (pavimentação e infraestrutura) do acesso sul do Campus 2 - USP São Carlos 126

Figura 33 - DJI Mavic Pro, bateria e controle remoto 127 Figura 34 - Coleta de pontos de controle: (i) GCP naturais e (ii) GCP artificial com alvo padronizado 129

.Figura 35 - Fluxo de trabalho de processamento fotogramétrico no Agisoft Photoscan 131

Figura 36 - Estrutura da base de dados 132

Figura 37 - Registro da trajetória de voo e imagens capturadas 140

Figura 38 - Ortomosaico gerado pelo PIX4D, mapa de elevação e exemplares das imagens levantadas.

Figura 39 - (a) Vista superior do posicionamento inicial de imagens. (b) Vista superior do modelo digital de superfície. (c) Sobreposição de imagens.............. 143 Figura 40 - Ortomosaico do Acesso Sul gerado pelo Pix4D. 
Figura 41 - Pós-processamento de nuvem de pontos no Autodesk Recap .......147

Figura 42 - Ortomosaico e localização dos GCP 06-11 no Acesso Sul

Figura 43 - Localização de câmeras e sobreposição de imagens no Acesso Sul 153

Figura 44 - Modelo Digital de Elevação (DEM) do Acesso Sul, processado no Agisoft PhotoScan.

Figura 45 - Ortomosaico e localização dos GCPs 01-04 da Rua 11, processados no Agisoft Photoscan.

Figura 46 - Localização de câmeras e sobreposição de imagens na Rua 11 ....158 Figura 47 - Modelo Digital de Elevação (DEM) da Rua 11, processado no Agisoft Photoscan 159

Figura 48 - Setorização de dados levantados e processado do Campus USP2163 Figura 49 - Registro de voos por setor 164

Figura 50 - Ortomosaico do Setor 1 | Fase 3 167

Figura 51 - Ortomosaico do Setor 2 | Fase 3 168

Figura 52 - Ortomosaico do Setor 3 | Fase 3 169

Figura 53 - Ortomosaico do Setor 4 | Fase 3 170

Figura 54 - Ortomosaico dos Setores 1, 2, 3 e 4 | Fase 3. 171

Figura 55 - Vista do modelo preliminar do Campus 2 da USP gerada no Autodesk InfraWorks 174

Figura 56 - Visão da nuvem importada na base de dados 175

Figura 57 - Importação de nuvens de pontos no Autodesk Recap 175

Figura 58 - Nuvem de pontos acesso sul pós-processada via Autodesk Recap 176

Figura 59 - Nuvens de pontos importadas no modelo BIM (???) 177

Figura 60 - Importação de nuvem de pontos no Autodesk InfraWorks 178 Figura 61 - Diferença de cotas entre nuvem de pontos e modelo preliminar de superfície (vista inferior)

Figura 62 - Geração de terreno a partir das nuvens de pontos importadas

Figura 63 - Modelagem de terreno a partir da nuvem de pontos e adjacências 181

Figura 64 - Vista dos marcadores de GCP no modelo 
Figura 65 - Modelagem preliminar do traçado de curvas horizontais do acesso sul 183

Figura 66 - Perspectiva do modelo do acesso sul............................................... 184

Figura 67 - Via do acesso sul modelada ............................................................ 185

Figura 68 - Vista em perspectiva da modelagem da Rua 11 ................................ 185

Figura 69 - Vista geral da modelagem de vias do Campus 2 da USP................. 186

Figura 70 - Vista da avenida central do Campus modelada ................................. 187

Figura 71 - Modelo de arquitetura da Biblioteca .................................................... 188

Figura 72 - Vista do modelo desenvolvido ........................................................... 189 


\section{LISTA DE ILUSTRAÇõES}

|lustração 1 - Cidade Jardim capa e contracapa

|lustração 2 - Direções e contexto.

Ilustração 3 - Sobre rodas e obras... .43

Ilustração 4 - Sob(re) perspectivas. .77

Ilustração 5 - Ferramentas a caminho. 121

Ilustração 6 - Vias de convergências.. 137

Ilustração 7 - Sobre fronteiras. .193

|lustração 8 - De dentro à fora do Campus 201 


\section{LISTA DE DIAGRAMAS}

Diagrama 1 - Organização da dissertação ....................................................................40

Diagrama 2 - Registro e regulamentação de RPAS.....................................................83

Diagrama 3 - Procedimentos de registro de RPAS.................................................. 85

Diagrama 4 - Esquema geral do método .............................................................. 135

Diagrama 5 - Softwares adotados em cada etapa do trabalho (após validação da

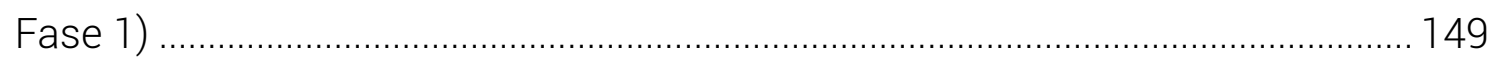




\section{LISTA DE QUADROS}

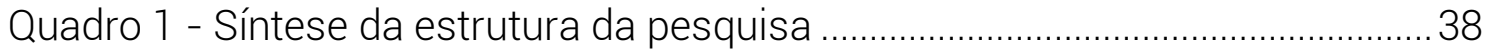

Quadro 2 - Conceitos de níveis de desenvolvimento ................................................58

Quadro 3 - Classificação de RPAS por peso segundo ANAC .................................... 82

Quadro 4 - Classificação de operações por visibilidade .............................................. 83

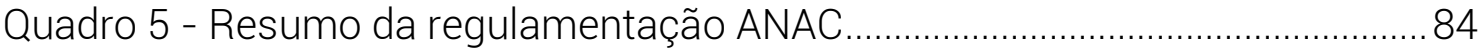

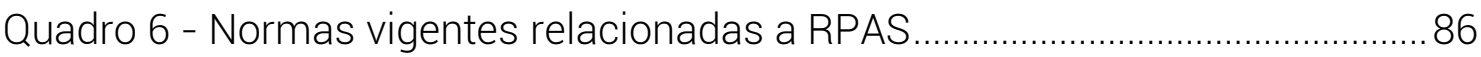

Quadro 7 - Classificação de técnicas de fotogrametria digital ............................... 92

Quadro 8 - Tipos aerodinâmicos simplificados de RPAS ........................................108

Quadro 9 - Modelos comerciais de RPA multirotores catalogados ......................110

Quadro 10 - Modelos comerciais de RPAS de asa fixa catalogados ...................113 


\section{LISTA DE TABELAS}

Tabela 1 - Principais Sistemas de Infraestrutura Urbana (classificação por função)

48

Tabela 2 - Acrônimos e significados de termos para modelagem de informações em infraestrutura. .56

Tabela 3 - Iniciativas governamentais brasileiras para disseminação de BIM ....66

Tabela 4 - Comparação entre estruturas de dados BIM e GIS ..................................74

Tabela 5 - Dados de processamento Rua 11 - Pix4D ............................................. 142

Tabela 6 - RMSE: Variância absoluta de Geolocalização de nuvem de pontos 142

Tabela 7 - Média de acurácia da geolocalização .................................................... 142

Tabela 8 - Dados de processamento Acesso Sul - Pix4D .................................... 146

Tabela 9 - RMSE Acesso Sul - variância absoluta de geolocalização de nuvem de

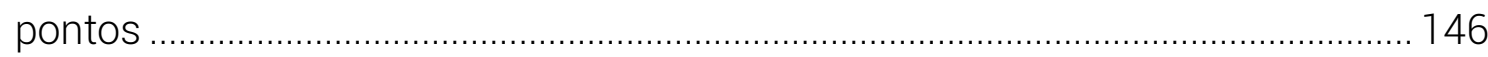

Tabela 10 - Média de acurácia da geolocalização ................................................... 146

Tabela 11 - Coordenadas geográficas dos pontos de controle (GCP) ISIRGAS2000

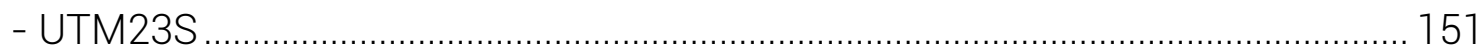

Tabela 12 - Dados de processamento do Acesso Sul no Agisoft PhotoScan... 155

Tabela 13 - RMSE dos pontos de controle do Acesso Sul.................................... 155

Tabela 14 - Dados de processamento da Rua 11, no Agisoft PhotoScan.......... 160

Tabela 15 - RMSE dos pontos de controle da Rua 11 .......................................... 160

Tabela 16 - Dados gerais de voos | Fase 3 ........................................................ 165 


\section{LISTA DE SIGLAS}

$2 D$

Bidimensional

3D Tridimensional

ABDI Associação Brasileira de Desenvolvimento Industrial

ABNT Associação Brasileira de Normas Técnicas

AECO Arquitetura, Engenharia, Construção e Operação

AIA American Institute of Architects

ANAC Agência Nacional de Avião Civil

ANATEL Agência Nacional de Telecomunicações

BIM Building Information Modeling

BNDES Banco Nacional de Desenvolvimento Econômico e Social

CAD Computer Aided Design

CBIC Câmara Brasileira da Indústria da Construção

CIM City Information Modeling

DSM Digital Surface Model - Modelo digital de superfície

DTM Digital Terrain Model - Modelo Digital de Terreno

DECEA Departamento de Controle do Espaço Aéreo

GCP

Ground Control Point - Ponto de Controle em Solo

GSD Ground Sample Distance - Distância de Amostragem do Solo

IPD Integrated Project Delivery

IoT Internet of Things - Internet das Coisas

MDIC Ministério da Industria, Comércio Exterior e Serviços

VANT Veículo Aéreo Não Tripulado (termo obsoleto)

RPAC-E Regulamento Brasileiro de Aviação Civil Especial

PMD Peso Máximo de Decolagem

SISANT Sistemas de Aeronaves Não Tripuladas

SfM Structure from Motion

SSoT Single Source of Truth - Única fonte de verdade

RTK Real Time Kinematic

VTOL Vertical Take-Off and Landing

PPK Post Processed Kinematic

RMSE Root-Mean-Square Error-Raiz quadrada do erro médio 

Gerir e manter a infraestrutura de cidades demanda um ferramental robusto capaz de lidar com informações detalhadas dos vários sistemas que a compõe. Esse ferramental deve abranger o manuseio de informações de construções (edificações e infraestrutura) existentes e novas, incorporando informações de projeto, operação e manutenção, com abordagens de curto, médio e longo prazo. O desafio em questão envolve uma série de fatores que influenciam sua complexidade: grande número de informações a gerenciar, extensas áreas a manter, indisponibilidade (ou escassez) de recursos, capacitação técnica, planejamento urbano, políticas de gestão coerentes, estrutura administrativa, entre outros.

Nesse contexto, um grande problema consiste na falta de informações precisas e detalhadas da infraestrutura existente. Além de permitir o registro de informações importantes dos sistemas construídos, a documentação de infraestrutura urbana é um valioso instrumento para operação e manutenção de ativos, constituindo-se como uma ferramenta fundamental para um desenvolvimento urbano.

Processos tradicionais de documentação baseados em Computer Aided Design (CAD) são fragmentados, comprometendo a integração de dados para gestão de ativos urbanos. Além disso, informações existentes não são devidamente atualizadas e intervenções ocorrem sem que haja registro consistente e integrado, gerando perdas recorrentes de informações ao longo do ciclo de vida de infraestrutura urbana.

Técnicas de medição direta, topografia e fotografia documental tradicionais possuem limitações, especialmente em se tratando de infraestrutura urbana, cujas dimensões de grande porte e seus subsistemas constituem complexas redes e fazem da documentação precisa e consistente um desafio.

Além disso, as técnicas tradicionais para levantamento e documentação de infraestrutura constituem processos lentos, custosos e ineficientes para o registro de grandes dimensões. De acordo com Rozenfeld et al. (2006), métodos tradicionais de desenvolvimento de projeto são caracterizados por processos fragmentados, forte hierarquia e controle, processos lineares segregados e com 
nichos de conhecimento isolados. Assim, o uso de tecnologias tradicionais pode acarretar incompatibilidades de projeto e inconsistências em documentações, e limitam-se a produtos bidimensionais elaborados de forma individual.

Para American Institute of Architects (2007), as metodologias tradicionais se baseiam em representações bidimensionais segmentadas, com ferramentas analógicas (como papel) e há a valorização de esforços individuais, enquanto projetos integrados se baseiam em tecnologias digitais para seu desenvolvimento com acessos multilaterais, interoperáveis, compartilhados e colaborativos.

Com novas tecnologias emergentes do desenvolvimento intenso de ferramentas computacionais dos últimos anos, há grandes avanços relacionados ao levantamento e processamento de dados tridimensionais (GROETELAARS, 2015). A somar nesse cenário, a popularização de aeronaves remotamente pilotadas (RPA), torna cada vez mais viável o emprego de métodos mais ágeis de levantamento, principalmente para grandes áreas urbanas e rurais.

Os RPAS contam com recursos de captura de imagem e vídeo com significativa qualidade, facilidade de operação e agilidade em tomadas aéreas. Adicionalmente, ferramentas de processamento de imagens possuem recursos capazes de gerar produtos tridimensionais com acurácia, através de técnicas de fotogrametria digital baseadas em Structure from Motion (SfM), em que algoritmos analisam imagens correlacionando pontos homólogos para gerar nuvens de pontos tridimensionais automaticamente.

Além das tecnologias de levantamento, as ferramentas computacionais de representação tridimensional têm evoluído significativamente nas últimas décadas. $\mathrm{O}$ advento de Building Information Modeling (BIM) representa um marco tecnológico de grande importância e é tido como tecnologia e nova metodologia de trabalho que virtualiza as construções incorporando informações do seu ciclo de vida de uma maneira colaborativa e ágil (COSTA, 2018). A tecnologia provê uma enorme quantidade de dados sendo capaz de lidar com diferentes tipos em um mesmo ambiente. Tais potencialidades são oportunas para construções existentes, em que as dificuldades de levantamento e gerenciamento de 
informações podem ser maiores que em construções novas (GIUDICE; DEL e OSELLO, 2013).

À medida que BIM se desenvolve como plataforma tecnológica aplicada à arquitetura e engenharia de edificações prediais, aproxima-se de uma escala maior: a modelagem de cidades e infraestrutura urbana. Cheng, Lu e Deng (2016) apontam que BIM tem sido largamente adotado na indústria da construção, mas seu uso para infraestrutura ainda é pouco explorado. Referenciado como City Information Modeling, CIM é compreendido como uma extensão do conceito de BIM aplicado a projetos urbanos (AMORIM, 2015).

O desenvolvimento de modelos BIM é dependente diretamente da qualidade de informações disponíveis. Assim, uma forma de preencher lacunas de informações de infraestrutura para fins de desenvolvimento de modelos de informação é o uso combinado de fotogrametria aérea e modelagem BIM. A pesquisa em questão situa-se nesse contexto, a fim de explorar as potencialidades de integração de tais tecnologias.

Em BIM o projeto é mais preciso e detalhado, uma vez que se utilizam componentes para representar de forma fiel o que se projeta, simulando o posicionamento espacial de geometrias complexas e prevendo possíveis colisões com outros componentes. Assim, soluções podem ser mais bem concebidas e problemas em obra minimizados, possibilitando a redução de retrabalhos e custos.

O desenvolvimento de projetos passa a antecipar resoluções críticas em momentos cujo risco financeiro é menor, uma vez que possibilita análises anteriores à construção, e há maior capacidade de influenciar a qualidade e detectar previamente oportunidades de melhoria. Para tanto, BIM promove a comunicação baseada em modelos digitais integrados, de forma que as diversas especialidades podem ser coordenadas por uma base de dados única de projetos vinculados entre si. A documentação passa a ser ancorada em uma "única fonte de verdade" (Single Source Of Truth - SSOT), o que é potencialmente benéfico para reduzir dados obsoletos e imprecisos, evitando que falhas na gestão de informação impliquem em falhas operacionais. 
Nessa perspectiva, BIM permite que não somente o projeto executivo seja elaborado, mas também o processo executivo seja simulado. Através da integração de informações de planejamento temporal, com BIM 4D (3D + "tempo") as etapas de construção podem ser analisadas e auxiliadas por ferramentas imersivas para identificação de não conformidades no planejamento. Além disso, com a incorporação de informações de custo (BIM 5D) o planejamento físicofinanceiro pode se tornar mais assertivo e diminuir riscos.

A hipótese que norteia o trabalho é que o uso integrado de técnicas de levantamento aerofotogramétrico e modelagem BIM para infraestrutura urbana beneficia a documentação e gestão de ativos urbanos, possibilitando superar as limitações de tecnologias em uso atualmente e servindo de base de informações inteligente para o desenvolvimento mais sustentável de infraestrutura urbana.

Como forma de confirmar a hipótese, a pesquisa desenvolve estudos de fundamentos teóricos e práticos considerando os seguintes eixos temáticos: (1) levantamento de dados por aerofotogrametria, (2) processamento de imagens e geração de nuvens de pontos por fotogrametria, (3) modelagem BIM para infraestrutura urbana.

Assim, o objetivo dessa pesquisa é a aplicação prática de técnicas de levantamento aerofotogramétrico e documentação para a elaboração de modelos BIM de infraestrutura com intuito de prover informações e documentar características projetuais de construções. Em síntese, o foco da pesquisa é estudar e explorar ferramentas BIM para modelagem de projetos de infraestrutura urbana utilizando:

- Métodos de levantamento aéreo com aeronaves remotamente pilotadas (RPA);

- Técnicas de fotogrametria digital para geração de nuvens de pontos a partir fotografias aéreas;

- Ferramentas de modelagem BIM e integração de produtos de levantamento aéreo. 


\section{JUSTIFICATIVA}

Obras de infraestrutura, em geral, possuem grande porte e envergadura de desenvolvimento que envolvem uma série de especialidades e profissionais por um longo período de tempo. Além disso, possuem uma vida útil de muitas décadas que exige soluções que considerem não somente aspectos de construção, mas fundamentalmente de operação e manutenção para que os gastos sejam amortizados e para que a sustentabilidade seja analisada considerando todo seu ciclo de vida.

No entanto, o emprego de tecnologias capazes de manipular grandes quantidades de dados e suportar o desenvolvimento de projetos de infraestrutura de maneira integrada para facilitar a coordenação e colaboração é pouco explorado. Utilizam-se principalmente ferramentas tradicionais como planilhas de cálculo, ferramentas CAD e editor de textos.

Segundo Cheng, Lu e Deng (2016), não há uma classificação universal para tipologias/disciplinas de infraestrutura civil. Em face à diversidade de disciplinas e de agentes envolvidos, o porte e consequente alto custo e tempo de duração do ciclo de vida, o gerenciamento de informações no desenvolvimento de projetos de infraestrutura perfaz uma malha complexa e numerosa.

O desenvolvimento de infraestrutura urbana é um tema de relevância global que diretamente se relaciona com agentes da área de Arquitetura, Engenharia, Construção e Operação (AECO). Além disso, a complexidade da integração de várias disciplinas (de projeto à operação) desafiam-nos a lidar com muitas informações de construção. Utilizar tecnologias que consigam operar inteligentemente grandes volumes de informações a favor de elucidar soluções melhores pode ser chave para os desafios reais.

A pesquisa em questão colabora para uma melhor compreensão de como as tecnologias de modelagem de informações podem ser empregadas no contexto de infraestrutura urbana proporcionando respostas aos desafios de operação e manutenção. Além disso, o emprego de modelagem de informações para 
infraestrutura possibilita a criação de relações entre dados existentes em uma base que pode ser progressivamente conectada a outros fluxos de dados, por exemplo, gestão de ativos urbanos, gestão de recursos naturais (água, eletricidade, gás), informações de trânsito, gestão de serviços e operação, segurança e outros.

BIM é uma tecnologia recente que foi possibilitada devido à intensa evolução de informática para AECO. Embora gradualmente adotada em diversos países, é uma tecnologia em amadurecimento e com limitações. A aplicação dessa para infraestrutura urbana é ainda mais recente e esbarra diretamente em recursos computacionais para lidar com grandes volumes de dados. Além disso, é pouca a produção bibliográfica sobre a integração entre tecnologias de modelagem BIM com de geoprocessamento (ALMEIDA e ANDRADE, 2015), o que é fundamental em empreendimentos horizontais onde aspectos de georreferenciamento têm grande influência.

É necessária uma melhor compreensão de como ferramentas modernas de levantamentos aéreos e modelagem de informações podem colaborar com a documentação e gestão de infraestrutura e como podem respaldar o desenvolvimento de infraestrutura mais sustentável sendo aparatos técnicos robustos de gestão de informações da construção.

Aborda-se a infraestrutura de um campus universitário, no qual há uma série de sistemas de infraestrutura similarmente a um pequeno centro urbano e que serve de experimento de modelagem da informação de suporte às demandas relacionadas a qualidade, economia e sustentabilidade.

Neste contexto, apresentam-se, sinteticamente, as seguintes justificativas desta pesquisa:

- A integração de métodos de fotogrametria aérea e BIM é um campo recente e pouco explorado e potencialmente benéfico para gestão e desenvolvimento sustentável de infraestrutura urbana;

- Apesar de uso intenso e mais consolidado para edificações verticais, BIM é pouco difundido para aplicações voltadas a infraestrutura; 
- A aplicação integrada de tecnologias de fotogrametria aérea e BIM para sistemas de infraestrutura urbana pode gerar dados precisos e úteis a atividades de manutenção e operação.

\section{OBJETIVOS}

O objetivo geral desta pesquisa é estudar a aplicação prática de técnicas de levantamento aerofotogramétricos (utilizando Structure from Motion - SfM) para a elaboração de modelos BIM de infraestrutura visando analisar suas potencialidades para fins de documentação. A proposição é desenvolvida alcançando os seguintes objetivos específicos:

- Aplicar métodos de levantamento aéreo estudando princípios e práticas da fotogrametria aérea para geração de nuvens de pontos por SfM, modelos digitais de superfície e ortofotos;

- Aplicar ferramentas BIM para documentação da infraestrutura estudando os fundamentos teóricos e práticos para a modelagem visando a integração com produtos de levantamentos aéreos; 


\section{ESTRUTURA DO TRABALHO}

Esta pesquisa é descrita conforme o Quadro 1 a seguir.

Quadro 1 - Síntese da estrutura da pesquisa

TEMA

BIM e Fotogrametria aérea para infraestrutura urbana

OBJETO Modelagem de informações de infraestrutura

EMPÍRICO

PROBLEMA Dados e informações sem padronização, segregados, desorganizados, obsoletos, incompatíveis e não integrados provocam lacunas de informação no desenvolvimento de novos projetos e manutenção de infraestrutura existente. Além disso, as informações existentes não são devidamente atualizadas e intervenções ocorrem sem que haja registro consistente e integrado, gerando perdas sistemáticas de informações ao longo do ciclo de vida de infraestrutura urbana e aumentando o risco de falhas operacionais.

HIPÓTESE O uso integrado de técnicas de levantamento aerofotogramétrico e modelagem BIM para infraestrutura urbana otimiza a documentação, servindo de base de informações estruturada para a gestão de ativos e desenvolvimento de projetos de infraestrutura.

QUESTÕES TECNOLOGIASDISPONIVEIS

Quais e como tecnologias de levantamento aéreo e modelagem BIM podem ser utilizadas para documentação de infraestrutura urbana?

GESTÃO E INFORMAÇÃO

Como otimizar o levantamento e documentação de infraestrutura urbana? 
MÉTODOS Pesquisa bibliográfica, com foco em projeto integrado de infraestrutura urbana, fotogrametria aérea digital e modelagem de informações.

Pesquisa de ferramentas computacionais de aquisição de dados, processamento de imagens aéreas e nuvens de ponto e modelagem BIM.

Pesquisa experimental de aplicação de tecnologias de levantamento aéreo, processamento de imagens por DSM e modelagem de informações de infraestrutura.

OBJETIVO Estudar e gerar modelos fotogramétricos a partir de imagens GERAL áreas adquiridas por RPAS com técnicas de levantamento automatizadas e integrar a modelos BIM para fins de documentação digital de obras de infraestrutura.

OBJETIVOS • Aplicar métodos de levantamento aéreo estudando princípios ESPECÍFICOS e práticas de fotogrametria aérea para geração de nuvens de pontos por SfM, modelos digitais de superfície e ortofotos;

- Aplicar ferramentas BIM para Infraestrutura estudando fundamentos teóricos e práticos de modelagem para integração com produtos de levantamentos aéreos;

Fase 1 | Estruturação e validação de ferramentas de levantamento, processamento e modelagem para áreas até 1 ha

Fase 2 | Aplicação da Fase 1

Fase 3 | Validação de levantamentos em áreas superiores a 1 ha

Fase 4 | Modelagem de resultados selecionados 


\section{ORGANIZAÇÃO DA DISSERTAÇÃO}

Esta dissertação de mestrado está organizada em quatro capítulos conforme Diagrama 1.

Diagrama 1 - Organização da dissertação

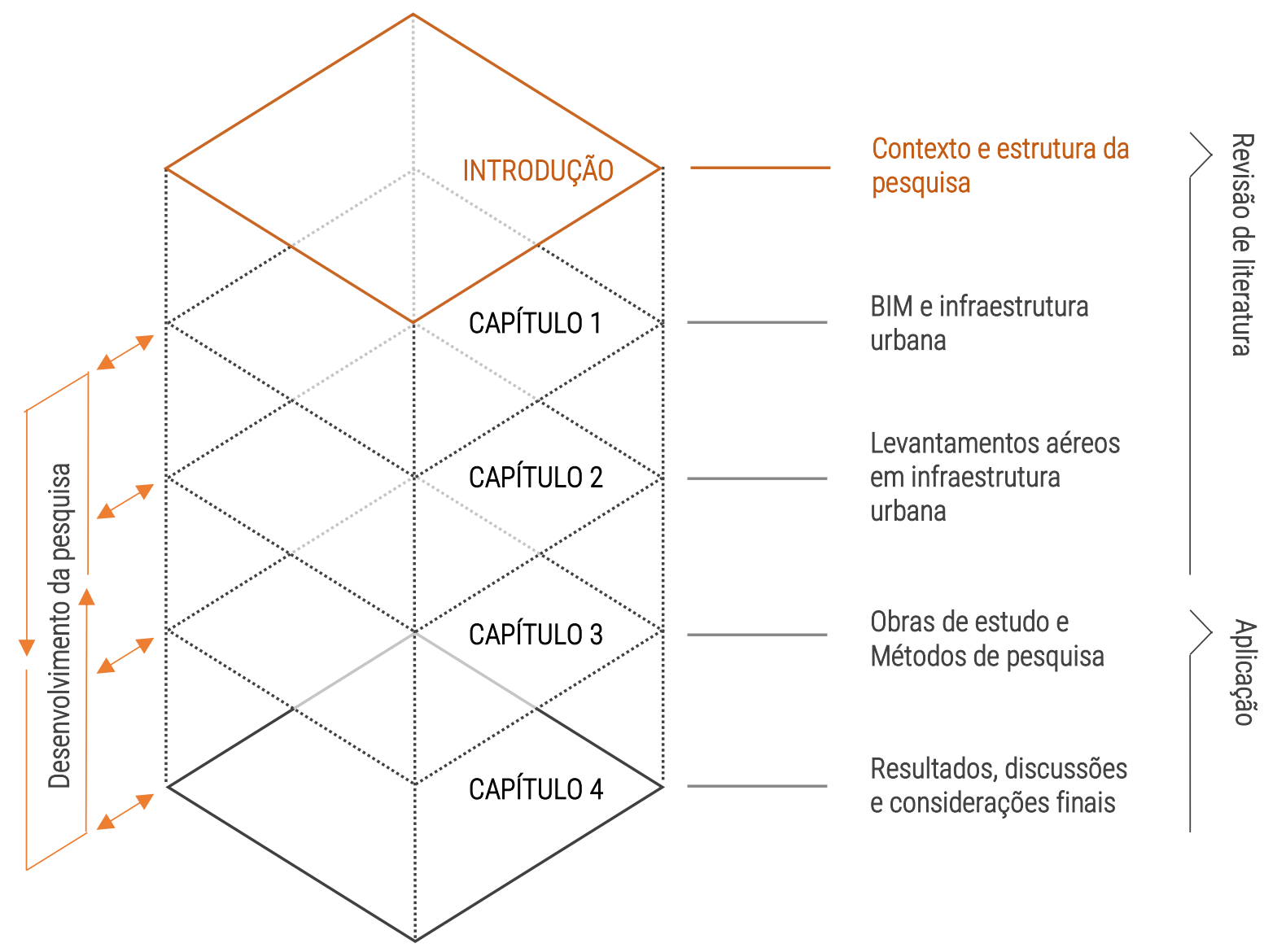

Fonte: Autor (2019)

CAPÍTULO 1 - "BIM e Infraestrutura Urbana" aborda os conceitos de Building Information Modeling e City Information Modeling, abrangendo aspectos teóricos e práticos e o processo de desenvolvimento de modelos. Apresenta alguns exemplos correlatos aos temas de estudo tidos como fundamentais para desenvolvimento dessa pesquisa.

CAPÍTULO 2 - "Levantamentos aéreos em Infraestrutura Urbana" conceitua técnicas e aplicações de levantamentos aéreos na construção civil, com foco em 
obras de infraestrutura. São também apresentados equipamentos e técnicas de processamento de imagens aéreas

CAPÍTULO 3 - "Método" apresenta as abordagens metodológicas da pesquisa, ferramentas utilizadas para coleta de dados, processamento e modelagem. Descreve também o método de análise de resultados e, por fim, apresenta o esquema geral dos métodos utilizados.

CAPÍTULO 4 - "Resultados, discussões e considerações finais" expõem os resultados obtidos pela pesquisa com respectivas análises sobre produtos gerados, considerações e limitações. 

Este capítulo apresenta os conceitos de Building Information Modeling focando em aplicações para infraestrutura urbana e abordando aspectos teóricos e práticos de desenvolvimento de modelos. Apresentam-se alguns exemplos correlatos com esta pesquisa abordando temas de estudo tidos como fundamentais para seu desenvolvimento.

\subsection{INTRODUÇÃO}

Crescentes desafios relacionados à escassez de recursos energéticos, mudanças climáticas, crescimento populacional e forte tendência de migração para centros urbanos, têm fomentado o interesse de pesquisadores, da indústria e de governos para a digitalização do ambiente construído como forma de melhor compreender sistemas e serviços de infraestrutura de cidades (HEATON e PARLIKAD, 2019).

O desafio em questão é abordado na Agenda 2030 (ONU, 2015) em 17 objetivos globais e 3 metas extraordinárias para que cidades se tornem mais inclusivas, seguras, resilientes e sustentáveis. Especificamente, o nono objetivo trata da inovação promovendo a necessidade de:

"9.1 Desenvolver infraestrutura de qualidade, confiável, sustentável e resiliente;

9.4 (...) modernizar a infraestrutura (...) com eficiência aumentada no uso de recursos e maior adoção de tecnologias (...)

9.5 Fortalecer a pesquisa científica (...) incentivando a inovação

9.a. Facilitar o desenvolvimento de infraestrutura sustentável

9.b. Apoiar o desenvolvimento tecnológico, pesquisa e inovação

9.c. Aumentar o acesso à tecnologia de informação e comunicação" (ONU, 2015).

A problemática relacionada ao desenvolvimento urbano contemporâneo, como aponta Woetzel, Rajadhyaksha e Frem (2018), relaciona-se ao estresse sobre o uso de recursos naturais em muitas cidades de países em desenvolvimento decorrente do crescimento urbano desorganizado. No Brasil, a população urbana foi de $81,25 \%$ para $84,35 \%$ entre 2000 e 2010 , segundo o Censo realizado pelo IBGE, crescimento que além de gerar pressões sobre espaços urbanos, quando extremo, pode levar ao esgotamento da capacidade de sua infraestrutura, à inacessibilidade a recursos naturais e, consequentemente, à indisponibilidade de 
serviços públicos. Esse crescimento deve ser amparado por práticas que promovam o desenvolvimento de cidades, adequando condições de serviço e infraestrutura urbana e minimizando estresses sobre sistemas existentes, razão pela qual o emprego de novas tecnologias, como BIM, se faz necessário. Na Figura 1, é apresentado o grau de vulnerabilidade relacionado ao estresse de recursos projetado para 2025 de 2600 cidades globais, das quais todas as cidades brasileiras foram classificadas com alto grau de estresse e vulnerabilidade.

Figura 1 - Nível de estresse por recursos de 2600 cidades

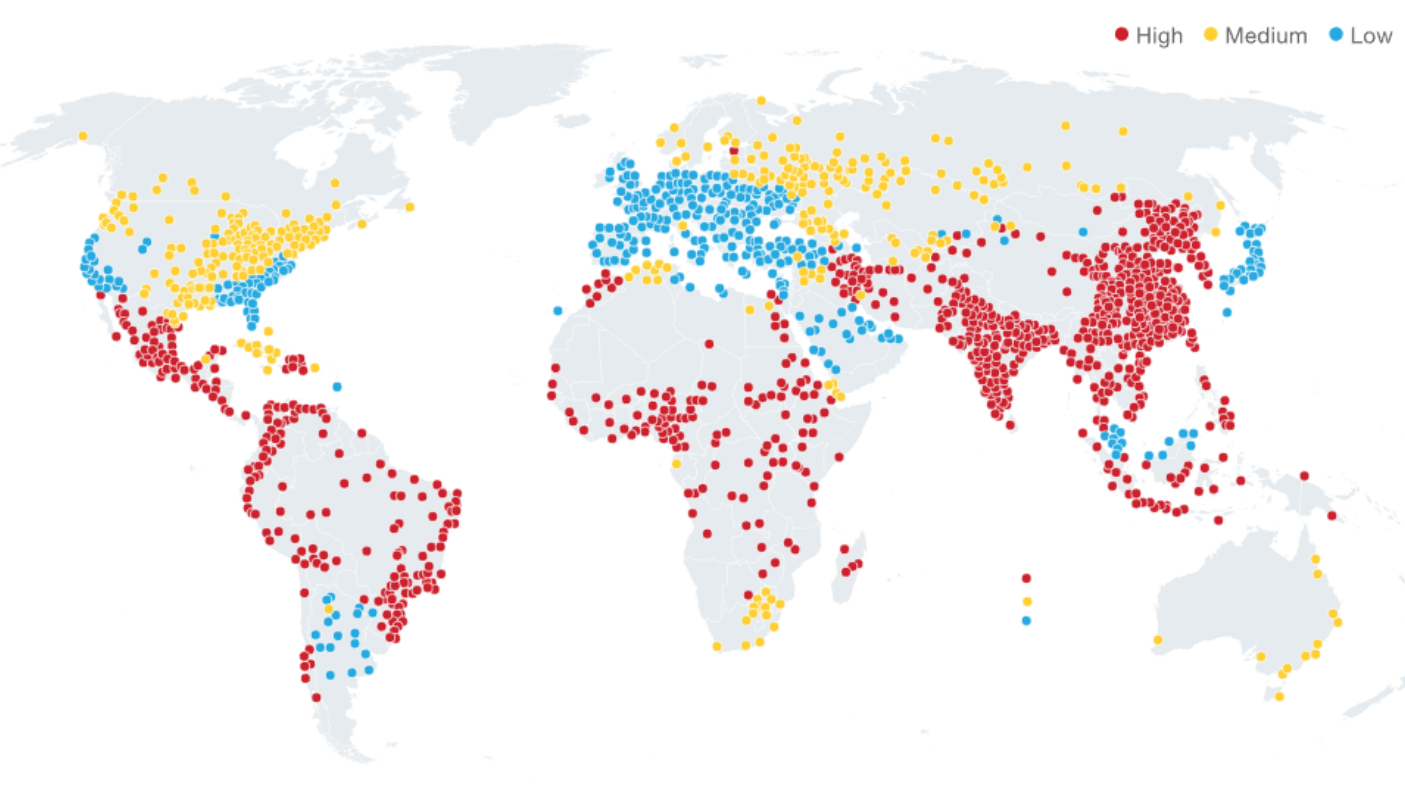

Fonte: Woetzel, Rajadhyaksha e Frem (2018)

Esse cenário coloca em discussão o desenvolvimento de infraestrutura urbana, trazendo à tona demandas por novas abordagens projetuais de desenvolvimento sustentável que considere não somente as fases de projeto e construção, mas sim, todo seu ciclo de vida e esferas ambientais, sociais e econômicas. Sob essa responsabilidade, é essencial compreender que a infraestrutura urbana é a interface entre os recursos naturais e atividades socioeconômicas (DONG et al., 2018), ademais os espaços urbanos são complexos, únicos e dinâmicos, lideradas por sua história, cultura e exigências dos seus cidadãos (HEATON e PARLIKAD, 2019). 
Para El-Diraby e Osman (2011), um dos principais domínios em que a tecnologia da informação pode apoiar é o gerenciamento de sistemas de infraestrutura civil, cuja complexidade da construção do ambiente urbano amplia as ineficiências das abordagens de ciclo de vida). Tais abordagens são desprovidas de mecanismos abordagens atuais baseadas em CAD e focadas em custos de curto prazo (versus efetivos para gerenciar e compartilhar conhecimento; e caracterizadas pela coordenação ineficiente e desenvolvimento esporádico de projetos (versus desenvolvimento coerente e integrado).

"(...) o desafio é captar recursos de informação que tenham a capacidade de informar o planejamento urbano de maneira oportuna e precisa; a fim de apoiar processos de formulação estratégica e permitir que os planejadores exerçam influência sobre a forma e o desenvolvimento futuros de cidades". (THOMPSON et al., 2016).

Diferentes soluções tecnológicas, expressas em conceitos de indústria 4.0, têm sido desenvolvidas para modelagem digital de sistemas urbanos. Entre tais tecnologias, BIM (Building Infomation Modeling) aparece como solução digital disruptiva cujo emprego, outrora particular a projetos de edificações, tem sido ampliado a demais setores e normalizado nacional e internacionalmente. Nesse contexto, nas seções seguintes é abordado um de seus usos proeminentes: BIM para infraestrutura urbana.

\subsection{INFRAESTRUTURA URBANA}

Antes de adentrar às aplicações de BIM em infraestrutura, é necessário compreender os sistemas de infraestrutura que compõem espaços urbanos. Partindo dessa premissa, os tópicos desta seção abordam definições de sistemas de infraestrutura urbana, aspectos relacionados ao desenvolvimento econômico, projeto integrado e digitalização de infraestrutura urbana.

\subsubsection{SISTEMAS DE INFRAESTRUTURA URBANA (SIU)}

Segundo Mascaró e Yoshinaga (2005), infraestrutura urbana compreende um conjunto de elementos que suportam a estrutura de uma cidade, por meio de 
sistemas e subsistemas que possibilitam o uso do espaço urbano. Os sistemas de infraestrutura urbana (SIU) podem abranger diversos tipos de infraestruturas, além de diferentes classificações. Segundo sua localização, tais sistemas podem ser classificados de acordo com a posição que ocupam no ambiente: nível aéreo, nível superficial ou nível subterrâneo. Segundo sua função, os sistemas podem abranger grandes áreas temáticas como transportes, água, esgoto, energia e comunicações; as quais são apresentadas na Tabela 1.

Tabela 1 - Principais Sistemas de Infraestrutura Urbana (classificação por função)

\begin{tabular}{|c|c|}
\hline Sistema & Descrição \\
\hline Viário & $\begin{array}{l}\text { Redes de circulação para receber veículos, bicicletas, pedestres etc. } \\
\text { Complementado pela rede de drenagem }\end{array}$ \\
\hline Sanitário & $\begin{array}{l}\text { Redes simétricas com fluxos opostos: rede de abastecimento de } \\
\text { água e rede de coleta de esgoto }\end{array}$ \\
\hline Energético & $\begin{array}{l}\text { Redes de geração e distribuição de energia elétrica para iluminação } \\
\text { e movimentação de motores. Redes de gás }\end{array}$ \\
\hline Comunicações & Redes de telefone e internet \\
\hline Edificações & Construções residenciais, comerciais, industriais e governamentais \\
\hline
\end{tabular}

Fonte: Adaptado de Mascaró e Yoshinaga (2005).

Os sistemas de infraestrutura urbana também podem ser identificados de acordo com sua importância e impacto no funcionamento de cidades, o que Carter (2015) classifica como: Infraestrutura Crítica, Infraestrutura de Emergência e Infraestrutura Social. Infraestrutura Crítica compreende sistemas de distribuição de energia, comunicações, transportes, distribuição de água e coleta e tratamento de esgoto. Infraestrutura de Emergência inclui postos médicos, hospitais, corpo de bombeiros, polícia, etc. Por fim, Infraestrutura Social é composta por escolas, órgãos administrativos, praças e espaços públicos.

Entre todos os sistemas, o viário é o mais delicado por (i) abranger mais da metade dos custos totais de urbanização, (ii) ocupar parcela significativa do solo (mais de 20\%), (iii) ser difícil aumentar sua capacidade em razão dos custos envolvidos e complexidade de intervenções e; (iv) por estar vinculado diretamente aos usuários, o que torna erros e acertos mais evidentes (MASCARÓ e YOSHINAGA, 2005, p. 13). 
Embora tal organização segmentada e sistemática seja importante para a compreensão de componentes da infraestrutura urbana, os SIU são interdependentes, com conexões físicas, sociais e econômicas delineadas por relações complexas e não necessariamente lineares (DERRIBLE, 2017). Abordagens multidisciplinares são fundamentais nesse contexto e devem considerar mecanismos integrados para o desenvolvimento de sistemas de infraestrutura.

\subsubsection{INFRAESTRUTURA URBANA E DESENVOLVIMENTO ECONÔMICO}

A infraestrutura representa parcela significativa de investimentos públicos, os quais apresentam relações proporcionais entre o capital investido e o impacto sobre o desenvolvimento econômico (RADÜNS, 2013). Segundo Mascaró e Yoshinaga (2005) um aumento de 1\% de investimento em infraestrutura urbana faz aumentar em 1 a 1,5\% a renda da população beneficiada. Um estudo recente da consultoria McKinsey a pedido do BNDES concluiu que o aumento de $1 \% \mathrm{em}$ investimentos de infraestrutura aumentaria o PIB brasileiro em 2,1\% em uma década (SINDUSCON-GO, 2019).

Amann et al. (2016) apontam que o déficit de infraestrutura brasileiro representa um dos principais entraves estruturais ao desenvolvimento. O cenário exposto na pesquisa relata que os problemas brasileiros não se limitam a uma área específica e abrangem diversos sistemas de infraestrutura, cuja razão reside na governança regulatória deficiente aliada ao histórico de negligência de investimento. Explicitam ainda que:

(i) [... com uma economia fortemente dependente das exportações de produtos baseados em recursos naturais, o Brasil sofre, em uma extensão surpreendente, limitações de qualidade e capacidade em sua infraestrutura portuária;

(ii) De 1,75 milhões de quilômetros de rodovias em 2012, apenas $18 \%$ eram pavimentados, representando uma deficiência significativa, em um cenário onde $60 \%$ dos fretes utilizam estradas. [...] Isso não seria tão crítico se a infraestrutura ferroviária fosse altamente desenvolvida.

(iii) [...] as cidades brasileiras estão entre as mais dependentes de automóveis do mundo [...] apresentando aumento de congestionamento e tempo de deslocamentos, além de 
acidentes de trânsito, poluição do ar, uso ineficiente de espaço público e dependência nacional de combustíveis fósseis. (AMANN et al., 2016).

Segundo o relatório "Desafios da Nação" (IPEA, 2018), o contexto de desenvolvimento urbano precário, onde a carência de infraestrutura é imperativo, leva a consequências graves, não somente em termos econômicos e sociais mas também em saúde pública. Por exemplo, a falta de saneamento básico atinge quase 100 milhões de brasileiros e o abastecimento de água tratada não alcança 35 milhões de brasileiros e detém média nacional de 38,29\% de perdas na distribuição (TRATABRASIL, 2019).

Além disso, quando recursos públicos destinados a infraestrutura não se convertem em serviços de qualidade e quantidade adequados, as deficiências afetam a vida urbana em cascata, diminuindo a produtividade, competitividade e a qualidade de vida. Problemas típicos do subdesenvolvimento (MASCARÓ e YOSHINAGA, 2005).

Cidades com um sistema de infraestrutura eficiente, ou seja, abastecidas por serviços como rede de esgoto, água, energia e telefonia oferecem melhorias à qualidade de vida da população, tanto no aspecto econômico quanto no social. Entretanto, as vantagens que a infraestrutura traz podem ser ofuscadas caso os recursos destinados a essa área não tenham embasamento técnico. Podem ocorrer projetos superfaturados, utilização de materiais de má qualidade e ainda a implantação de sistemas sub ou superdimensionados para a demanda. (RADÜNS, 2013, p. 14)

É necessário considerar ainda que tais desafios ultrapassam fronteiras administrativas e exigem planejamento e gestão integrados que amparem o desenvolvimento de espaços urbanos e sejam prévios a sua ocupação e consolidação (IPEA, 2018). Nessa direção, construir cidades do século XXI requer soluções de informática coerentes e orientadas (EL-DIRABY e OSMAN, 2011).

\subsubsection{PROJETO INTEGRADO DE INFRAESTRUTURA}

As cidades se expandiram e aumentaram sua complexidade. Na prática os sistemas de infraestrutura se tornaram cada vez mais interdependentes, no entanto, o planejamento e o projeto urbanos são ainda distribuídos em agentes separados, com administrações limitadas a cada sistema de infraestrutura, 
abordando-os como contíguos independentes (DERRIBLE, 2017). Um contraexemplo dessa visão, que exemplifica a interdependência de SIU, é quando uma obra na rede de água e esgoto interfere no funcionamento da via, por esta recobrir as primeiras.

Derrible (2017) também argumenta que o planejamento e projeto de sistemas de infraestrutura tem sido falho por considerar que suas várias disciplinas seguem uma estrutura lógica em árvore, delineadas apenas por relações lineares em torno de uma perspectiva de sistema estável e de curto prazo, quando tais sistemas possuem relações orgânicas não-lineares, além de longo ciclo de vida. Assim, uma melhor integração entre os sistemas de infraestrutura é potencialmente benéfica para tornar as cidades mais sustentáveis e resilientes, e é imperativo utilizar ferramentas de projeto capazes de lidar com tal natureza.

Segundo Grimsey e Lewis (2002), a construção de sistemas de infraestrutura tem características como larga escala, longo ciclo de vida, longo tempo de desenvolvimento, necessidade de altos investimentos de baixa liquidez, o que resulta em projetos complexos e altamente especializados. Geralmente possuem estruturas complexas e de múltiplas escalas, incluindo diversas instalações que podem se estender horizontalmente por quilômetros e necessitar de detalhamento centimétrico (SHAHROUR; ALILECHE e ALFURJANI, 2017).

Além disso, é necessário considerar que a alta complexidade, alto custo e longa duração implicam em altos riscos e podem reduzir drasticamente a viabilidade de projetos de infraestrutura mal formulados. Nesse sentido, a avaliação e identificação de riscos devem ser claras e conduzidas sob a perspectiva do ciclo de vida, abrangendo desde os estudos de viabilidade até as etapas de operação, com monitoramento contínuo (ZOU; WANG e FANG, 2008).

Por fim, a complexidade referida envolve questões de planejamento e projeto urbano, obras, gestão de ativos urbanos e sistemas de infraestrutura, os quais demandam de ferramental integrado para sustentar serviços existentes com qualidade adequada e possibilitar expansões, melhorias, redução de custos e, em síntese, torná-los mais eficientes (AMORIM, 2016). 


\subsubsection{DIGITALIZAÇÃO DE INFRAESTRUTURA URBANA}

Segundo Sandkuhl (2019), o conceito de digitalização pode ser compreendido como um esforço para converter informações, processos, produtos e serviços e um forma que pode ser processada e suportada por tecnologias de informação. Além disso, como representação digital de conceitos fundamentais às atividades humanas, a digitalização pode aumentar a importância da informação, dados e conhecimento (ZIMMERMANN et al., 2016).

No setor industrial, a digitalização ou transformação digital é parte fundamental da quarta revolução industrial. Também descrita como Industria 4.0, tal transformação envolve mudanças radicais de processos e adoção de tecnologias para melhorar a qualidade e produtividade a partir da conexão entre os sistemas virtual e real gerando fluxos de informação do físico-para-digital-para-físico (CRAVEIRO et al., 2019).

Por analogia, o conceito de Construção 4.0 se baseia na adoção de tecnologias digitais para melhorar a produtividade, reduzir atrasos e custos, melhorar a segurança, gerenciar projetos complexos e recursos com mais eficiência (CRAVEIRO et al., 2019). Nesse sentido, a digitalização tem sido empregada para reduzir problemas de coordenação entre agentes, integrar disciplinas, melhorar colaboração entre equipes e, por consequência, mitigar riscos e custos imprevistos (ou negligenciados) em projetos de infraestrutura (DEBASIS SARKAR, 2016).

Segundo Parrot e Warshaw (2017), o conceito de "digital twins", ou "gêmeos digitais", parte dessa ideia para criar réplicas virtuais do ambiente construído, utilizando-as para visualizar problemas de forma integrada e, assim, desenvolver soluções entre as partes envolvidas (KAEWUNRUEN e LIAN, 2019). Os modelos digitais gerados podem compreender geometrias tridimensionais de componentes e um conjunto de informações semânticas a respeito de materiais, estimativas de custos, funções e relações entre componentes (LU e BRILAKIS, 2019). 
Em se tratando de espaços urbanos, esses modelos digitais têm aplicações em planejamento urbano, cadastramento, visualização e análise de dados geográficos, gerenciamento de ativos, gestão de crises, mitigação de inundações etc. (SHAHROUR; ALILECHE e ALFURJANI, 2017). Podem ser também utilizados como base para o emprego de outras tecnologias relacionadas a $\operatorname{loT}^{1} \mathrm{e}$ smartcities.

Para cidades emergentes em países em desenvolvimento, como o Brasil, a utilização de modelos digitais de espaços urbanos pode ser benéfica para a compreensão de processos de urbanização. Além disso, oferecem novas e aprimoradas oportunidades ao planejamento urbano e permitem que a tomada de decisão e alocação de recursos tenham apreciação de impacto simulada, integrando conhecimento para o gerenciamento de espaços urbanos (THOMPSON et al., 2016).

Por outro lado, o emprego de tecnologias de informação deve ser considerado de forma cautelosa por não ser capaz de resolver ou remediar todos os problemas urbanos, e sim, operar como ferramenta de interpretação aplicada ao processo de planejamento e projeto de cidades (THOMPSON et al., 2016). Além disso, os sistemas atuais baseados em dados estáticos não são capazes de lidar com a "natureza subjetiva e variável de tomadas de decisão", à luz do conhecimento técnico abarcar não somente questões de software, mas também práticas de trabalho e o julgamento humano (EL-DIRABY e OSMAN, 2011).

Tais ressalvas mostram que é crucial a definição clara das tecnologias empregadas em termos dos tipos de informações necessárias a cada fase de desenvolvimento, do formato de dados utilizado e dos processos de trabalho relacionados, de modo a mitigar perdas de informações e melhorar a habilidade de comunicação entre as partes interessadas (SUCHOCKI, 2015). Como exemplo, El-Diraby e Osman (2011) destacam que o avanço das redes sociais enfatiza a importância da comunicação humana conjunta a sistemas de informática, em

${ }^{1}$ IOT: Internet of Things, em potuguês, internet das coisas. 
contraste com os protocolos atuais da indústria baseados em técnicas verbais e papel.

O que se concebe por "dados" e "informações" também deve ser bem compreendido e distinguido, pois não necessariamente o volume de ambos é igual (OLAYA, 2014). Esses conceitos são entendidos da seguinte maneira:

Dados: são simples conjuntos de valores de elementos que utilizamos para representar algo.

Informações: são dados interpretados, providos de significados coerentes ao seu próprio conteúdo. (OLAYA, 2014.Traduzido pelo autor)

Nesse sentido, Goonetillake, Lark e Li (2018) apontam que quando o uso de dados é claramente definido há mais valor adicionado às informações coletadas. Em processos tradicionais, há um grande volume de dados de construção inexplorados por não serem conectados e valorizados como informações estratégicas para fases posteriores, especialmente em gerenciamento de grandes ativos. Sem dizer que um vasto volume de dados provavelmente será descartado ao longo do tempo. Em outras palavras, são perdidas informações que podem ter grande valor no futuro, quando haverá mais demandas de manutenção.

Por fim, Amorim (2015) destaca BIM como um novo paradigma da evolução de tecnologias digitais em face à complexidade crescente dos "Sistemas do Mundo Real", em que a modelagem digital é vista como ferramenta potencial para prover uma visão sistêmica de espaços urbanos, virtualizando suas edificações e sistemas de infraestrutura para buscar soluções através de meios digitais.

\subsection{MODELAGEM DA INFORMAÇÃO DA CONSTRUÇÃO}

Nesta seção são abordadas definições gerais de BIM e aplicações em infraestrutura, níveis de maturidade e difusão de BIM no Brasil e, por fim, são apresentados sucintamente alguns softwares BIM com aplicações para projeto de infraestrutura. 


\subsubsection{TERMOS E DEFINIÇÕES GERAIS}

Compreender o que é modelagem da informação da construção (tradução de Building Information Modeling - BIM) é uma condição básica para aplicá-lo em infraestrutura urbana.

Segundo Eastman et al. (2008), BIM representa o processo de desenvolvimento e uso de um modelo virtual para o planejamento, concepção, construção e operação de uma de edificação. O modelo resultante é um conjunto de dados rico, orientado a objetos, inteligente e de representação digital paramétrica de elementos de construção (AZHAR, 2011).

Fundamentalmente, BIM parte da criação de modelos digitais tridimensionais progressivamente desenvolvidos e conectados com informações de diversas disciplinas de projeto; no entanto, BIM não é apenas um modelo geométrico. Succar (2009) define BIM como um conjunto de tecnologias de modelagem, processos e políticas para gerenciar dados de projeto de forma digital ao longo do ciclo de vida de construções.

Inicialmente as aplicações de BIM foram adotadas na arquitetura e, em seguida, ampliaram-se para outras disciplinas de projeto. À medida que seu uso se intensificou em edificações, aproximou-se de uma escala maior: a modelagem de cidades e da infraestrutura urbana.

BIM para infraestrutura não é uma aspiração; é um processo gerenciado para alavancar a tecnologia disponível a fim de compreender o contexto de um projeto, explorar e avaliar opções, fornecendo um conjunto abrangente e acurado de dados. (SUCHOCKI, 2015, traduzido pelo autor)

Em um cenário amplo, o tema tem sido tratado e desenvolvido por diferentes áreas do conhecimento, pelas quais diversos termos foram cunhados para as tecnologias em questão, vide Tabela 2. 
Tabela 2 - Acrônimos e significados de termos para modelagem de informações em infraestrutura

\begin{tabular}{ll}
\hline Acrônimo & Significado \\
\hline BIM & Building Information Modeling \\
BrIM & Bridge Information Modeling \\
CAD & Computer-Aided Design \\
CIM & Civil Integrated Management \\
CiM & Civil information Modeling \\
CIM & Computer-Integrated Management \\
CIM & Construction Information Management \\
CIM & Construction Information Modeling \\
VDC & Virtual Design and Construction \\
\hline
\end{tabular}

Fonte: Adaptado de Costin et al. (2018).

Além das nomenclaturas apresentadas, outro significado recorrente é City Information Modeling (CIM), termo compreendido como uma extensão do conceito de BIM aplicado ao contexto urbano (AMORIM, 2015).

A par das nomenclaturas apresentadas e a fim de manter uma abordagem coerente, nesse trabalho se adota o termo BIM para modelagem de infraestrutura urbana, considerando CIM e demais termos derivações da primeira.

\subsubsection{DIMENSÕES DE MODELOS BIM}

Utilizado como um inventário de ciclo de vida para modelar e coletar informações relacionadas a construções, BIM partilha um princípio integrador como um robusto banco de dados (ALMEIDA e ANDRADE, 2015). Um modelo integrado deve servir como um banco de dados manuseável por todas as especialidades de projeto, construtores e gestores (FABRICIO, 2013). Integração e interoperabilidade são questões centrais de modelagem BIM, vieses que a promovem como ferramenta colaborativa de trabalho com grande potencial de integrar outras tecnologias e disciplinas (SUCCAR; SHER; WILLIAMS, 2013).

Conceitualmente, um modelo BIM pode ser entendido como uma representação multidimensional das características físicas e funcionais de uma construção, cujo desenvolvimento pode focar em fases específicas do seu ciclo de vida, como 
planejamento de atividades e estimativa de custos de obras, análises de desempenho energético e aplicações para gerenciamento de operação e manutenção (CBIC, 2016a).

Assim, se informações de planejamento de atividades e de custo forem adicionadas a um modelo geométrico, então, são gerados modelos 4D e 5D, respectivamente. Outros usos, como análises de desempenho energético e gerenciamento de manutenção e operação, são dispostos em modelos designados 6D e 7D (SECRETARIA DE INFRAESTRUTURA E LOGÍSTICA DEPARTAMENTO DE GESTÃO DE PROJETOS E OBRAS, 2018). Desse modo, tais dimensões conceituais podem ser compreendidas como formas descritivas de introduzir diferentes tipos de dados e informações nos modelos.

As diferentes abordagens retratadas na dimensões BIM referidas não necessariamente são concebidas em um mesmo modelo ou arquivo de trabalho, seja em função das capacidades de software, seja pelas especialidades dos profissionais envolvidos (CBIC, 2016a). A depender da configuração de diferentes equipes de trabalho, o modelo pode ser desenvolvido de forma segmentada por meio de modelos distintos para cada disciplina, posteriormente concatenados em um "modelo federado" ou "modelo compartilhado" para análises de compatibilidade, verificação e validação de informações (CIRIBINI; MASTROLEMBO VENTURA e PANERONI, 2016).

Nesse aspecto, os formatos para troca e integração de dados são questões fundamentais para garantir o acesso a informações, interoperabilidade e compatibilidade entre arquivos.

\subsubsection{NÍVEL DE DESENVOLVIMENTO - ND (LOD)}

A criação de modelos BIM é progressiva e se relaciona aos sucessivos processos e etapas de projetos (ABDI, 2017). O desenvolvimento de conteúdo de informações é a essência da modelagem BIM, como um processo gradual antecipatório que torna possível corrigir digitalmente não conformidades, conduzindo os agentes de projeto a adotarem mentalidades e protocolos que podem mitigar riscos (CIRIBINI, 2013). 
O desenvolvimento de modelos BIM pode ser medido por meio do conceito de nível de desenvolvimento (ND) ou LOD (Level Of Development), no qual são estabelecidos em escala crescente os diferentes graus de definição para o modelo, como esquematizado na Figura 2 e conceituados no Quadro 2.

Figura 2 - Níveis de desenvolvimento de modelos BIM

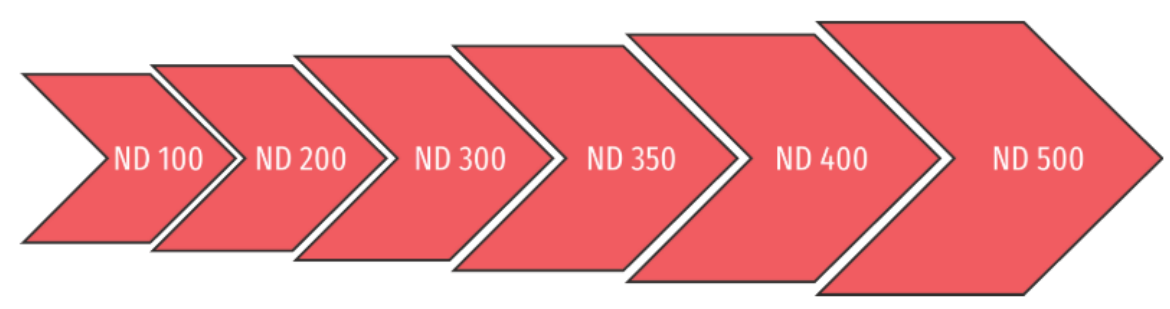

Fonte: ABDI (2017).

Quadro 2 - Conceitos de níveis de desenvolvimento

\section{ND (LOD) CONCEITO}

0 elemento do modelo é representado no Modelo com um símbolo ou outra

100 representação genérica. Informações relacionadas ao elemento podem ser derivadas de outros elementos do modelo.

0 elemento do modelo é representado no Modelo como um sistema genérico,

200 objeto ou montagem com quantidades aproximadas, tamanho, forma, localização e orientação. Informações não gráficas podem ser anexadas ao elemento.

0 elemento do modelo é representado no Modelo como um sistema, objeto ou 300 conjunto específico em termos de quantidade, tamanho, forma, localização e orientação. Informações não gráficas podem ser anexadas ao elemento.

0 elemento do modelo é representado no Modelo como um sistema, objeto ou conjunto específico em termos de quantidade, tamanho, forma, localização,

350 orientação e interfaces com outros sistemas de construção. Informações não gráficas podem ser anexadas ao elemento.

0 elemento do modelo é representado no Modelo como um sistema, objeto ou conjunto específico em termos de quantidade, tamanho, forma, localização,

400 orientação com detalhes, fabricação, montagem e informações de instalação. Informações não gráficas podem ser anexadas ao elemento.

0 elemento é uma representação verificada em campo em termo de tamanho, 500 forma, localização, quantidade e orientação. Informações não gráficas podem ser anexadas ao elemento. 
CBIC (2016b) e ABDI (2017) ressaltam a importância de distinguir o "nível de desenvolvimento" de "nível de detalhe". Este último diz respeito somente ao volume e complexidade de detalhes inseridos nos elementos modelados, o que não necessariamente é condizente com a maturidade do projeto. Por outro lado, "nível de desenvolvimento" é uma medida mais ampla que considera o nível de confiança das informações associadas aos elementos do modelo, resultante de processos decisórios no desenvolvimento e a maturidade de projeto.

No entanto, as classificações de LOD são focadas em projetos de edificações e não cobrem claramente as áreas de infraestrutura, em termos de como as informações devem ser tratadas ao longo do ciclo de vida de projetos e quais níveis devem ser atingidos por cada agente (HIJAZI e OMAR, 2017).

Tolmer et al. (2017) ressaltam que as abordagens de LOD existentes não são suficientes e nem sempre coerentes para projetos de infraestrutura urbana, os quais necessitam convergir dados de diferentes escalas (locais e territoriais). Determinar de forma genérica um único LOD para todo o projeto pode ser incoerente com as especificidades e requerimentos de cada disciplina. Por exemplo, um modelo contendo edificações, sistemas de infraestrutura e dados geográficos pode possuir definições heterogêneas de seus componentes em função de diferentes graus de precisão de dados topográficos levantados, indefinições durante fases projetuais, ou mesmo inexistência de informações (sistemas subterrâneos antigos, por exemplo).

Adicionalmente, Tolmer et al. (2017) propõem uma abordagem para determinar as classes de LOD decompondo-o em (i) nível detalhe (tratando da complexidade geométrica, dimensionalidade e aparência de componentes); (ii) nível de informação (relativo aos atributos semânticos / não geométricos); e (iii) nível de abstração (para identificar e determinar os objetos relevantes a serem considerados para cada uso BIM). Destacam-se também três estágios de análise necessários:

1. Identificar requerimentos e semântica para cada elemento a ser modelado;

2. Por meio de abstrações, traduzir a semântica em objetos e sistemas, com funções determinadas e estruturadas de acordo com cada disciplina;

3. Determinar padrões para o intercâmbio de informações. 
Por fim, cabe ressaltar de Hijazi e Omar (2017) a necessidade de descrever claramente formatos de dados e plataformas considerando os vários setores da indústria da construção, cobrindo suas limitações e as dos softwares também. Em especial, a ampliação do uso de BIM em infraestrutura depende fundamentalmente de tais definições.

\subsubsection{NÍVEIS DE MATURIDADE}

Uma forma de medir a implementação de BIM é através do conceito de nível de maturidade. Succar (2009) organiza esse conceito partindo de um nível zero (Pré BIM) e, em seguida, divide em três graus principais de maturidade: 1. Objetos baseados em Modelagem, 2. Modelos baseados em Colaboração e 3. Rede baseada em Integração. Baseando-se no conceito de Projeto integrado, tais níveis têm como objetivo o desenvolvimento integrado de projetos, o que é apresentado de forma encadeada na Figura 3.

Figura 3 - Níveis de implementação BIM
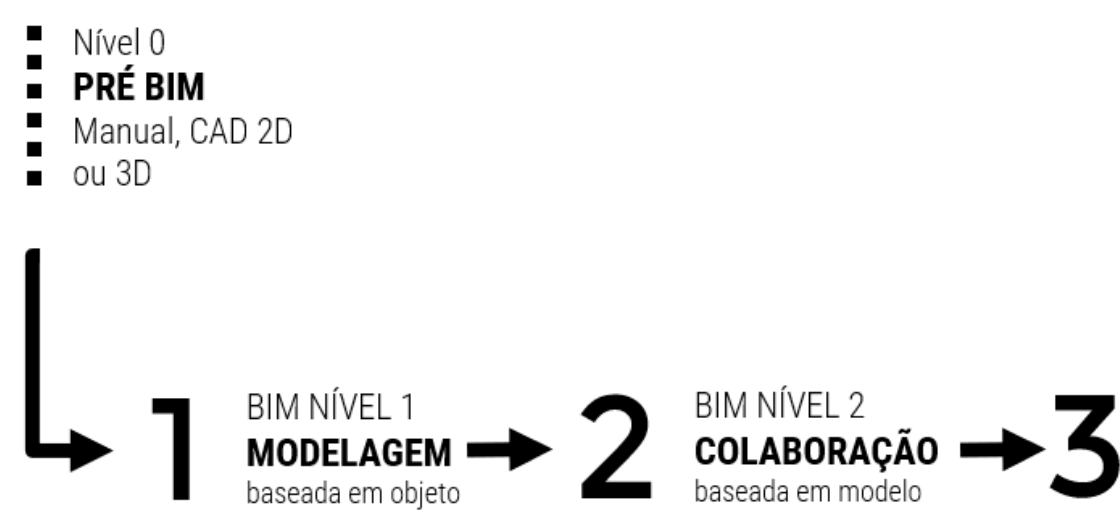

BIM NÍVEL 3
INTEGRAÇÃo
baseada em nuvem

Projeto integrado

IPD

Objetivo de longo prazo de BIM

Fonte: Adaptado de Succar (2009).

A diferença entre níveis é baseada no nível de colaboração entre partes envolvidas e de integração de informações, parâmetros crescentes a cada estágio. Além 
disso cada estágio é definido pelos tipos de dados disponíveis em um modelo. Assim, segundo BSI (2013):

No nível 0 (Pré BIM), ferramentas CAD são utilizadas para gerar desenhos baseados em linhas, formas, hachuras. A colaboração é baseada no compartilhamento segmentado de documentos digitais e impressões.

No nível 1, os desenhos (2D) são combinados com modelos geométricos em um ambiente comum de dados, embora a colaboração ainda seja limitada. A integração de dados e interoperabilidade são parciais.

No nível 2, outras dimensões são adicionadas aos modelos como gerenciamento de tempo (4D) e cálculos de custos (5D). Nesse nível a colaboração é considerada total enquanto a interoperabilidade parcial, utilizando modelos distintos.

No nível 3, a integração e interoperabilidade são consideradas totais. Adiciona-se a sexta dimensão relativa ao gerenciamento de utilidades (facilities management)

Figura 4 - Modelo de maturidade BIM

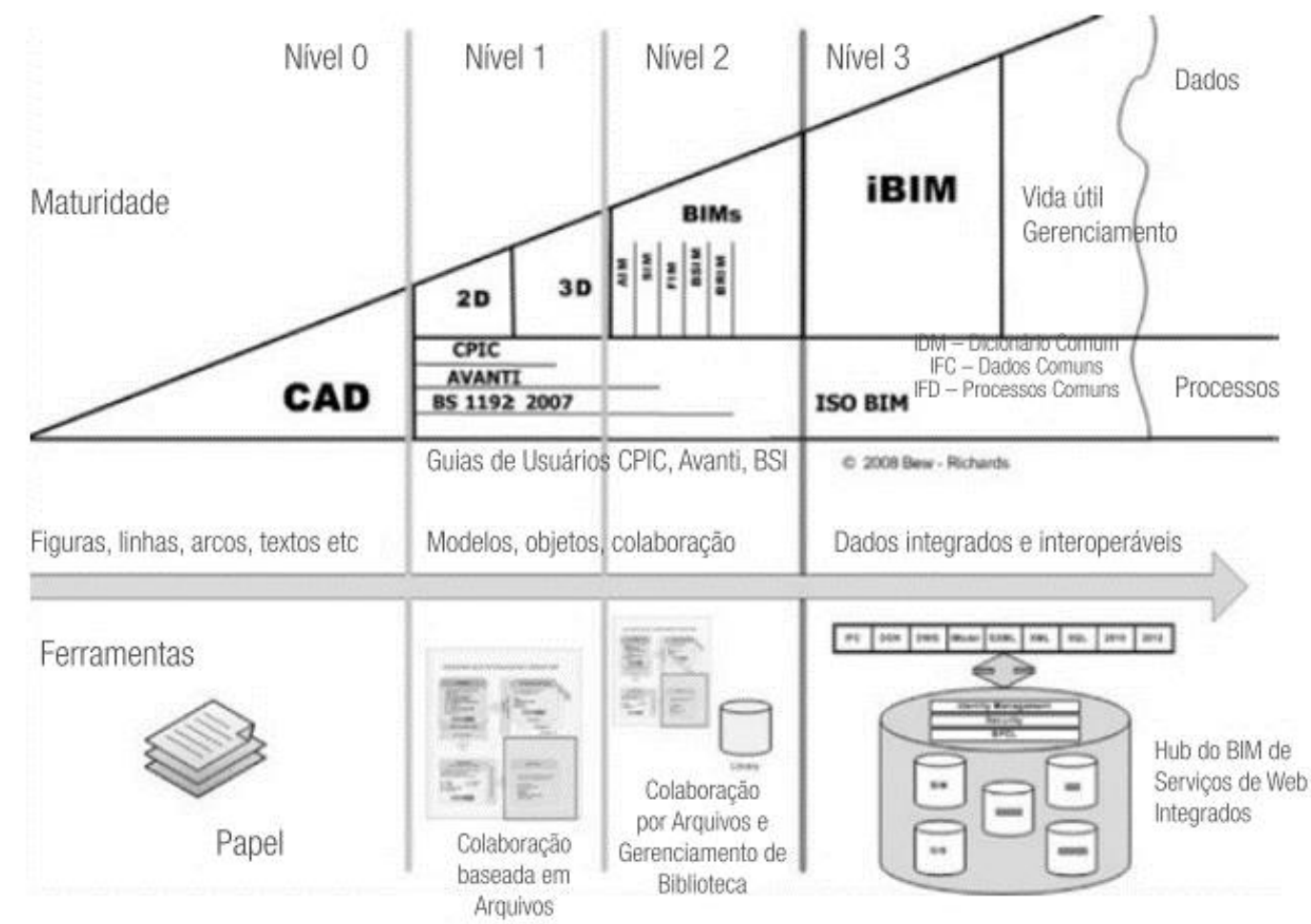

Fonte: BSI (2013) e MDIC (2015). 
Em síntese, a Figura 4 apresenta o modelo de maturidade BIM de Bew e Richards (2008), organizando os níveis de maturidade BIM e os respectivos dados disponíveis, bem como a indicação dos graus de colaboração e integração em reta crescente.

\subsubsection{DIFUSÃO DE BIM NO BRASIL}

Sob a luz do conceito de projeto integrado (Integrated Project Delivery - IPD), a implantação de BIM abre novas formas de gerenciar a informação na construção civil, impactando as várias etapas de um empreendimento, do projeto à obra, da aquisição de materiais à manutenção (FABRICIO, 2013). Nesse sentido, Succar e Kassem (2015) apontam BIM como a expressão atual da inovação na indústria da Arquitetura, Engenharia, Construção e Operação (AECO), onde seus conceitos e ferramentas têm encorajado mudanças organizacionais e individuais de forma revolucionária e evolutiva.

Tais mudanças requerem que os elos de toda cadeia produtiva adotem novas posturas e formas de trabalho, o que por um lado tem potencial de desencadear progressos ao setor, mas por outro, insere desafios em como adotar uma nova plataforma tecnológica, dispor condições de viabilidade e consolidar ferramentas que, de fato, conjuguem abordagens multidisciplinares e abranjam todo o ciclo de vida de uma construção. Radüns (2013) ressalta que BIM exige uma nova forma de pensar o processo de projeto, a qual traz, na essência, a padronização dos sistemas na construção e a interação virtual entre os envolvidos.

De acordo com Ciribini (2013), embora a modelagem BIM possa ser relacionada às atividades de planejamento, ela as transcende como processo conceitual antecipatório orientado a metas e que pode ser fundamental à gestão de obras em função das práticas baseadas em integração e colaboração na resolução de conflitos.

Segundo pesquisa realizada pela McGraw Hill (2014), a difusão de BIM no Brasil é recente e em grande parte (70\%) implementada há poucos anos - quando comparada a outros países -, como apresenta a Figura 5. 
Figura 5 - Tempo de implementação de BIM por empresas (por região/país)

\begin{tabular}{|c|c|c|c|c|}
\hline & $\square 1-2$ anos $\square 3$ & nos $\square-10$ anos & - 11 anos ou mais & \\
\hline EUA \& Canadá & $14 \%$ & & $28 \%$ & $8 \%$ \\
\hline Japão \& Coréia do Sul & $25 \%$ & $55 \%$ & & $17 \%$ \\
\hline Australia \& Nova Zelândia & $39 \%$ & $50 \%$ & & $9 \% \quad 2 \%$ \\
\hline Reino, França \& Alemanha & $47 \%$ & & $41 \%$ & $3 \% \quad 9 \%$ \\
\hline Brasil & $70 \%$ & & $27 \%$ & $3 \%$ \\
\hline
\end{tabular}

Fonte: Adaptado de McGrawHill (2014).

Em se tratando de projetos de infraestrutura, o mesmo estudo aponta que a utilização de BIM é menos significativa que em edificações, no entanto, o Brasil figura na terceira posição mundial, com a utilização de BIM por $28 \%$ dos contratantes estudados, vide Figura 6.

Entre exemplos brasileiros, ressalta-se o uso de BIM para a infraestrutura do Metrô de São Paulo, o qual desde de 2012 promove sua utilização em atividades de projeto e construção de vias e estações (MAINARDI NETO, 2016, p. 25-26). Outro exemplo é da Secretaria de Infraestrutura e Logística do estado do Paraná, cuja adoção de BIM foi estabelecida no plano de metas 2015-2018 e, juntamente com os estados de Santa Catarina e Rio Grande do Sul, a REDE BIM GOV SUL tem sido desenvolvida afim de promover ações integradas de fomento à implantação de BIM (PARANÁ, 2018).

Em um panorama em que a indústria da construção brasileira é uma das maiores do mundo ( $2 \%$ da indústria global), a utilização de BIM pode gerar impactos positivos e significativos (i) na eficiência e sustentabilidade do setor; (ii) na previsibilidade e retorno de investimentos e (iii) nas exportações e crescimento econômico (MDIC, 2015). 
Figura 6 - Porcentagem de Contratantes que utilizam BIM por tipologias de projeto (por país)

\begin{tabular}{|c|c|c|c|c|c|c|c|c|c|}
\hline \multicolumn{10}{|l|}{ Projetos de edificações } \\
\hline & \multicolumn{2}{|c|}{$\begin{array}{l}\text { Acima de } \\
40 \%\end{array}$} & \multicolumn{2}{|c|}{$30 \%-40 \%$} & \multicolumn{2}{|c|}{$15 \%-29 \%$} & \multicolumn{3}{|c|}{ Abaixo de $15 \%$} \\
\hline & $\begin{array}{l}\text { Reino } \\
\text { Unido }\end{array}$ & França & $\begin{array}{l}\text { Alema- } \\
\text { nha }\end{array}$ & EUA & $\begin{array}{c}\text { Canad } \\
\text { á }\end{array}$ & Brasil & Japão & $\begin{array}{l}\text { Coréia } \\
\text { do sul }\end{array}$ & $\begin{array}{l}\text { Aus } / N \\
Z\end{array}$ \\
\hline $\begin{array}{l}\text { Comerciais (escritórios, } \\
\text { varejo, hoteis) }\end{array}$ & $69 \%$ & $68 \%$ & $59 \%$ & $66 \%$ & $54 \%$ & $53 \%$ & $63 \%$ & $48 \%$ & $70 \%$ \\
\hline $\begin{array}{l}\text { Intitucionais (educação, } \\
\text { saúde, religião) }\end{array}$ & $61 \%$ & $32 \%$ & $31 \%$ & $77 \%$ & $41 \%$ & $31 \%$ & $23 \%$ & $35 \%$ & $39 \%$ \\
\hline $\begin{array}{l}\text { Governamentais (tribunais, } \\
\text { embaixadas, cívico/esportes e } \\
\text { convenções) }\end{array}$ & $54 \%$ & $10 \%$ & $22 \%$ & $68 \%$ & $44 \%$ & $12 \%$ & $0 \%$ & $51 \%$ & $37 \%$ \\
\hline Residencial multifamiliar & $33 \%$ & $35 \%$ & $44 \%$ & $18 \%$ & $26 \%$ & $19 \%$ & $23 \%$ & $20 \%$ & $26 \%$ \\
\hline Residencial unifamiliar & $17 \%$ & $19 \%$ & $22 \%$ & $1 \%$ & $10 \%$ & $16 \%$ & $0 \%$ & $1 \%$ & $4 \%$ \\
\hline \multicolumn{10}{|l|}{ Outros projetos } \\
\hline & $\begin{array}{l}\text { Reino } \\
\text { Unido }\end{array}$ & França & $\begin{array}{l}\text { Alema- } \\
\text { nha }\end{array}$ & EUA & $\begin{array}{c}\text { Canad } \\
\text { á }\end{array}$ & Brasil & Japão & $\begin{array}{l}\text { Coréia } \\
\text { do sul }\end{array}$ & $\begin{array}{c}\text { Aus/N } \\
Z\end{array}$ \\
\hline $\begin{array}{l}\text { Infraestrutura (estradas, } \\
\text { pontes, túneis, barragens, } \\
\text { água e esgoto) }\end{array}$ & $33 \%$ & $19 \%$ & $16 \%$ & $14 \%$ & $31 \%$ & $28 \%$ & $13 \%$ & $24 \%$ & $25 \%$ \\
\hline Industrial e manufatura & $26 \%$ & $23 \%$ & $19 \%$ & $35 \%$ & $36 \%$ & $31 \%$ & $47 \%$ & $24 \%$ & $34 \%$ \\
\hline Energia (geração, óleo e gás) & $20 \%$ & $13 \%$ & $3 \%$ & $18 \%$ & $28 \%$ & $12 \%$ & $0 \%$ & $21 \%$ & $16 \%$ \\
\hline $\begin{array}{l}\text { Mineração / Recursos } \\
\text { naturais }\end{array}$ & $6 \%$ & $0 \%$ & $0 \%$ & $4 \%$ & $18 \%$ & $6 \%$ & $0 \%$ & $1 \%$ & $11 \%$ \\
\hline
\end{tabular}

Fonte: Adaptado de McGrawHill (2014)

McKinsey Global Institute (2017) aponta ainda ser imperativo considerar (i) a necessidade de ajustes e padronização em modelos regulatórios para melhor transparência no setor; (ii) reenquadrar modelos contratuais considerando práticas de projeto integrado (IPD); (iii) repensar processos construtivos, utilizando conhecimento para inovar; (iv) adotar rigorosos processos de planejamento e conceitos de construção enxuta, tecnologias digitais como BIM 4D e 5D, novos materiais e automação avançada; e (iv) capacitar continuamente a mão-de-obra.

Nesse sentido, Succar (2009) descreve a implantação de BIM como um processo socio-técnico, caracterizado por três esferas fundamentais: tecnologia, processos e pessoas. Segundo ABDI (2017, p. 10):

- Tecnologia: diz respeito a infraestrutura de softwares, hardware, sistema de comunicação (rede local e internet) e demais aparatos tecnológicos necessários à operação de modelos BIM. 
- Pessoas: abrange os recursos humanos envolvidos, as demandas de capacitação de equipes na utilização de recursos e a incorporação de conhecimentos de tecnologias BIM.

- Processos: trata da compreensão de práticas a serem adotadas em termos de planos de trabalho, métodos de comunicação, funções das partes envolvidas, especificações de entregáveis e demais relações entre partes internas e externas

A interseção entre as dimensões apresentadas (vide Figura 7) conjuga Procedimentos, Normas e Boas práticas para o uso das tecnologias BIM (ABDI, 2017), os quais têm sido desenvolvidos por diferentes organizações. Nesse aspecto, iniciativas importantes foram tomadas nos últimos anos para ampliar e regulamentar o uso de BIM no Brasil, como a "estratégia nacional de disseminação de BIM" (MDIC, 2018) e programas pilotos governamentais.

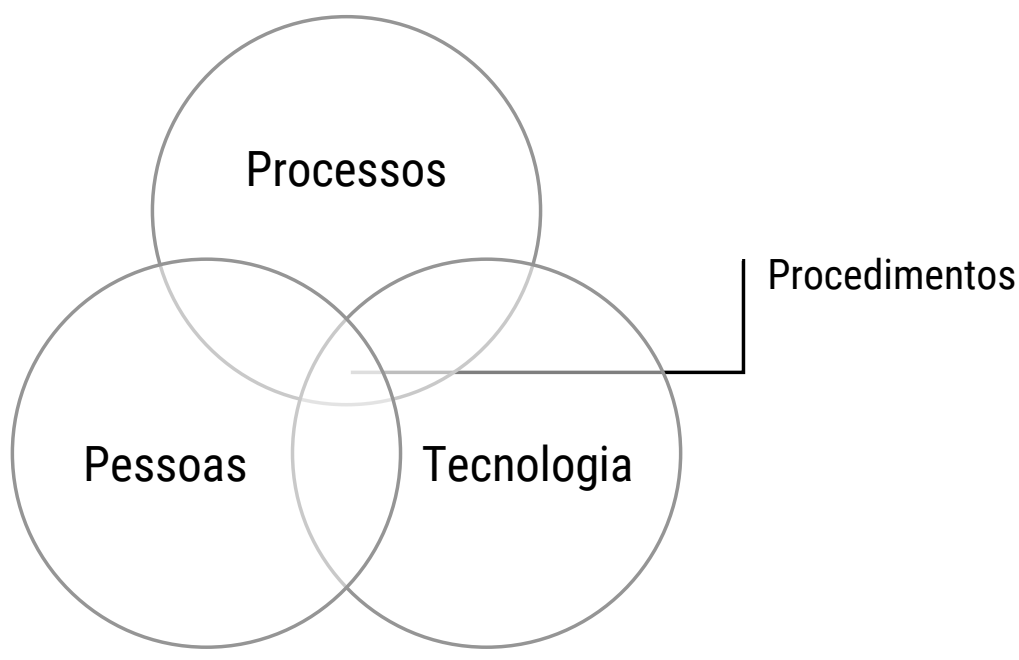

Fonte: Adaptado de ABDI (2017).

A estratégia brasileira prevê metas até 2028 de incentivo e desenvolvimento continuados, além de mobilização do setor para difundir, capacitar e regulamentar a utilização de BIM. Tais metas focam em aumentar a produtividade, reduzir custos e elevar o PIB do setor de construções (MDIC, 2018). outras iniciativas e publicações nacionais também podem ser destacadas (Tabela 3). 
Tabela 3 - Iniciativas governamentais brasileiras para disseminação de BIM

\begin{tabular}{|c|c|}
\hline Publicação & Referência \\
\hline $\begin{array}{l}\text { Decreto } 9.377 \text { - Instituição da estratégia } \\
\text { Nacional de disseminação de BIM; }\end{array}$ & Governo Federal (2018) \\
\hline $\begin{array}{l}\text { Guia 1: Processo de projeto BIM } \\
\text { Guia 2: Classificação da informação BIM } \\
\text { Guia 3: Planejamento e gestão de serviços } \\
\text { da construção } \\
\text { Guia 4: Contratação e elaboração de } \\
\text { projetos BIM na arquitetura e engenharia } \\
\text { Guia 5: Avaliação de desempenho } \\
\text { energético em Projetos BIM } \\
\text { Guia 6: A implantação de processos BIM }\end{array}$ & $\begin{array}{l}\text { Coletânea de Guias BIM da ABDI- } \\
\text { MDIC (2017) }\end{array}$ \\
\hline $\begin{array}{l}\text { Estruturação do escritório de projeto para } \\
\text { a implantação do BIM }\end{array}$ & $\begin{array}{l}\text { Guia AsBea de boas práticas em BIM } \\
\text { - Fascículo } 1 \text { (2013) }\end{array}$ \\
\hline $\begin{array}{l}\text { Fluxo de Projetos em BIM: Planejamento e } \\
\text { Execução GTBIM }\end{array}$ & $\begin{array}{l}\text { Guia AsBea de boas práticas em BIM } \\
\text { - Fascículo } 2 \text { (2015) }\end{array}$ \\
\hline Guias BIM CBIC & CBIC \\
\hline Caderno BIM do Estado de Santa Catarina & $\begin{array}{l}\text { (SECRETARIA DE INFRAESTRUTURA } \\
\text { E LOGÍSTICA DEPARTAMENTO DE } \\
\text { GESTÃO DE PROJETOS E OBRAS, } \\
\text { 2018); }\end{array}$ \\
\hline Biblioteca nacional de componentes BIM & ABDI (2019) \\
\hline $\begin{array}{l}\text { Diálogos setoriais para BIM no Brasil e na } \\
\text { União Europeia } 2015\end{array}$ & MDIC (2015) \\
\hline Projetos piloto governamentais: & $\begin{array}{l}\text { DNIT-PROARTE, BIM no Exército } \\
\text { Brasileiro, BIM no Ministério da } \\
\text { Saúde, BIM na ANAC. }\end{array}$ \\
\hline
\end{tabular}

Fonte: Autor (2019).

Embora essas iniciativas forneçam informações fundamentais e relevantes para o domínio de conhecimento e para ampliar a difusão de BIM no Brasil, é necessário considerar que os atuais planos de gerenciamento BIM são focados em edificações, em termos dos padrões, requisitos e ambientes de dados comuns (HIJAZI e OMAR, 2017). Desse modo:

- as abordagens BIM para projetos de infraestrutura necessitam de adaptações tecnológicas para que o uso seja promovido e se integre a normas brasileiras; 
- a padronização de famílias de componentes, templates de projeto e ferramentas de apoio para projetos urbanos deve ser continuamente ampliada; e

- a integração de dados geográficos e modelos BIM deve ser facilitada e amadurecida.

\subsubsection{SOFTWARES BIM PARA INFRAESTRUTURA}

Diferentes ferramentas BIM têm sido desenvolvidas para modelagem de sistemas de infraestrutura urbana. Fabricantes como Autodesk e Bentley figuram entre os grandes players do setor, dispondo de conjuntos de soluções específicas para projetos de infraestrutura urbana. Neste trabalho, foram adotados os softwares da Autodesk, especificamente o Autodesk Infraworks, o Autodesk Recap e o Autodesk Civil 3D

O InfraWorks é um software de estudos preliminares de infraestrutura urbana, com suporte para processos de modelagem BIM. Utilizado principalmente em etapas de concepção e estudos de viabilidade de sistemas de infraestrutura urbana, o software permite a criação de modelos digitais de espaços urbanos a partir de dados 2D CAD, modelos geométricos, dados SIG e imagens raster. Permite a geração de superfícies topográficas a partir de nuvens de pontos e imagens de satélite (AUTODESK, 2019a).

Possui ferramentas organizadas para três abordagens: (i) vias de transporte, (ii) pontes e túneis e (iii) hidráulica e drenagem urbana. Na concepção de projetos viários permite a modelagem de vias a partir de superfícies topográficas do terreno com a utilização de biblioteca de componentes paramétricos disponibilizada para cada país. Permite a visualização de seções transversais e longitudinais de vias e determinação de materiais e parâmetros como declividade, velocidade de tráfego, raios mínimos de curva e superelevação para diferentes seções. Na modelagem de pontes e túneis, o software possui biblioteca com modelos paramétricos para a edição independente de componentes de acordo com as necessidades de projeto. Para sistemas de água e esgoto e drenagem, o 
software permite a modelagem georreferenciada de componentes (dutos, calhas e caixas coletoras, poços de visita e inspeção etc.). Permite também a limitação de bacias hidrográficas para cálculo estimado de vazões.

Além disso, o software dispõe de ferramentas dinâmicas para análise da modelagem de terrenos, de mensuração de distâncias horizontais, verticais, áreas, volumes e de inclinação de terreno com classificações automáticas em formato de mapas de elevação. Tais ferramentas permitem simular inundações analisando componentes de drenagem e características topográficas do terreno.

A integração de nuvens de pontos é feita por meio do software Autodesk Recap, no qual é feita a conversão de formatos, registro e segmentação de nuvens de pontos. O Recap possui ferramentas para registro e edição de nuvens de pontos, possibilitando configurações de sistemas de coordenada e preparando arquivos para serem integrados ao InfraWorks (AUTODESK, 2019b).

A integração com dados SIG é possibilitada pela interface com o software ArcGIS. Outros softwares de projeto BIM como Autodesk Civil 3D e Autodesk Revit também possuem interfaces nativas no InfraWorks.

O Infraworks foi adotado nesse trabalho para a integração de modelos BIM com dados espaciais, vindos de levantamentos aéreos e outros dados existentes, conforme apresentado na Figura 8. 


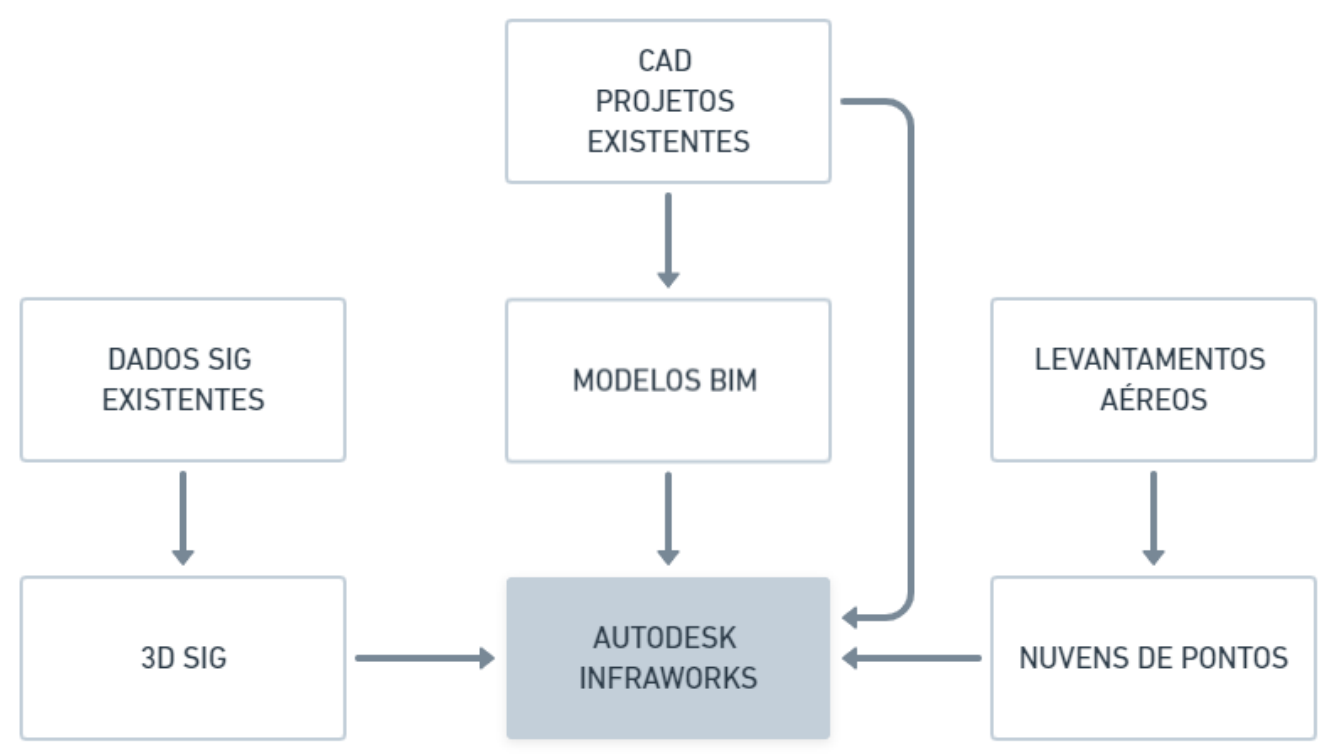

Fonte: Adaptado de Baik, Yaagoubi e Boehm (2015).

Alguns benefícios no uso do Infraworks em projetos de infraestrutura são: integração de múltiplos dados em uma mesma base georreferenciada; ferramentas de comunicação via web para auxiliar em processos colaborativos e possibilitar acesso interoperável; análises e estudos ágeis utilizando ferramentas de projeto dinâmicas e com atualização de dados em tempo real (AUTODESK, 2019a).

Por fim, a utilização do Infraworks permite visualização integrada de modelos, o que instrumenta a tomada de decisão com dados integrados de disciplinas e cenários simulados por proposta de projeto.

O Civil 3D, software desenvolvido pela Autodesk, dispõe de ferramentas para detalhar projetos preliminares desenvolvidos no InfraWorks. Possuem ferramentas para projeto, detalhamento e documentação de estradas e vias urbanas, intersecções, redes de abastecimento de água e coleta, drenagem urbana, coleta de esgoto e modelagem geotécnica (AUTODESK, 2019c).

Nele é possível criar modelos detalhados de obras integrando dados topográficos, componentes de vias e redes de tubulações de forma paramétrica. Além disso, 
possui interface com outros softwares BIM da Autodesk como Revit para projeto de edificações, NavisWorks para modelagem 4D, e Dynamo para programação de rotinas automatizadas de modelagem.

\subsubsection{BIM E DOCUMENTAÇÃO DE INFRAESTRUTURA}

A documentação de infraestrutura baseada em BIM possibilita que a indústria expanda sua capacidade de explorar informações projetuais focando no valor dos dados, e não somente em rotinas de desenho e representação, como ocorre em CAD (SUCHOCKI, 2015). Para além da visão curta e segmentada dos métodos tradicionais, "BIM preconiza a gestão de informação ao longo de todo ciclo de vida de um ativo, com abordagens gerenciadas para coletar e usar informações ao longo de suas fases".(SUCHOCKI, 2015)

No entanto, Goonetillake, Lark e Li (2018) ponderam que o desafio é conseguir manusear de forma segura o grande volume de informações do ciclo de vida de construções. É necessário compreender os requerimentos de vários usuários ao longo do tempo e possibilitar a filtragem de informações de acordo com o valor de importância para cada um em particular, de modo a estabelecer como a informação deve ser estruturada, qual documentação e formato são necessários, e como será manuseada.

Ainda sim, Debasis Sarkar (2016) defende que o uso de BIM pode possibilitar a projetos de infraestrutura melhor coordenação e alocação de recursos, melhorando o controle de qualidade e o gerenciamento de equipamentos, materiais e segurança. Permite também visualizar potenciais economias, bem como monitorar desvios de planejamento de obras, em tempo e custo. Com isso, é possível antecipar resoluções críticas para fases cujo risco financeiro é menor e há maior capacidade de influenciar a qualidade do projeto, além de detectar previamente oportunidades de melhoria. Tais princípios são ilustrados pela curva de MacLeamy (Figura 9). 
Figura 9 - Curva de MacLeamy: comparativo entre processos tradicionais baseados em CAD e processos BIM
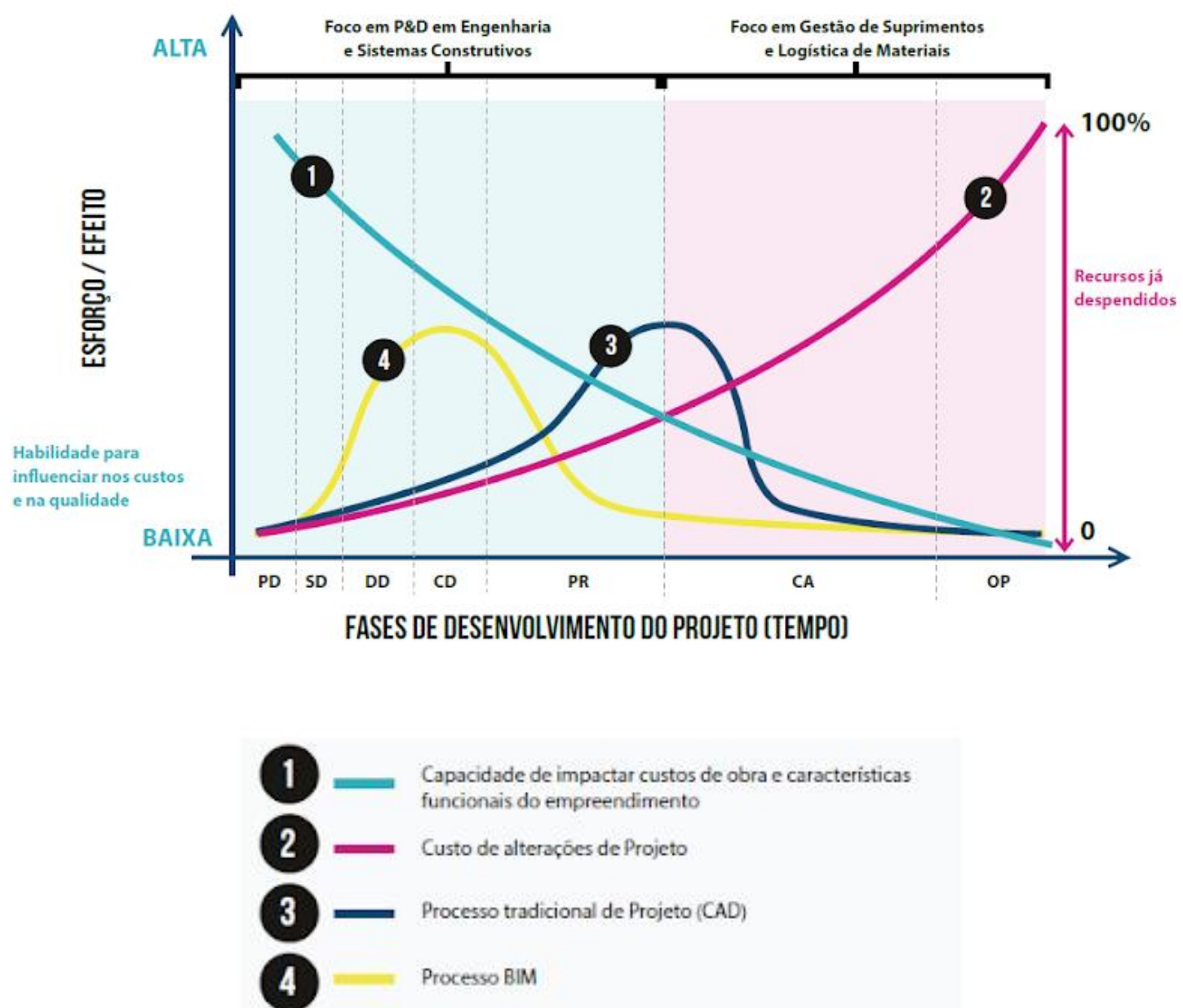

Fonte: Adaptado de CBIC (2016b)

Entre as razões, BIM promove a comunicação e colaboração baseada em modelos digitais, de forma que as diversas especialidades podem ser coordenadas por uma base única de projetos. Em outras palavras, a documentação técnica passa a ser ancorada em uma única fonte de verdade, do inglês single source of truth (SSOT), o que é potencialmente benéfico para reduzir dados obsoletos e imprecisos e minimizar o risco de falhas na gestão de informação gerarem falhas operacionais.

Em fases de pré-construção, Fanning et al. (2014) retratam a utilização de BIM no desenvolvimento de projetos apontando resultados de redução de 5 a $9 \%$ nos custos da construção, em uma análise comparativa de projetos de infraestrutura viária. Além disso, observam que a ferramenta possibilita aos gestores ver, 
organizar e monitorar dados de coleções distintas de ativos, embora pelas ferramentas atuais seja necessário melhorar a padronização e compatibilização de formatos de dados geoespaciais e a integração de BIM e GIS.

As possibilidades de criar relações entre parâmetros de componentes BIM permitem otimizar processos de projeto de infraestrutura evitando erros decorrentes de dados duplicados e favorecendo o controle de elementos de projeto em análises geotécnicas, como exemplificam Osello, Rapetti e Semeraro (2017) com simulações estruturais e geotécnicas de fases de construção e estimativas de custos utilizando famílias paramétricas com alto nível de detalhamento.

Para fase de construção, modelos 3D, 4D e 5D permitem lidar com a complexidade e diversidade de requisitos de componentes em projetos de infraestrutura. Chong et al. (2016) demonstraram a utilização de modelos para simular cenários logísticos do canteiro de obra, de modo a evitar congestionamentos e monitorar o progresso de atividades com mais eficiência. Observam também a necessidade de melhor integração de informações geográficas para lidar com grandes dimensões, típicas de projetos viários, prevendo o emprego complementar de técnicas topográficas e GIS.

Nesse sentido, as grandes extensões e a alta complexidade de projetos de infraestrutura demandam segurança e consistência de dados para desenvolvimento de projetos, construção e manutenção de seus ativos. Seguindo esse mesmo raciocínio, o porto de Roterdã-Holanda exemplifica o uso de BIM para o gerenciamento de sistemas de infraestrutura, sendo fundamental para o gerenciamento do amplo espectro de informações heterogêneas e diversos agentes envolvidos (empresas, autoridades, instituições, público, entre outros). Como forma de facilitar tomadas de decisão, os modelos digitais do porto permitiram diferentes níveis de detalhamento e a organização de informações de acordo com a distribuição dos sistemas de infraestrutura: acima do solo (edifícios, ruas, equipamentos, topografia), subterrâneas (tubulações, túneis, dados geológicos), no ar (equipamentos de medição, radar) e na água (sensores marinhos). Zlatanova e Beetz (2012) citam resultados que envolvem melhorias no 
fluxo de informações internas e externas, aumento de produtividade, disposição de novos meios para verificar, atualizar, corrigir e alertar inconsistências e atualizações de dados.

Por fim, o emprego de BIM para manutenção de infraestruturas em fases de pósconstrução dá suporte a prevenção de falhas operacionais e manutenção de níveis aceitáveis de serviços (MARZOUK e ABDEL ATY, 2012). Na prática, possibilita acesso a informações de componentes para ações preventivas e corretivas, catalogação integrada de diferentes sistemas, rastreabilidade do histórico de ações já realizadas, compartilhamento de informações entre agentes envolvidos e melhor visualização de dados de ativos.

\subsubsection{BIM E INFORMAÇÕES GEOGRÁFICAS}

Informações geográficas são essenciais para que a associação de modelos tridimensionais seja condizente com o posicionamento real de edificações e sistemas de infraestrutura. Assim, modelos BIM para infraestrutura urbana podem ser desenvolvidos utilizando tecnologias complementares como (i) Sistemas de Informação Geográfica (SIG) para incorporar informações geoespaciais existentes (KANG e HONG, 2015; LIU et al., 2017; ZHU et al., 2018) e (ii) Sensoriamento remoto para fazer novos levantamentos de dados (COLOMINA e MOLINA, 2014; EISENBEISS, 2009; VOLK; STENGEL e SCHULTMANN, 2014).

Tratando do primeiro, um Sistema de Informações Geográficas (SIG) é compreendido por:

\footnotetext{
"[...] conjunto de hardware e software voltado para aquisição, manutenção e uso de dados cartográficos [...] É tanto um sistema de bases de dados com capacidades específicas para dados georrefenciados, como um conjunto de operações para trabalhar com esses dados. Em certo modo, um SIG é um mapa de ordem superior. [...] um mapa é uma representação de um conjunto de dados espaciais. [...] um SIG contém não somente esses dados e sua representação, mas as operações que podem ser feitas sobre o mapa." (OLAYA, 2014).
}

BIM e SIG são originários de áreas de conhecimento distintas. Enquanto BIM pertence ao domínio de Arquitetura, Engenharia, Construção e Operação; SIG é um desenvolvimento das ciências geoespaciais e ambientais. A integração de tais 
tecnologias é um tópico de interesse crescente na literatura recente e reflete a ideia de mesclar modelos BIM que contenham um conjunto rico de informações de construção com as capacidades de georreferenciamento de informações de modelos SIG (ZHU et al., 2018).

Nesse mesmo raciocínio, Stojanovski (2013) pondera que na arquitetura de edificações houve uma evolução de tecnologias CAD para BIM, porém em urbanismo, onde sistemas SIG predominam, isso não se deu da mesma maneira. Nesse cenário de desenvolvimento tecnológico, BIM para infraestrutura urbana pode ser também compreendido como "[...] uma expansão do conceito de SIG enriquecida com visualizações multinível e multiescala e ferrametas de projeto." (STOJANOVSKI, 2013).

Na Tabela 4 apresenta-se uma breve comparação qualitativa entre BIM e SIG, em que BIM é colocado com tecnologia que trabalha em uma escala Micro de detalhes, enquanto SIG em uma escala Macro.

Tabela 4 - Comparação entre estruturas de dados BIM e GIS

\begin{tabular}{|c|c|c|}
\hline & BIM & SIG \\
\hline Tipo de dados & $\begin{array}{l}\text { Dados de construções } \\
\text { tridimensionais e semânticos }\end{array}$ & $\begin{array}{l}\text { Infraestrutura urbana } \\
\text { (blocos, ruas, terreno etc.) }\end{array}$ \\
\hline Limites do sistema & Construção & $\begin{array}{l}\text { Globo terrestre/ região } \\
\text { geográfica específica }\end{array}$ \\
\hline Modelo de coordenadas & Coordenadas relativas & Coordenadas geográficas \\
\hline $\begin{array}{l}\text { Dimensões } \\
\text { consideradas }\end{array}$ & $\begin{array}{l}\text { Dimensão temporal e ênfase } \\
\text { na construção e seu ciclo de } \\
\text { vida }\end{array}$ & $\begin{array}{l}\text { Dimensões espaciais e } \\
\text { ênfase em aspectos } \\
\text { socioeconômicos }\end{array}$ \\
\hline
\end{tabular}

Fonte: Adaptado de Dutt et al. (2017).

Ressalva-se que o foco inicial dos sistemas SIG é sobre dados bidimensionais e semânticos, e sua capacidade de representação tridimensional ainda é limitada. Por outro lado, BIM parte da representação tridimensional para incorporar outros tipos de dados. Nesse sentido, BIM e SIG são complementares considerando que de um lado SIG complementa BIM fazendo ligações com o "mundo externo", enquanto de outro, BIM insere SIG em ambientes de projeto de construções específicas. Ressalta-se, porém, que SIG e BIM operam ainda de forma 
independente, sendo necessária interoperabilidade mais abrangente e efetiva (ZHU et al., 2018).

Para Barazzetti (2018), BIM e GIS são similares à luz de permitirem que usuários acessem informações de projeto por meio de representações gráficas, no entanto, com diferentes objetos e diferentes semânticas. A integração de tais tecnologias combina vantagens de modelagem paramétrica de elementos construtivos com conjuntos de dados geoespaciais. Porém, as informações de bases de dados de satélites não são suficientes para modelagem BIM, o que requer levantamentos adicionais, além de modelagem manual especializada.

Por sua vez, sensoriamento remoto se refere à "(...) obtenção de imagens à distância, sobre a superfície terrestre. Estas imagens são adquiridas através de sensores remotos (...) a bordo de aeronaves ou de satélites (...)" (INPE, 2019). Para o levantamento de dados geoespaciais de infraestrutura urbana a utilização de sensoriamento remoto é particularmente útil tendo em vista as características dimensionais de grande porte a que tais projetos remetem. Esse emprego é abordado no Capítulo 2, o qual trata de uma tecnologia crescente na construção civil: as aeronaves remotamente pilotadas, popularmente conhecidas como drones. 


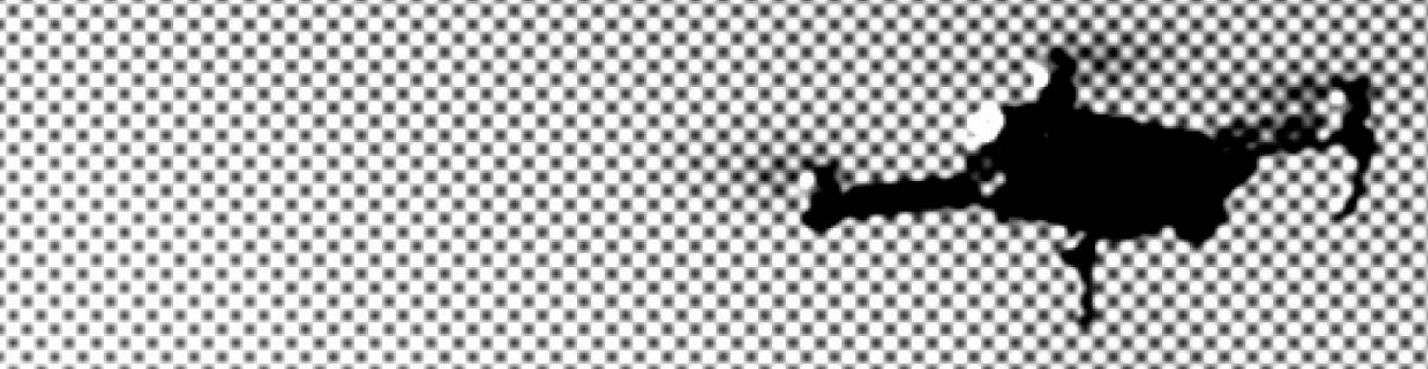

\section{LEVANTAMENTOS AÉREOS EM - INFRAESTRUTURA URBANA}

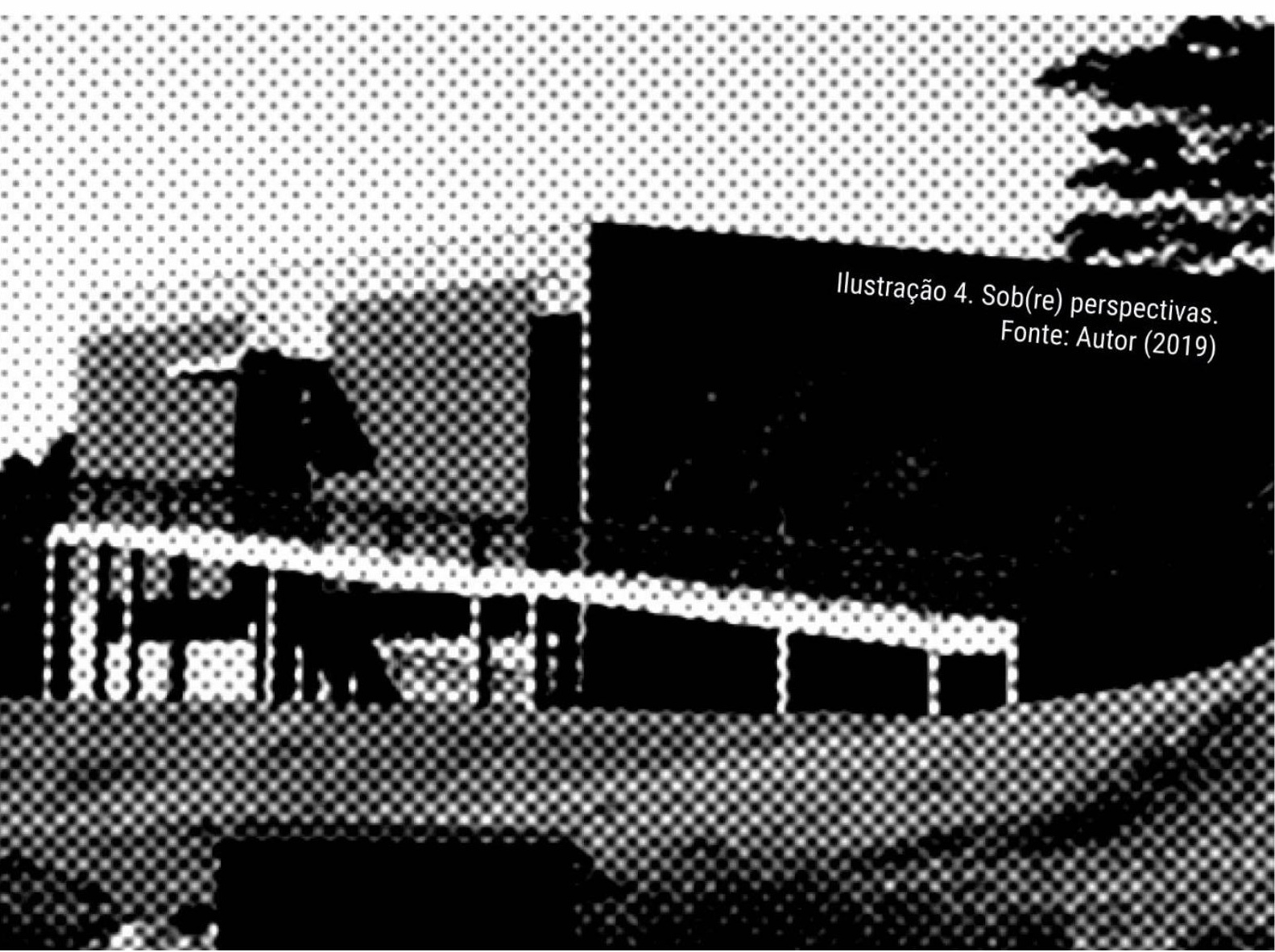




\subsection{INTRODUÇÃo}

O levantamento de informações sobre obras de infraestrutura pode ser complexo e caro. Necessita reunir informações de fontes diversas como diário de obra, fotografias, arquivos digitais e físicos de projeto com alterações e atualizações, registros métricos para acompanhamento de progresso etc. Como apresentado no Capítulo 1, a tecnologia BIM pode ser utilizada ao longo do ciclo de vida de construções para integrar informações de projeto.

Complementarmente, os levantamentos aéreos com aeronaves não tripuladas possibilitam coletar informações durante e após as obras de forma eficiente e com bom custo-benefício para atualizar modelos BIM de documentação afim de auxiliar o gerenciamento de ativos de infraestrutura urbana.

Este capítulo apresenta um recorte de tecnologias de levantamento aéreo, tratando inicialmente do contexto tecnológico, dos de restituição fotogramétrica e, por fim, de características principais de aeronaves e sensores embarcados.

\subsection{LEVANTAMENTOS AÉREOS COM RPAS}

Esta seção tem por objetivo contextualizar a utilização de aeronaves remotamente pilotadas apresentando tópicos de regulamentações brasileiras e exemplificando aplicações.

\subsubsection{BREVE CONTEXTO}

Nos últimos anos, há um crescente emprego de aeronaves remotamente pilotadas (RPAS) em diversos setores, abrangendo aplicações agrícolas, florestais, de atendimento a emergências e desastres, de vigilância civil, monitoramento de tráfego, inspeção de edificações e infraestrutura, mapeamento e modelagem geométrica de superfícies, entre outros. Esse desenvolvimento é recente. Durante o século XX as aplicações de RPAS eram voltadas 
predominantemente a fins militares (MELO et al., 2017; NEX e REMONDINO, 2014; RAKHA e GORODETSKY, 2018a). Somente a partir do início do século XXI, com novas tecnologias e interesses comerciais, as aplicações para uso civil se intensificaram e se popularizaram. A partir de então, RPAS têm sido utilizados para diversos propósitos, sendo fonte de dados espaciais para estudar e explorar localidades (RAKHA e GORODETSKY, 2018b).

Com o significativo desenvolvimento tecnológico, a miniaturização de componentes e o aumento de suas capacidades, os RPAS emergiram como ferramenta importante para várias aplicações, cujo crescimento como serviço tem sido alavancado na agricultura, construção e indústria (DELOITTE, 2018). A previsão para 2020 é que o mercado global movimente U\$22 bi, crescimento que tem na "Inovação Centrada no Consumidor" uma de suas razões principais, segundo Deloitte (2018).

Grandes empresas de tecnologia têm explorado esse mercado, como exemplo, a Amazon mantém em desenvolvimento um serviço de entregas com RPAS e em 2019 anunciou sua aeronave híbrida para início de atividades previsto para até 2020 (WILKE, 2019). Desde 2014, a Wings - empresa criada pelo Google - opera em fase de testes o seu serviço de entregas em Canberra-Austrália (BBC, 2019), apresentando-o como meio de transporte mais rápido, econômico e menos poluente (WING e GOOGLE, 2018).

Startups também têm atraído investimentos para o setor, o correspondente ao surgimento de mais de 300 empresas desde 2000 no desenvolvimento de componentes, sistemas e aplicações (COHN et al., 2017). A par disso, chama a atenção o conglomerado suíço considerado polo de desenvolvimento tecnológico de RPAS, contendo mais de 50 startups, além dos Institutos Federais de Tecnologia em Lausanne e Zurich, que juntos colaboram com o renome de "Vale do Silício dos Drones" (DRONECODE, 2018; LUCIEN, 2018; SWISS INFO, 2018). No Brasil, o setor de RPAS estimou faturamento de R\$ 300 milhões em 2017 e crescimento de $30 \%$, sendo que $40 \%$ das aeronaves são utilizadas no agronegócio (RURAL, 2018). 
Nesse cenário de uso crescente, são pertinentes questionamentos acerca da maturidade tecnológica dos serviços com RPAS. Essa maturidade diz respeito ao grau de desenvolvimento de RPAS e da infraestrutura de apoio para assegurar, em linhas gerais, a confiabilidade operacional. Em outras palavras, dependente não somente de contínuos aprimoramentos tecnológicos, mas também do estabelecimento de mecanismos de regulação e infraestrutura para suportar as diversas aplicações (COHN et al., 2017). Alguns usos com maior nível de maturidade, segundo Cohn et al. (2017), envolvem inspeções de curto alcance, capturas de imagem com ou sem análises, realização de tarefas repetitivas ou difíceis, entretenimento e propaganda.

No entanto, para compreender como operar RPAS no Brasil, na seção seguinte são apresentadas regulamentações brasileiras em vigor.

\subsubsection{REGULAMENTAÇÕES BRASILEIRAS PARA RPAS}

O uso de RPAS é regulamentado pela Agência Nacional de Aviação Civil (ANAC), por meio do Regulamento Brasileiro de Aviação Civil Especial (RBAC) no 94, de 3 de maio de 2017 (início do vigor). Além da ANAC, as operações de RPAS devem respeitar as normativas do Departamento de Controle do Espaço Aéreo (DECEA) e da Agência Nacional de Telecomunicações (Anatel).

A ANAC, através do Regulamento Brasileiro de Aviação Civil Especial (DECEA, 2017), separa as aeronaves remotamente pilotadas em duas categorias principais: (i) aeromodelos, usados para fins recreativos, e (ii) RPA, aeronave remotamente pilotada utilizada para fins não recreativos, como operações comerciais, corporativas ou experimentais. Além disso, as aeronaves são subdivididas em três classes de acordo com seu peso máximo de decolagem (PMD), considerado como a soma dos pesos do equipamento, da bateria ou combustível e de possíveis cargas (Quadro 3). 
Classe 1 - RPA: Peso máximo de decolagem maior que $150 \mathrm{~kg}$

Classe 2 - RPA: Peso máximo de decolagem maior que $25 \mathrm{~kg}$ e até $150 \mathrm{~kg}$

Classe 3 - RPA: Peso máximo de decolagem de até $25 \mathrm{~kg}$

Fonte: ANAC (2017a).

Pelo regulamento RBAC no 94 (DECEA, 2017), as aeronaves com peso máximo de decolagem maior que $250 \mathrm{~g}$ devem ser registradas no Sistema de Aeronaves não Tripuladas (SISANT), tanto para operações recreativas como para uso professional. Além disso, para os operadores regulamenta-se que:

"Todos os operadores de aeromodelos e de aeronaves RPA com peso máximo de decolagem de até $250 \mathrm{~g}$ são considerados licenciados, sem necessidade de possuir documento emitido pela ANAC.

Serão obrigatórias licença e habilitação emitidas pela ANAC apenas para pilotos de operações com aeronaves não tripuladas RPA das classes 1 (peso máximo de decolagem de mais de $150 \mathrm{~kg}$ ) ou 2 (mais de $25 \mathrm{~kg}$ e até $150 \mathrm{~kg}$ ) ou da classe 3 (até $25 \mathrm{Kg}$ ) que pretendam voar acima de 400 pés.

Pilotos remotos de aeronaves não tripuladas RPA das classes 1 (mais de $150 \mathrm{~kg}$ ) e 2 (mais de $25 \mathrm{~kg}$ e até $150 \mathrm{~kg}$ ) deverão possuir ainda o Certificado Médico Aeronáutico emitido pela ANAC ou, em alguns casos, pelo DECEA.

Pilotos da classe 3 (até $25 \mathrm{~kg}$ ) que pretendam operar acima de 400 pés também estão obrigados a portar o Certificado Médico Aeronáutico (CMA). Para voar abaixo dessa altitude, dispensa-se o CMA". (ANAC, 2017b, grifo do autor).

Outro ponto importante é a classificação das operações de RPAS em função do alcance visual do piloto e a necessidade de utilização de lentes, binóculos e/ou outros observadores. No Quadro 4 são apresentados os diferentes tipos de operações, observa-se que operações além do alcance visual (BVLOS) ou acima de $120 \mathrm{~m}$ de altura necessitam de registros adicionais (ANAC, 2017b). 
Quadro 4 - Classificação de operações por visibilidade

\begin{tabular}{l|l}
\hline OPERAÇÃO & DESCRIÇÃO \\
\hline BVLOS & $\begin{array}{l}\text { Operação na qual a aeronave está fora do alcance visual do piloto, } \\
\text { mesmo com o uso de lentes e observadores; }\end{array}$ \\
\hline VLOS & $\begin{array}{l}\text { Operação na qual o piloto mantém o contato visual direto com a } \\
\text { aeronave; }\end{array}$ \\
\hline EVLOS & $\begin{array}{l}\text { Operação na qual o piloto só é capaz de manter contato visual } \\
\text { com a utilização de lentes, binóculos e outros observadores. }\end{array}$
\end{tabular}

Fonte: Adaptado de ANAC (2017a).

A partir da classificação do RPAS, sua finalidade de uso e características de visada da operação pretendida, são determinados: a documentação necessária para regulamentação de operação da aeronave, a necessidade de aprovação ou autorização de projeto de voo, o limite de idade do piloto, a necessidade de certificação médica (CMA), e a licença e habilitação do piloto. No Diagrama 2 e no Quadro 5 a seguir, são apresentados, em resumo, os procedimentos de regulamentação estipulados pela ANAC.

Diagrama 2 - Registro e regulamentação de RPAS

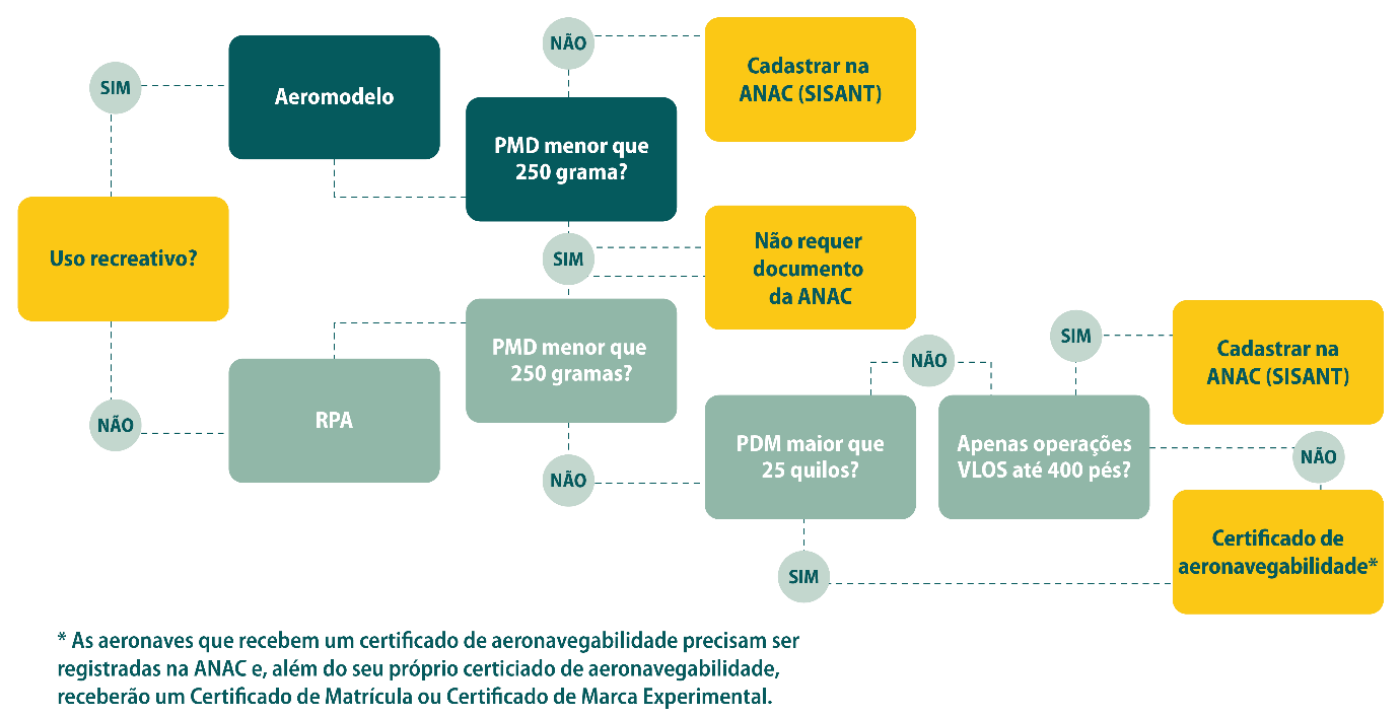

Fonte: ANAC (2018). 


\begin{tabular}{|c|c|c|c|c|}
\hline & $\begin{array}{l}\text { RPA } \\
\text { Classe } 1\end{array}$ & $\begin{array}{l}\text { RPA Classe } \\
2\end{array}$ & RPA Classe 3 & Aeromodelos \\
\hline Registro da aeronave? & Sim & Sim & Sim & Sim \\
\hline $\begin{array}{l}\text { Aprovação ou } \\
\text { autorização do projeto? }\end{array}$ & Sim & Sim & $\begin{array}{l}\text { Apenas BVLOS } \\
\text { ou acima de } 400 \\
\text { pés }(120 \mathrm{~m})\end{array}$ & \\
\hline $\begin{array}{l}\text { Limite de idade para } \\
\text { operação? }\end{array}$ & Sim & Sim & Sim & Não \\
\hline Certificado médico? & Sim & Sim & Não & Não \\
\hline Licença e Habilitação & $\operatorname{sim}$ & Sim & $\begin{array}{l}\text { Apenas para } \\
\text { operações acima } \\
\text { de } 400 \text { pés }\end{array}$ & $\begin{array}{l}\text { Apenas para } \\
\text { operações acima de } \\
400 \text { pés }\end{array}$ \\
\hline Local de operação & \multicolumn{4}{|c|}{$\begin{array}{l}\text { A distância da aeronave não tripulada NÃO poderá ser inferior a } 30 \\
\text { metros horizontais de pessoas não envolvidas e não anuentes com } \\
\text { a operação. } 0 \text { limite de } 30 \text { metros não precisa ser observado caso } \\
\text { haja uma barreira mecânica suficientemente forte para isolar e } \\
\text { proteger as pessoas não envolvidas e não anuentes. Esse limite não } \\
\text { é aplicável para operações por órgão de segurança pública, de } \\
\text { polícia, de fiscalização tributária e aduaneira, de combate a vetores } \\
\text { de transmissão de doenças, de defesa civil e/ou do corpo de } \\
\text { bombeiros, ou operador a serviço de um destes. }\end{array}$} \\
\hline
\end{tabular}

Fonte: Adaptado de (2017a).

Observa-se que o modelo da aeronave deve estar registrado na ANATEL para que possam ser solicitadas as autorizações de operação e de voo. Além desse registro, deve-se fazer o cadastro da aeronave no sistema SISANT e registrar as operações na plataforma on-lineSARPAS do DECEA. Os procedimentos relatados, são também apresentados no Diagrama 3. 


\section{REGULARIZAÇÃO DE RPAS}

\begin{tabular}{|c|c|c|}
\hline $\begin{array}{l}1{ }^{\text {a }} \text { PASSO } \\
\text { ANATEL }\end{array}$ & $\begin{array}{l}2^{\circ} \text { PASSO } \\
\text { ANAC }\end{array}$ & $\begin{array}{l}3^{\circ} \text { PASSO } \\
\text { DECEA }\end{array}$ \\
\hline Homologar RPAS & $\begin{array}{l}\text { Solicitar } \\
\text { autorização para } \\
\text { operação }\end{array}$ & $\begin{array}{l}\text { Requerer } \\
\text { autorização de vôo }\end{array}$ \\
\hline $\begin{array}{l}\text { 1. Verificar se o RPAS } \\
\text { está homologado na } \\
\text { ANATEL }\end{array}$ & $\begin{array}{l}\text { 1. Verificar requisitos da } \\
\text { RBAC-E } 94 \text { de acordo com } \\
\text { a categoria do RPAS }\end{array}$ & $\begin{array}{l}\text { 1. Cadastrar usuário na } \\
\text { plataforma SARPAS } \\
\text { 2. Cadastrar o RPAS }\end{array}$ \\
\hline $\begin{array}{l}\text { 2. Caso não esteja } \\
\text { homologado, seguir as } \\
\text { instruções da agência }\end{array}$ & $\begin{array}{l}\text { 2. Realizar o cadastro por } \\
\text { meio do SISANT } \\
\text { 3. Elaborar avaliação de } \\
\text { risco operacional de } \\
\text { acordo com a IS } \\
\text { E-94-003. }\end{array}$ & $\begin{array}{l}\text { 3. Solicitar autorização de } \\
\text { voo de acordo com as } \\
\text { características da } \\
\text { operação (tipo de } \\
\text { operação, altura, } \\
\text { localização, data, etc) }\end{array}$ \\
\hline
\end{tabular}

Fonte: Autor (2019).

A ANAC estabelece também, pela Instrução Suplementar IS No E94-003, os procedimentos para elaboração e avaliação de risco operacional de aeronaves não tripuladas, nos quais são considerados os perigos da operação quanto a sua probabilidade de ocorrência, severidade, tolerabilidade, riscos associados e medidas mitigatórias para pelo menos três situações de risco em um voo: (i) perda de conexão; (ii) existência de tráfego aéreo no local; e (iii) presença de pessoas não anuentes (ANAC, 2017c).

Como medida de segurança, as aeronaves devem estar seguradas para danos a terceiros em caso de acidentes:

É obrigatório possuir seguro com cobertura contra danos a terceiros nas operações de aeronaves não tripuladas de uso não recreativo acima de $250 \mathrm{~g}$ (exceto as operações de aeronaves pertencentes a entidades controladas pelo Estado). (ANAC, 2017c).

Pontua-se também que há uma série de outras normas dos órgãos mencionados acima tratando diretamente do uso de RPAS que, em suma, são apresentadas no Quadro 6. 


\section{NORMAS VIGENTES}

\section{Agência Nacional de Aviação Civil (Anac)}

- RBAC-E 94, de 2 de maio de 2017 - Requisitos Gerais para Aeronaves não Tripuladas de uso Civil

- RBAC 21, de 29 de novembro de 2011 - Certificado de Autorização de Voo Experimental

- RBHA 91, de 20 de março de 2003 - Regras Gerais de Operação Para Aeronaves Civis

\section{Agência Nacional de Telecomunicações (Anatel)}

- Resolução ñ 242, de 30 de novembro de 2000 - Regulamento para Certificação e Homologação de Produtos para Telecomunicações

- Resolução no 506, de $1^{0}$ de julho de 2008 - Regulamento sobre Equipamentos de Radiocomunicação de Radiação Restrita

- Resolução no 635, de 9 de maio de 2014 - Regulamento sobre Autorização de Uso Temporário de Radiofrequências

- Portaria 465, de 22 de agosto de 2007 - Aprovar a NORMA No 01/2007, anexa a esta Portaria, que estabelece os procedimentos operacionais necessários ao requerimento para a execução do Serviço Especial para fins Científicos ou Experimentais

\section{Departamento de Controle Aéreo (Decea)}

- ICA 100-40, 10 de março de 2017 - Sistemas de Aeronaves Remotamente Pilotadas e 0 Acesso ao Espaço Aéreo Brasileiro

- ICA 100-12, de 31 de julho de 2014 - Regras do Ar

- ICA 100-37, de 28 de abril de 2014 - Serviços de Tráfego Aéreo

\section{Secretaria da Receita Federal do Brasil}

- Bens do Viajante

Fonte: Ministério de Infraestrutura (2015). 


\subsubsection{APLICAÇÕES DE RPAS EM LEVANTAMENTOS}

No contexto urbano, o levantamento de infraestrutura existente é fundamental para as análises dos sistemas que a compõe, servindo de base para intervenções, ampliações, documentação de edificações e de ativos urbanos, e para alimentar bases de dados ou modelos de informação. Levantamento pode ser definido como:

(1) Processo de medição e de registro das formas de um objeto visando sua representação gráfica; (2) 0 resultado desse processo, ou ainda, (3) os dois sentidos simultaneamente. (GROETELAARS, 2015, p. 59).

Nessa atividade, a utilização de levantamentos aerofotogramétricos com RPAS tem crescido em relação a métodos tradicionais pela rapidez e facilidade na obtenção de resultados, uma vez que o levantamento e processamento podem ser automatizados (BARBASIEWICZ; WIDERSKI e DALIGA, 2018). Tais possibilidades eram inacessíveis no passado, quando se deveria recorrer a empresas de fotogrametria analógica com aviões tripulados, cujo alto custo podia tornar inviáveis tais tipos de levantamentos.

RPAS são referidos como sistemas de baixo custo (AJAYI; PALMER e SALUBI, 2018; KOEVA et al., 2018; NEX e REMONDINO, 2014; RUZGIENE et al., 2015) com reduzido número de procedimentos de decolagem e pouso em comparação com aeronaves tripuladas tradicionais, e permitem cobrir áreas de larga escala e gerar registros de superfícies físicas com precisão (NEX e REMONDINO, 2014). Em comparação com outros métodos, seu emprego também permite atingir alta complexidade de detalhes e cobertura quilométrica de áreas, conforme mostra a Figura 10 em termos da amplitude de cobertura (eixo horizontal) e a complexidade/nível de detalhe de produtos tridimensionais gerados (eixo vertical) por diferentes tecnologias. 
Figura 10 - Tecnologias de levantamento: cobertura x nível de detalhes

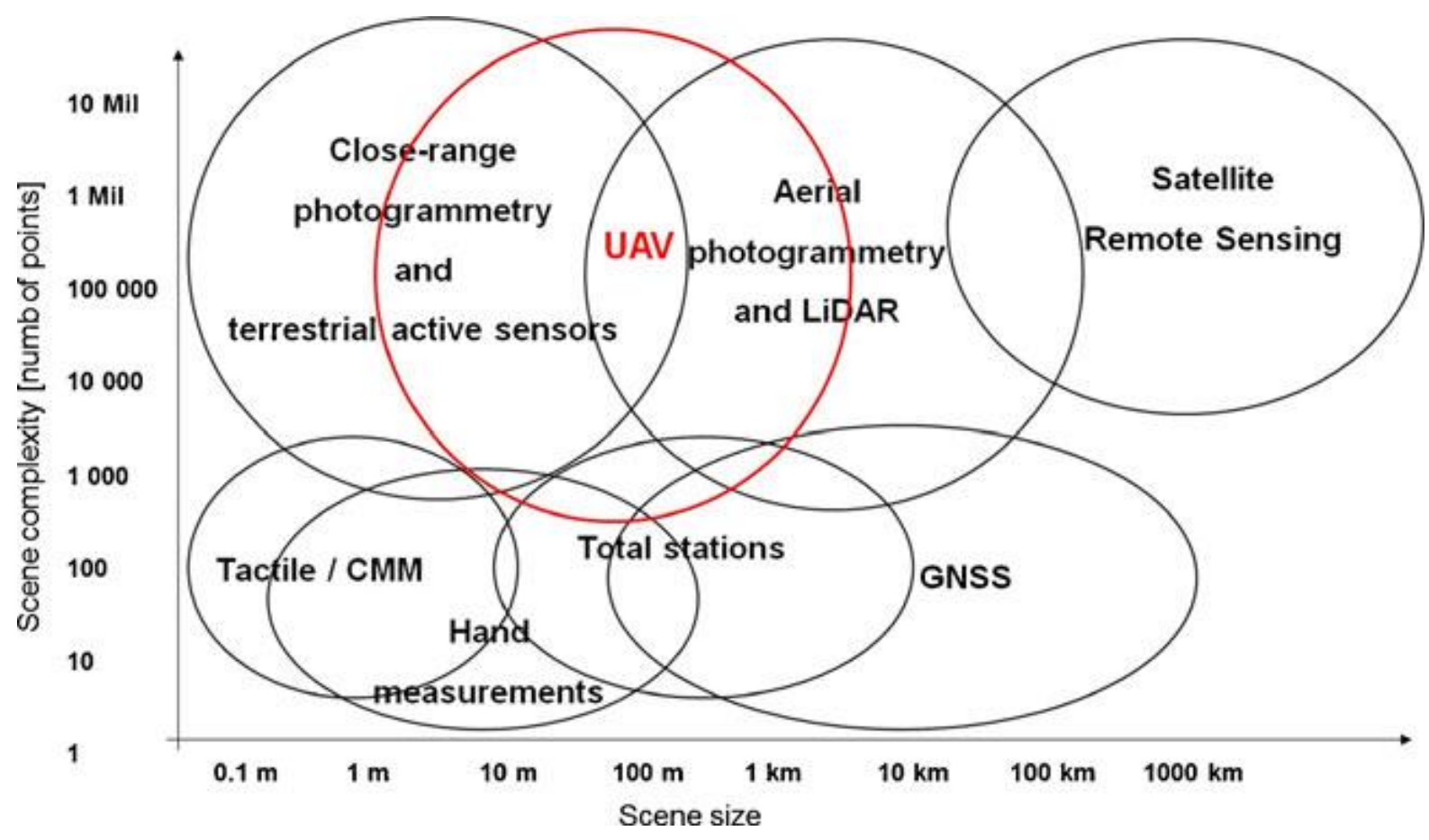

Fonte: Remondino (2011).

As características de RPAS operarem remotamente em áreas de difícil acesso, a estabilidade e controle de voo, capacidade de carga, flexibilidade de uso de diferentes câmeras/sensores e, por fim, a portabilidade, fazem de RPAS alternativas mais vantajosas e econômicas para gerar dados para inspeção, mapeamento e modelagem geométrica (NEX e REMONDINO, 2014). Adicionalmente, tais aeronaves são oportunidade potencial para otimizar procedimentos ora repetitivos, arriscados e vezes impossíveis, como exemplos: cobrir grandes áreas em menor tempo, acessar lugares remotos, inseguros e inacessíveis (GAŠPAROVIĆ et al., 2017).

Tratando de situações de alto risco por exemplo, o levantamento com RPAS permite acesso a regiões sem colocar a vida do piloto em perigo, mas possibilitando aproximação visual com objetos de interesse (RUZGIENE et al., 2015). Essas situações podem ocorrer em sistemas de infraestrutura urbana e são comuns a enchentes, terremotos, desabamentos, rompimento de barragens, regiões serranas, cachoeiras, cânions etc.

Como exemplo, destaca-se o estudo conduzido por Izumida, Uchiyama e Sugai (2017) para mapear e analisar as consequências de modificações topográficas 
causadas por inundações em regiões próximas ao rio Kinu, em 2015, no Japão. Com mesmo intuito, Zeybek e Şanlioğlu (2019) ressaltam que o uso de RPAS é crucial para processos de tomada de decisão em gerenciamento de riscos naturais, podendo ser utilizado em análises de deformações, por exemplo.

Em construções, as situações dessa natureza podem ser exemplificadas de várias formas: em inspeções de segurança em canteiros de obras (ÁLVARES; COSTA e MELO, 2018), em fachadas e telhados de edifícios (FREIMUTH e KÖNIG, 2018), pontes e viadutos elevados (SEO; DUQUE e WACKER, 2018), linhas de transmissão de energia, torres de comunicação, plantas industriais, inspeções de perdas de calor com a utilização de câmeras termográficas - como abordam Rakha e Gorodetsky (2018b), mapeamentos e levantamentos cadastrais (KOEVA et al., 2018), ou ainda auxiliar profissionais a validar determinado trabalho (COHN et al., 2017).

Além disso, a inspeção com RPAS pode ser automatizada com apoio de modelos BIM como apresenta o estudo realizado por Freimuth e König (2018) demonstrando ser possível utilizar modelos BIM 4D georreferenciados para escolher elementos a inspecionar e gerar rotas de voo seguras para inspeção e monitoramento do progresso de obras - considerando, inclusive, os obstáculos existentes.

Seis tendências principais de aplicações de RPAS são destacadas no setor de construção:

(1) Inspeção de edificações, referida como a coleta e uso de dados para avaliação de condições de edificações

(2) Avaliação de danos, referida ao uso de dados coletados por RPAS para avaliação de danos em edificações

(3) Levantamento e mapeamento, referindo-se à aquisição de dados espaciais e temporais de fenômenos utilizando RPAS

(4) Inspeções de segurança, referindo-se às avaliações periódicas em canteiros de obras com base em critérios de segurança

(5) Monitoramento de progresso de atividades a partir de dados visuais coletados com RPAS

(6) Outros, referindo-se à manutenção de edificações, mensurações de áreas e volumes.

Fonte: Adaptado de Zhou e Gheisari (2018).

Um exemplo é a medição de elementos de fachadas altas em que a utilização de técnicas tradicionais implicaria em condições inseguras, gastos adicionais e uso de equipamentos de elevação, além de que as medições diretas poderiam ser 
insatisfatórias para documentação de algum elemento com formas não lineares. Outro exemplo, em particular, são levantamentos de infraestrutura urbana cujo emprego de métodos tradicionais (estações totais, trenas, níveis etc.) implica em um longo tempo de levantamento e com restrições de pontos de mensuração registrados.

Assim, a aplicação de técnicas de fotogrametria é viabilizada para casos em que não é possível a utilização de técnicas tradicionais de medição e/ou seu uso implicaria em processos com acuidade insatisfatória e resultados onerosos. Linder (2006) destaca ainda que mensurar com fotos significa mensurar sem a necessidade de contato físico com objetos, o que colabora com os exemplos apontados anteriormente.

\subsection{DA IMAGEM AÉREA À MODELAGEM FOTOGRAMÉTRICA}

Nessa seção são apresentados conceitos de fotogrametria aérea, planejamento de voos de captura e tópicos de processamento de imagens. São apresentados

\subsubsection{PRINCÍPIOS BÁSICOS DE FOTOGRAMETRIA DIGITAL}

De acordo com Fritsch (1999), fotogrametria é uma ciência e tecnologia de aquisição e processamento de imagens fotográficas para determinação de formas, posição e características geométricas a fim de gerar modelos virtuais tridimensionais. Ciência de mensuração do campo de geodesia e sensoriamento remoto (SR), a fotogrametria utiliza técnicas para obter informações geométricas de objetos representados em fotografias (LINDER, 2006).

As técnicas de fotogrametria se baseiam em princípios da estereoscopia, os quais descrevem a capacidade da visão humana de perceber diferenças de profundidade por meio de perspectivas ligeiramente diferentes de um objeto dadas pelos nossos olhos (SHOLARIN e AWANGE, 2015), como mostra a Figura 11. Sob essa analogia, a fotogrametria pode ser compreendida como uma 
aplicação biomimética sucedida da visão humana para mensurar por meio de imagens.

Figura 11 - Vista estereoscópica de sobreposição de duas imagens mostrando o mesmo objeto por diferentes ângulos. A impressão da terceira dimensão aparece no espaço formando um modelo estereoscópico.

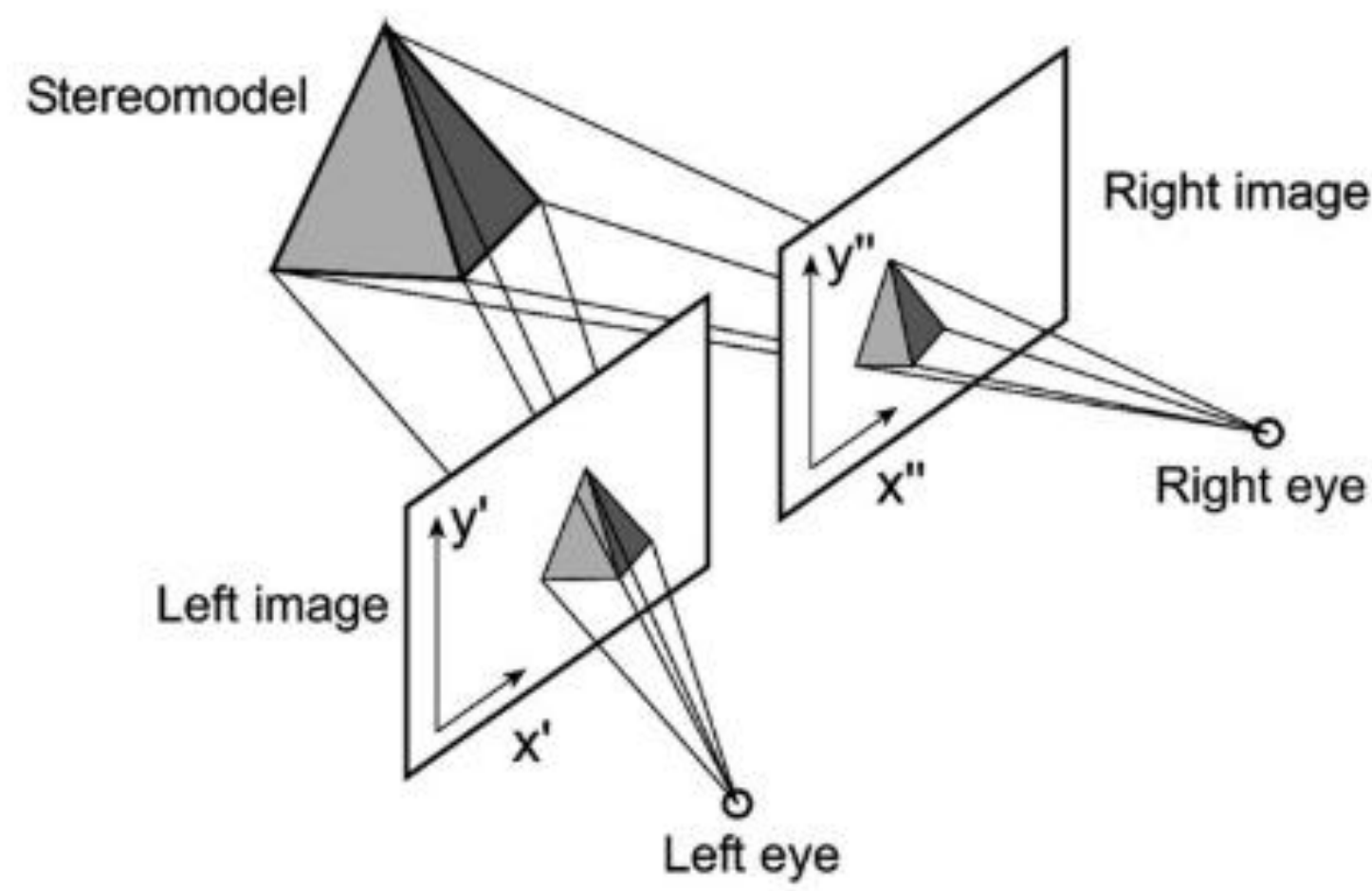

Fonte: Sholarin e Awange (2015).

Canuto (2017) classifica as técnicas de fotogrametria digital de acordo com (1) tipos de restituição, (2) posicionamento da câmera e (3) nível de automação do processamento (Quadro 7). 


\begin{tabular}{|c|c|c|}
\hline TIPOS DE RESTITUIÇÃO & $\begin{array}{l}\text { POSICIONAMENTO DA } \\
\text { CÂMERA }\end{array}$ & NÍVEL DE AUTOMAÇÃO \\
\hline $\begin{array}{l}\text { Monoresituição - método } \\
\text { mais simples e rápido, } \\
\text { porém limitado e menos } \\
\text { preciso. Utiliza-se uma } \\
\text { fotografia para obtenção de } \\
\text { ortofotos } \\
\text { Estereorrestituição - } \\
\text { método mais automatizado } \\
\text { e adequado para formas } \\
\text { mais complexas, a técnica } \\
\text { consiste na geração de } \\
\text { modelo geométrico de } \\
\text { superfície texturizado ou } \\
\text { não. Utilizam-se fotografias } \\
\text { paralelas entre si, com } \\
\text { grandes áreas de } \\
\text { sobreposição e em } \\
\text { diferentes posições } \\
\text { Restituição de múltiplas } \\
\text { fotografias - método para } \\
\text { superfícies bem definidas } \\
\text { permitindo a identificação } \\
\text { interativa dos pontos } \\
\text { homólogos. No processo o } \\
\text { objeto deve ser fotografado } \\
\text { em diversas posições, com } \\
\text { no mínimo três fotografias } \\
\text { por face }\end{array}$ & $\begin{array}{l}\text { Terrestre - quando o } \\
\text { equipamento está } \\
\text { posicionado próximo à } \\
\text { superfície } \\
\text { Aérea - quando o } \\
\text { equipamento é } \\
\text { transportado por } \\
\text { helicópteros, aeronaves } \\
\text { ou drones. Com } \\
\text { aplicações em áreas } \\
\text { maiores como } \\
\text { levantamento cadastral } \\
\text { urbano e rural, } \\
\text { monitoramento, } \\
\text { prevenção de desastres } \\
\text { ambientais } \\
\text { Orbital - quando os } \\
\text { sensores estão } \\
\text { posicionados nos } \\
\text { satélites. Assim como a } \\
\text { fotogrametria aérea, a } \\
\text { orbital é utilizada para } \\
\text { levantar grandes áreas }\end{array}$ & $\begin{array}{l}\text { Automático - processo } \\
\text { com programas que } \\
\text { permitem automatizar } \\
\text { todas as etapas de } \\
\text { processamento - } \\
\text { restituição, correlação de } \\
\text { pontos homólogos e } \\
\text { geração de modelos. } \\
\text { Atualmente esse processo } \\
\text { tem sido usado para } \\
\text { modelos de formas } \\
\text { complexas e irregulares } \\
\text { devido ao desenvolvimento } \\
\text { de ferramentas de } \\
\text { automação que garantem } \\
\text { rapidez e precisão na } \\
\text { geração de modelos. } \\
\text { Structure from Motion (SfM) } \\
\text { é um exemplo de método } \\
\text { automático }\end{array}$ \\
\hline
\end{tabular}

Fonte: Adaptado de Canuto (2017, p. 49).

Segundo Historic England (2017), as técnicas fotogramétricas permitem transformar objetos descritos no sistema de coordenadas bidimensional (2D) de 
imagens para o sistema de coordenadas 3D do "mundo real". Essas transformações são baseadas em equações de colinearidade, as quais possibilitam a definição de pontos do objeto no espaço 3D por meio da identificação e projeção espacial de pontos comuns entre duas ou mais imagens, também chamados de pontos homólogos ou de ligação - tie points. A partir desses pontos, outros são projetados por interpolação gerando uma nuvem de pontos. Os pontos gerados pela aplicação das equações de colinearidade são espacialmente orientados de acordo com parâmetros geométricos do sistema "câmera e lente", a chamada "orientação interna". Por outro lado, possuem orientação externa descrevendo sua posição em x, y e z e a atitude da câmera durante a captura. O resultado dessas orientações é uma reconstrução virtual (ou restituição) preliminar sem escala e sem orientação, mas que pode ser escalonada e orientada em um sistema de referência introduzindo pontos de coordenadas conhecidas como restrição, os chamados pontos de controle em solo (GCP - Ground Point Control) (HISTORIC ENGLAND, 2017). Na Figura 12, ilustra-se a combinação de imagens aéreas para restituição de pontos da superfície mapeada.

Figura 12 - Projeção de pontos de ligação e de controle das imagens para reconstrução 3D da superfície do solo

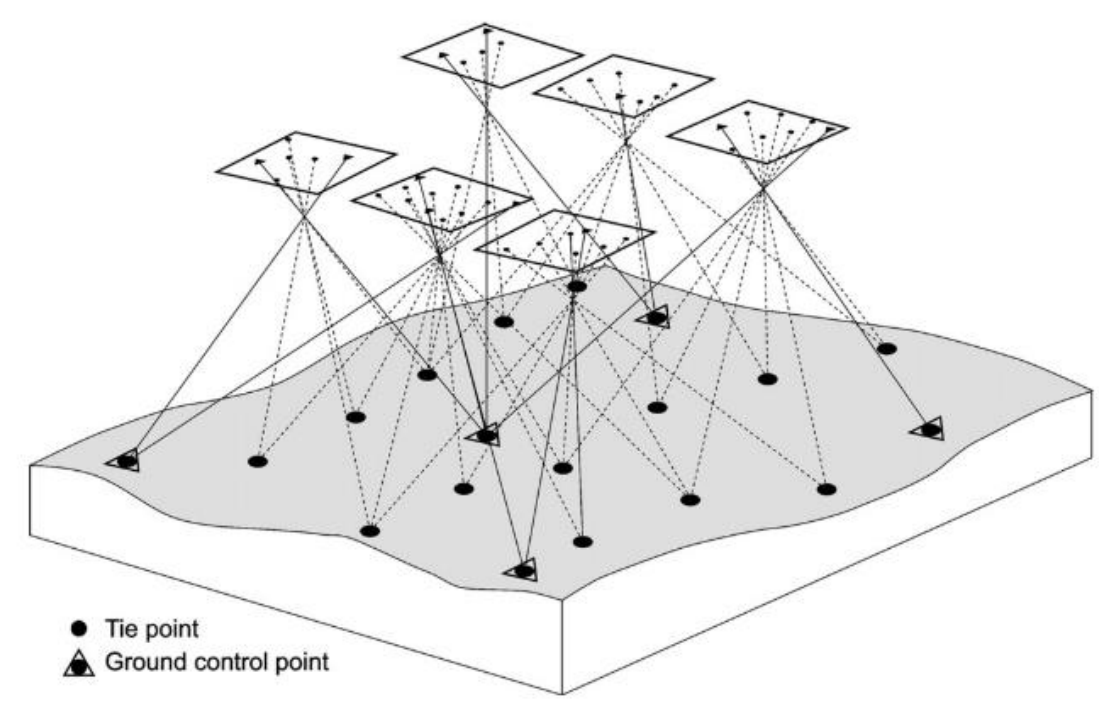

Fonte: Sholarin e Awange (2015). 
Além de nuvem de pontos, a restituição fotogramétrica também produz outros produtos como ortofotos, modelos digitais de superfície (DSM) e modelos digitais de terreno (DTM).

\subsubsection{Planejamento de voos}

O planejamento de voos deve garantir que haja sobreposição de imagens para que os princípios de colinearidade possam ser aplicados e os produtos fotogramétricos sejam gerados. Assim, a trajetória do voo de captura deve possibilitar que cada imagem se sobreponha à próxima em ao menos $60 \%$, e em ao menos 20\% das laterais (HISTORIC ENGLAND, 2017; SHOLARIN e AWANGE, 2015), como apresentado na Figura 13.

Figura 13 - Trajetória de voo e sobreposição de áreas capturadas pelas imagens

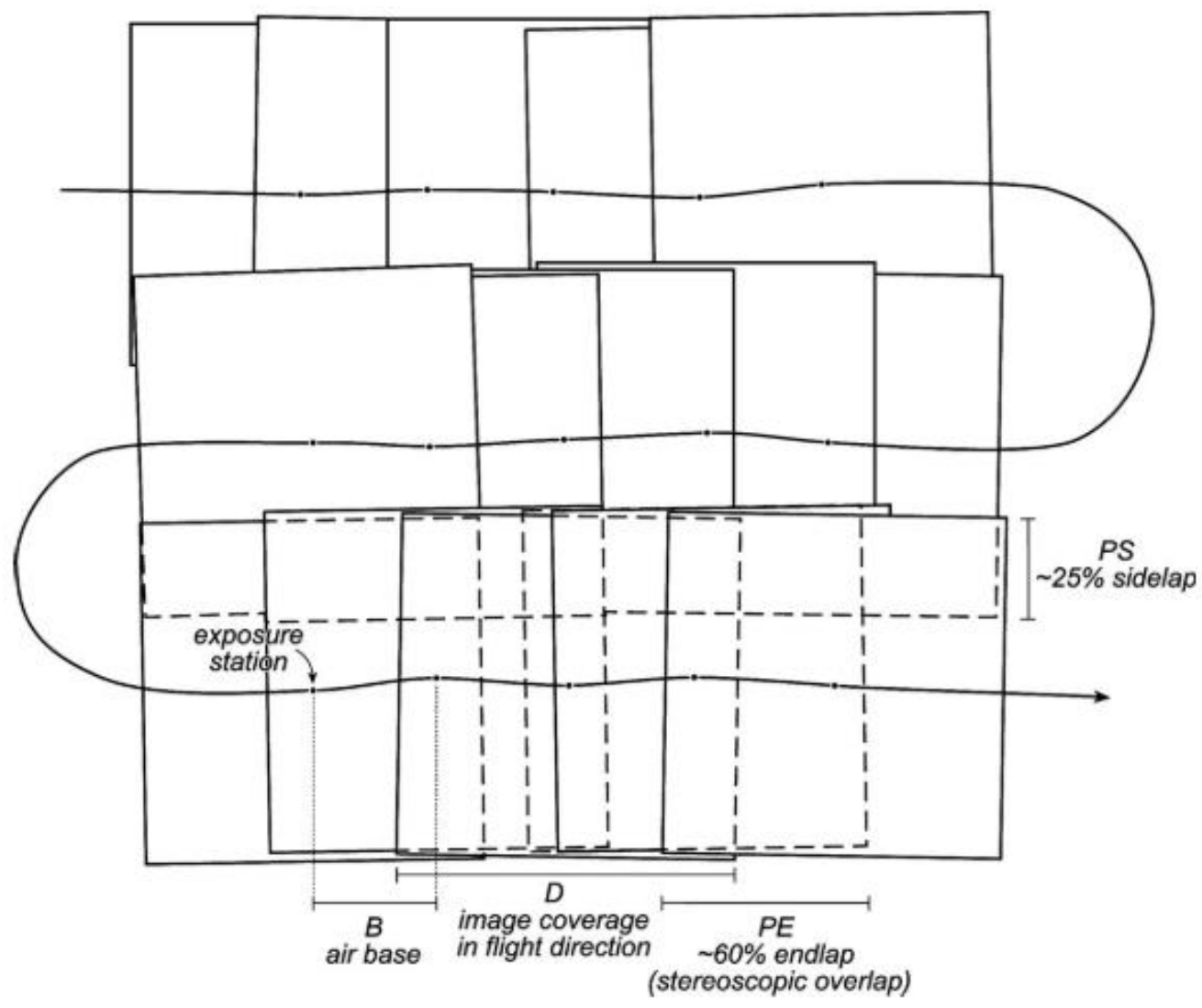

Fonte: Sholarin e Awange (2015).

As capturas podem ser realizadas por meio de voos manuais ou automáticos: 
- Os voos manuais são aqueles em que o operador tem total comando da rota da aeronave por meio do controle remoto. São exemplos os voos para simples reconhecimento da área de mapeamento, voos de inspeção ou mapeamentos cuja operação manual é requerida em função da necessidade de maior controle visual e dificuldade de estabelecer rotas automáticas pela existência de obstáculos. Nessas aplicações, as aeronaves com sensores anti-choque e proteções adicionais contra colisões devem ser consideradas.

- Os voos automáticos são aqueles em que a trajetória da aeronave e as capturas de dados são pré-programadas, o piloto somente acompanha a execução do plano de voo (Figura 14) e na ocorrência de algum problema ou emergência pode assumir o controle, retornando a aeronave à base. A automatização de voos permite a configuração prévia de direções de voo utilizando softwares baseados em mapas digitais, nos quais são estabelecidos o ponto de decolagem/pouso (homepoint), os pontos de interesse a cobrir (waypoints) e o traçado da rota sobre a área de interesse, além de outros parâmetros como a altura de voo, velocidade, sobreposição de capturas, inclinação da câmera, configurações de disparo de capturas etc. Em sequência, o plano de voo georreferenciado é transferido para o sistema de navegação da aeronave para execução. Entre exemplos de softwares para o planejamento de voos automáticos, apontam-se o DJI Terra, o Dronedeploy, o Pix4Capture e o QGroundControl.

A Figura 14 ilustra a visualização de um plano de voo automático em execução no qual a trajetória planejada é visualizada em tempo real pelo controle remoto da aeronave. Na figura também é apresenta uma das imagens capturadas no levantamento como exemplo. 
Figura 14 - Visualização de plano de voo no software Pix4Capture e uma das imagens capturadas

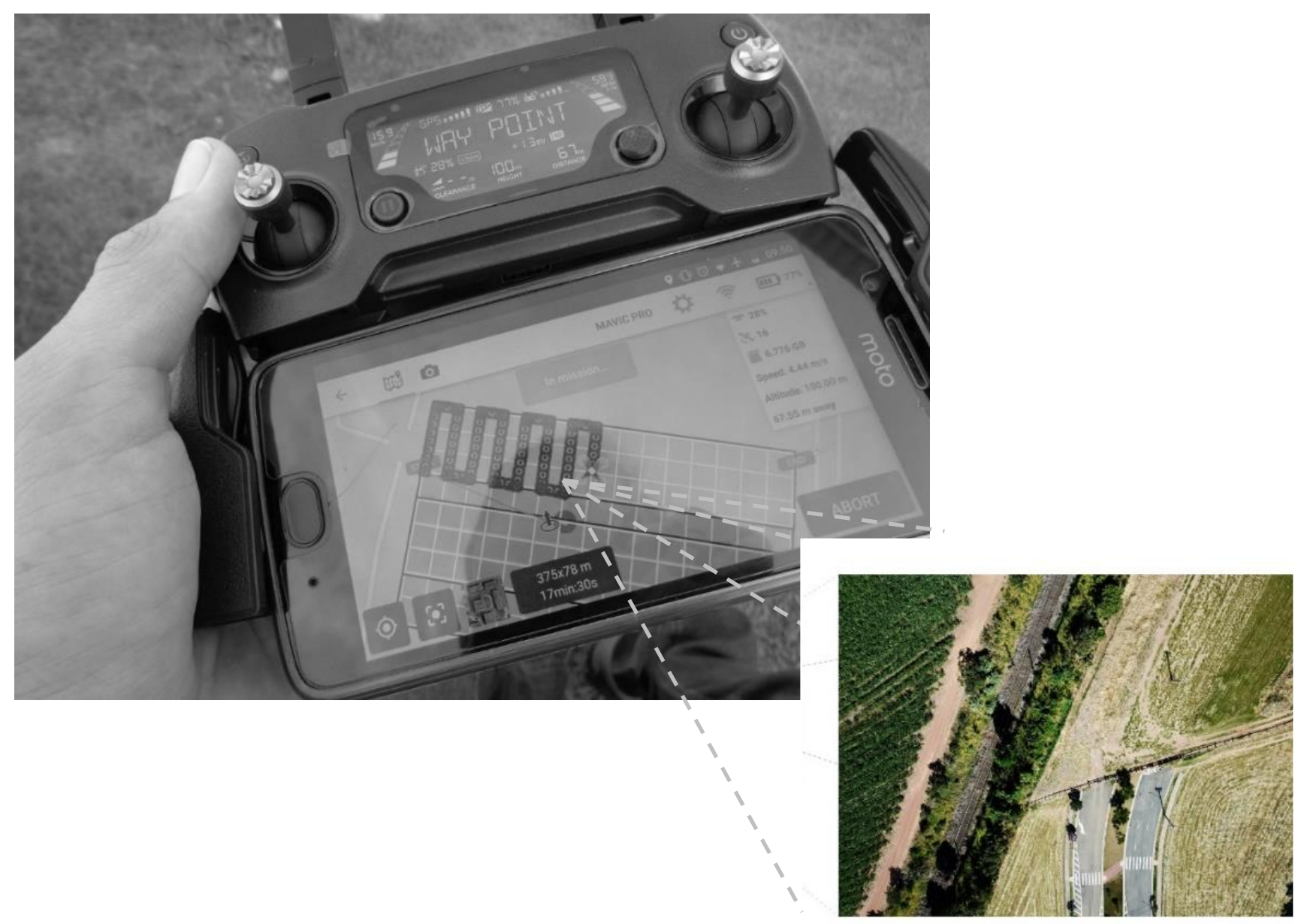

Fonte: Autor (2019)

Na elaboração do plano de voo deve-se analisar as condições de segurança da aeronave e do local, os riscos envolvidos, o tempo total da operação frente a autonomia, as condições meteorológicas, a necessidade de observadores e recursos adicionais de comunicação e o registro e autorização de voo pelos órgãos competentes. Tais verificações devem ocorrer de forma sistemática para minimizar a probabilidade de falhas e diminuir os riscos envolvidos. A favor da prudência, sugere-se a utilização de checklists de voo, como o apresentado no Anexo 1 - Checklist de voo, página 215. 


\subsubsection{Qualidade de imagens}

A qualidade de imagens é um fator significante para acurácia dos produtos de fotogrametria (RUZGIENE et al., 2015). Em outras palavras, quanto maior for a qualidade das imagens aéreas capturadas, melhor será o resultado do processamento fotogramétrico.

Segundo Figueiredo e Figueiredo (2018), a qualidade da fotografia depende do balanceamento da exposição do sensor da câmera às condições do ambiente, de modo que é fundamental ajustar a sensibilidade ISO, a abertura do diafragma e a velocidade do obturador, parâmetros estes interdependentes (Figura 15).

Figura 15 - Diagrama de exposição e o triângulo ISO, abertura e velocidade do obturador

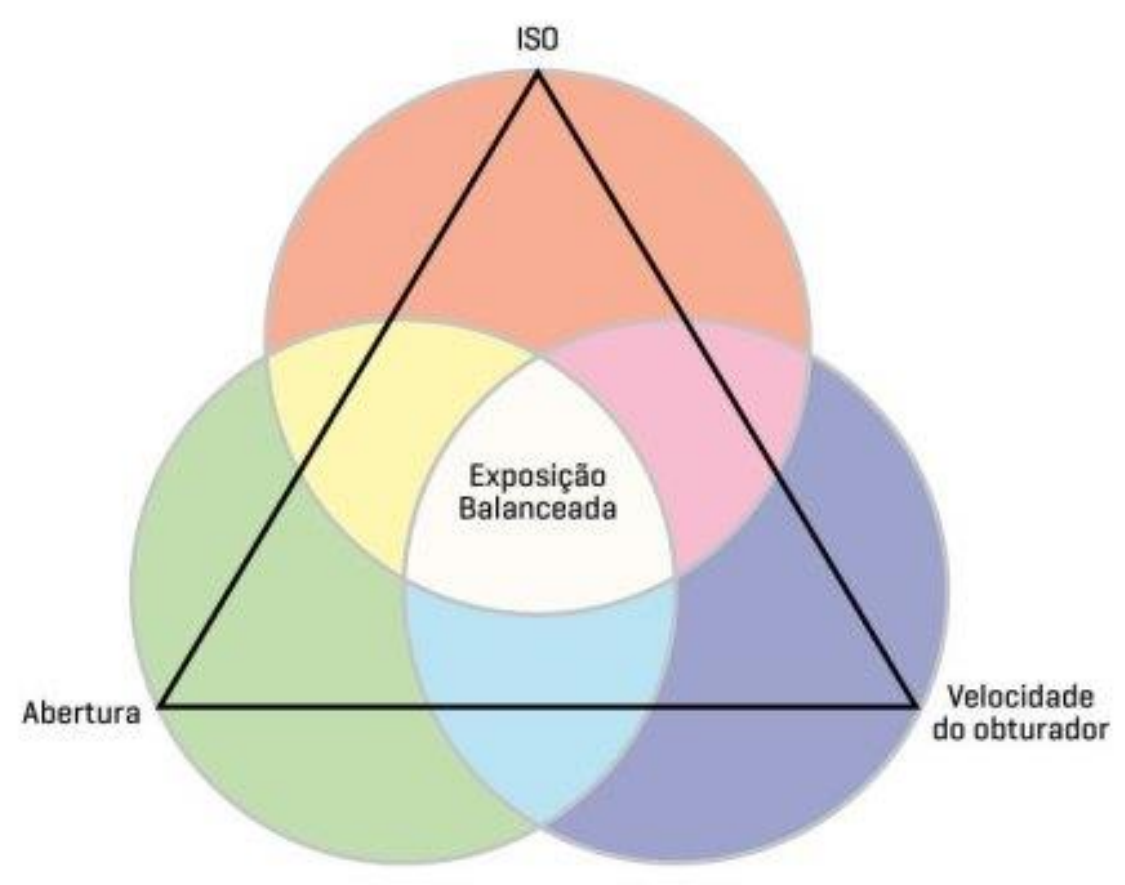

Fonte: Figueiredo e Figueiredo (2018)

Figueiredo e Figueiredo (2018) conceituam que:

- A sensibilidade ISO é a medida da sensibilidade do sensor da câmera à luz. Quanto maior o fator ISO, maior será a sensibilidade à luz, e mais clara a fotografia será. Quando o ajuste do número ISO é inadequado, a imagem 
pode ser registrada com ruídos de efeito granulado. Usualmente, empregase o valor de ISO 100;

- A abertura do diafragma controla a área do orifício ótico, determinando a quantidade de luz que será captada. Assim, quando maior a abertura, mais luz e mais claro será o registro pelo sensor.

- A velocidade do obturador é o fator que determina o tempo de exposição do sensor à luz ambiente, de modo que quanto mais rápida a velocidade do obturador menor será a exposição do sensor.

O tripé ISO, Abertura e Velocidade do obturador pode ser equalizado manual ou automaticamente antes da realização de voos (DJI, 2017a). No caso de se perceber que o registro da imagem está inadequado durante o voo, é possível compensar o valor da exposição, tornando-a mais clara ou escura (DJI, 2017b). No entanto, essa função depende de cada equipamento e necessita que a câmera esteja configurada no modo automático de balanceamento. Também devem ser observados outros parâmetros como balanço de brancos, formato de arquivo de gravação e configurações de foco (DJI, 2017a).

Além dos parâmetros mencionados, a qualidade das capturas com RPAS para fotogrametria é influenciada pela velocidade da aeronave e pela altura de voo (proximidade com a superfície a ser mapeada). De forma que, quanto maior a velocidade da aeronave e menor a altura de voo, maior deverá ser a velocidade de abertura do obturador para que não ocorra distorções decorrentes do deslocamento da aeronave durante a captura, o chamado efeito rolling shutter (FIGUEIREDO e FIGUEIREDO, 2018).

\subsubsection{GSD}

A altura de voo determina também a resolução das imagens, uma vez que quanto mais longe da superfície mapeada, menor será a capacidade de enxergar detalhes. Por outro lado, quanto mais perto estivermos da superfície de interesse, menor será a área capturada em uma imagem, o que implica em mais imagens a serem capturadas para uma mesma área e mais tempo de levantamento. Além 
disso, deve-se considerar a existência de obstáculos na rota de voos mais baixos para evitar colisões.

Uma forma de determinar a resolução de imagens que necessitamos em um levantamento é através do conceito de GSD, sigla de "Ground Sample Distance" ou - em tradução literal - "Distância de Amostragem do Solo". Por definição, GSD é distância medida sobre o solo correspondente ao afastamento entre os centros de dois pixels ${ }^{2}$ adjacentes em uma imagem (HISTORIC ENGLAND, 2017). Portanto, GSD representa a resolução espacial de uma imagem e é medida em centímetros por pixel.

Em termos práticos, GSD é inversamente proporcional ao nível de detalhamento, ou seja, quanto maior for o GSD maior será a porção de solo corresponde descrita em um pixel. Assim, se o GSD de uma imagem for de $10 \mathrm{~cm} / \mathrm{px}$, objetos menores que 10 cm não serão representados no mapeamento (NETO, 2018).

\subsubsection{SfM - Structure from Motion}

No contexto de fotogrametria, Structure from Motion (SfM) é uma tecnologia de restituição por varredura de fotografias e representa o estado da arte de técnicas automatizadas de softwares para fotogrametria. SfM correlaciona automaticamente conjuntos de pixels de várias fotos gerando uma nuvem de pontos tridimensional e malhas geométricas Triangular Irregular Network (TIN) de superfícies, também conhecidas como modelos digitais de superfície (GROETELAARS, 2015, p 73).

O processo de geração de tais produtos é descrito na Figura 16.

2 Pixelé o termo originário de "Picture Element" e é a menor unidade de uma imagem digital, o que define sua resolução (NETO, 2018). 
Figura 16 - Fluxo geral do processamento por fotogrametria

\section{Processos}

Saídas

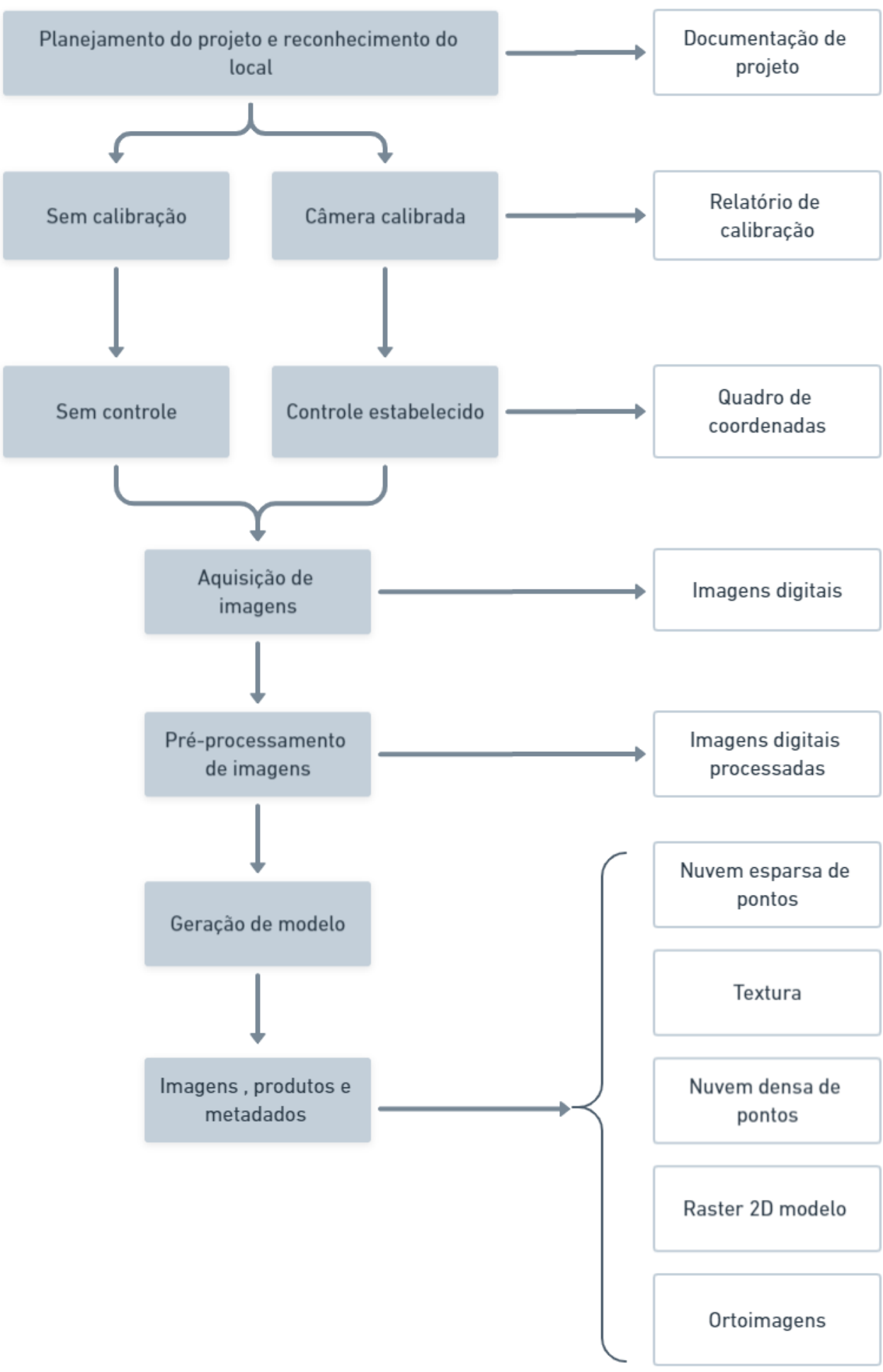

Fonte: Adaptado Historic England (2017). 
O processamento automatizado é a característica principal de SfM, cuja replicabilidade e controle de qualidade dos resultados fazem com que a técnica seja amplamente utilizada em diversas aplicações. Como apresentado no Quadro 7, esse processo tem sido empregado na geração de modelos de formas complexas e irregulares para garantir rapidez e precisão na geração de modelos (CANUTO, 2017). Além disso, permite a utilização de diferentes tipos de imagens (aéreas, terrestres, termográficas ou multiespectrais).

Particularmente ao uso de imagens aéreas para modelagem de componentes superficiais, o uso de SfM é vantajoso para lidar com as grandes extensões de levantamentos de urbanos e rurais, as quais aludem a quantidades significativas de imagens e dados capturados. A técnica é apropriada para virtualizar formas naturalmente irregulares de terreno e de estruturas existentes complexas, como exemplificam Altuntas; Pehlivanli e Kurban (2017) para pontes viárias e Rakha e Gorodetsky (2018b) para documentação de edificações.

O emprego de SfM reforça a ideia apresentada no Capítulo 1 de gerar dados tridimensionais para criar "gêmeos digitais" ou "modelos geométrico" de construções para documentação, a partir de imagens. Por essa razão, a capacidade de transformar um conjunto de imagens bidimensionais em um modelo geométrico é complementar ao desenvolvimento de modelos BIM de infraestrutura urbana por replicar as características geométricas de elementos de interesse e gerar documentação digital abrangendo modelos geométricos, nuvens de pontos e ortoimagens com cores reais, alta definição visual e precisão centimétrica (NEX e REMONDINO, 2014; REMONDINO et al., 2011).

\subsubsection{Softwares de processamento de imagens}

Há uma variedade de softwares para processamento de imagens. Neste trabalho, foram adotados os softwares Pix4D, Autodesk Recap e Agisoft PhotoScan, dos quais algumas das principais características são apresentadas nessa seção.

O Pix4D é um software baseado em computação em nuvem que possui ferramentas de captura e controle de voos autônomos (Pix4D Capture), processamento de nuvens de pontos, ferramentas de análise e compartilhamento 
via web de dados espaciais (PIX4D, 2019). Na Figura 17 é apresentado o fluxo de trabalho coberto pelo software, no qual é possível elaborar e operar planos de voo, processar e analisar resultados em plataforma web compartilhada.

Figura 17 - Fluxo de trabalho no Pix4D - da captura à análise de resultados

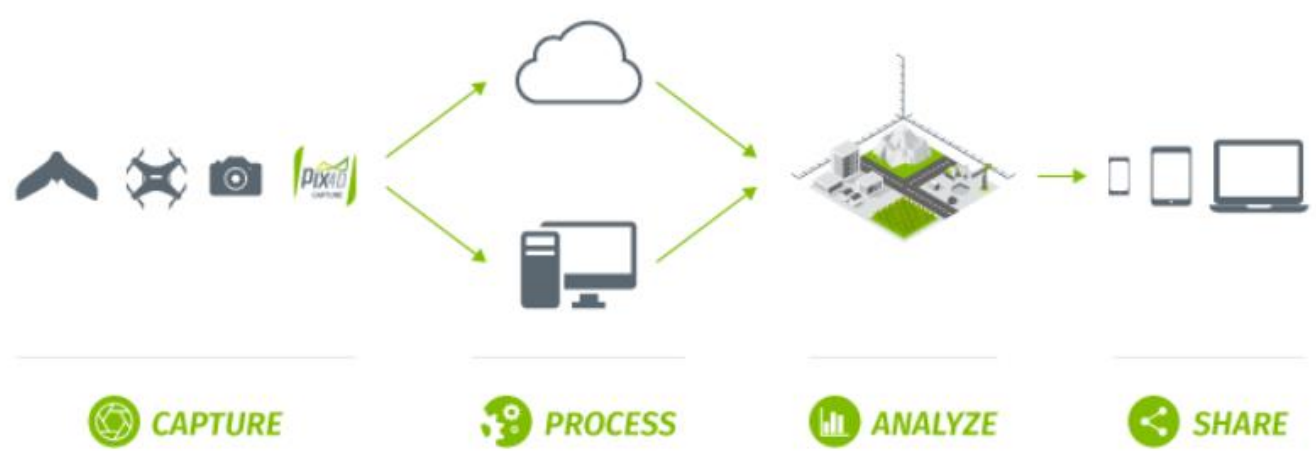

Fonte: PIX4D (2019).

Na Figura 18 é apresentada a interface do software com um exemplo de resultados processados.

Figura 18 - Interface web Pix4D

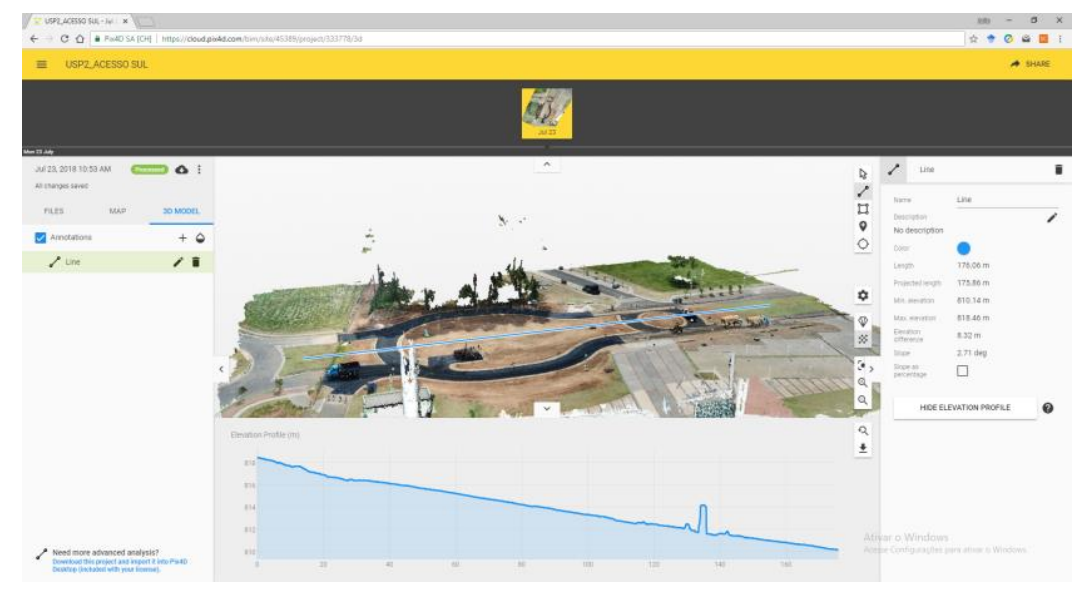

Fonte: Autor (2019).

O Autodesk Recap também é baseado em plataforma de computação em nuvem.

O software permite a criação de modelos geométricos a partir de imagens coletadas e possui ferramentas para manuseio e edição de nuvem de pontos. Como apresentado no Capítulo 1, o Recap possui compatibilidade com Autodesk InfraWorks, e é utilizado para manuseio e conversão de nuvens de pontos para 
formatos compatíveis com modelos BIM da suíte de softwares da Autodesk (AUTODESK, 2019b). A Figura 19 apresenta a interface do Recap com um exemplo de nuvem de pontos em escala de cor de acordo com a cota $z$.

Figura 19 - Interface Autodesk Recap Pro

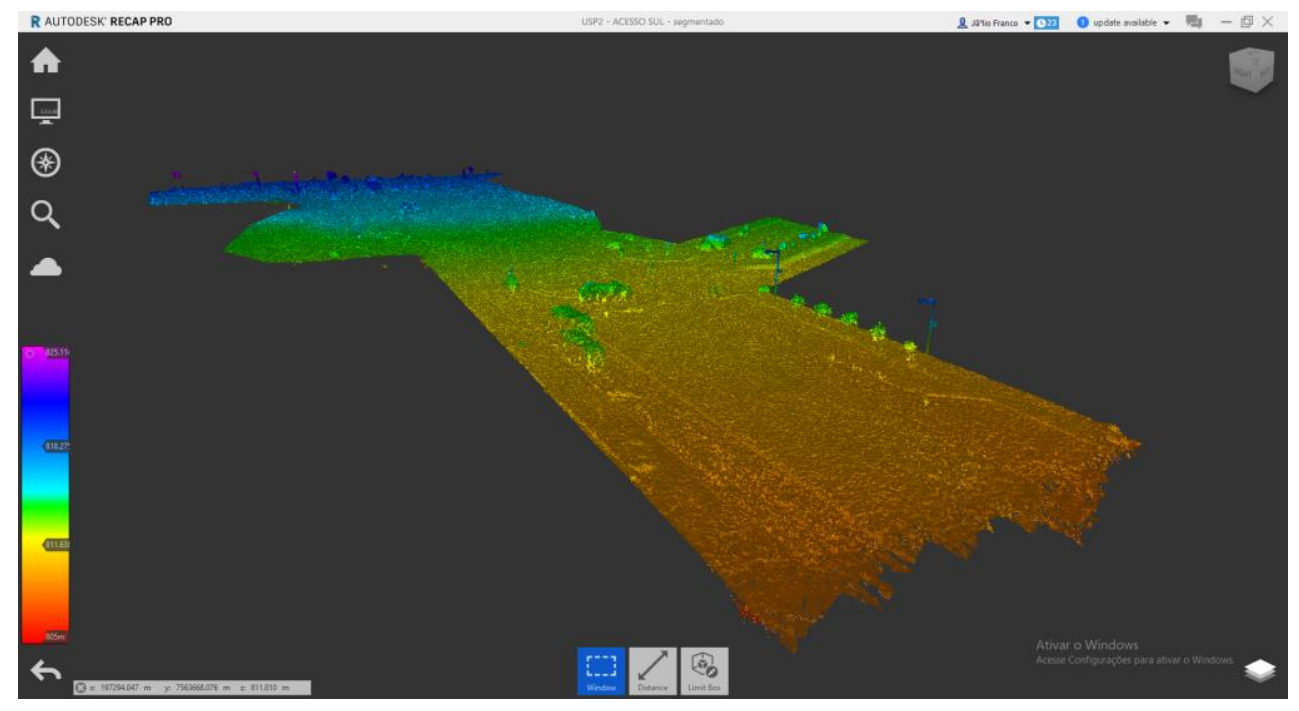

Fonte: Autor (2019)

Por fim, o Agisoft PhotoScan é um software fotogramétrico de processamento de imagens digitais e geração de dados espaciais tridimensionais. Permite processar vários tipos de imagem e suporta "projetos" com múltiplas câmeras. Permite também gerar, editar e classificar nuvens de pontos, além de modelos digitais de superfície e ortomosaicos georreferenciados. Nele é possível inserir dados de pontos de controle para aumentar a acurácia do processamento. Além disso, o software possui ferramentas para medição de distâncias, áreas e volumes e é capaz de processar imagens RGB, NIR, termográficas e multiespectrais ${ }^{3}$ (AGISOFT, 2019). A interface do software é apresentada na Figura 20.

${ }^{3}$ Ver seção 2.4.3 Câmeras e sensores embarcados, página 95. 
Figura 20 - Interface Agisoft Photoscan

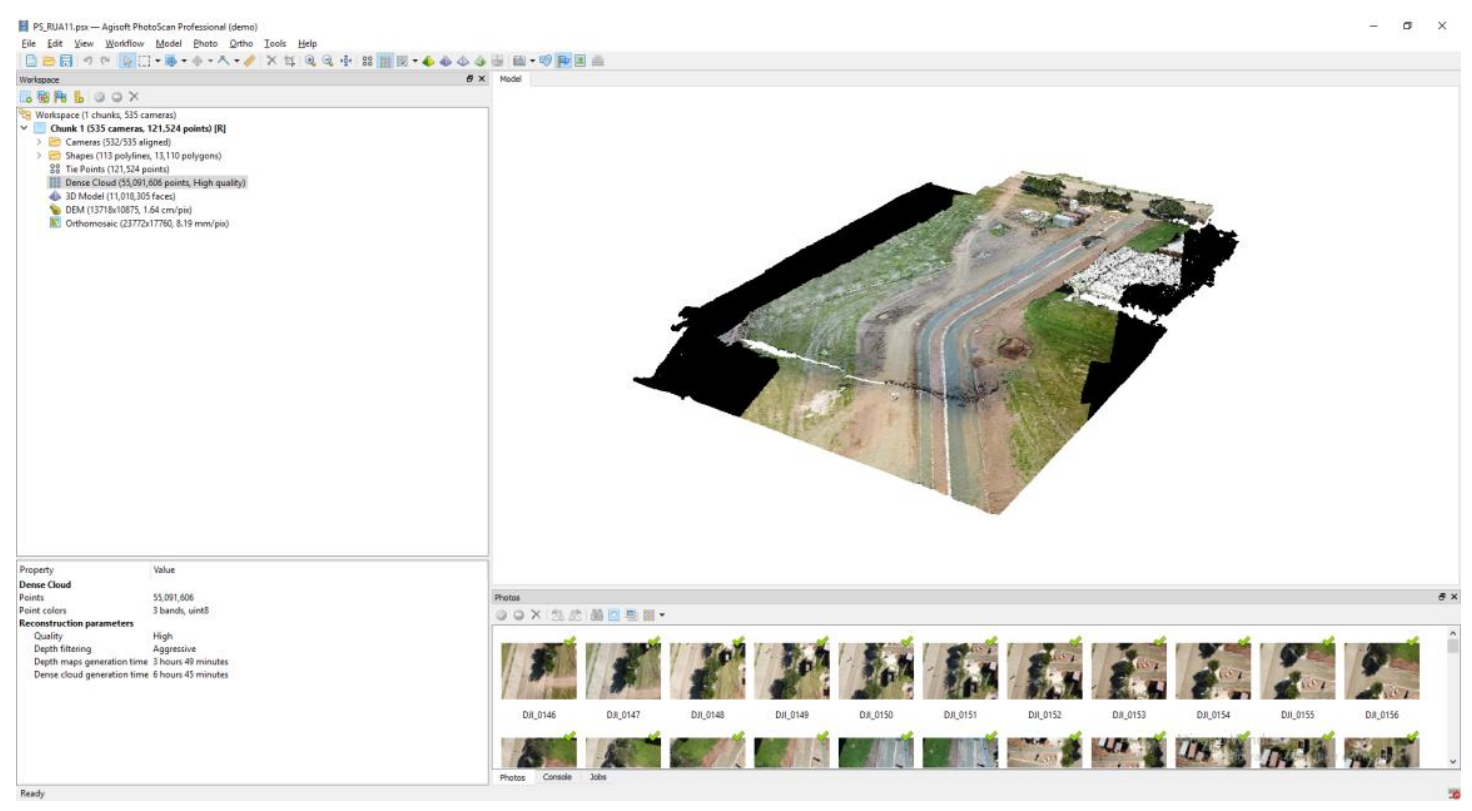

Fonte: Autor (2019)

Na Figura 21, é apresentado um fluxo geral de trabalho no PhotoScan. 
Figura 21 - Processamento fotogramétrico por SfM via Agisoft Photoscan.
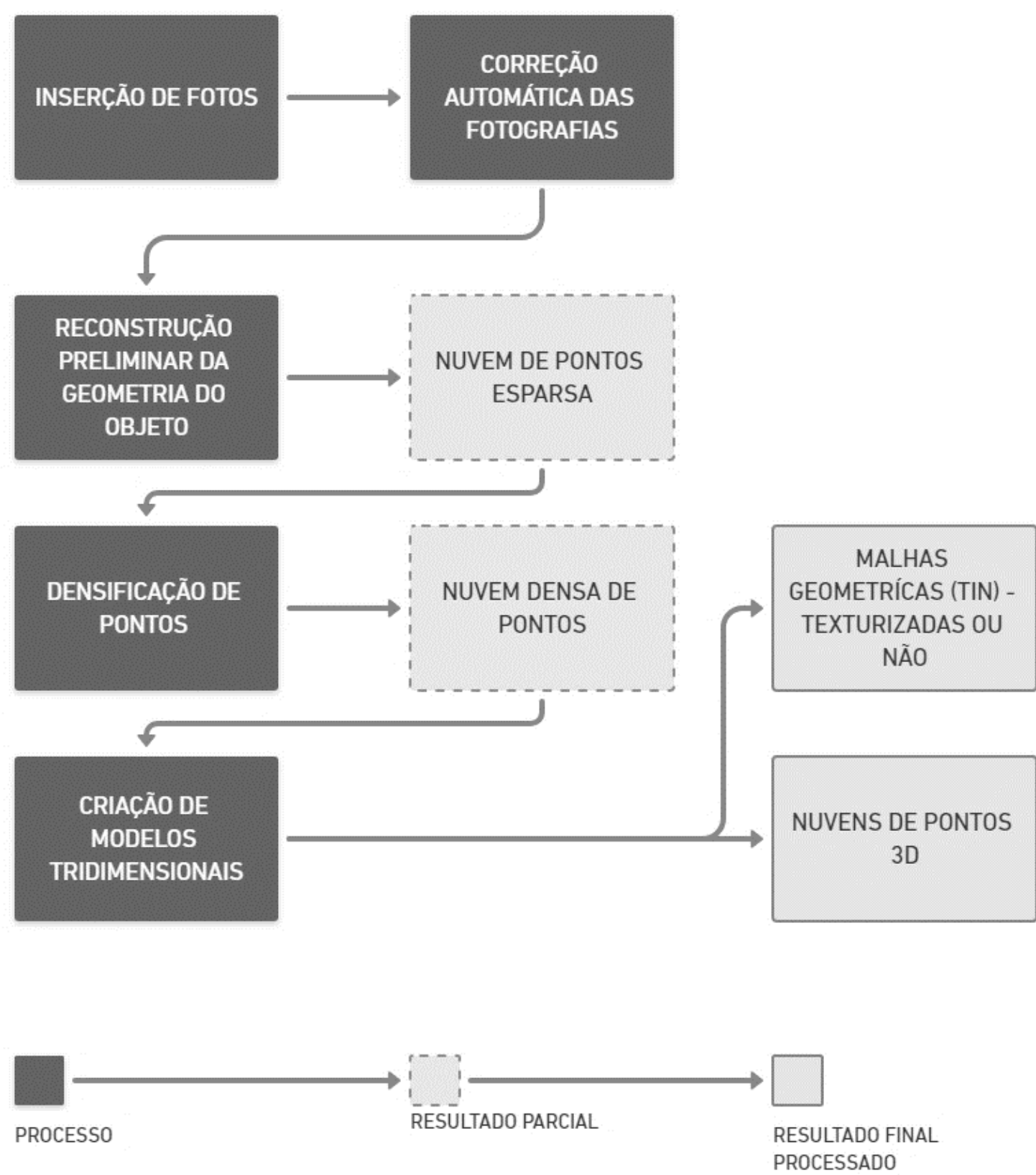

Fonte: Adaptado de Groetelaars (2015, p. 73) 


\subsection{DEFINIÇÕES DE SISTEMAS DE AERONAVES REMOTAMENTE PILOTADAS}

Como exposto, Sistemas de Aeronaves Remotamente Pilotadas (RPAS), ou drones, têm se popularizado em aplicações para diversos campos da ciência e engenharia. Também denominadas de VANT (Veículos Aéreos Não Tripulados termo obsoleto), essas aeronaves são pilotadas por controle remoto via rádio frequência e são comumente equipadas de câmeras fotográficas capazes de capturar imagens e vídeos, além de dados de outros sensores embarcados (FLOREANO e WOOD, 2015).

Para esclarecer os termos utilizados para essas aeronaves, o Departamento de Controle do Espaço Aéreo brasileiro (DECEA) define:

\footnotetext{
VANT, Veículo Aéreo Não Tripulado (tradução do termo UAV - Unmanned Aerial Vehicle), é o termo utilizado para se referir a todo e qualquer equipamento que acesse o espaço aéreo em que não há a presença de um ser humano a bordo. O termo VANT é considerado obsoleto pela Organização da Aviação Civil Internacional (OACl) conforme documentação Doc 10019, Manual On RPAS, da OACl.

RPAS (Remotely Piloted Aircraft System) é o termo técnico e padronizado internacionalmente pela $\mathrm{OACl}$ para se referir aos sistemas de aeronaves remotamente pilotadas utilizadas com propósitos não recreativos.

Drone é o termo utilizado de forma coloquial e popular para se referir aos equipamentos remotamente pilotados. Drone, cuja tradução significa "zangão", foi oriundo do tipo de trabalho que esses equipamentos costumam produzir que lembra o som emitido por um zangão em voo." (DECEA, 2018).
}

Cabe ainda ressaltar que o termo é "RPA" diz respeito apenas à aeronave, enquanto "RPAS" engloba seus subsistemas embarcados e todo aparato de apoio para operação de voos. Assim, RPAS compreendem: a Aeronave, a Estação de Pilotagem Remota (RPS), os dispositivos de controle de voo e georreferenciamento, os dispositivos de comunicação e visualização, e por fim os dispositivos de coleta de dados (Figura 22). 


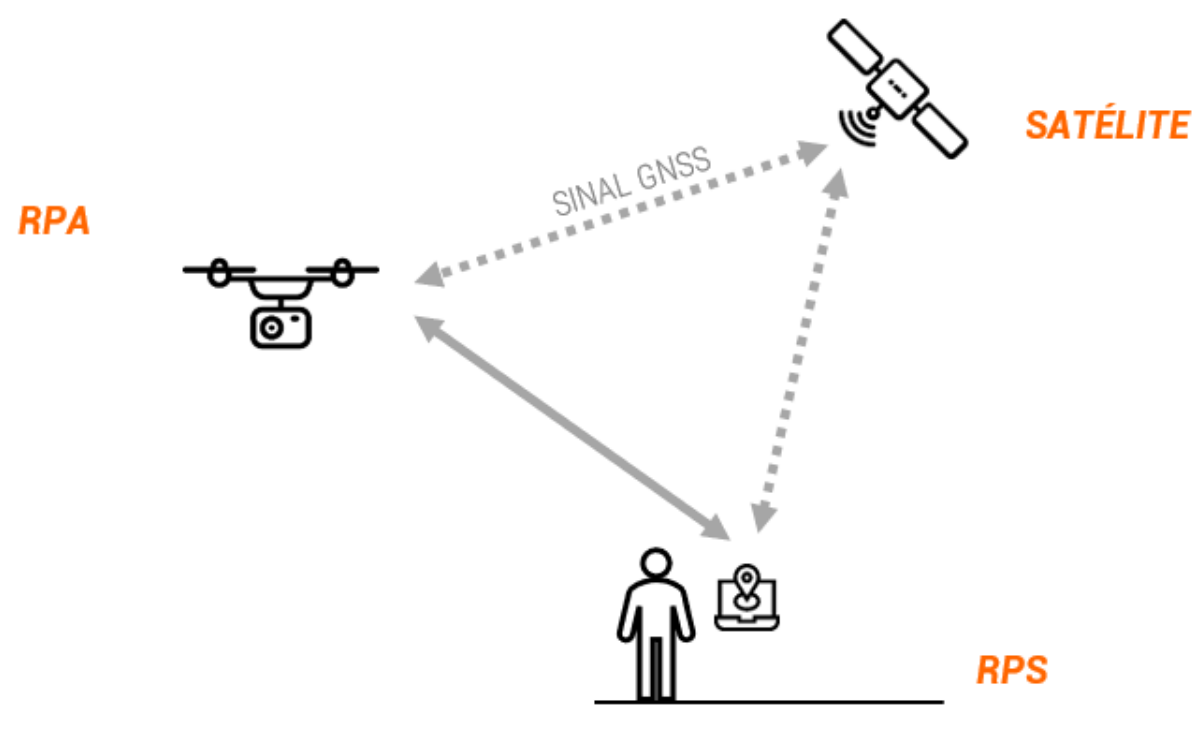

Fonte: Autor (2019).

Há diversas configurações disponíveis no mercado, contemplando modelos de vários formatos, preços e fabricantes nacionais e internacionais. As seções seguintes tratam dos tipos de aeronaves e características principais, os dispositivos de controle de voo e georreferenciamento, os sistemas de planejamento e controle de voo e, por fim, características de sensores embarcados.

\subsubsection{TIPOS DE AERONAVES}

RPAS são sistemas que utilizam as reações aerodinâmicas com o ar para voar, por meio de asas e/ou rotores (DECEA, 2018). Tomando-se por base a forma de decolagem e pouso, há dois principais tipos: as aeronaves com decolagem e pouso horizontais, tipicamente de asa fixa (semelhantes a aviões); e aeronaves com decolagem e pouso verticais, multirrotores (quatro ou mais), semelhantes a helicópteros (TANG e SHAO, 2015). Há também modelos híbridos de asas fixas que usam hélices para assistir a decolagem e pouso, verticalizando-os. Com esse mesmo propósito, há modelos que utilizam paraquedas de pouso. No Quadro 8 são apresentadas tipologias e conceitos simplificados da aerodinâmica de RPA. 


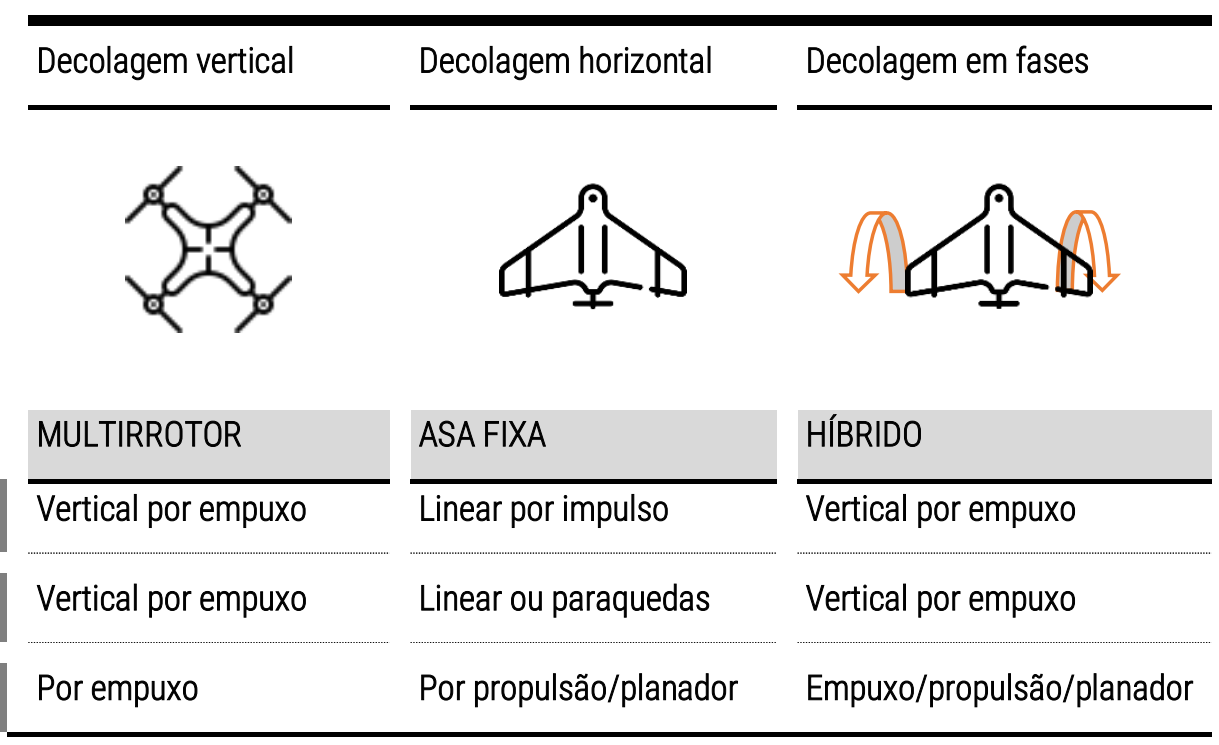

Fonte: Adaptado de Grandl, Cachay e Salib (2018).

As características de cada RPAS determinam a maneira e as possibilidades do levantamento aéreo. De modo que é necessário compreender suas capacidades e limites, correlacionando-os com as finalidades de uso, para decidir qual modelo é mais apropriado a cada aplicação (LIU et al., 2014). Nesse sentido, Siebert e Teizer (2014) pontuam que a seleção do RPAS deve considerar critérios como (i) dimensões da área a ser levantada, (ii) altitude necessária para operação, (iii) o tipo de câmera a ser utilizada, (iv) existência de obstáculos físicos, (v) espaço para pouso e decolagem e (vi) segurança de terceiros.

Para compreender os diferentes aspectos relacionados às aeronaves e seus sistemas, nas subseções seguintes são apresentadas as características principais de cada tipo.

\subsubsection{RPAS multirrotores}

RPAS multirrotores funcionam como "mini-helicópteros": sua sustentação se dá pelo empuxo gerado por suas hélices, e a decolagem e pouso são verticais ${ }^{4}$ e sem auxílio de impulsos externos (FIGUEIREDO e FIGUEIREDO, 2018). Esse tipo de

${ }^{4}$ Vertical Take-Off and Landing - VTOL 
equipamento permite estabilidade de voo e tomadas verticais para captura de dados, o que possibilita aproximação a objetos de interesse e favorece inspeções de fachadas e torres de energia, por exemplo. Esses sistemas são mais suscetíveis a condições ambientais como vento e a operação é limitada a pequenas áreas (EISENBEISS, 2009, p. 35-36).

Comercialmente, esse tipo de aeronave tem se popularizado, e há uma diversidade de modelos (FLOREANO e WOOD, 2015). Em geral, os modelos são de pequeno porte, alguns inclusive articulados e com proteções externas contra impacto. Assim, a portabilidade é uma característica notória dessa categoria, embora isso possa limitar a quantidade de sensores embarcados e baterias, o que pode significar menor tempo de voo, menor área de cobertura e tipos restritos de dados capturados.

O tempo de voo, ou autonomia, varia de acordo com o equipamento, mas a ordem de grandeza é de 30 min nos equipamentos de pequeno porte (Qadro 9). A autonomia de cada equipamento é condicionada a aspectos internos, como eficiência de motores e sistemas de controle e comunicação, aerodinâmica, quantidade de baterias etc.; e externos, como as condições de vento e parâmetros de planejamento de voo estabelecidos pelo piloto.

No Quadro 9, é apresentado um recorte de modelos catalogados para utilização na construção civil. O quadro 9 contém dados de peso máximo de decolagem, autonomia de voo, tipo de câmera e diferenciais notados. 


\begin{tabular}{|c|c|c|c|c|c|}
\hline Marca & Modelo & $\begin{array}{r}\text { Peso } \\
\text { (g) }\end{array}$ & $\begin{array}{l}\text { Autonomia } \\
\text { (min) }\end{array}$ & Câmeras & Diferencial \\
\hline \multirow[t]{7}{*}{ DJI } & $\begin{array}{l}\text { Phanton } \\
4 \text { PRO } \\
\text { V2.0 }\end{array}$ & 1375 & 30 & $\begin{array}{l}\text { RGB 20MP, } \\
\text { integrada } \\
\text { Estabilizador } \\
\text { triaxial }\end{array}$ & $\begin{array}{l}\text { Sensores anti-choque: } \\
\text { Frontal, traseiro, inferior, } \\
\text { lateral e superior }\end{array}$ \\
\hline & $\begin{array}{l}\text { Phanton } \\
\text { 4 RTK }\end{array}$ & 1391 & 30 & $\begin{array}{l}\text { RGB 20MP, } \\
\text { integrada } \\
\text { Estabilizador } \\
\text { triaxial }\end{array}$ & $\begin{array}{l}\text { Georreferenciamento de } \\
\text { precisão RTK/PPK }\end{array}$ \\
\hline & $\begin{array}{l}\text { Mavic } \\
\text { Pro }\end{array}$ & 743 & 27 & $\begin{array}{l}\text { RGB, } 12 \mathrm{MP} \text {, } \\
\text { integrada. } \\
\text { Estabilizador } \\
\text { triaxial }\end{array}$ & $\begin{array}{l}\text { Sensores anti-choque: } \\
\text { frontal, inferior. }\end{array}$ \\
\hline & $\begin{array}{l}\text { Mavic } 2 \\
\text { Pro }\end{array}$ & 907 & 31 & $\begin{array}{l}\text { RGB 20MP, } \\
\text { integrada } \\
\text { Estabilizador } \\
\text { triaxial }\end{array}$ & $\begin{array}{l}\text { Sensores anti-choque: } \\
\text { Frontal, traseiro, inferior, } \\
\text { lateral e superior }\end{array}$ \\
\hline & $\begin{array}{l}\text { Mavic } 2 \\
\text { Zoom }\end{array}$ & 905 & 31 & $\begin{array}{l}\text { RGB 12MP, } \\
\text { integrada } \\
\text { Estabilizador } \\
\text { triaxial }\end{array}$ & $\begin{array}{l}\text { Sensores anti-choque: } \\
\text { Frontal, traseiro, inferior, } \\
\text { lateral e superior }\end{array}$ \\
\hline & Inspire 2 & $\begin{array}{l}3440 \\
*\end{array}$ & 27 & Variável & $\begin{array}{l}\text { Sensores anti-choque: } \\
\text { Frontal, inferior. }\end{array}$ \\
\hline & $\begin{array}{l}\text { Matrice } \\
200\end{array}$ & & & Variável & Alta capacidade de carga \\
\hline Flyability & Elios II & 1450 & 10 & $\begin{array}{l}\text { RGB+Térmic } \\
\text { a }\end{array}$ & $\begin{array}{l}\text { Chassis contra colisões em } \\
\text { espaços confinados. } \\
\text { Câmeras com } \\
\text { movimentação vertical de } \\
180^{\circ} \text { e luzes ajustáveis para } \\
\text { inspeções }\end{array}$ \\
\hline \multirow[t]{3}{*}{ Microdrone } & Md4-200 & 1100 & 25 & Variável & Alta capacidade de carga \\
\hline & $\begin{array}{l}\text { Md4- } \\
1000 \\
\end{array}$ & 6000 & 45 & Variável & $\begin{array}{l}\text { Georreferenciamento de } \\
\text { precisão RTK }\end{array}$ \\
\hline & $\begin{array}{l}\text { Md4- } \\
3000\end{array}$ & & 45 & Variável & $\begin{array}{l}\text { Georreferenciamento de } \\
\text { precisão RTK/PPK }\end{array}$ \\
\hline $\begin{array}{l}\text { Nuvem } \\
\text { UAV }\end{array}$ & Spectral & 2400 & 60 & Variárel & Autonomia de voo \\
\hline
\end{tabular}

* Desconsiderando o peso da câmera e estabilizador 
Quadro 9 (Continuação) - Modelos comerciais de RPA multirotores catalogados

\begin{tabular}{|c|c|c|c|c|c|}
\hline Marca & Modelo & $\begin{array}{l}\text { Peso } \\
\text { (g) }\end{array}$ & $\begin{array}{l}\text { Autonomia } \\
\text { (min) }\end{array}$ & Câmeras & Diferencial \\
\hline \multirow[t]{3}{*}{ Parrot } & Anafi & 320 & 25 & $\begin{array}{l}\text { RGB } \\
\text { integrada } \\
\text { Estabilizador } \\
\text { triaxial }\end{array}$ & $\begin{array}{l}\text { Câmera com } \\
\text { movimentação vertical de } \\
180^{\circ}\end{array}$ \\
\hline & $\begin{array}{l}\text { Anafi } \\
\text { Thermal }\end{array}$ & 315 & 26 & $\begin{array}{l}\text { RGB + } \\
\text { infravermelh } \\
\text { o integradas }\end{array}$ & $\begin{array}{l}\text { Câmera com } \\
\text { movimentação vertical de } \\
180^{\circ} \text {. Câmera térmica } \\
\text { integrada }\end{array}$ \\
\hline & $\begin{array}{l}\text { Blue- } \\
\text { grass }\end{array}$ & 1850 & 25 & $\begin{array}{l}\text { RGB + } \\
\text { multiespectr } \\
\text { al }\end{array}$ & $\begin{array}{l}\text { Câmera multiespectral } \\
\text { integrada }\end{array}$ \\
\hline Skydrone & Strix-Ag & - & - & $\begin{array}{l}\text { RGB + } \\
\text { multiespectr } \\
\text { al }\end{array}$ & Câmera multiespectral \\
\hline Yuneec & H520 & 1645 & 28 & Variável & $\begin{array}{l}\text { Georreferenciamento de } \\
\text { precisão RTK/PPK. Câmera } \\
\text { com movimentação } \\
\text { horizontal de } 360^{\circ}\end{array}$ \\
\hline
\end{tabular}

* Desconsiderando o peso da câmera e estabilizador

Fonte: Autor (2019).

\subsubsection{RPAS de asa fixa}

Os modelos de asa fixa se assemelham a "pequenos aviões". O voo é baseado nas forças de sustentação geradas pela velocidade do ar em relação a aeronave, cujo formato aerodinâmico das asas cria diferenças de pressão responsáveis por gerar forças perpendiculares à superfície da asa, permitindo-a planar. As aeronaves são dotadas de motores à bateria para propulsão, e ailerons (flaps) para controle da trajetória de voo (EISENBEISS, 2009). Quanto à decolagem, os procedimentos são assistidos por impulso mecânico (elásticos e catapultas) ou manual. O pouso pode ser linear ("de barriga") ou por paraquedas, a depender de cada modelo (ABER, MARZOLFF e RIES, 2010a).

Em função da capacidade da aeronave planar, há economia de energia na propulsão e, consequentemente, o tempo/autonomia de voo é maior (WANG et al., 2017) - podendo chegar a mais de duas horas. Além disso, a aerodinâmica da 
aeronave possibilita alcançar velocidades maiores. Com maior autonomia e mais velocidade, esses modelos são capazes de cobrir maiores áreas.

O porte desses equipamentos é maior em relação aos multirrotores e pode ser analisado através de sua envergadura, medida entre uma ponta e outra das asas. Obviamente, as dimensões maiores diminuem sua portabilidade para transporte, mas possibilitam maior capacidade de carga (payload), o que significa poder embarcar outros sensores, baterias maiores, e cobrir áreas maiores. Há modelos em que as asas podem ser desmontadas, a favor da portabilidade no transporte, embora isso possa demandar mais tempo e cuidado de preparação para voo.

No Quadro 10, são apresentados modelos e características gerais de aeronaves disponíveis do mercado, no formato de um recorte de fabricantes nacionais e internacionais catalogados para uso em mapeamento e construção civil. 


\begin{tabular}{|c|c|c|c|c|c|}
\hline Marca & Modelo & Origem & $\begin{array}{l}\text { Autonomia } \\
\text { (min) }\end{array}$ & Câmeras & Observações \\
\hline \multirow[t]{2}{*}{ Horus } & $\underline{\text { Verok }}$ & $\begin{array}{l}\text { Nacion } \\
\text { al }\end{array}$ & 120 & Variável & $\begin{array}{l}\text { Georreferenciamento de } \\
\text { precisãor RTK/PPK. } \\
\text { Catapulta e Paraquedas. }\end{array}$ \\
\hline & Maptor & $\begin{array}{l}\text { Nacion } \\
\text { al }\end{array}$ & 60 & $\begin{array}{l}\text { RGB } 20 \\
\text { MP }\end{array}$ & $\begin{array}{l}\text { Decolagem com } \\
\text { Catapulta. Pouso linear }\end{array}$ \\
\hline \multirow[t]{2}{*}{$\begin{array}{l}\text { Nuvem } \\
\text { UAV }\end{array}$} & Batmap I & $\begin{array}{l}\text { Nacion } \\
\text { al }\end{array}$ & 90 & Variável & $\begin{array}{l}\text { Decolagem com } \\
\text { Catapulta. Pouso linear }\end{array}$ \\
\hline & Batmap II & $\begin{array}{l}\text { Nacion } \\
\text { al }\end{array}$ & 180 & Variável & $\begin{array}{l}\text { Georreferenciamento de } \\
\text { precisãor RTK/PPK. } \\
\text { Catapulta e Paraquedas. }\end{array}$ \\
\hline \multirow[t]{2}{*}{ Sensefly } & $\begin{array}{l}\text { eBee } \\
\text { classic }\end{array}$ & $\begin{array}{l}\text { Interna } \\
\text { c. }\end{array}$ & 50 & Variável & $\begin{array}{l}\text { Decolagem rom } \\
\text { impulso manual. Pouso } \\
\text { linear. }\end{array}$ \\
\hline & eBee X & $\begin{array}{l}\text { Interna } \\
\text { c. }\end{array}$ & 90 & Variável & $\begin{array}{lr}\text { Georreferenciamento de } \\
\text { precisão } \\
\text { Decolagem } \\
\text { impulso manual. Pouso } \\
\text { linear. }\end{array}$ \\
\hline \multirow[t]{2}{*}{ Skydrones } & $\underline{\text { Quantix }}$ & $\begin{array}{l}\text { Interna } \\
\text { c. }\end{array}$ & 45 & $\begin{array}{l}\text { RGB + } \\
\text { NDVI } \\
\text { Multiespe } \\
\text { C. }\end{array}$ & $\begin{array}{l}\text { Híbrido (Decolagem e } \\
\text { pouso verticais) }\end{array}$ \\
\hline & Zangão V & $\begin{array}{l}\text { Interna } \\
\text { c. }\end{array}$ & 60 & Variável & $\begin{array}{l}\text { Georreferenciamento de } \\
\text { precisão RTK. Catapulta } \\
\text { e Paraquedas. }\end{array}$ \\
\hline Wingtra & $\frac{\text { Wingtraon }}{\underline{\mathrm{e}}}$ & $\begin{array}{l}\text { Interna } \\
\text { c. }\end{array}$ & 120 & Variável & $\begin{array}{l}\text { Georreferenciamento de } \\
\text { precisão RTK/PPK. } \\
\text { Híbrido (Decolagem e } \\
\text { pouso verticais) }\end{array}$ \\
\hline \multirow[t]{3}{*}{ Xmobots } & Arator 5B & $\begin{array}{l}\text { Nacion } \\
\text { al }\end{array}$ & 87 & Variável & $\begin{array}{l}\text { Georreferenciamento de } \\
\text { precisão RTK. Catapulta } \\
\text { e Paraquedas. }\end{array}$ \\
\hline & Echar 20D & $\begin{array}{l}\text { Nacion } \\
\text { al }\end{array}$ & 180 & Variável & $\begin{array}{l}\text { Georreferenciamento de } \\
\text { precisão RTK. Catapulta } \\
\text { e Paraquedas. }\end{array}$ \\
\hline & $\frac{\text { Nauru }}{500 B}$ & $\begin{array}{l}\text { Nacion } \\
\text { al }\end{array}$ & 600 & Variável & $\begin{array}{l}\text { Georreferenciamento de } \\
\text { precisão RTK. Catapulta } \\
\text { e Paraquedas. }\end{array}$ \\
\hline
\end{tabular}

Fonte: Autor (2019). 


\subsubsection{RPAS Híbridos}

Modelos híbridos combinam as características aerodinâmicas de aeronaves de asa fixa com a capacidade de decolagem e pouso verticais dos multirrotores (WINGTRA, 2018). Tais aspectos permitem a esses RPAS decolar de lugares em que aeronaves de asa fixa não teriam espaço suficiente para tal, e sobrevoar área superior à que multirrotores sobrevoariam em um único voo. Modelos como o Skydrone-Quantix e Wingtra (Figura 23) utilizam flaps para fazer a transição entre a decolagem/pouso vertical e o voo.

Figura 23 - RPAS híbridos Skydrone-Quantix e Wingtra em transição para voo horizontal
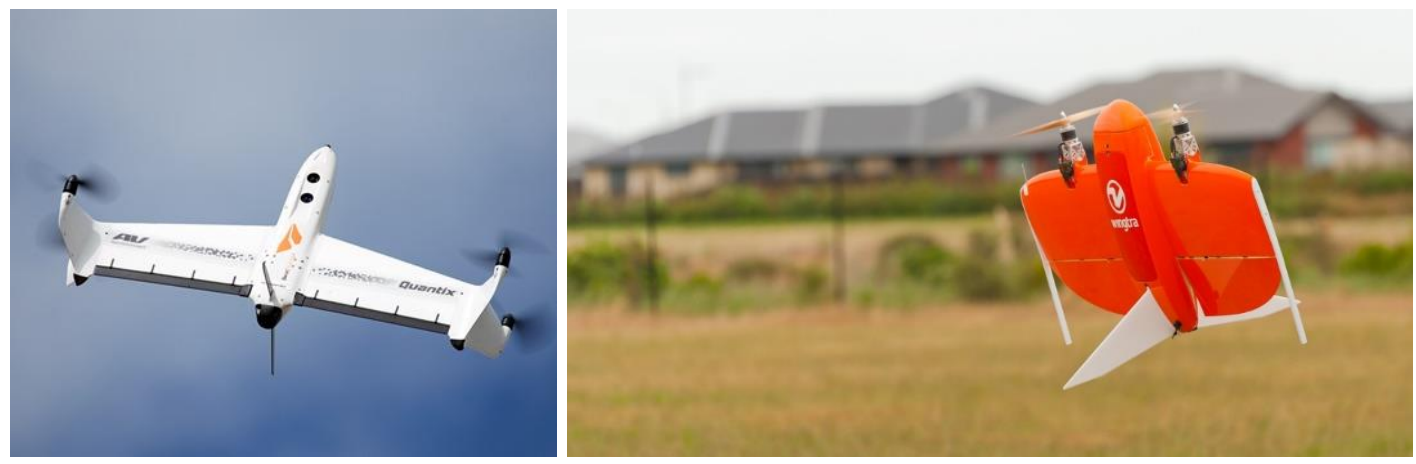

Fonte: a) Skydrones (2019), b) Wingtra (2018).

Outros como o Carbonix Volanti (Figura 24a) e o Google-Wing (Figura 24b) utilizam hélices adicionais para fornecer empuxo vertical para decolagem/pouso e voo.

Figura 24 - (a) RPAS Carbonix-Volanti e (b)RPAS Google-Wing

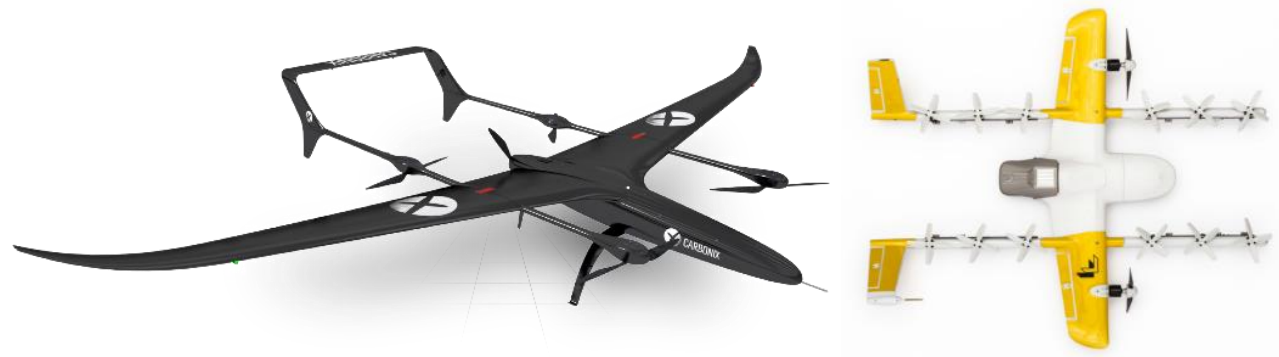

Fonte: a) Carbonix (2019), b) Google-Wing (2018). 


\subsubsection{SISTEMAS DE CONTROLE DE VOO}

Para o controle da trajetória de voo, RPAS são equipados com receptores GNSS e sensores inerciais com giroscópios e acelerômetros (IMU - Unidade de Medida Inercial), dispositivos que permitem reconhecer sua posição, alinhamento, inclinação e velocidade (SIEBERT e TEIZER, 2014). Graças ao desenvolvimento e miniaturização desses componentes eletrônicos embarcados e de dispositivos de controle em Terra é possível operar manualmente ou planejar trajetórias de voo para serem executadas em campo com precisão e remotamente (EISENBEISS, 2009; FLOREANO e WOOD, 2015).

Além dos módulos eletrônicos embarcados e softwares de controle de voo, podem ser utilizados dispositivos adicionais mais precisos para garantir a qualidade dos dados obtidos em termos de georreferenciamento, escala e orientação de modelos fotogramétricos satisfatórios.

Na sequência, são apresentados os sistemas RTK e PPK utilizados para correção de coordenadas geográficas de dados levantados. Apresenta-se também o método por pontos de controle em solo (GCPs) também utilizado para melhorar a orientação espacial de dados e garantir qualidade de modelos fotogramétricos.

\subsubsection{Sistemas RTK e PPK}

O sistema RTK (Real Time Kinematic) usa uma base estática em solo com receptor GNSS de precisão para aferir e determinar correções diferenciais, em tempo real, do posicionamento da aeronave (ZHANG, 2017). A base registra as coordenadas de onde foi posicionada, utilizando-as como referência estática para verificar se a rota executada pela aeronave foi como a prevista e, se não, aplicar as correções necessárias. Tais correções são aplicadas tanto na rota da aeronave como nas coordenadas registradas em cada imagem, utilizando um sistema de telemetria. Esse sistema depende de conexão adequada entre a base em solo, o RPAS e o sinal de satélite, caso contrário os registros podem ser inconsistentes (HORUS, 2018). 
O funcionamento do sistema Post Processed Kinematic (PPK) é similar ao RTK, no entanto, a correção não é feita em tempo real e não depende da conexão por telemetria. Os dados geográficos são armazenados na aeronave e na base estática e são processados e corrigidos após o voo (ZHANG, 2017). Assim, as correções não ficam sujeitas a imprecisões decorrentes de interrupções no sinal de telemetria, como pode acontecer com RTK (HORUS, 2018). Além disso, PPK permite níveis de acurácia de ordem subcentimétrica (WINGTRA, 2018).

A Figura 25 apresenta esquematicamente as diferenças entre os sistemas RTK e PPK.

Figura 25 - Esquema de funcionamento dos sistemas de correção RTK e PPK
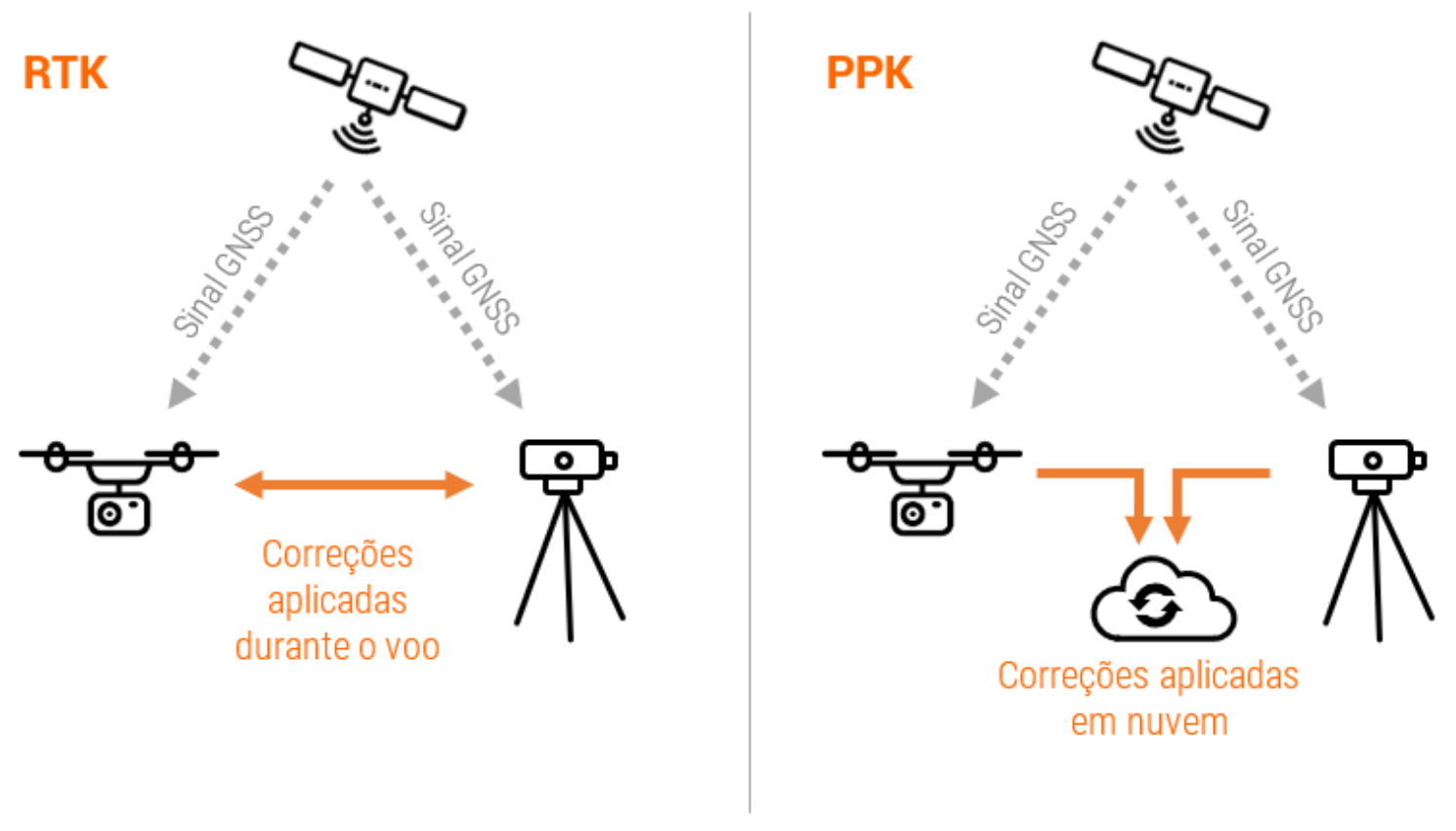

Fonte: Adaptado de Zhang (2017).

\subsubsection{Pontos de controle em solo (GCP's)}

Em RPAS de baixo custo, a acurácia dos módulos de GNSS é frequentemente limitada além de usualmente não possuírem sistemas RTK ou PPK (KOEVA et al., 2018). Nesse caso, é necessário utilizar pontos de controle em solo (GCP) como método suplementar para manter a qualidade do georreferenciamento e, consequentemente dos produtos fotogramétricos. 
GCP são pontos sinalizados em solo cujas coordenadas são conhecidas - ou determinadas com outros métodos topográficos (estação total, GNSS etc.). Os pontos de controle podem ser naturais, como marcações pré-existentes, cantos de sarjeta ou outros vértices bem definidos e identificáveis nas imagens. Também podem ser propositadamente colocados, e assim tidos como artificiais por meio da utilização de alvos de sinalização dispostos ao longo da área a ser levantada (ABER; MARZOLFF e RIES, 2010b) (Figura 26). Para tanto, os GCP devem ser distribuídos ao longo da área mapeada de maneira uniforme, cobrindo a extensão da bordas à região central da área mapeada (MARTínEZ-CARRICONDO et al., 2018).

Os GCP são utilizados para orientação de modelos fotogramétricos, mas também podem ser utilizados como pontos de conferência dos produtos gerados. Nesse caso, são considerados pontos de checagem e não são utilizados durante o processamento. Os pontos de checagem são utilizados após o processamento, sendo comparados com as coordenadas correspondentes do modelo fotogramétrico gerado pelos desvios nos eixos $x$, y e z (WAYNE, 2014).

Figura 26 - Exemplos de GCP: levantamento de coordenadas geográficas de quina de calçada utilizada como GCP naturais e alvo artificial disposto em solo
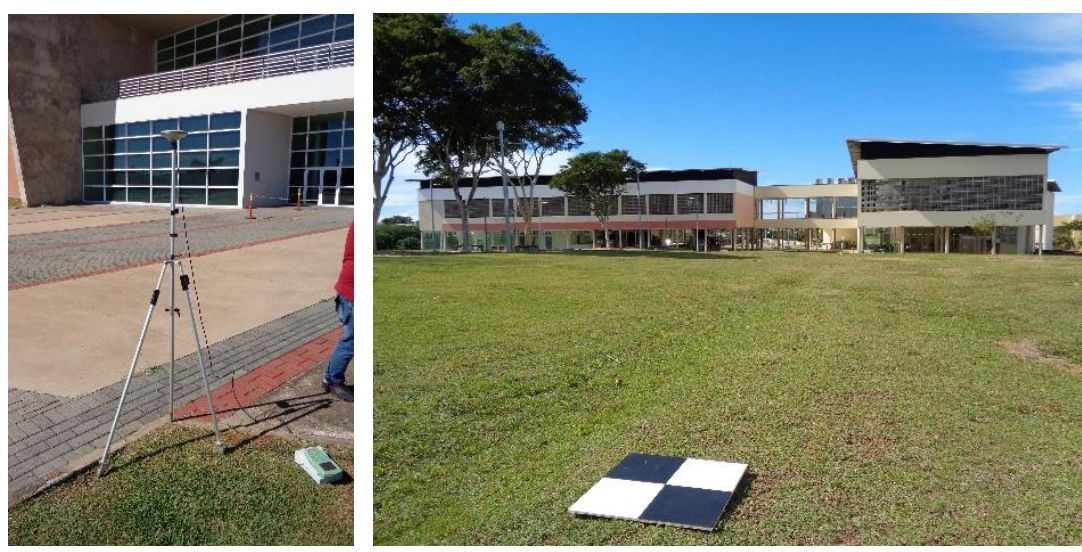

Fonte: Autor (2019)

Comparativamente, o uso de RTK e PPK reduz o tempo consumido no levantamento de campo, diminuindo a quantidade de GCP necessários e possibilitando que levantamentos de larga escala sejam ágeis, viáveis e acurados (STÖCKER et al., 2017). Não somente o georrefereciamento de produtos é 
significativamente aprimorado quando se emprega sistemas RTK, como as deformações são reduzidas (GERKE e PRZYBILLA, 2016). No entanto, a utilização de RTK e PPK demanda investimentos maiores em equipamentos, mas os resultados são melhores. Outra questão é que o uso de RTK não necessariamente elimina o emprego de GCP, pois estes podem ser utilizados na conferência de produtos finais.

\subsubsection{CÂMERAS E SENSORES EMBARCADOS}

Levantamento de imagens aéreas é um tipo de sensoriamento remoto, o que significa obter informações de um objeto à distância por meio de câmeras e sensores, em outras palavras, conseguir visualizar e analisar algo sem contato físico direto. As ondas eletromagnéticas são responsáveis por "carregar" as informações das superfícies materiais até os sensores, os quais possuem sensibilidade relativa a determinadas faixas do espectro eletromagnético, descritas pelo comprimento de onda correspondente (ABER; MARZOLFF e RIES, 2010c).

Figura 27 - Espectro da luz visível em micrometros de comprimento de onda. Bandas: Azul (0.4-0.5 mm), Verde (0.5-0.6), e vermelho (0.6-0.7), Ultravioleta-Próximo 0.3-

0.4, Infravermelho-Próximo 0.7-1.5.

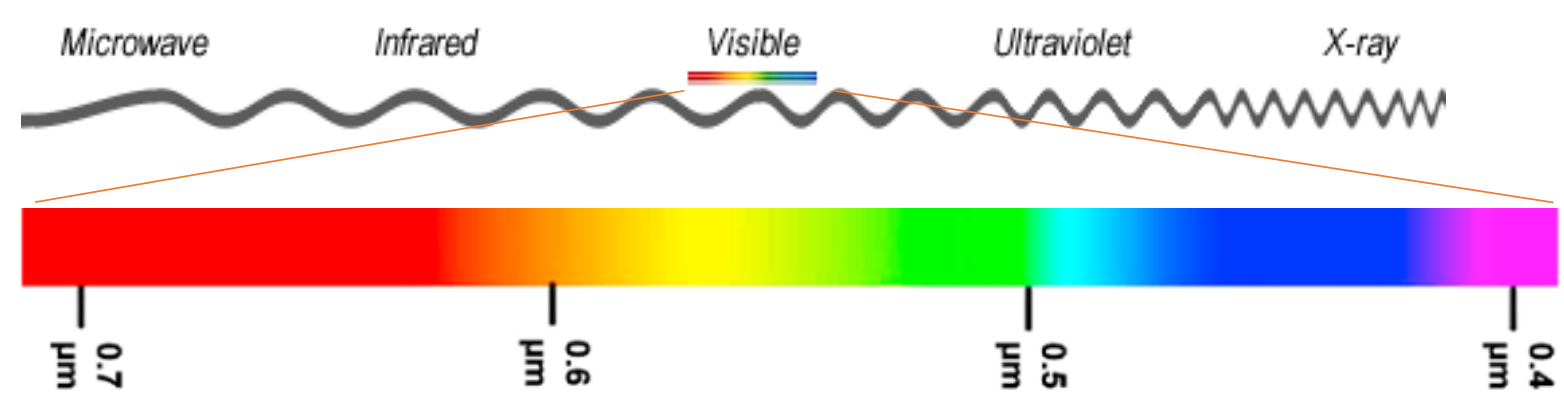

Fonte: Adaptado de Aber, Marzolff e Ries (2010c). Figura sem escala

Cada material reage à luz de forma diferente, refletindo, absorvendo ou transmitindo diferentes comprimentos de onda com diferentes intensidades. Essa capacidade de refletir, absorver ou transmitir radiações é medida percentualmente pelos parâmetros refletância, absortância e transmitância, respectivamente (INPE, 2019). 
Os sensores ópticos captam a luz incidente refletida pelos materiais e posteriormente o sinal captado pode ser analisado por meio de uma curva de refletância - forma de representação que relaciona a porcentagem de luz refletida pelo material versus o comprimento de onda correspondente. A depender do comportamento ao longo do espectro, os materiais podem ser distinguidos e identificados a partir de seus padrões de reflexão, também chamados de assinaturas espectrais (INPE, 2019).

Há diversos tipos de câmeras/sensores no mercado, sensíveis a diferentes faixas do espectro luminoso e capazes de distinguir diferentes materiais, convertendo os sinais capturados em imagens na faixa do espectro visível para que informações normalmente invisíveis aos olhos humanos se tornem visíveis. A seguir são descritos sucintamente os seguintes tipos: RGB, NIR, termográficas, multiespectrais e hiperespectrais.

Em câmeras RGB, ou câmeras fotográficas, a faixa de operação se encontra no espectro visível ao olho humano, compreendido entre a cor vermelha $(0,6-0,7$ mm) e a azul 0,4-0,5 mm (ABER; MARZOLFF e RIES, 2010c). Seu funcionamento é baseado na captura das faixas de Vermelho, Verde e Azul RGB (Red, Green and B/ue) e são câmeras comuns às RPAS, variando aspectos de construção, resolução e qualidade.

As câmeras NIR (Near InfraRed, ou Infravermelho Próximo) operam no final do espectro vermelho e início do infravermelho. Por sua vez, as câmeras termográficas operam na faixa de radiações infravermelhas e são utilizadas para aferir a temperatura de superfícies materiais.

As câmeras multiespectrais são dispositivos capazes de capturar múltiplas faixas do espectro simultaneamente, utilizando múltiplos sensores embutidos. Na Figura 28 são esquematizadas faixas de captura como exemplo, compreendendo o espectro visível (bandas 1, 2 e 3), o infravermelho (banda 4) e o infravermelho próximo (banda 5). 
Figura 28 - Representação de faixas captadas por câmeras multiespectrais (imagem sem escala)

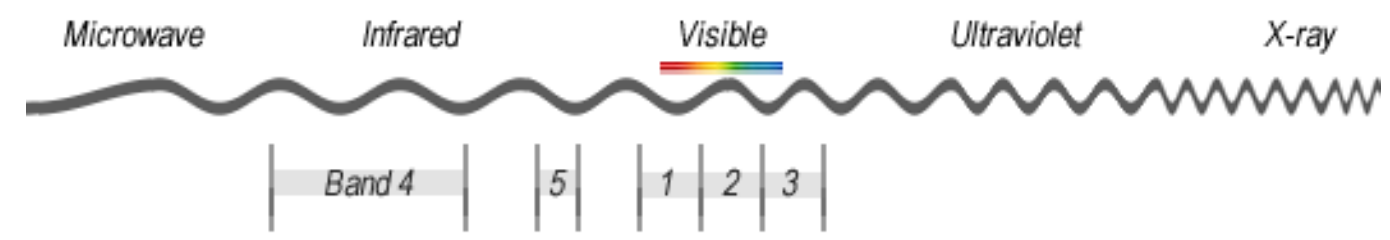

Fonte: GIS Geography (2019).

Por fim, as câmeras hiperespectrais, assim como as multiespectrais, são dispositivos capazes de capturar múltiplas faixas do espectro simultaneamente. No entanto, diferenciam-se pelo número superior de faixas de captura, as quais são mais estreitas e contíguas (adjacentes e não sobrepostas) e os dados obtidos mais discretizados que de câmeras multiespectrais (GIS GEOGRAPHY, 2019).

Figura 29 - Representação de faixas captadas por câmeras hiperespectrais (imagem sem escala)

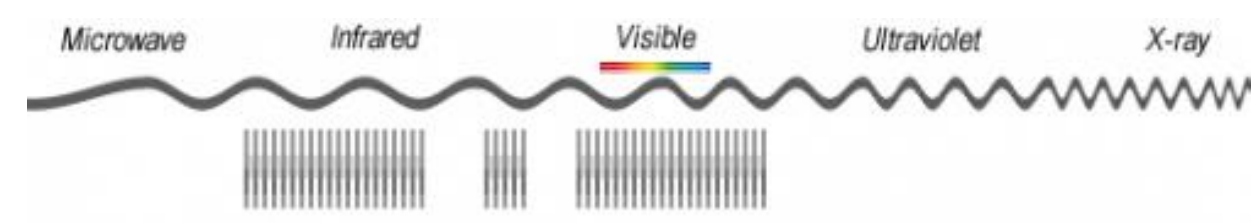

Fonte: GIS Geography (2019). 
O propósito deste trabalho é estudar a aplicação prática de técnicas de levantamento aerofotogramétricos (utilizando Structure from Motion - SfM) para a elaboração de modelos BIM de infraestrutura visando analisar suas potencialidades para fins de documentação.

Para atingir esse objetivo, dois locais de estudo foram escolhidos para levantamento aéreo e modelagem: as obras da Rua 11 e do Acesso Sul do campus 2 da Universidade de São Paulo em São Carlos. Os conjuntos de imagens coletados foram utilizados para gerar nuvens de pontos, modelos DSM e ortomosaicos, tratados aqui como produtos fotogramétricos. Dados de GNSS também foram coletados nos locais de estudo para serem utilizados como pontos de controle (GCP) e georreferenciar as imagens durante o processamento. Os produtos fotogramétricos foram processados nos softwares Agisoft PhotoScan e Pix4D e, por fim, prosseguiu-se com a modelagem BIM utilizando os softwares Autodesk Revit, Recap e InfraWorks.

Nas seções seguintes são apresentados detalhes sobre as obras de estudos e os procedimentos adotados para a aquisição de imagens, a coleta de dados de pontos de controle, o processamento fotogramétrico e a modelagem BIM. 


\subsection{OBRAS DE ESTUDO}

Duas obras foram analisadas para gerar modelos fotogramétricos a partir de levantamentos com RPAS. Ambas são localizadas no Campus 2 da USP São Carlos-SP e são apresentadas na Figura 30.

A decolagem e pouso foram realizados próximos aos locais de estudo. A aeronave utilizada é homologada na Anatel e registrada na ANAC em conjunto com o piloto/pesquisador. Os voos foram registrados e autorizados pelo DECEA através do sistema SARPAS.

O local de estudo 1 se trata das obras da Rua 11, novo acesso à Biblioteca do Campus 2, cuja planta esquemática é apresentada na Figura 31. Pelo fácil acesso ao local, a existência de diferentes tipologias de construções e mudanças leves de elevação, o local compõe um campo versátil e favorável aos testes de levantamento.

O outro local de estudo é o novo acesso ao Campus 2 da USP, o Acesso Sul, cuja planta esquemática é apresentada na Figura 32. Trata-se de uma obra viária envolvendo movimentação de terra e pavimentação. 0 terreno é predominantemente plano, mas contém vegetação de grande porte ao redor, torres de energia no canteiro central e edificações de grande porte esparsas. Essa composição de elementos acrescenta desafios ao levantamento representativos de ambientes urbanos - e complementa o estudo 1 na Rua 11. 
Figura 30 - Localização da Rua 11 e do Acesso Sul do Campus 2 - USP São Carlos

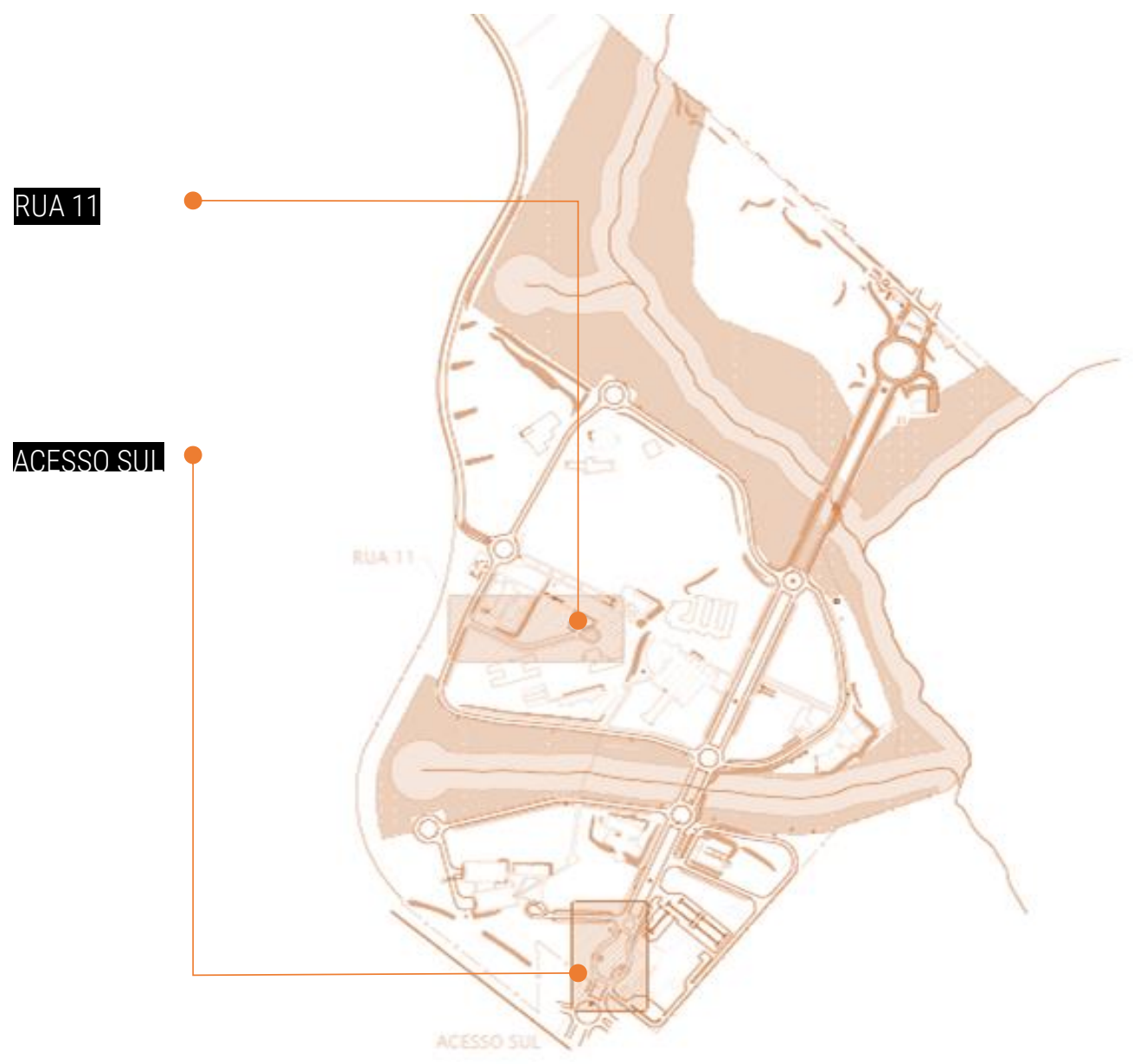

Fonte: SEF (2016).

Figura 31 - Planta esquemática da Rua 11 do Campus 2 - USP São Carlos

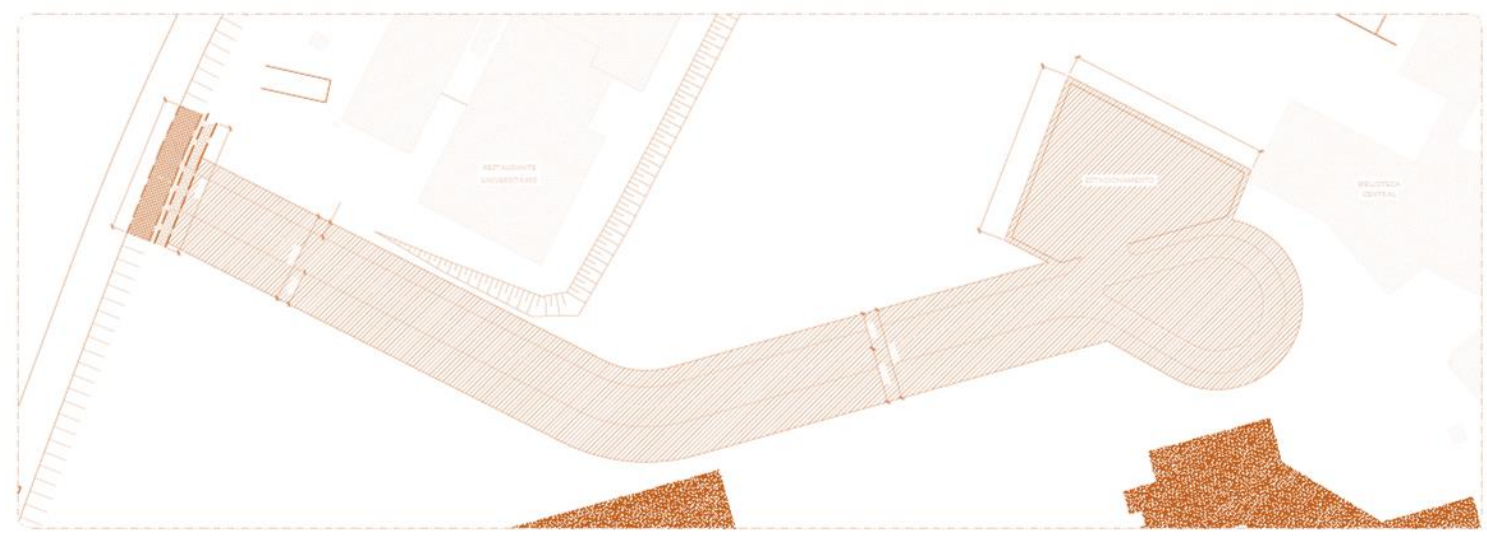

Fonte: SEF (2016). 
Figura 32 - Planta esquemática de intervenções (pavimentação e infraestrutura) do acesso sul do Campus 2 - USP São Carlos

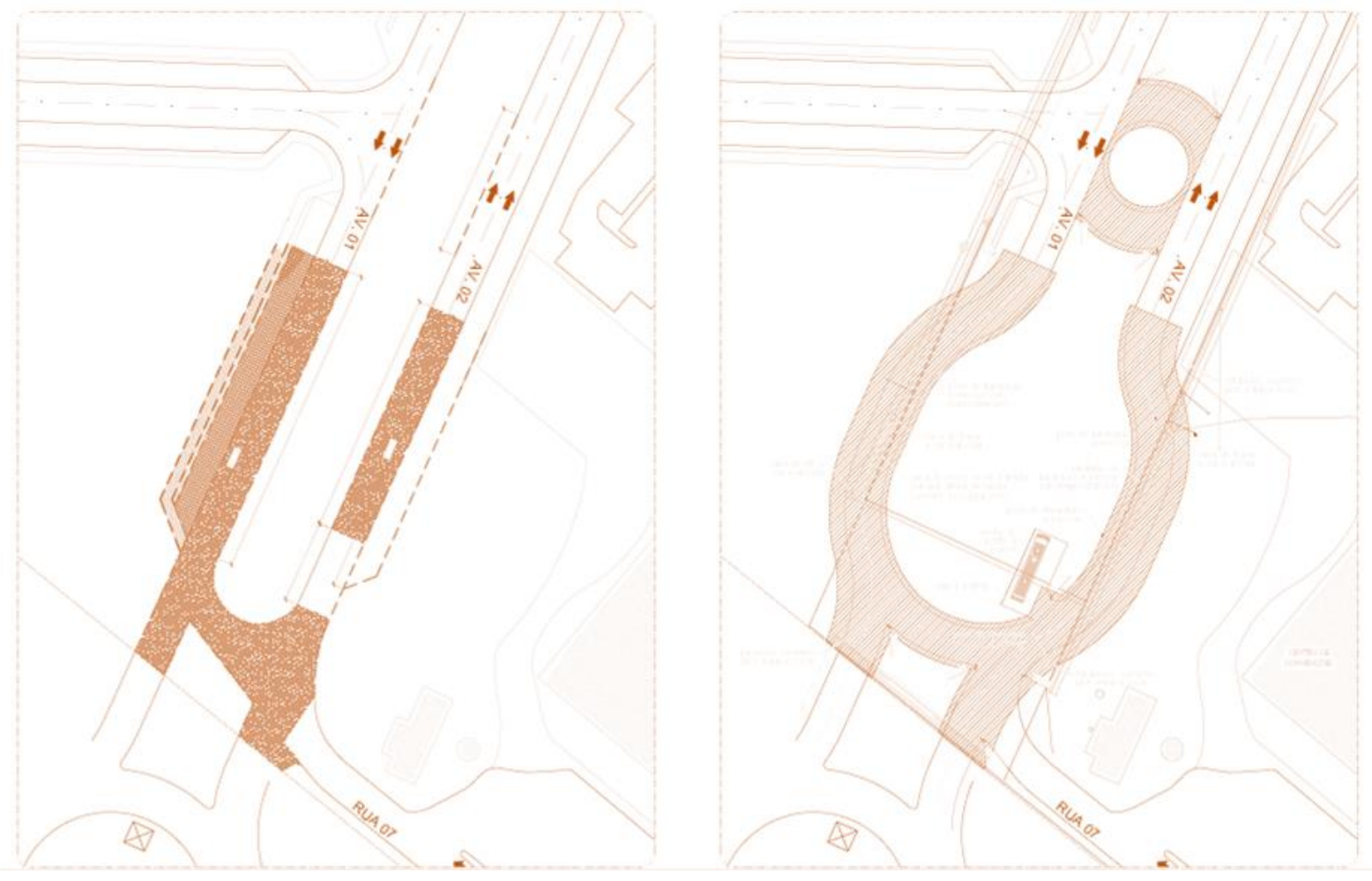

Fonte: SEF (2016).

\subsection{AQUISIÇÃO DE IMAGENS}

A RPA utilizada foi o Mavic Pro da DJI (Figura 33). Trata-se de um multirrotor quadricoptero de $743 \mathrm{~g}$ - Classe 3 - e diâmetro aproximado de $30 \mathrm{~cm}$. A autonomia nominal de voo é de cerca de 25 minutos em condições de pouco vento (DJI, 2019) e a distância máxima de viagem aproximada de 13 km, pode ser pilotada manualmente ou de forma automática. A aeronave é equipada com sensores de proximidade contra obstáculos e uma câmera digital RGB integrada com resolução de 12,35 megapixe/s e estabilizador mecânico de três eixos. 0 controle remoto permite acoplar um smartphone para servir de dispositivo de controle de voo. 


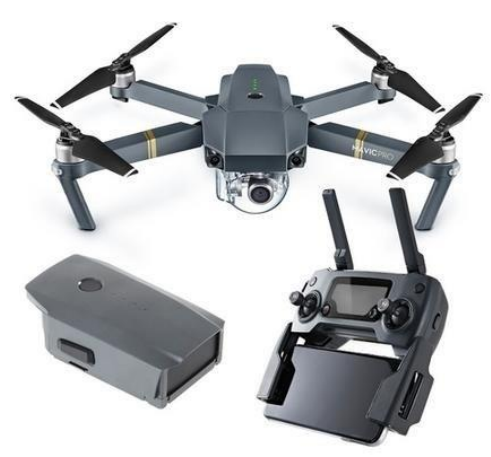

Fonte: DJI (2016)

Três softwares foram empregados na aquisição de imagens. O primeiro foi o Pix4Capture, software de planejamento e controle de voo. O Pix4Capture utiliza uma plataforma para smartphones baseada em mapa para estabelecer planos de voo customizados para as áreas de levantamento. O plano de voo é ajustado interativamente e compreende parâmetros como: trajetória de voo georreferenciada com disparos de câmeras coordenados, altitude e velocidade de voo, sobreposição de imagens (overlap) e angulação da câmera. A segunda aplicação utilizada foi o DJI GO 4, software do mesmo fabricante da aeronave e utilizado para calibragem de bússolas, da unidade inercial, atualização de softwares e ajustes de parâmetros do equipamento antes do voo. O terceiro foi o UAV Forecast, utilizado para conferir as condições climáticas para cada operação. A aeronave foi utilizada para aquisição de diferentes conjuntos de imagens dos locais de estudo. Os levantamentos e processamentos foram realizados em quatro fases, abrangendo os seguintes aspectos:

Na Fase 1 foram realizados testes de validação e aprendizagem de técnicas de levantamento com RPAS.

Na Fase 2 foram realizados levantamentos aéreos com a utilização de pontos de controle em solo (conforme descrição na seção seguinte).

Na Fase 3 foram realizados levantamentos cobrindo as obras de estudo e demais edificações e infraestrutura do campus para contextualização espacial e 
verificação de operabilidade de modelos fotogramétricos de áreas de grande escala.

$\mathrm{Na}$ Fase 4 foram selecionados e pós-processados alguns produtos fotogramétricos das Fases 2 e 3 para modelagem BIM.

\subsection{COLETA DE DADOS DE GNSS}

Pontos de GNSS (Global Navigation Satellite System) foram coletados nos locais de estudo como pontos de controle em solo (GCP) para georreferenciar as imagens e os modelos fotogramétricos produzidos. Foram utilizados pontos naturais e alvos posicionados em solo ao longo das áreas de interesse, e as coordenadas do centro de cada um foram determinadas utilizando um GPS geodésico. Na etapa de processamento, esses pontos são identificados nas imagens e suas respectivas coordenadas geográficas são inseridas como referências precisas para melhorar a acurácia dos produtos processados.

Os alvos foram produzidos para esta pesquisa com chapas quadradas de madeira, pintadas em preto e branco e de dimensões de 500 × 500 mm (Figura 34). DroneDeploy (2018) e Pix4D (2018) recomendam no mínimo cinco GCP distribuídos ao longo da área de interesse. Além dos alvos, foram levantadas coordenadas geográficas de outros pontos naturais de referência também visíveis nas imagens capturadas, como quinas de sarjetas, cantos de calçadas etc. No total, 5 pontos de controle foram coletados em torno da Biblioteca e Rua 11 e 7 pontos foram coletados no Acesso Sul. 
Figura 34 - Coleta de pontos de controle: (i) GCP naturais e (ii) GCP artificial com alvo padronizado
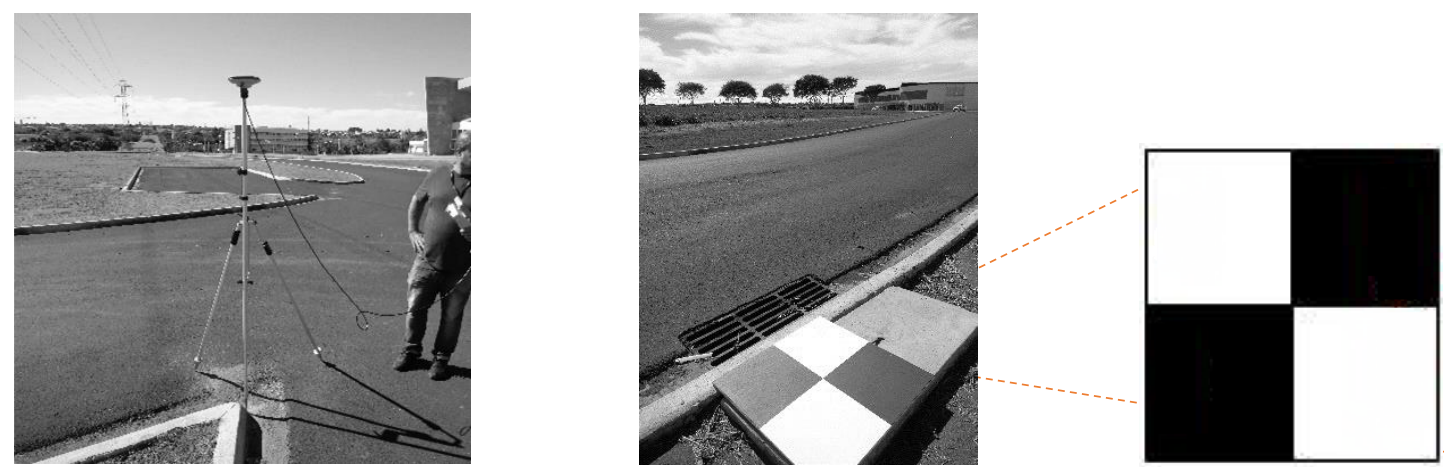

Fonte: Autor (2019).

O sistema de GNSS Leica GX-1230 foi utilizado na captura de pontos da área de estudo. Os pontos foram coletados com uma estação móvel de GPS geodésico, composta por receptor, tripé regulável com nível bolha e antena externa fixada no topo. As medições foram realizadas ponto a ponto por meio da combinação de satélites GPS e GLONASS com tempo de triangulação de 5 minutos e pósprocessadas em laboratório com precisão próxima a $1 \mathrm{~cm}$. Após a coleta os pontos foram exportados no formato do sistema de referência geodésico SIRGAS2000 em coordenadas UTM 23 Sul. O SIRGAS é o sistema definido como Datum Geodésico padrão para o Brasil pelo Instituto Brasileiro de Geografia e Estatística (IBGE) e abrange a América do Sul (IBGE - INSTITUTO BRASILEIRO DE GEOGRAFIA E ESTATÍSTICA, 2019).

\subsection{PROCESSSAMENTO DE IMAGENS E GERAÇÃO DE PRODUTOS FOTOGRAMÉTRICOS}

Pix4D e Agisoft PhotoScan v1.4.2 são os softwares de fotogrametria que foram utilizados para gerar nuvens de pontos, ortomoisacos e DSM. O processamento no Pix4D é em nuvem, podendo processar até 2500 imagens simultaneamente. 0 processamento no PhotoScan é em computador local e pode processar até 1000 imagens simultaneamente. 
O PhotoScan é amplamente utilizado para engenharia fotogramétrica, sensoriamento remoto, animações computacionais e na aviação (BARBASIEWICZ; WIDERSKI e DALIGA, 2018). Inicialmente o software detecta pontos homólogos entre as imagens e juntamente com os dados de GPS coletados, reconstrói digitalmente a orientação e a posição da câmera no momento da captura. Em seguida, há uma reconstrução preliminar da geometria das superfícies capturadas, gerando uma nuvem esparsa de pontos no espaço. A nuvem de pontos é então densificada, de modo que a quantidade de pontos e a resolução da reconstrução digital são aumentadas significativamente. A nuvem densa de pontos resultante é interpolada formando uma rede irregular triangular (Triangular Irregular Network - TIN), da qual serão gerados modelos digitais de superfície ou terreno. Conjuntos de pixe/s das imagens originais são recordados, mesclados e projetados sobre esses modelos para gerar modelos geométricos texturizados e ortomosaicos georreferenciados (GROETELAARS, 2015, p. 73).

Os pontos de GPS coletados são também inseridos no PhotoScan, no formato CSV ${ }^{5}$. Esses arquivos são importados juntamente com as imagens durante o processamento e utilizam o sistema geográfico SIRGAS 2000. Para isso, as coordenadas geográficas constantes nos metadados de cada imagem foram convertidas do sistema WGS84 para o SIRGAS 2000. Os GCP são detectados automaticamente pelo software ou inseridos manualmente por marcadores geográficos, os quais são conferidos imagem por imagem e, em seguida, correlacionados com as respectivas coordenadas geográficas aferidas pelo GPS geodésico.

Os procedimentos metodológicos mencionados são resumidos na Figura 35.

\footnotetext{
${ }^{5}$ CSV (Comma-separated values) é um formato de arquivo de texto cujos valores são ordenados e separados por vírgulas.
} 
.Figura 35 - Fluxo de trabalho de processamento fotogramétrico no Agisoft Photoscan

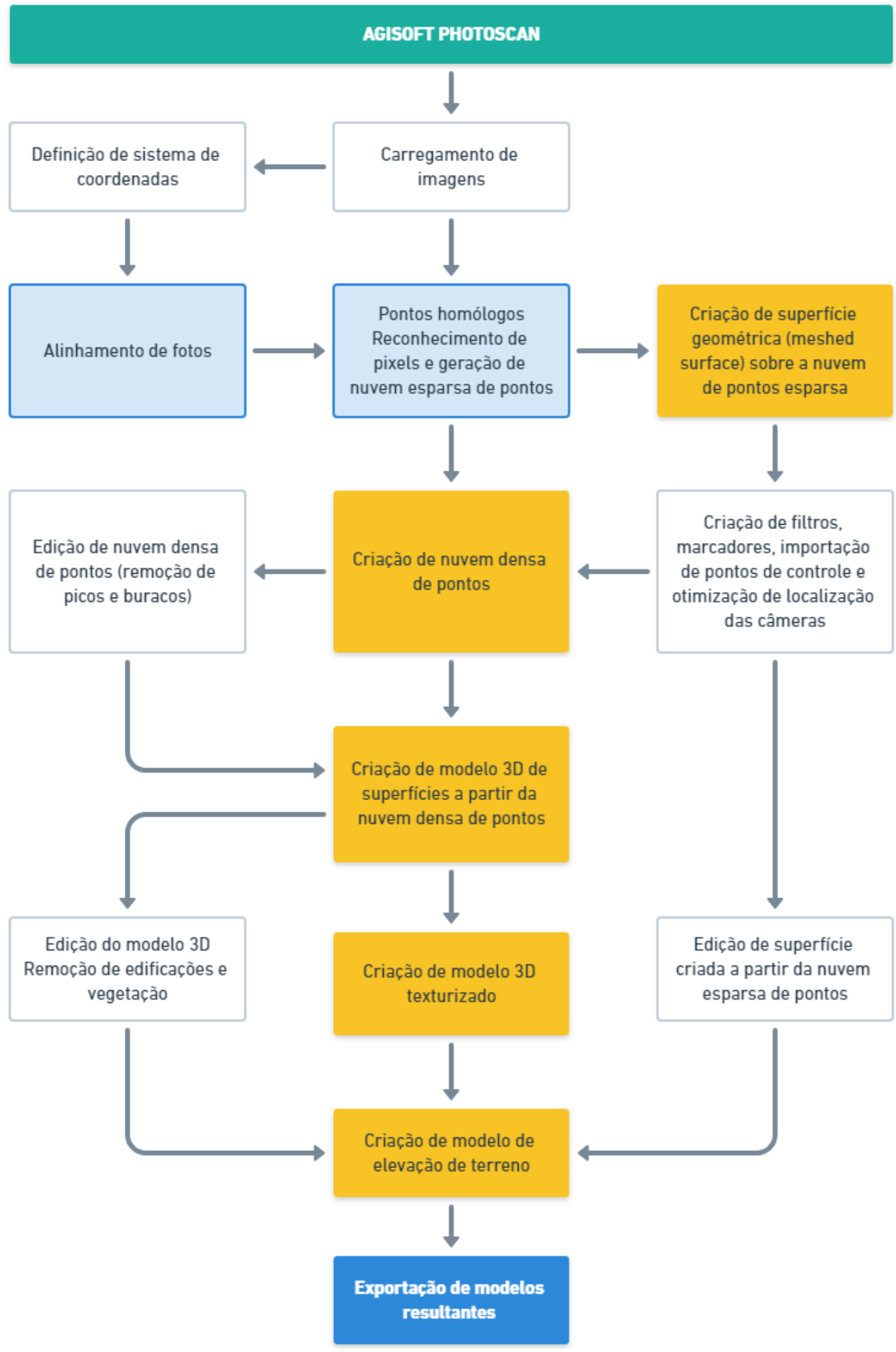

Fonte: Adaptado de Ajayi, Palmer e Salubi (2018).

A avaliação dos resultados é baseada na qualidade dos produtos obtidos em função dos erros calculados durante o processamento e documentados nos 
relatórios extraídos do Pix4D e Agisoft PhotoScan. As métricas resultantes são apresentadas na seção de Resultados e Discussões, e deram base para responder as questões da pesquisa quanto a consistência e acurácia do método para gerar resultados confiáveis e precisos para modelagem de infraestrutura.

\subsection{MODELAGEM BIM}

O modelo BIM foi estruturado no software Autodesk InfraWorks 2019 incorporando arquivos de formatos de CAD, BIM, imagens de satélite e nuvem de pontos. A elaboração do modelo BIM tem como objetivo a integração de dados de projetos referentes às obras estudadas, de forma a conectar informações de diferentes fontes a um modelo central (base de dados), compreendendo a organização disposta na Figura 36.

Figura 36 - Estrutura da base de dados

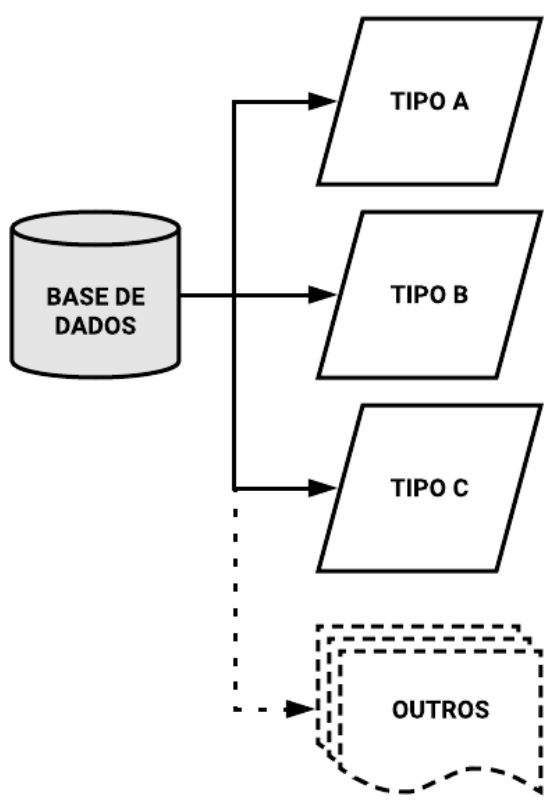

Fonte: Autor (2019). 
TIPO A: Imagens de satélite e mapas do Autodesk InfraWorks

TIPO B: Nuvens de pontos geradas por este trabalho

TIPO C: Documentos de projetos original no formato *.CAD e modelos BIM desenvolvidos no Autodesk Revit

OUTROS: Compreende dados de desenvolvimentos futuros - não tratados nessa pesquisa - que poderão ser incorporados.

A modelagem das obras de estudo foi realizada diretamente no InfraWorks a partir das nuvens de pontos levantadas e de arquivos de projeto, utilizando componentes específicos para vias urbanas brasileiras, disponibilizados através do Country Kit Brasil Autodesk. Tais componentes são baseados nas normas Departamento Nacional de Estradas de Rodagem (DNER, 1999).

As etapas de modelagem seguiram a ordem:

1. Importação de nuvens de pontos dos levantamentos aéreos, via Autodesk Recap;

2. Importação e posicionamento de arquivos CAD de implantação das obras e de edificações do campus;

3. Modelagem do terreno com base nas nuvens importadas

a. 1a fase: automática com ferramentas próprias do InfraWorks

b. 2a fase: manual com emprego de ferramentas de terraplenagem em áreas não cobertas pelas nuvens de pontos

4. Modelagem de volumetrias de edificações a partir das nuvens de pontos e imagens de satélite para identificação das edificações do Campus;

5. Modelagem de vias utilizando componentes brasileiros baseados nas normas do Departamento Nacional de Estradas de Rodagem (DNER, 1999);

6. Modelagem contextual: árvores, elementos das proximidades, pontos de interesse como GCP, torres de energia, caixas d'água, pontes do eixo principal do campus,

7. Importação e posicionamento de modelo BIM da Biblioteca. 


\subsection{MÉTODO DE ANÁLISE DE RESULTADOS}

$\mathrm{Na}$ aquisição de imagens os resultados são analisados manualmente verificando se problemas de foco e se a exposição foi balanceada. Também se verifica se a imagem sofreu alguma anomalia decorrente do efeito rolling shutter ${ }^{6}$ e se a inclinação da câmera fotográfica foi como estabelecida no plano de voo. Assim, são selecionadas apenas imagens com foco adequado, exposição balanceada e perspectiva coerente com a prevista no plano de voo.

Na coleta de dados de GNSS os resultados são analisados por meio da determinação da qualidade das coordenadas de posição dos pontos de controle em solo (GCP). A qualidade da coordenada é expressa pela raiz quadrada da soma dos quadrados dos desvios em Leste, Norte e Altitude.

Os produtos fotogramétricos decorrentes do processamento de imagens são analisados através do relatório de processamento gerado automaticamente pelos softwares utilizados. Nesses relatórios são quantificados e qualificados os modelos fotogramétricos gerados e os erros métricos correspondentes. São também apresentadas as resoluções dos ortomosaicos (GSD) e a densidade das nuvens de pontos obtidas. Além disso, os produtos são analisados visualmente para identificação de áreas com distorções inadequadas que demandem novos levantamentos e/ou ajustes em parâmetros de processamento.

Por fim, os resultados da modelagem BIM são analisados em termos dos níveis de desenvolvimento e detalhe obtidos. São também analisadas as ferramentas utilizadas em termos de operabilidade e recursos de modelagem e edição disponíveis. A integração de diferentes dados também é abordada verificando a estabilidade e comportamento das ferramentas utilizadas frente a grandes volumes de dados. Por último, analisa-se a disposição de formatos de transferência de dados e como o modelo BIM poderá ser alimentado, editado ou atualizado, e quais as limitações percebidas nesse processo.

\footnotetext{
${ }^{6}$ Ver seção 2.3.1.2 Qualidade de imagens, página 72.
} 


\subsection{ESQUEMA GERAL DO MÉTODO}

O Diagrama 4 sintetiza o método empregado nesta pesquisa.

Diagrama 4 - Esquema geral do método

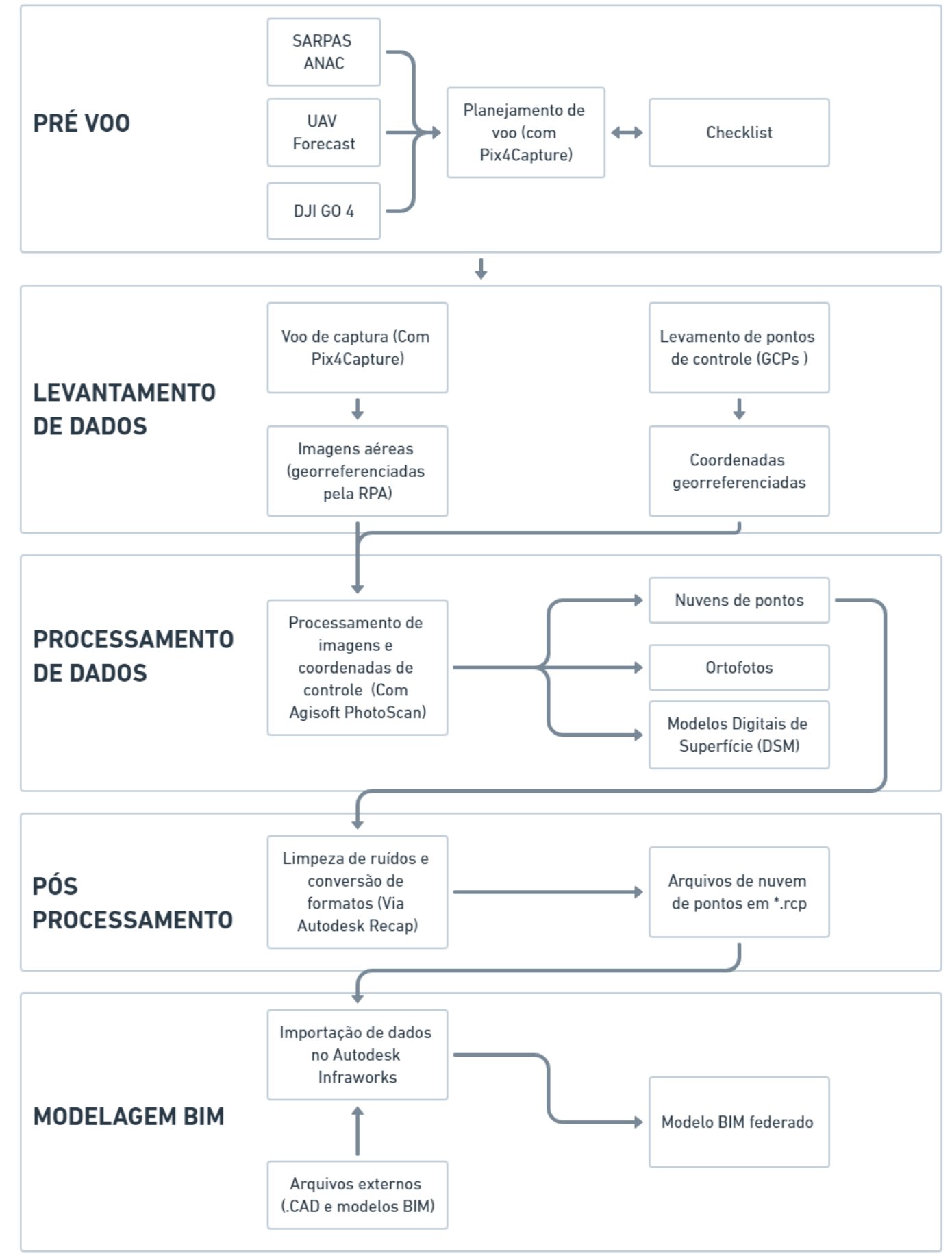

Fonte: Autor (2019). 


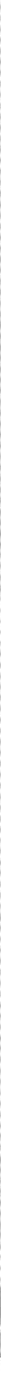

\section{RESUlTADOS \& • DISCUSSÕES}

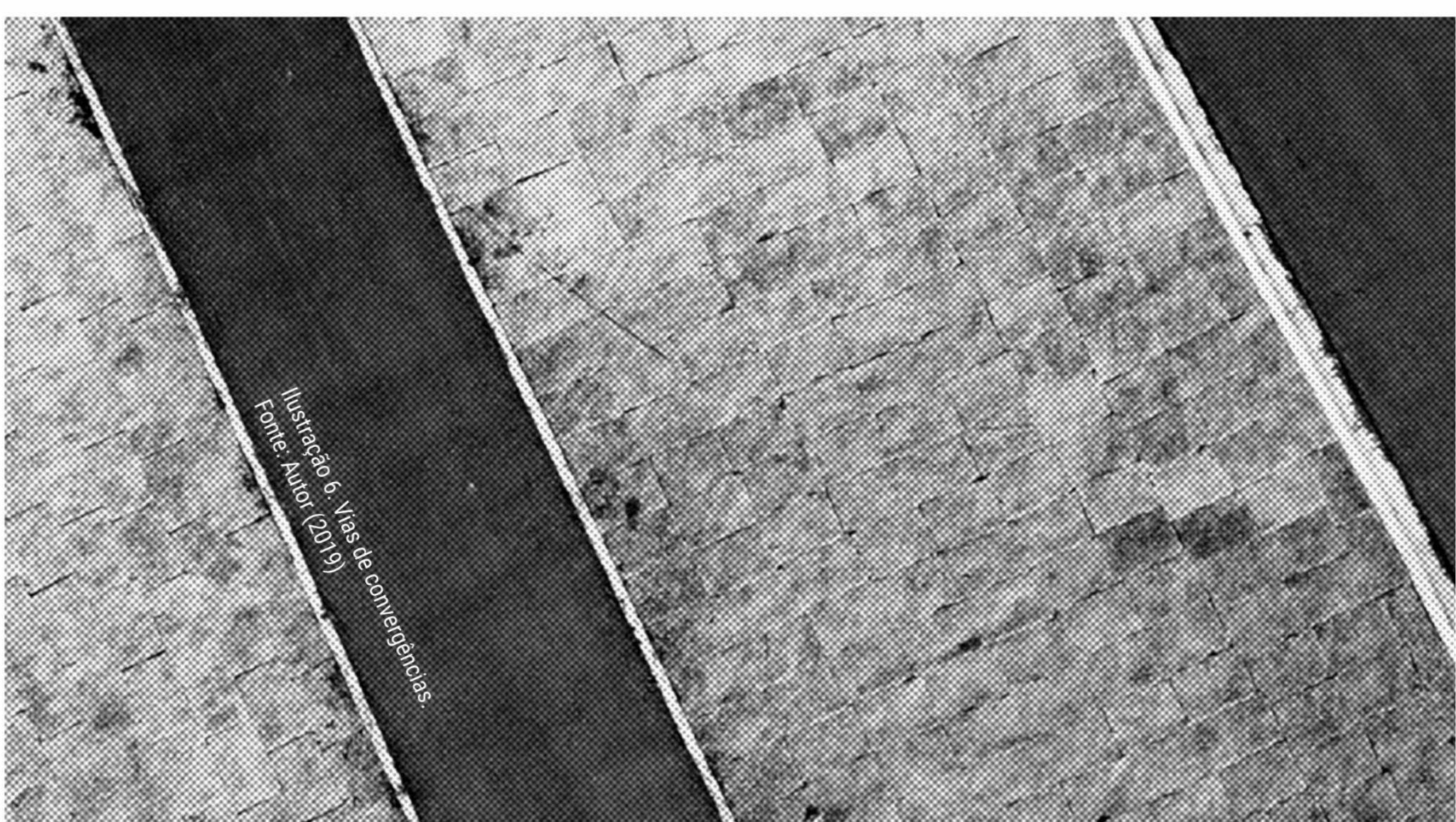


Nesse capítulo são apresentados os resultados da geração de produtos fotogramétricos e o desenvolvimento de modelo BIM integrado. Os produtos são divididos em quatro seções, correspondentes a (i) Fase 1 - Testes de validação de ferramentas de levantamento e processamento, (ii) Fase 2 - Levantamentos georreferenciados com GCP, (iii) Fase 3 - Levantamento do Campus e (iv) Fase 4 - Modelo BIM.

A seção da Fase 1 foi dividida em produtos da Rua 11 e do Acesso Sul, métricas e análise de ferramentas utilizadas. A seção da Fase 2 está dividida em pontos de controle coletados e produtos de levantamentos da Rua 11 e do Acesso Sul. A seção Fase 3 apresenta levantamentos no restante da área construída do campus, dividindo-o em setores. E, por fim, a seção Fase 4 apresenta o modelo unificado desenvolvido para documentação.

\subsection{FASE 1- TESTES DE VALIDAÇÃO}

A Fase 1 compreendeu estudos e testes para validação de técnicas de levantamentos com RPA e a estruturação de procedimentos de aquisição e processamento de imagens. Como resultados são apresentados registros de levantamentos parciais durante as últimas fases de obras da Rua 11 e do Acesso Sul. São também apresentadas análises das ferramentas utilizadas focando na estruturação de processos de levantamento aéreo e processamento de imagens. As questões envolvidas nessa etapa tratam de (i) quais as características dos modelos fotogramétricos gerados utilizando os dados de GNSS da aeronave para orientação? e; (ii) quais as etapas e softwares adotados do levantamento ao processamento?

\subsubsection{RUA 11 / ACESSO À BIBLIOTECA}

Nas figuras a seguir são apresentados os resultados obtidos de voo automático a $50 \mathrm{~m}$ de altura para levantamento aéreo da obra e geração de modelos fotogramétricos pelo software Pix4D e Agisoft PhotoScan. 537 imagens foram 
obtidas em 28 de março de 2018 utilizando o software Pix4capture, com plano de voo de malha dupla e 90\% de sobreposição entre imagens (Figura 37). Os modelos produzidos atingiram GSD de 0,82 cm/px, área de cobertura aproximada de 1,3 ha, nuvem de pontos densa com 30 milhões pelo Pix4D Cloud, e 55 milhões de pontos pelo Agisoft PhotoScan (Figura 38).

Figura 37 - Registro da trajetória de voo e imagens capturadas

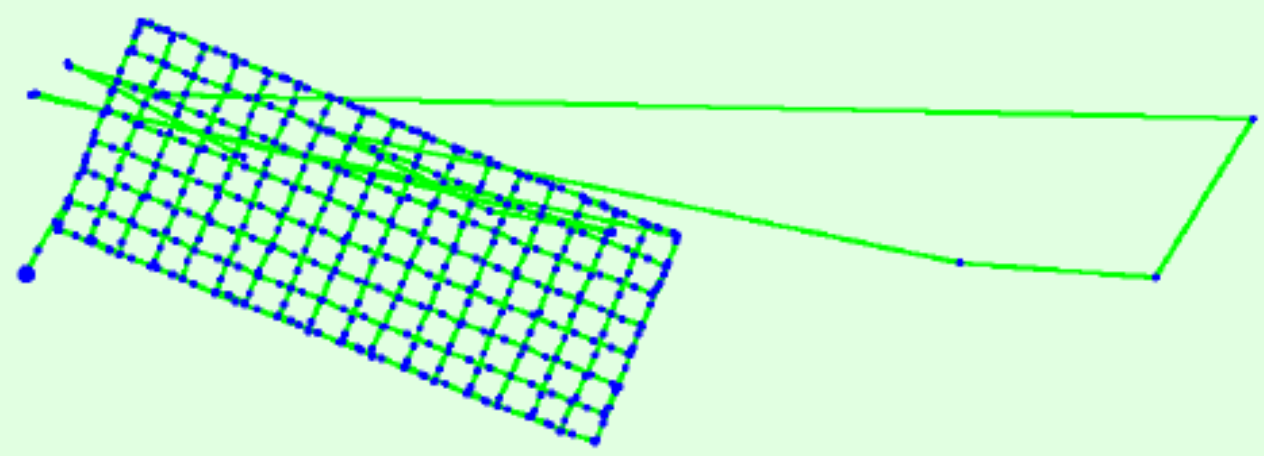

Fonte: Autor (2019) 
Figura 38 - Ortomosaico gerado pelo PIX4D, mapa de elevação e exemplares das imagens levantadas

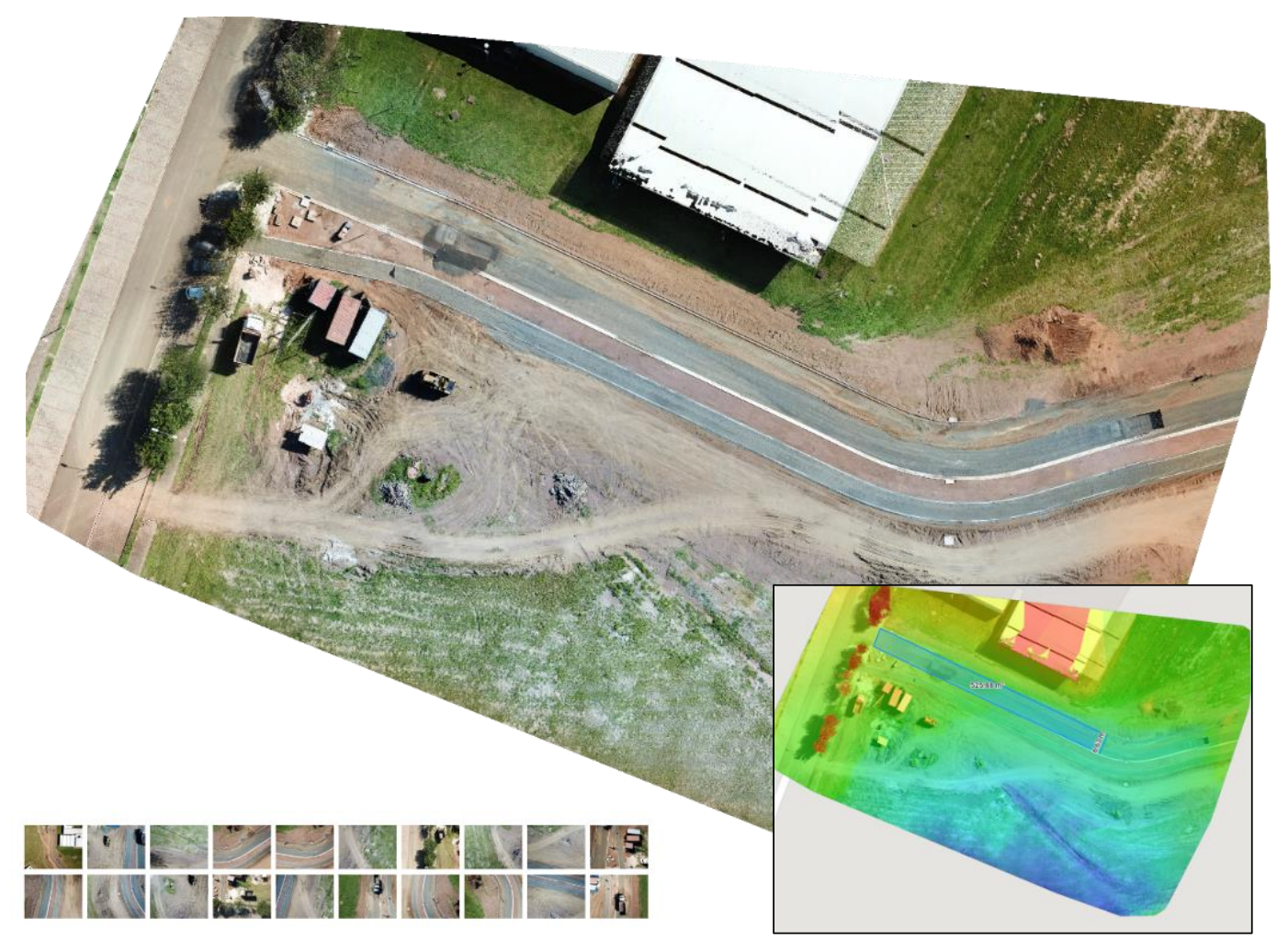

Fonte: Autor (2019).

A Tabela 5 sumariza as informações métricas extraídas dos produtos gerados nas obras da Rua 11 a partir do processamento realizado. 


\begin{tabular}{lr}
\hline Geral & Pix4D \\
\hline Imagens & 537 \\
\hline Altura de voo & $25 \mathrm{~m}$ \\
\hline Pontos de controle & $0,013 \mathrm{~km}^{2}$ \\
\hline Área coberta & \\
\hline Sistema de Coordenadas & \\
\hline Nuvem de pontos & 3025182 \\
\hline Pontos de ligação & \\
\hline Pontos da nuvem densa & $0,82 \mathrm{~cm} / \mathrm{pix}$ \\
\hline DEM - Modelo Digital de Elevação & zone $23 \mathrm{~S}$ \\
\hline GSD & $10659.4 \mathrm{pts} / \mathrm{m}^{3}$ \\
\hline Densidade de Pontos & \\
\hline Ortomosaico & $0,82 \mathrm{~cm} /$ pix
\end{tabular}

Fonte: Autor (2019).

Tabela 6 - RMSE: Variância absoluta de Geolocalização de nuvem de pontos

\begin{tabular}{lllll}
\hline $\operatorname{Erro} X(\mathrm{~m})$ & Erro Y $(\mathrm{m})$ & $\operatorname{Erro~Z}(\mathrm{m})$ & $\operatorname{Erro~XY}(\mathrm{m})$ & Total $(\mathrm{m})$ \\
\hline 0,521 & 0,284 & 1,129 & 0,594 & 1,276
\end{tabular}

Fonte: Autor (2019).

Tabela 7 - Média de acurácia da geolocalização

$\begin{array}{ccc}X(m) & Y(m) & \text { Erro } Z(m) \\ 5,0 & 5,0 & 10,0\end{array}$

Fonte: Autor (2019).

Conforme Tabela 5, os produtos obtiveram definição subcentimétrica (GSD=0,82 cm/pix). Pela Tabela 6, o eixo z obteve a maior variância absoluta de geolocalização da nuvem de pontos com 1,129 m. A raiz quadrada do erro médio 
(variância considerando os eixos x, y e z que descreve a proximidade entre valores obtidos) foi de $1,276 \mathrm{~m}$

Pela Tabela 7 a média da acurácia em x e y foi de 5 m e de 10 m no eixo z, esse valor descreve a proximidade da medida do valor verdadeiro de geolocalização.

\subsubsection{ACESSO SUL}

Na Figura 39 são apresentados os resultados obtidos de voo automático a 25 m de altura para levantamento aéreo, processamento de modelos fotogramétricos e teste de integração com modelos BIM. 412 imagens foram obtidas em 22 de março de 2018 utilizando o software Pix4capture com plano de voo de malha dupla e 90\% de sobreposição entre imagens (Figura 39). Os modelos produzidos atingiram GSD de 0,82 cm/px (Figura 40), área de cobertura aproximada de 1,3 ha, nuvem de pontos densa com 30 milhões de pontos pelo Pix4DCloud. A nuvem de pontos foi exportada e pós processamento no Autodesk Recap, onde ruídos de processamento foram removidos e o arquivo *.rcp preparado. Por fim, a nuvem de pontos *.rcp foi importada no Autodesk InfraWorks para teste de operabilidade.

Figura 39 - (a) Vista superior do posicionamento inicial de imagens. (b) Vista superior do modelo digital de superfície. (c) Sobreposição de imagens
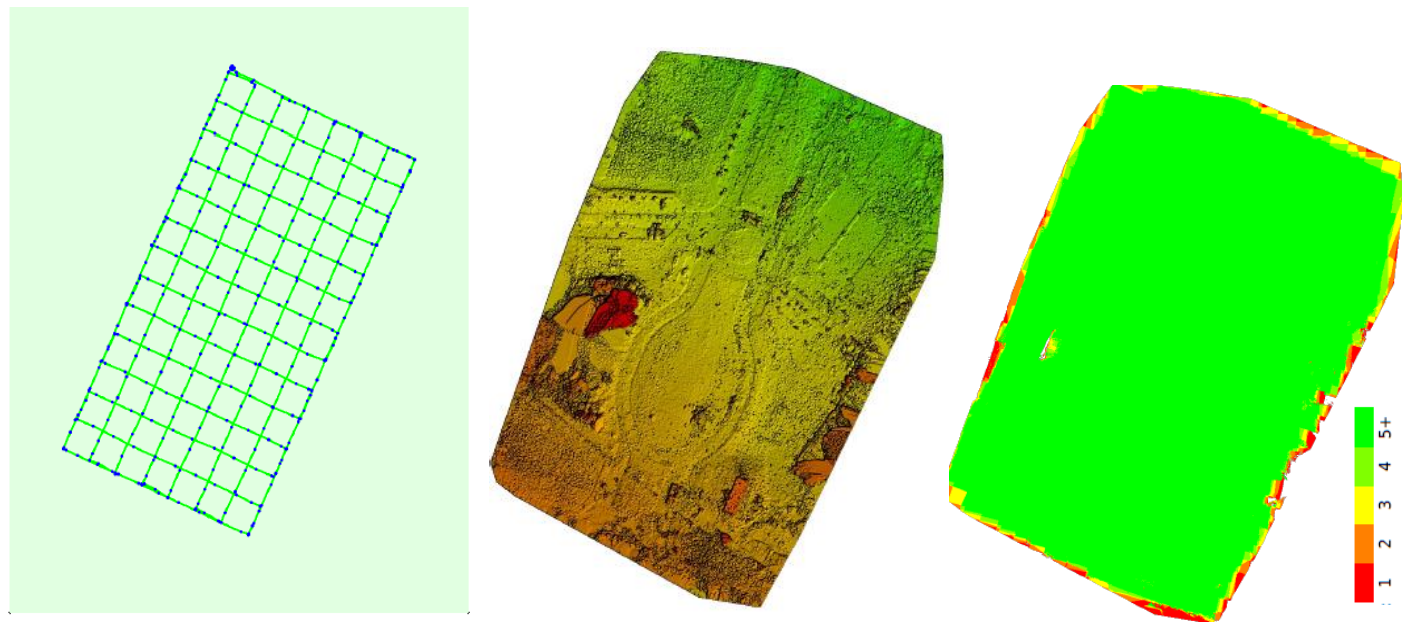

Fonte: Autor (2019).

Na Figura 39a as linhas verdes representam a trajetória realizada pela aeronave e os pontos azuis os pontos de captura. Na Figura 39b o modelo digital de terreno 
antes da densificação é apresentado em cores representativas das elevações de cada ponto (hipsometria). E na Figura 39c é apresentado o grau de sobreposição de imagens para cada região do ortomosaico, cujas áreas vermelhas e amarelas indicam cobertura por até três imagens (para as quais os resultados podem apresentar distorções), e as áreas verdes indicam cobertura por 5 ou mais imagens (melhor condição de processamento). Na Figura 40 é apresentado o ortomosaico do Acesso sul gerado nessa fase. 
Figura 40 - Ortomosaico do Acesso Sul gerado pelo Pix4D

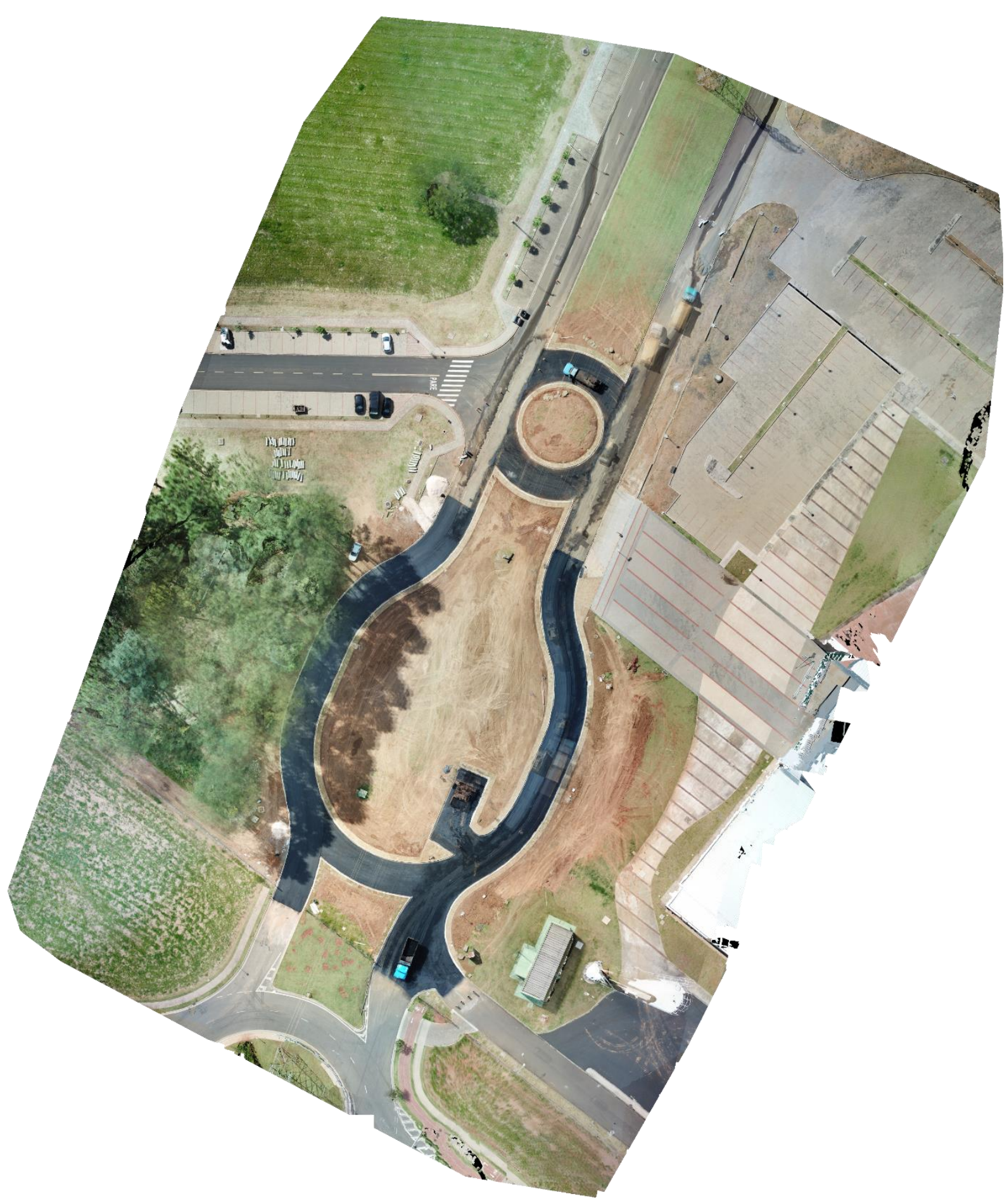

Fonte: Autor (2019). 
A Tabela 8 e a Tabela 9 sumarizam as informações métricas extraídas dos produtos gerados nas obras do Acesso Sul a partir do processamento realizado.

Tabela 8 - Dados de processamento Acesso Sul - Pix4D

\begin{tabular}{lr}
\hline Geral & Pix4D \\
\hline Imagens & 412 \\
\hline Altura de voo & 50 \\
\hline Pontos de controle & $0,032 \mathrm{~km}^{2}$ \\
\hline Área coberta & WGS 84/UTM zone 23S \\
\hline Sistema de Coordenadas & 35936 \\
\hline Nuvem de pontos & 22699914 \\
\hline Pontos de ligação por imagem & $1,52 \mathrm{~cm} / \mathrm{pix}$ \\
\hline Pontos da nuvem densa & 1721,58 pts/m³ \\
\hline DEM - Modelo Digital de Elevação & \\
\hline GSD & $1,52 \mathrm{~cm} / \mathrm{pix}$ \\
\hline Densidade de Pontos & \\
\hline Ortomosaico & \\
\hline GSD & \\
\hline
\end{tabular}

Fonte: Autor (2019).

Tabela 9 - RMSE Acesso Sul - variância absoluta de geolocalização de nuvem de pontos

\begin{tabular}{ccccc}
\hline Erro X $(m)$ & Erro Y $(m)$ & Erro Z $(m)$ & Erro XY $(m)$ & Total $(m)$ \\
\hline 0,403 & 0,361 & 1,949 & 0,541 & 2,022
\end{tabular}

Fonte: Autor (2019).

Tabela 10 - Média de acurácia da geolocalização

\begin{tabular}{ccc}
\hline$X(m)$ & $Y(m)$ & Erro Z $(m)$ \\
\hline 5,0 & 5.0 & 10,0 \\
\hline
\end{tabular}

Fonte: Autor (2019). 
Conforme Tabela 8, os produtos obtiveram definição abaixo de $2 \mathrm{~cm}(\mathrm{GSD}=1,52$ $\mathrm{cm} /$ pix), o que significa que objetos menores que isso serão não identificáveis. Pela Tabela 9, o eixo z obteve a maior variância absoluta de geolocalização da nuvem de pontos com 1,949 m. A raiz quadrada do erro médio (variância considerando os eixos $x$, y e $z$ que descreve a proximidade entre valores obtidos) foi de 2,022 m. Pela Tabela 10, a média da acurácia em x e y foi de $5 \mathrm{~m}$ e de $10 \mathrm{~m}$ no eixo $z$, esse valor descreve a proximidade da medida do valor verdadeiro de geolocalização.

$\mathrm{Na}$ Figura 41 são apresentadas as nuvens de ponto pós-processadas no Autodesk Recap, onde foram removidos ruídos de processamento e as áreas laterais às vias de interesse. Além disso, o arquivo original foi convertido do formato *.pts para o formato *.rcp, visando a integração com o modelo BIM.

Figura 41 - Pós-processamento de nuvem de pontos no Autodesk Recap

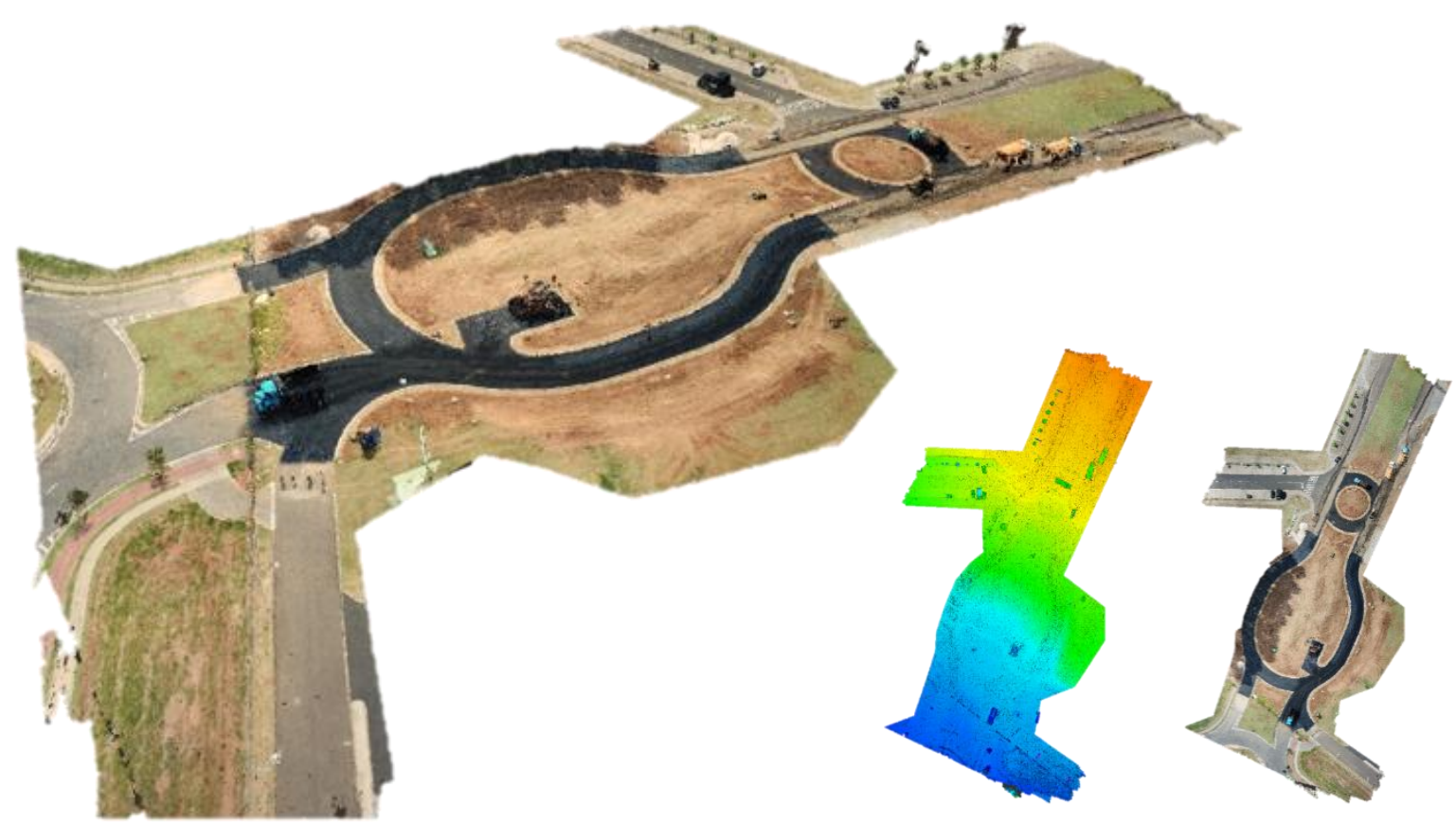

Fonte: Autor (2019). 


\subsubsection{ANÁLISE DE RESULTADOS | FASE 1}

Os estudos de fotogrametria digital foram fundamentais para melhor compreensão dos processos de levantamento e processamento, envolveram desde o aprendizado de procedimentos aerofotogramétricos para agilizar a organização de dados e facilitar o processamento, a detalhes técnicos dos softwares para controle de qualidade dos produtos gerados.

Os resultados demonstraram resolução espacial satisfatória para a geração de modelos fotogramétricos, embora o tempo de processamento tenha sido significativo utilizando processamento local (no caso do Agisoft PhotoScan). No entanto, mesmo sendo capaz de gerar modelos geométricos com alta resolução de pontos, o georreferenciamento sem auxílio de pontos de controle e/ou sistemas RTK/PPK se mostrou insatisfatório para garantir a confiabilidade métrica dos produtos gerados. Houve imprecisões significativas de orientação, com rotações e translações notáveis nos modelos gerados, de modo que a utilização estrita de coordenadas geográficas do receptor GNSS da aeronave para georreferenciamento não foi suficiente para garantir precisão de modelos fotogramétricos. Consequente, é necessário utilizar meios complementares de georreferenciamento para possibilitar a elaboração de modelos BIM precisos, uma vez que o sistema de coordenadas é comum às tecnologias em questão.

Sobre a qualidade dos produtos gerados, conclui-se que embora os ortomosaicos e modelos fotogramétricos possam ter proporções visualmente aceitáveis, não necessariamente são exatos em escala e em orientação geoespacial. Esse fato exige o emprego de ferramentas adicionais para garantir não somente sua precisão, mas sua exatidão. Na falta de ferramentas precisas de orientação como as apontadas, os modelos geométricos gerados devem ser utilizados apenas para fins de reconhecimento aéreo, registro fotográfico sem escala ou como forma de verificar a qualidade de imagens (foco, nitidez, etc.) e validar dados de levantamento.

Quanto aos softwares empregados, a combinação de tecnologias se mostrou uma estratégia plausível para aproveitar o melhor de cada software e otimizar 
globalmente os processos de levantamento e documentação. Assim, a partir das experiências nessa fase, a combinação de tecnologias adotada nos levantamentos é composta pelos seguintes softwares:

- Pix4DCapture para o planejamento de voos automáticos

- Pix4D-BIM para processamento de imagens em nuvem

- Autodesk Recap para pós tratamento da nuvem de pontos (segmentação, e remoção de ruídos) e conversão de formato para integração com Autodesk InfraWorks

- Agisoft Photoscan para processamento local de imagens

- Autodesk Revit para modelagem de edificações

- Autodesk InfraWorks para registro de nuvens de pontos e integração com outros modelos BIM.

No Diagrama 5, os softwares listados acima são representados de acordo com seu uso em cada etapa, do levantamento a modelagem. A partir deste resultado o método de pesquisa foi ajustado como indica a descrição no Capítulo 3, seção 3.6 Esquema geral do método, página 134.

Diagrama 5 - Softwares adotados em cada etapa do trabalho (após validação da Fase 1)

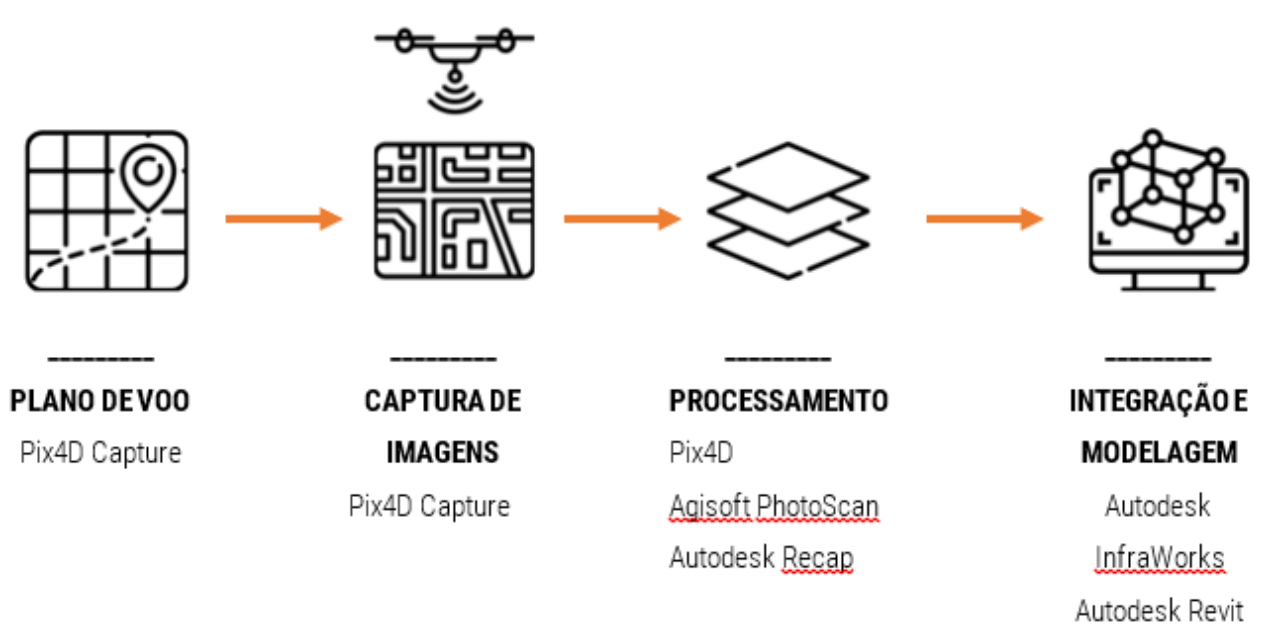

Fonte: Autor (2019). 


\subsection{FASE 2 - LEVANTAMENTOS GEORREFERENCIADOS COM GCPS}

A Fase 2 compreendeu levantamentos nas áreas de estudo utilizando pontos de controle em solo (GPC) para georreferenciar os modelos fotogramétricos durante o processamento. Esse método é apontado na análise de resultados da Fase 1 como indispensável para a orientação, escala e controle de qualidade de produtos. Assim, nas subseções seguintes são apresentadas as coordenadas dos pontos de controle coletados por GNSS, os produtos gerados e as métricas correspondentes.

\subsubsection{PONTOS DE CONTROLE COLETADOS POR GNSS}

A Tabela 11 apresenta as coordenadas geográficas dos Pontos de Controle (GCP) coletadas conforme descrito na seção 3.3 Coleta de dados de GNSS - pág. 128. Os GCP foram utilizados no georreferenciamento de imagens da Rua 11 (GCP 01 05) e do Acesso Sul (GCP 06-12). 
Tabela 11 - Coordenadas geográficas dos pontos de controle (GCP)| SIRGAS2000 UTM23S

\begin{tabular}{|c|c|c|c|c|c|c|c|c|}
\hline GCP & Leste (m) & Norte (m) & $\begin{array}{l}\text { Altitude } \\
\text { (m) }\end{array}$ & $\begin{array}{l}\text { Altitude } \\
\text { (m) }\end{array}$ & $\begin{array}{c}\text { Desvio } \\
\text { Leste } \\
\text { (m) }\end{array}$ & $\begin{array}{c}\text { Desvio } \\
\text { Norte } \\
\text { (m) }\end{array}$ & $\begin{array}{l}\text { Desvio } \\
\text { Altitude } \\
\text { (m) }\end{array}$ & $\begin{array}{l}\text { Qualidade } \\
\text { Coord. }{ }^{7}\end{array}$ \\
\hline 01 & 197238,1649 & 7564098,2125 & 837,4876 & & 0,0017 & 0,0020 & 0,0042 & 0,0050 \\
\hline 02 & 1971 & 75640 & & & 0,00 & 0,0031 & & 0,0071 \\
\hline 03 & 19705 & 75641 & 840,5 & & 0,0043 & 0,0021 & & 0070 \\
\hline 04 & & & & & & & & \\
\hline 05 & 087 & 380 & 837,0 & & 0,0017 & 0,0020 & & 0,0091 \\
\hline 06 & 19729 & 75636 & & & 0,0026 & 0,0020 & & 0,0071 \\
\hline 07 & 197323,4237 & 7563617,6030 & 836,5428 & 842,7028 & 0,0107 & 0,0049 & 0,0100 & 0,0155 \\
\hline 08 & 197329,6866 & 7563574,5526 & & & 0,0160 & 0,0076 & & 0,0221 \\
\hline 09 & 197270,8930 & 7563533,1518 & 839,0812 & 845,2411 & 0,0119 & 0,0059 & 0,01 & 0,0169 \\
\hline 10 & 19726 & 7563 & 837, & 843,6 & 0,03 & 0,03 & & 0,1152 \\
\hline 11 & 197271,8081 & 756361 & 839,7644 & 845,9244 & 0,0020 & 0,0024 & 0,0058 & 0,0066 \\
\hline 12 & 197171,9846 & 7563642,4296 & 838,3452 & 844,5052 & 0,0095 & 0,0046 & 0,0093 & 0,0141 \\
\hline
\end{tabular}

Fonte: Autor (2019).

A Figura 42 apresenta a localização dos GCP 06-11 utilizados no Acesso Sul e a Figura 45 apresenta a localização dos GCP 01-04 utilizados na Rua 11. O GCP10 foi desconsiderado no processamento em função da qualidade da coordenada divergir dos demais em uma ordem de grandeza acima.

\subsubsection{PRODUTOS FOTOGRAMÉTRICOS}

\subsubsection{Acesso Sul - Produtos}

Da Figura 42 à Figura 44 são apresentados os resultados obtidos no processamento pelo Agisoft PhotoScan das 237 imagens coletadas no Acesso Sul com pontos de controle referidos na Tabela 11. O voo foi planejado no Pix4Capture para $50 \mathrm{~m}$ de altura, com sobreposição de 80\%. O ortomosaico

\footnotetext{
${ }^{7}$ A Qualidade da coordenada é expressa pela raiz quadrada da soma dos quadrados dos desvios em Leste, Norte e Altitude.
} 
obteve GSD 1,52 cm/px, área de cobertura de 2,4 ha. A nuvem de pontos densificada é de cerca de 4,7 milhões de pontos.

Figura 42 - Ortomosaico e localização dos GCP 06-11 no Acesso Sul

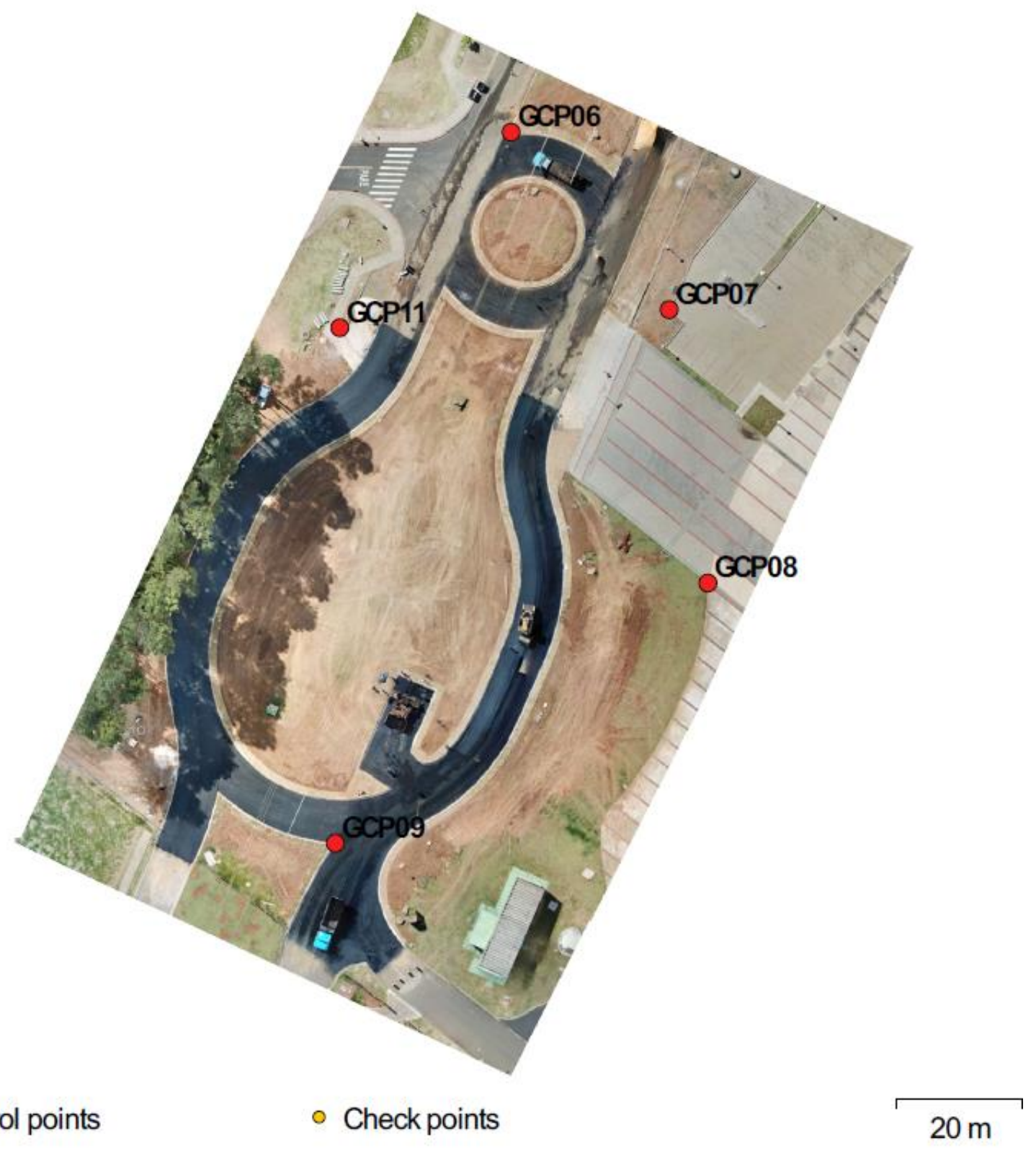

Fonte: Autor (2019) 
Figura 43 - Localização de câmeras e sobreposição de imagens no Acesso Sul
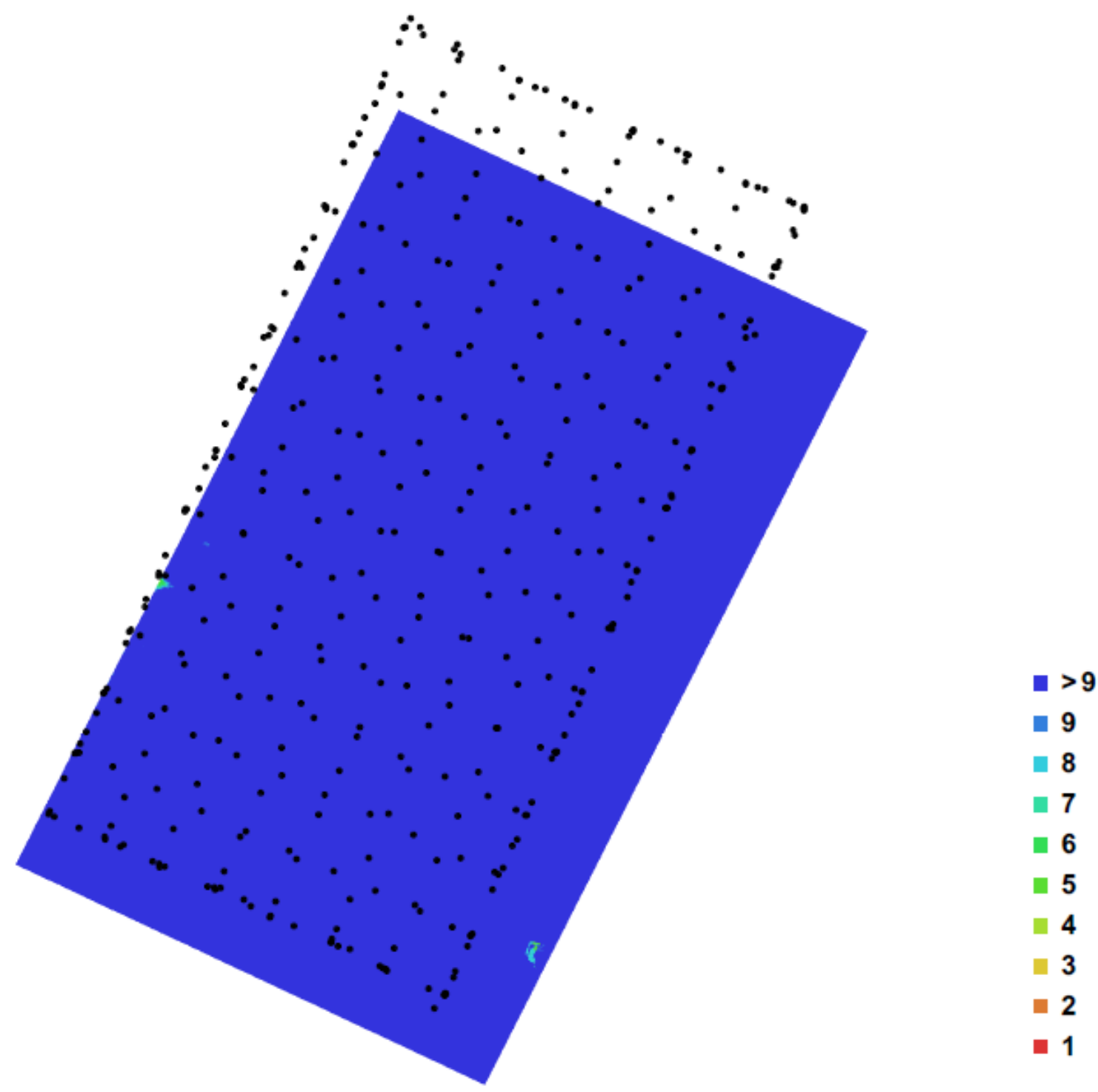

$20 \mathrm{~m}$

Fonte: Autor (2019). 
Figura 44 - Modelo Digital de Elevação (DEM) do Acesso Sul, processado no Agisoft PhotoScan

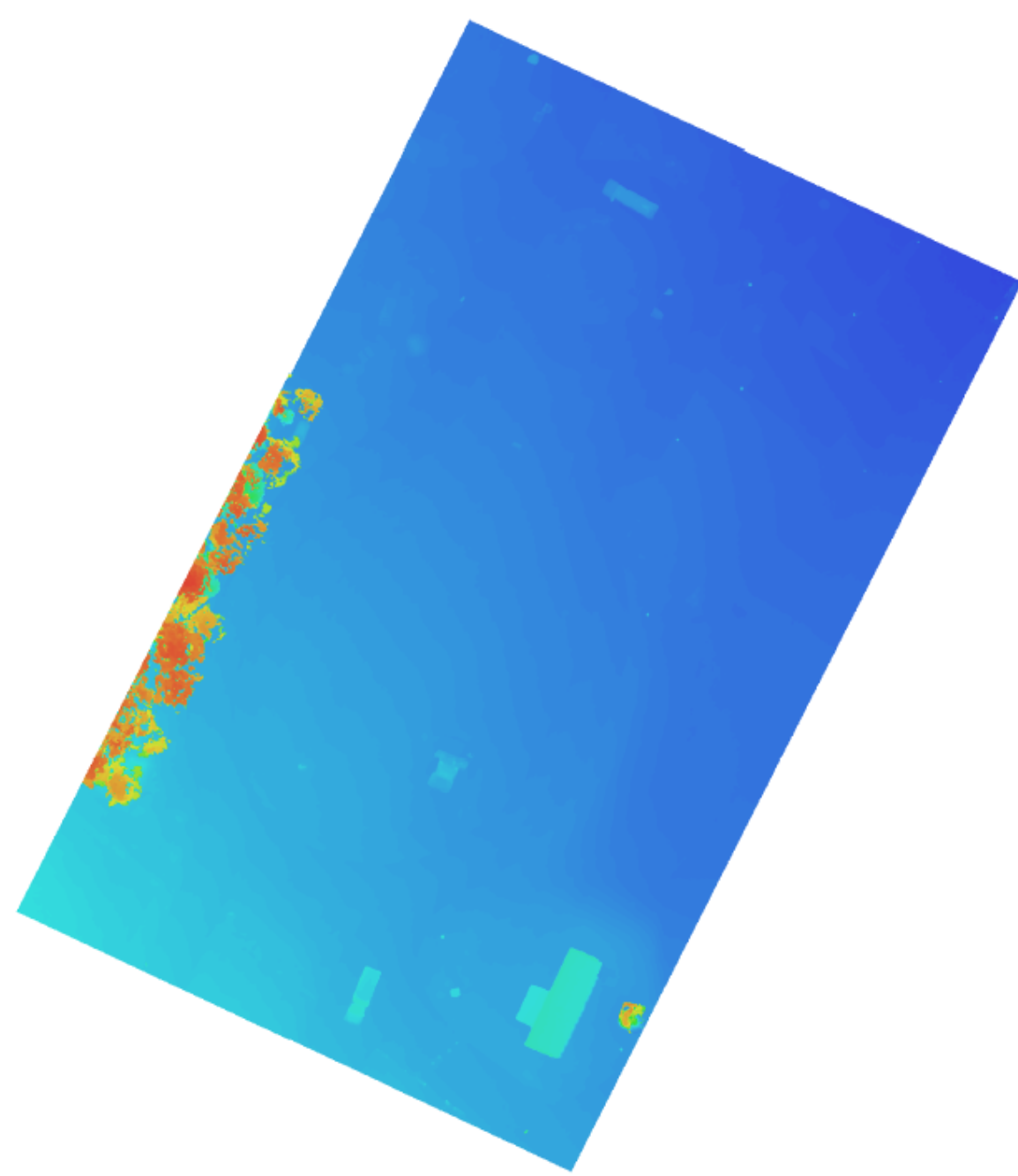

$20 \mathrm{~m}$

Fonte: Autor (2019) 


\subsubsection{Acesso Sul - Métricas}

A Tabela 12 sumariza as métricas obtidas nos produtos fotogramétricos da área de estudo Acesso Sul a partir dos relatórios de processamento extraídos do Agisoft PhotoScan. A Tabela 13 apresenta os erros dos pontos de controle após o processamento das imagens.

Tabela 12 - Dados de processamento do Acesso Sul no Agisoft PhotoScan

\begin{tabular}{ll}
\hline Geral & 237 \\
\hline Imagens & $49,3 \mathrm{~m}$ \\
\hline Altura de vôo & 5 \\
\hline Pontos de controle & $0,0243 \mathrm{~km}^{2}$ \\
\hline Área coberta & SIRGAS 2000 / UTM zone 23S \\
\hline Sistema de Coordenadas & $($ EPSG:.31983) \\
& \\
\hline Nuvem de pontos & 79,577 \\
\hline Pontos de ligação & 8.345 .089 \\
\hline Pontos da nuvem densa & \\
\hline DEM - Modelo Digital de Elevação & $6,07 \mathrm{~cm} / \mathrm{pix}$ \\
\hline GSD & 271 pontos/m² \\
\hline Densidade de Pontos & $1,52 \mathrm{~cm} / \mathrm{pix}$ \\
\hline Ortomosaico & \\
\hline GSD & \\
\hline
\end{tabular}

Fonte: Autor (2019).

Tabela 13 - RMSE dos pontos de controle do Acesso Sul

\begin{tabular}{llllll}
\hline $\operatorname{ErroX}(m)$ & $\operatorname{Erro~Y}(m)$ & Erro Z $(m)$ & $\operatorname{Erro~XY~}(m)$ & Total $(m)$ & Imagem (pix) \\
\hline 0,0139 & 0,01521 & 0,978 & 0,206 & 0,9989 & 2,254
\end{tabular}

Fonte: Autor (2019). 


\subsubsection{Rua 11 - Produtos}

Da Figura 45 à Figura 47 são apresentados os resultados obtidos no processamento pelo Agisoft PhotoScan das 113 imagens coletadas na Rua 11 utilizando pontos de controle artificiais predispostos na área de interesse. 0 voo foi planejado no Pix4D para $60 \mathrm{~m}$ de altura, sobreposição de $70 \%$. O ortomosaico obteve GSD 1,81 cm/px, área de cobertura de 3 ha. A nuvem de pontos densificada é de 6,7 milhões de pontos. 
Figura 45 - Ortomosaico e localização dos GCPs 01-04 da Rua 11, processados no Agisoft Photoscan

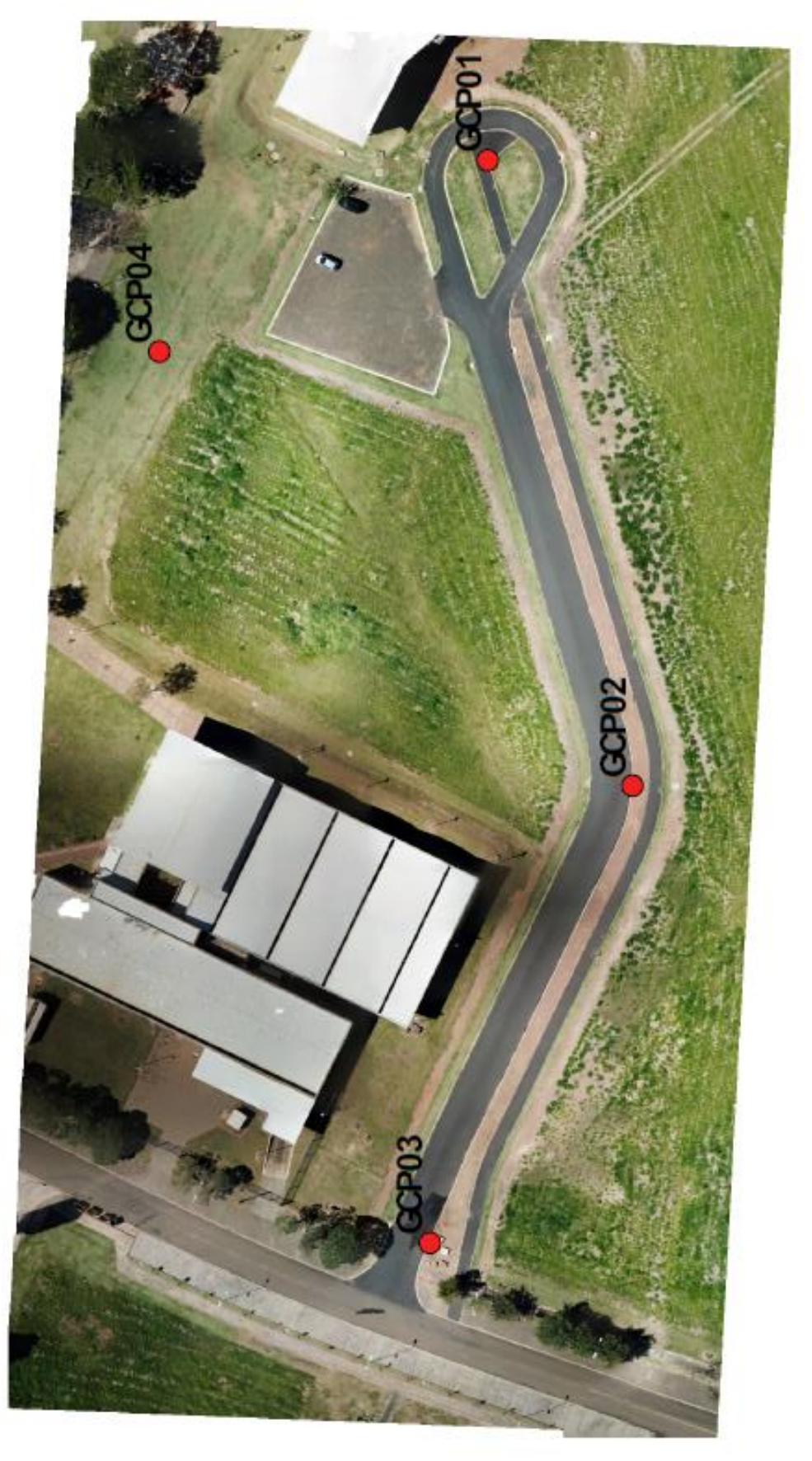

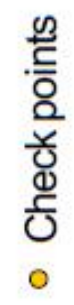

$\frac{2}{1}$
$\frac{1}{0}$
$\frac{2}{0}$
등
0

Fonte: Autor (2019). 
Figura 46 - Localização de câmeras e sobreposição de imagens na Rua 11

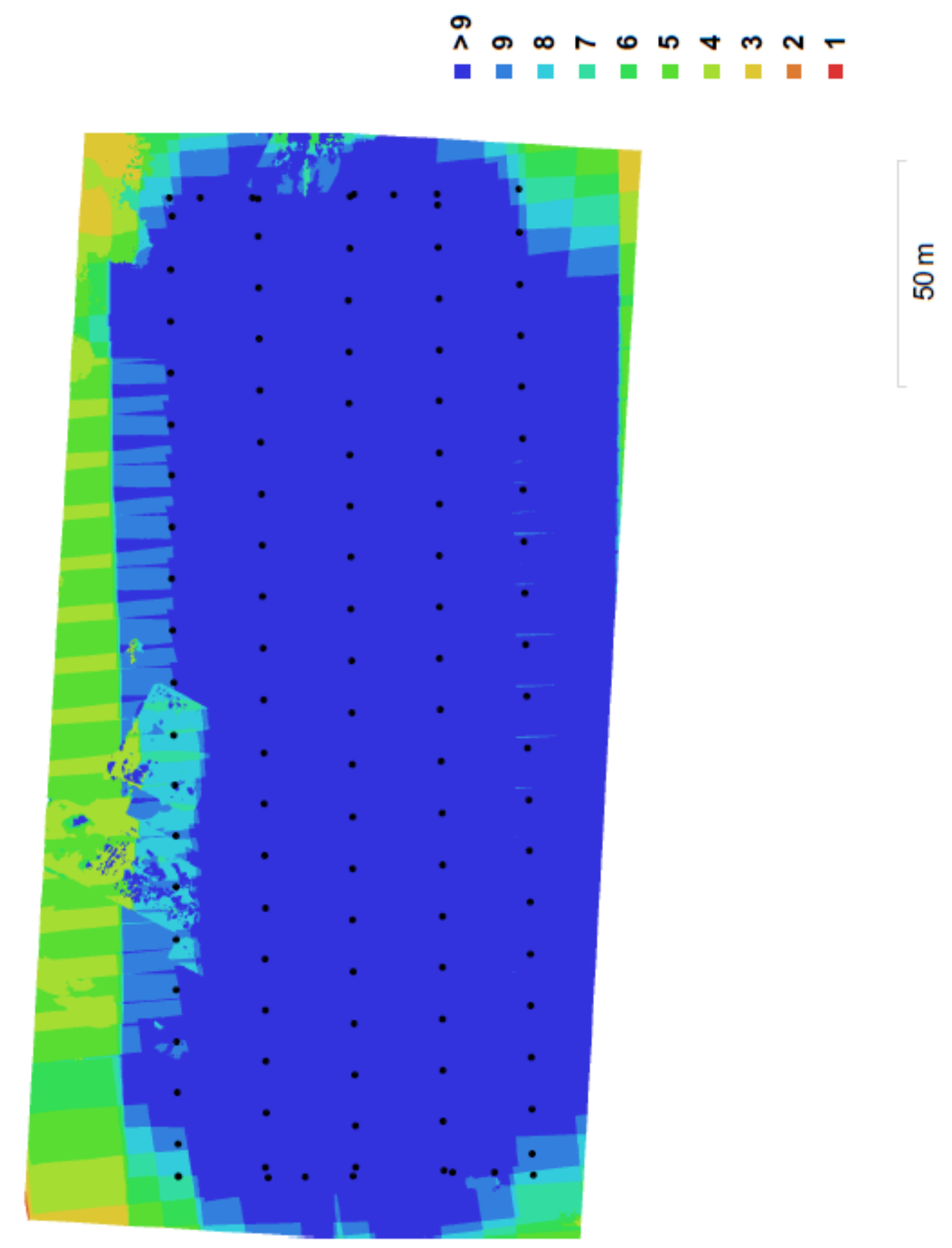

Fonte: Autor (2019) 
Figura 47 - Modelo Digital de Elevação (DEM) da Rua 11, processado no Agisoft PhotoScan

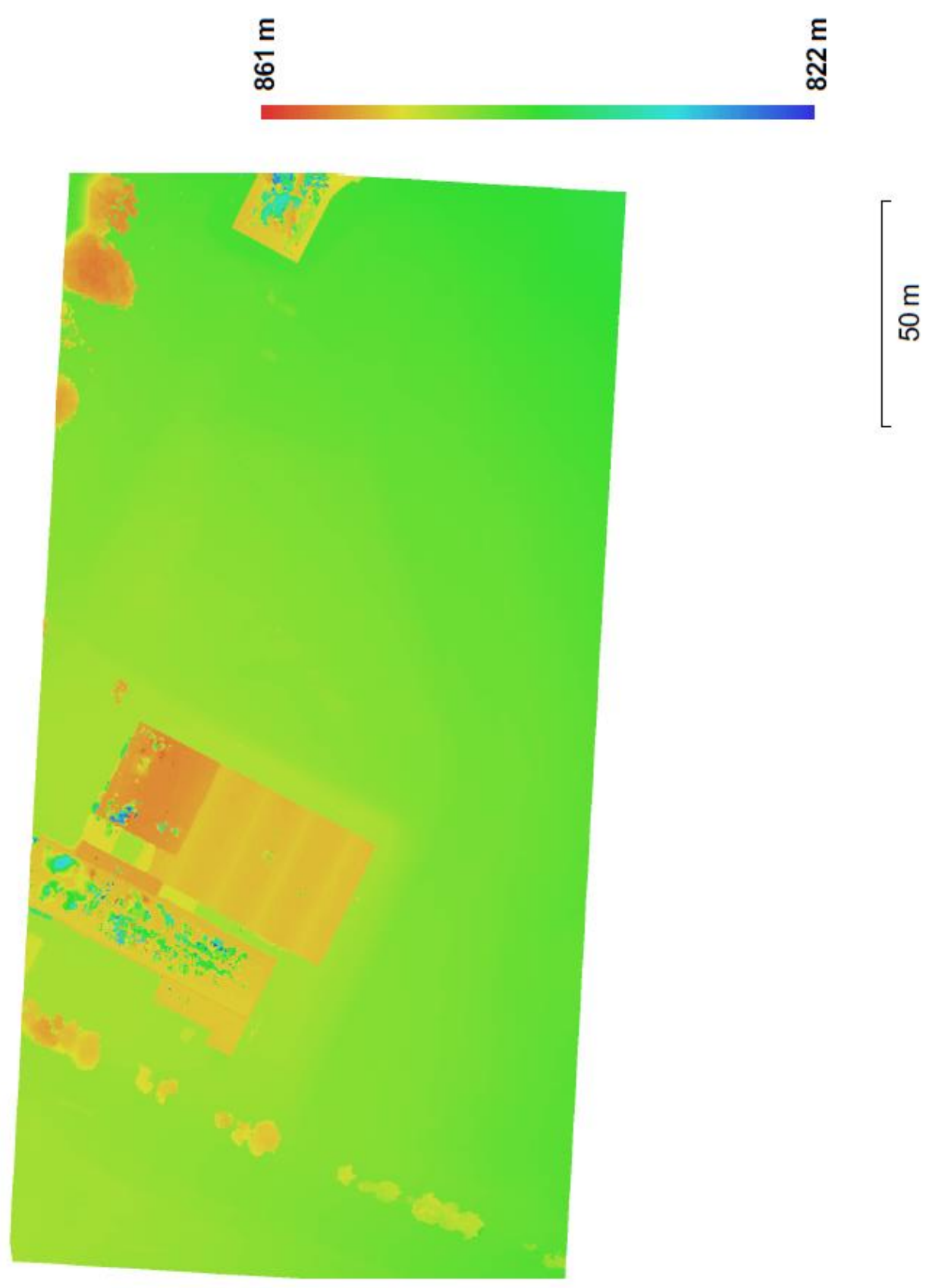

Fonte: Autor (2019). 


\subsubsection{Rua 11 - Métricas}

A Tabela 14 sumariza as métricas obtidas nos produtos fotogramétricos da área de estudo Rua 11 a partir dos relatórios de processamento extraídos do Agisoft PhotoScan. A Tabela 15 apresenta os erros dos pontos de controle após o processamento das imagens.

Tabela 14 - Dados de processamento da Rua 11, no Agisoft PhotoScan

\begin{tabular}{ll}
\hline Geral & \\
\hline Imagens & 113 \\
\hline Altura de vôo & $58,6 \mathrm{~m}$ \\
\hline Pontos de controle & 4 \\
\hline Área coberta & $0,0301 \mathrm{~km}^{2}$ \\
\hline Sistema de Coordenadas & SIRGAS 2000 / UTM zone 23S \\
\hline Nuvem de pontos & \\
\hline Pontos de ligação & 62.985 \\
\hline Pontos da nuvem densa & 6.753 .632 \\
\hline DEM - Modelo Digital de Elevação & \\
\hline GSD & $7,24 \mathrm{~cm} / \mathrm{pix}$ \\
\hline Densidade de Pontos & $191 \mathrm{pontos} / \mathrm{m}^{2}$ \\
\hline Ortomosaico & $1,81 \mathrm{~cm} / \mathrm{pix}$ \\
\hline GSD
\end{tabular}

Fonte: Autor (2019)

Tabela 15 - RMSE dos pontos de controle da Rua 11

\begin{tabular}{cccccc}
\hline $\operatorname{ErroX}(\mathrm{m})$ & $\operatorname{Erro} \mathrm{Y}(\mathrm{m})$ & $\operatorname{Erro} \mathrm{Z}(\mathrm{m})$ & $\operatorname{ErroXY}(\mathrm{m})$ & Total $(\mathrm{m})$ & $\begin{array}{c}\text { Imagem } \\
(\mathrm{pix})\end{array}$ \\
\hline 0,024 & 0,041 & 0,423 & 0,047 & 0,426 & 0,748 \\
\hline
\end{tabular}

Fonte: Autor (2019). 


\subsubsection{ANÁLISE DE RESULTADOS | FASE 2}

A utilização de GCP possibilitou a orientação dos produtos fotogramétricos para serem integrados ao modelo BIM, diminuindo consideravelmente os erros em relação aos produtos da Fase 1. Tanto pontos de controle naturais como artificiais possibilitaram orientação condizente dos modelos fotogramétricos. No entanto, a utilização de alvos demonstrou mais eficiência no processamento em função da identificação ser automatizada no Agisoft PhotoScan, enquanto a identificação de pontos de naturais deve ser feita manualmente em cada foto, o que torna o processo menos preciso e mais árduo quanto maior for a quantidade de imagens a serem registradas. Tal imprecisão pode ser notada no valores maiores dos erros em x, y e z, comparando a Tabela 13 com a Tabela 6 e Tabela 15 com a Tabela 9.

Para levantamentos periódicos e de larga escala, deve ser considerado o investimento em sistemas automáticos de georreferenciamento para otimização de trabalhos em campo e melhor acurácia nos resultados. Ressalta-se que a utilização de GCP deve ser considerada mesmo com o uso de sistemas automáticos como ferramenta de verificação e controle de qualidade dos produtos gerados, uma vez que erros inerentes ao levantamento e processamento. Os GCP podem ser permanentes para que levantamentos periódicos utilizem dos mesmos pontos de controle, desde que a aferição de coordenadas tenha manutenção periódica.

Por fim, atenta-se que o desenvolvimento de modelos BIM de edificações também deve ser georreferenciado com pontos de controle de coordenadas determinadas para que haja coerência entre o local físico e os modelos digitais, ou seja, para que as informações tenham verossimilhança de gêmeos digitais. Tais referências devem adotar o mesmo sistema de coordenadas para que a integração com outros modelos BIM, como os abordados neste trabalho, seja coerente e facilitada. 


\subsection{FASE 3 - MAPEAMENTO DO CAMPUS}

A fase 3 abrangeu toda a área construída do campus, contendo as principais edificações e infraestruturas existentes. O foco foi gerar dados para contextualização espacial das obras da Rua 11 e Acesso Sul e ampliar a área de abrangência de estudo para verificar as capacidades de levantamento e processamento de grandes áreas a partir dos equipamentos utilizados. Os resultados focam em analisar a integração de nuvens de pontos no modelo BIM de grandes áreas urbanas (maiores que 1 ha) utilizando uma parte limitada dos produtos gerados para analisar o desempenho do modelo BIM e indicar formas de otimização.

\subsubsection{PRODUTOS FOTOGRAMÉTRICOS}

Foram gerados ortomosaicos para verificação da qualidade das imagens capturadas, via Pix4D, os quais são apresentados por setor nas figuras $54-57$. Os produtos fotogramétricos podem ser georreferenciados como demonstram os resultados da Fase 2, no entanto, neste trabalho tal tarefa foi aplicada apenas em parte do setor 2 em função da otimização de recursos computacionais. A integração dos demais setores é colocada como atividade futura sugerida ao setor de gestão de infraestrutura do Campus.

No total, foram realizados 22 voos entre os dias 21 de janeiro e 2 de fevereiro de 2019. O planejamento e execução de voos foram realizados com margem de $30 \%$ de segurança sobre a autonomia da aeronave, segmentando a área do campus até sua cobertura total. Os voos foram realizados a $100 \mathrm{~m}$ de altura, em planos de voo de grade dupla com 90\% de sobreposição, totalizando 8.685 imagens capturadas e cobertura de 70,5 ha (Tabela 16).

Após o levantamento, os voos foram agrupados em quatro setores principais (Figura 48), e processados de acordo com os limites de quantidade de fotos no Pix4D e Agisoft Photoscan. O Setor 1 compreende a região do Acesso Sul. O Setor 2 é situado na região central do campus e compreende a Rua 11, a Biblioteca, o 
Restaurante Universitário, o Centro de Apoio Didático e outros departamentos. 0 Setor 3 compreende a região dos departamentos de Química e Engenharia Ambiental. O Setor 4 compreende o Acesso principal (norte) e Edifícios administrativos.

Figura 48 - Setorização de dados levantados e processado do Campus USP2

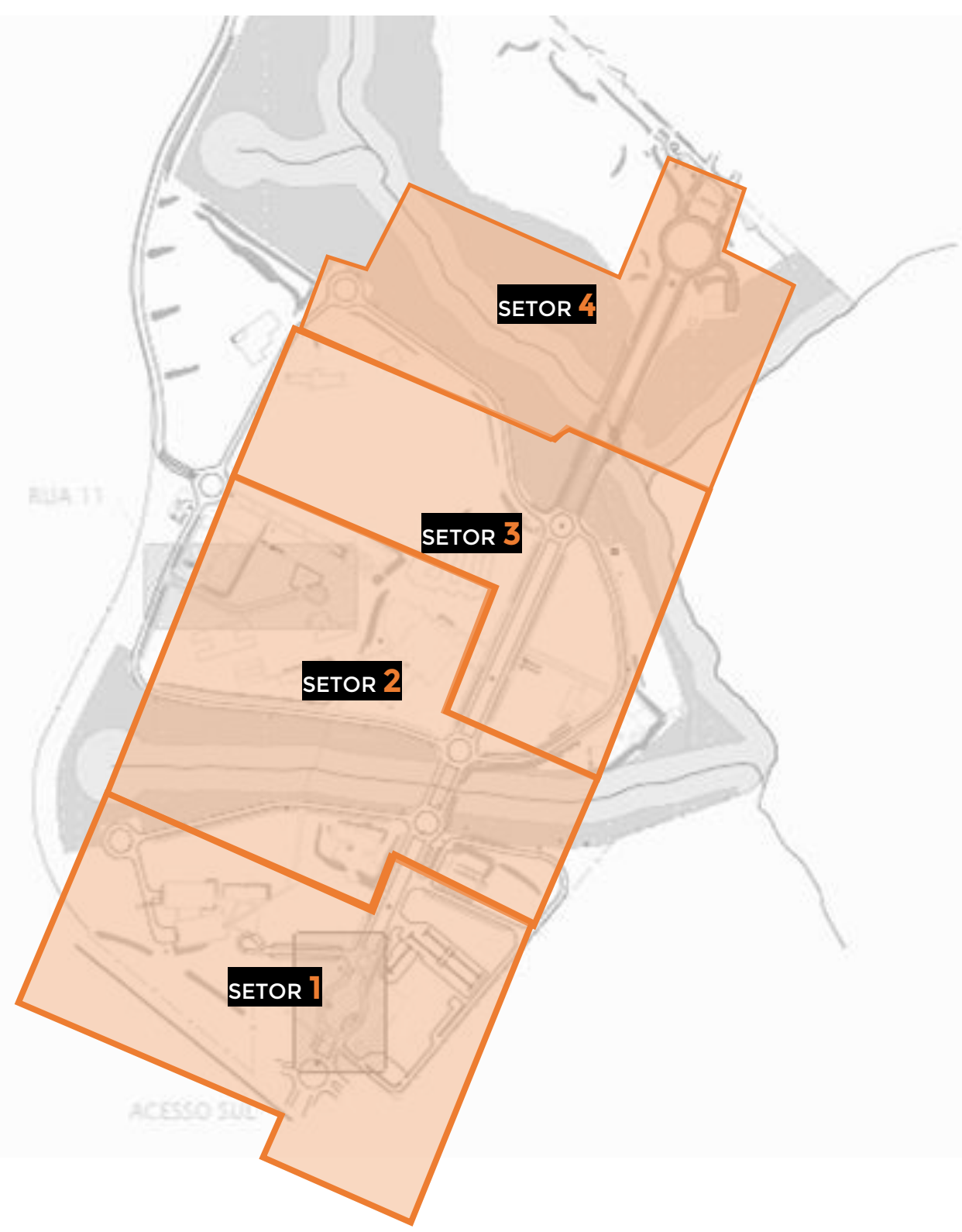

Fonte: Autor (2019).

Os voos pertencentes a cada setor são representados na Figura 49, na qual são indicados o número de controle do voo e os limites de cobertura estabelecidos nos respectivos planos de voo elaborados via Pix4Capture. 
Figura 49 - Registro de voos por setor
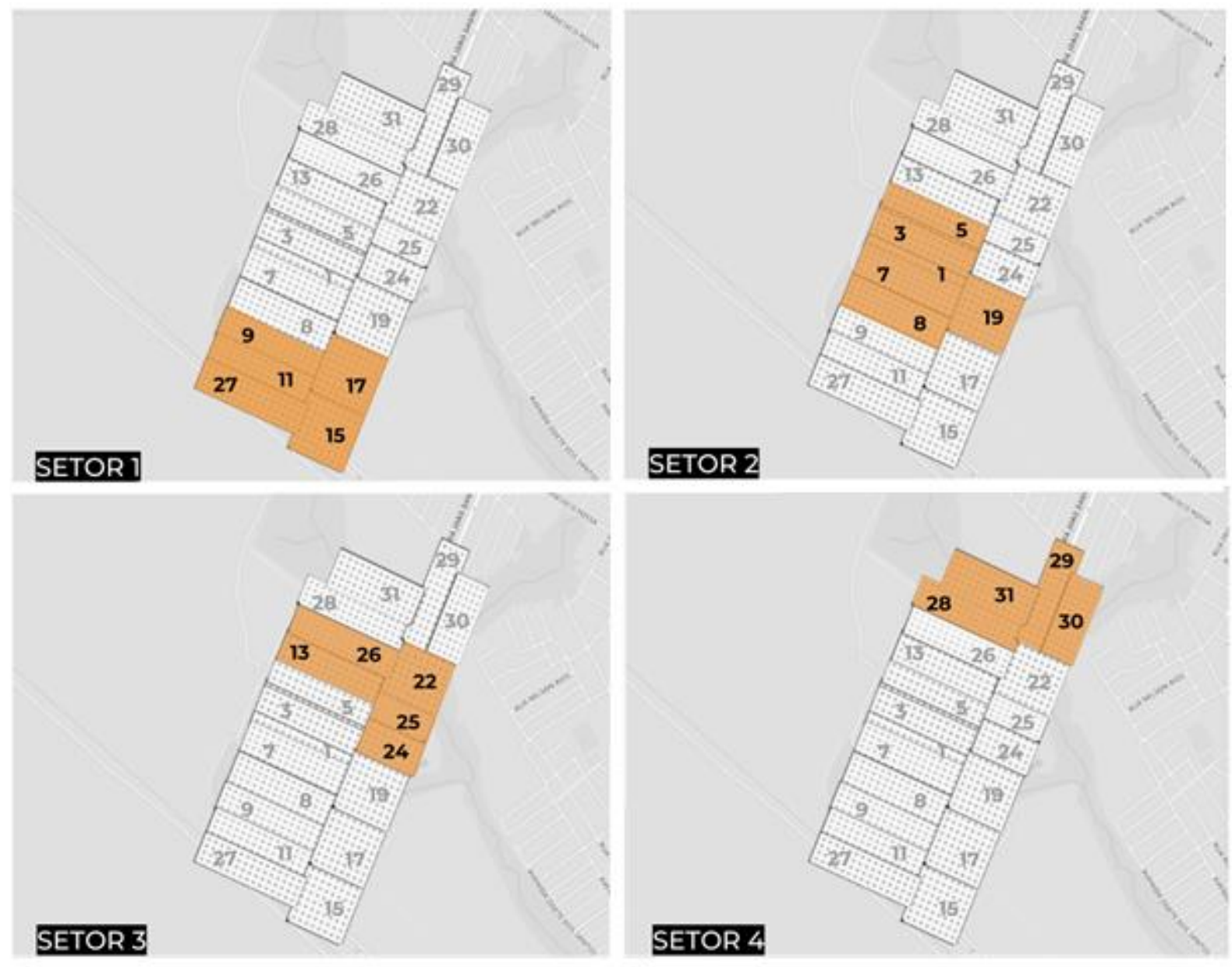

$N^{\circ}$ de controle de voo

Indicaçäo de voos pertencentes a Área de cobertura cada setor

Fonte: Autor (2019)

Na Tabela 16, os dados gerais de registro de cada voo são apresentados com as coordenadas do ponto de decolagem, a área coberta no plano de voo, a quantidade de imagens capturadas e observações de eventos ocorridos durante as operações. Ao todo, o levantamento necessitou de 7 dias (meio período de campo por dia). Da Figura 50 à Figura 53, são apresentados os ortomosaicos 
correspondentes aos Setores de 1 a 4 e, na Figura 54, apresenta-se o ortomosaico unificado de todos os setores elaborado a partir do processamento simultâneo de todas as imagens coletadas no PIX4D.

Tabela 16 - Dados gerais de voos | Fase 3

\begin{tabular}{|c|c|c|c|c|}
\hline V00 & LOCAILIZAÇÃO & ÁREA (ha) & IMAGENS & OBS \\
\hline 1 & $\begin{array}{l}-22.001871^{\circ}- \\
47.932132^{\circ}\end{array}$ & 5,7 & 364 & $\begin{array}{l}\text { Dificuldades em iniciar planos de voo. } \\
\text { Voo interrompido por bateria baixa (20\%) }\end{array}$ \\
\hline 3 & $\begin{array}{l}-22.001786^{\circ}- \\
47.932093^{\circ}\end{array}$ & 2,9 & 447 & - \\
\hline 5 & $\begin{array}{l}-22.000945^{\circ}- \\
47.931690^{\circ}\end{array}$ & 2,9 & 443 & - \\
\hline 7 & $\begin{array}{l}-22.002937^{\circ}- \\
47.932624^{\circ}\end{array}$ & 0,4 & 369 & $\begin{array}{l}\text { Dificuldades em iniciar planos de voo. } \\
\text { Voo interrompido por bateria baixa ( } 20 \%)\end{array}$ \\
\hline 8 & $\begin{array}{l}-22.003826^{\circ}- \\
47.933030^{\circ}\end{array}$ & 4,1 & 386 & $\begin{array}{l}\text { Dificuldades em iniciar planos de voo. } \\
\text { Voo interrompido por bateria baixa } \\
(20 \%) \text {. Perda de comunicação com o } \\
\text { smartphone durante o voo, operação via } \\
\text { RC. }\end{array}$ \\
\hline 9 & $\begin{array}{l}-22.004653^{\circ}- \\
47.933432^{\circ}\end{array}$ & 3,4 & 506 & - \\
\hline 11 & $\begin{array}{l}-22.005379^{\circ} \\
-47.9333763^{\circ}\end{array}$ & 3,4 & 485 & $\begin{array}{l}\text { Perda de comunicação com } 0 \\
\text { smartphone durante o voo, operação via } \\
\text { RC. }\end{array}$ \\
\hline 12 & $\begin{array}{l}-22.006125^{0}- \\
47.934128\end{array}$ & 3,6 & 444 & $\begin{array}{l}\text { Todas as imagens capturadas sem } \\
\text { nitidez. Refazer levantamento }\end{array}$ \\
\hline 15 & $\begin{array}{l}-22.007098^{\circ}- \\
47.931596^{\circ}\end{array}$ & 3,9 & 346 & - \\
\hline 17 & $\begin{array}{l}-22.005452^{0}- \\
47.930823^{\circ}\end{array}$ & 3,9 & 410 & $\begin{array}{l}\text { Perda de comunicação com } 0 \\
\text { smartphone durante o voo, operação via } \\
\text { RC. }\end{array}$ \\
\hline
\end{tabular}

Fonte: Autor (2019). 
Tabela 16 (Continuação) - Dados gerais de voos | Fase 3

\begin{tabular}{|c|c|c|c|c|}
\hline V00 & LOCAILIZAÇÃO & ÁREA (ha) & IMAGENS & OBS \\
\hline 19 & $\begin{array}{l}-22.003800^{\circ}- \\
47.930025^{\circ}\end{array}$ & 3,9 & 336 & $\begin{array}{l}\text { Perda de comunicação com } 0 \\
\text { smartphone durante o voo, operação via } \\
\text { RC. }\end{array}$ \\
\hline 22 & $\begin{array}{l}-22.000541^{\circ}- \\
47.928470^{\circ}\end{array}$ & 3,9 & 331 & $\begin{array}{l}\text { Dificuldades em iniciar planos de voo. } \\
\text { Falha na calibração da bússula. }\end{array}$ \\
\hline 24 & $\begin{array}{l}-22.002485^{\circ}- \\
47.929363^{\circ}\end{array}$ & 2,4 & 336 & $\begin{array}{l}\text { Falha em rota de voo. } 0 \text { voo abortado e } \\
\text { refeito }\end{array}$ \\
\hline 25 & $\begin{array}{l}-22.001675^{\circ}- \\
47.928984^{\circ}\end{array}$ & 1,6 & 186 & $\begin{array}{l}\text { Dificuldades em iniciar planos de voo e } \\
\text { sincronizar app Pix4capture. }\end{array}$ \\
\hline 26 & $\begin{array}{l}-21.999466^{\circ}- \\
47.930966^{\circ}\end{array}$ & 3,3 & 502 & - \\
\hline 14 & $\begin{array}{l}-21.999421^{\circ}- \\
47.930946^{\circ}\end{array}$ & 3,7 & 276 & $\begin{array}{l}\text { Perda de comunicação com } 0 \\
\text { smartphone durante o voo. Voo abortado }\end{array}$ \\
\hline 13 & $\begin{array}{l}-22.000205^{\circ}- \\
47.931327^{\circ}\end{array}$ & 3,7 & 515 & - \\
\hline 27 & $\begin{array}{l}-22.006125^{\circ}- \\
47.934128\end{array}$ & 3,6 & 520 & $\begin{array}{l}\text { Retrabalho do voo } 12 \text {. Perda de } \\
\text { comunicação com o smartphone durante } \\
\text { o voo, operação via RC. }\end{array}$ \\
\hline 28 & $\begin{array}{l}-21.998630^{\circ}- \\
47.930612^{\circ}\end{array}$ & 3,5 & 522 & $\begin{array}{l}\text { Perda de comunicação com } 0 \\
\text { smartphone durante o voo, operação via } \\
\text { RC. }\end{array}$ \\
\hline 29 & $\begin{array}{l}-21.998116^{\circ}- \\
47.927870^{\circ}\end{array}$ & 3,3 & 333 & - \\
\hline 30 & $\begin{array}{l}-21.998807^{\circ}- \\
47.927105^{\circ}\end{array}$ & 3,0 & 289 & 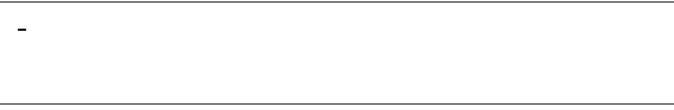 \\
\hline 31 & $\begin{array}{l}-21.997871^{\circ} \\
-47.929879^{\circ}\end{array}$ & 0,3 & 339 & $\begin{array}{l}\text { Eixo do estabilizador da câmera travou } \\
\text { durante o voo. Voo precisou ser refeito. }\end{array}$ \\
\hline $\begin{array}{c}22 \\
\text { voos }\end{array}$ & & 70,5 & 8685 & \\
\hline
\end{tabular}

Fonte: Autor (2019). 
Figura 50 - Ortomosaico do Setor 1 | Fase 3
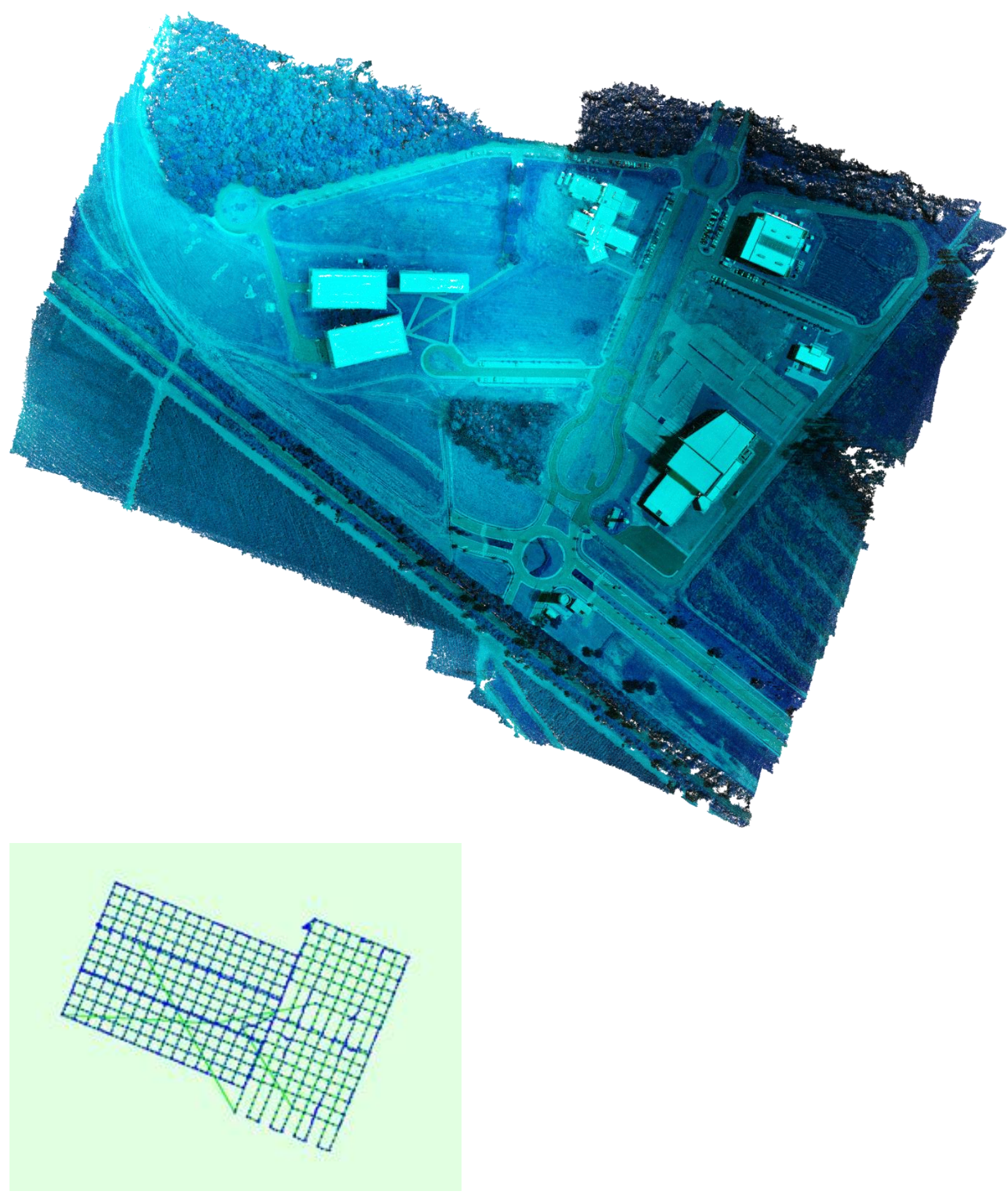

Fonte: Autor (2019). 
Figura 51 - Ortomosaico do Setor 2 | Fase 3

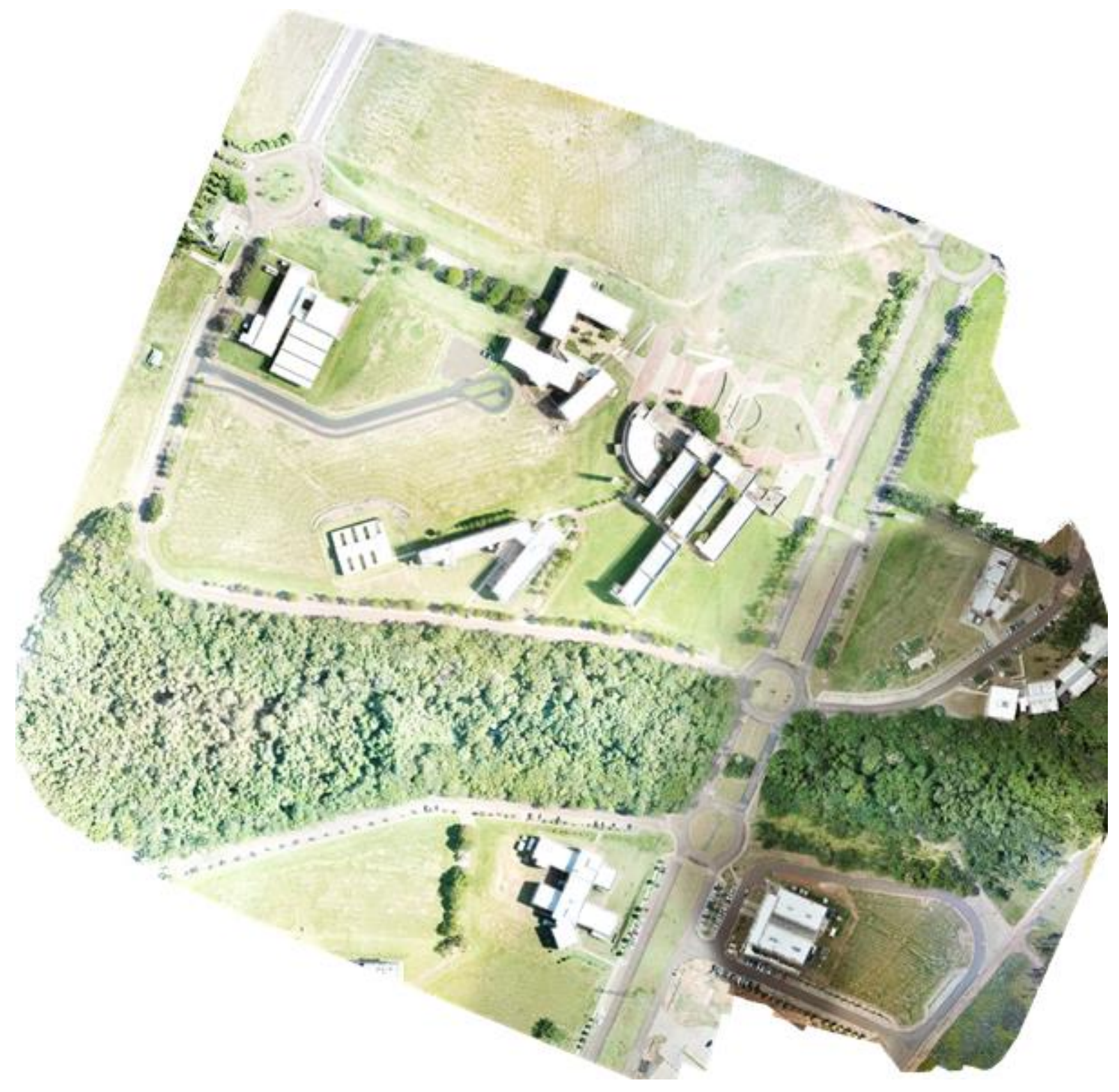

Fonte: Autor (2019). 
Figura 52 - Ortomosaico do Setor 3 | Fase 3

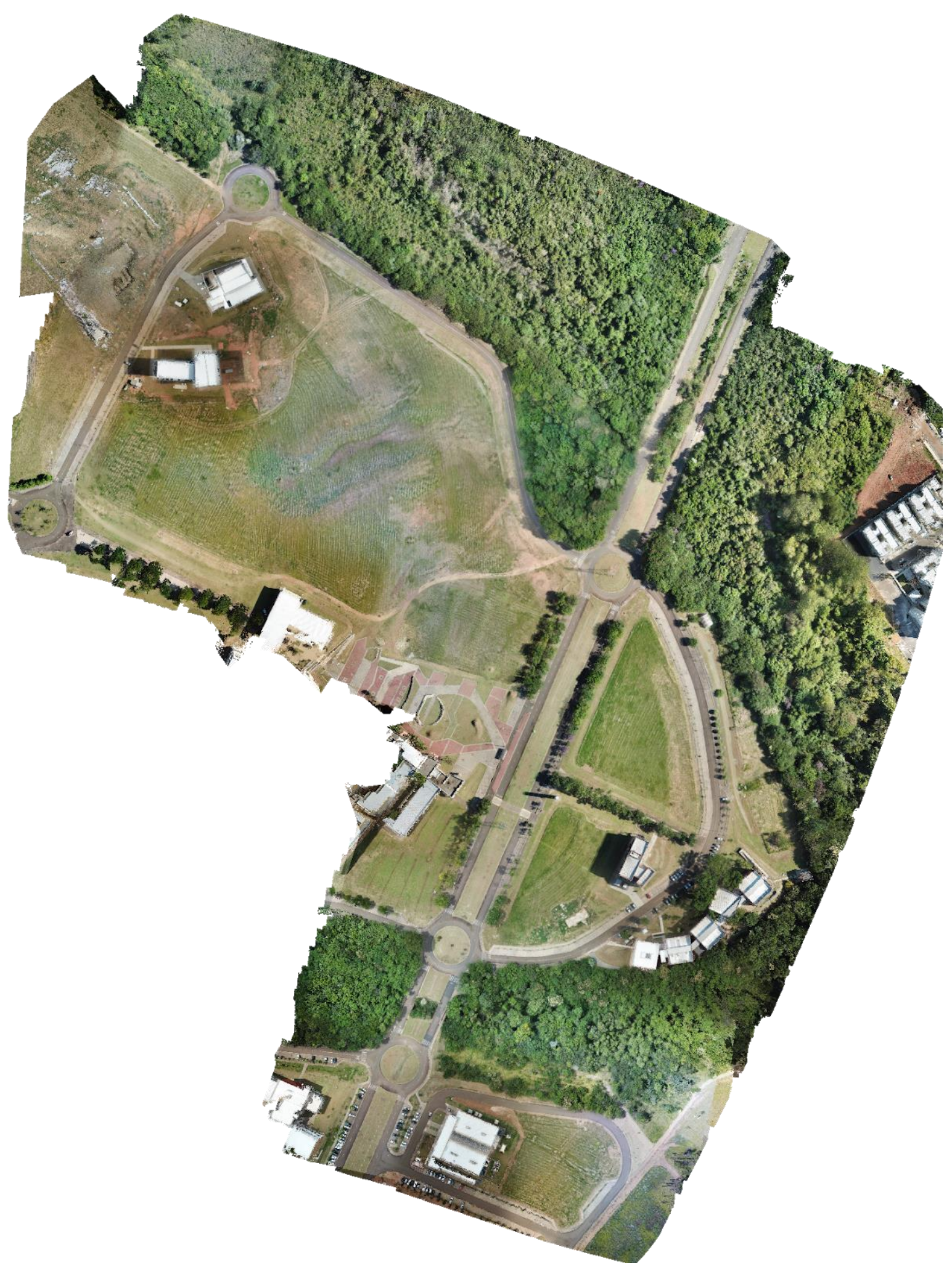

Fonte: Autor (2019). 
Figura 53 - Ortomosaico do Setor 4 | Fase 3

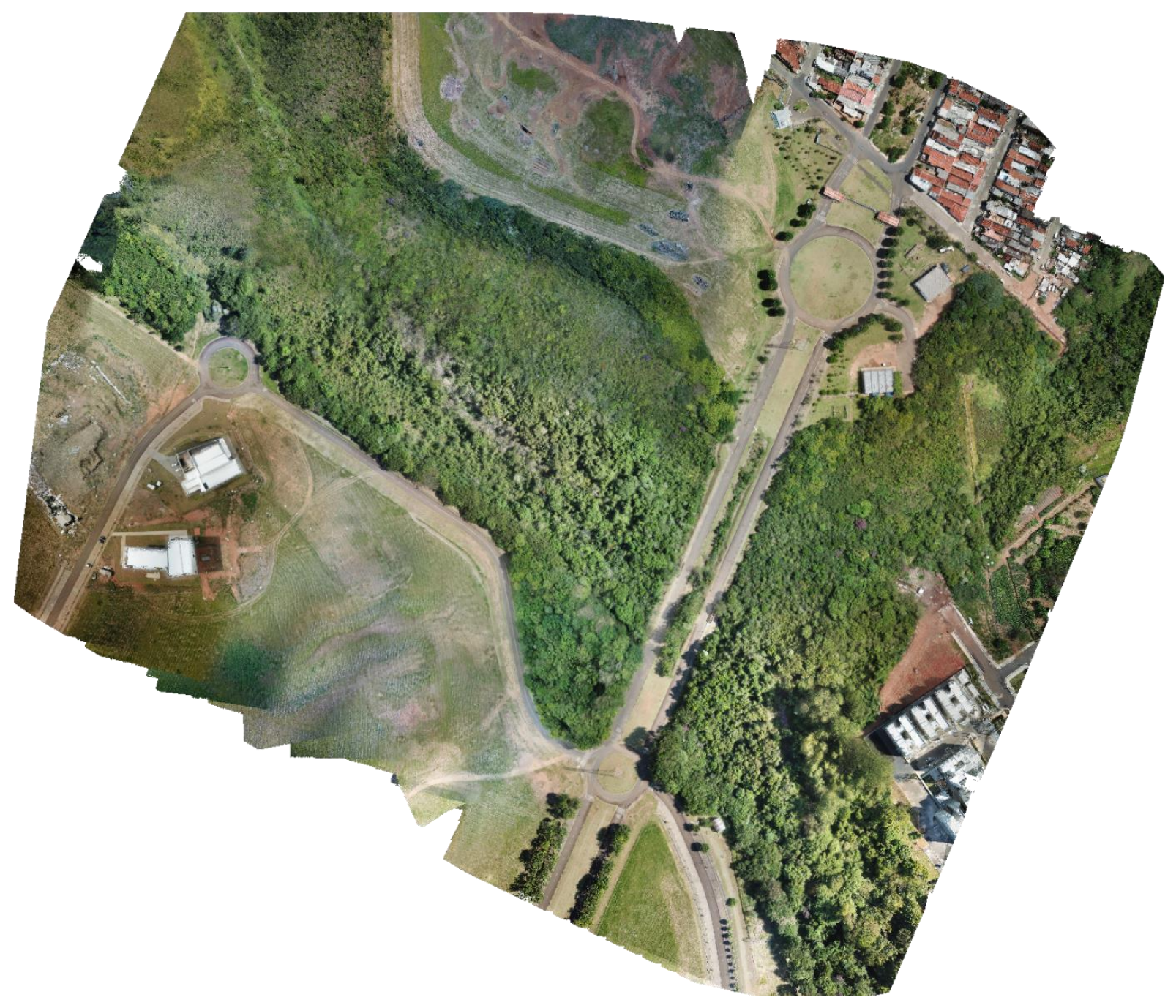

Fonte: Autor (2019). 
Figura 54 - Ortomosaico dos Setores 1, 2, 3 e 4 | Fase 3

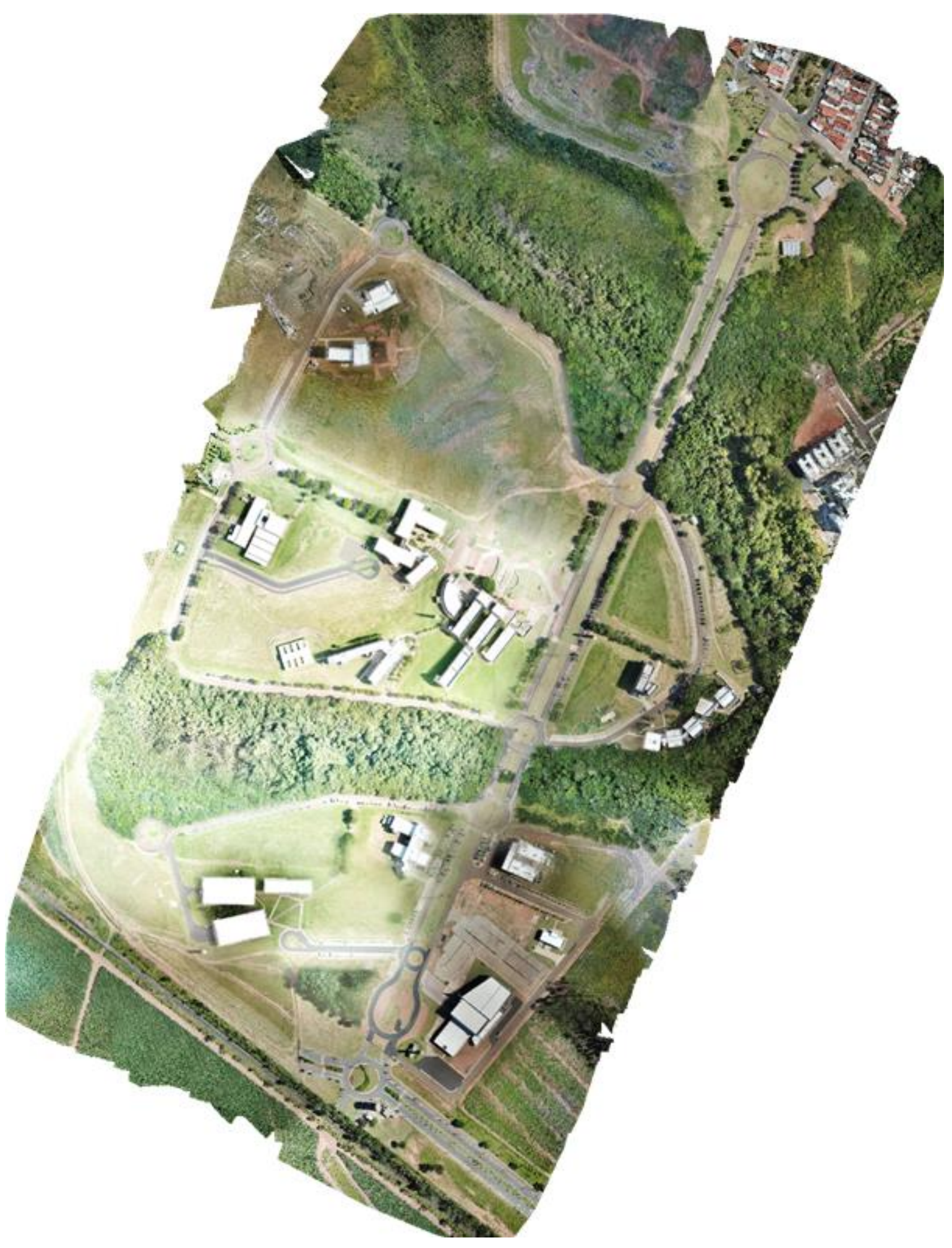

Fonte: Autor (2019). 


\subsubsection{ANÁLISE DE RESULTADOS | FASE 3}

O equipamento utilizado possibilitou o mapeamento de edificações e infraestrutura viária do campus com significativa agilidade, considerando que os 22 voos foram realizados em 7 dias (em meio período de cada dia) e cobriram aproximadamente 70 ha, o que seria inviável utilizando técnicas tradicionais de levantamento. Assim, o uso de RPAS multirrotores para levantamentos de infraestrutura viária no USP-São Carlos se mostrou satisfatório, embora demande mais tempo de levantamento do que aeronaves de asa fixa.

Nos produtos gerados foram verificadas variações de luminosidade das imagens, com regiões mais esbranquiçadas principalmente no Setor 2. Tais irregularidades se devem a variações de luz entre dias e horários diferentes das capturas, o que denota a necessidade de melhor correção de exposição do sensor durante os voos. O procedimento de correção de exposição pode ser feito antes ou durante os voos por meio de botões dedicados no controle remoto da aeronave, porém, tal ajuste não é automático e demanda experiência do operador em perceber variações de luz entre diferentes levantamentos.

Os levantamentos podem ainda ser otimizados reduzindo-se a sobreposição de imagens no plano de voo e aumentando a altura de voo para $120 \mathrm{~m}$ (valor permitido para essa classe de aeronave). No entanto, deve-se considerar que a resolução da imagens e produtos diminuirá com tais alterações e os alvos de GCP devem ser maiores do que os utilizados na Fase 2, uma vez que aqueles não se mostraram suficientemente definidos para alturas superiores a $60 \mathrm{~m}$, conforme as capturas realizadas (e considerando a resolução da câmera embarcada).

Por esse aspecto, o georreferenciamento por pontos de controle naturais pode ser uma alternativa viável (embora menos precisa), sem a necessidade de alvos de grandes dimensões. Deve ser considerada a utilização e aferição da rede de marcos geodésicos do Campus para georreferenciar futuros levantamentos e para estruturar um monitoramento periódico de infraestrutura. Dessa mesma forma, tais tecnologias também podem ser aplicadas a novas obras do Campus como forma de acompanhamento de progresso. Ademais, o uso pode ser 
ampliado a outros campipara auxiliar à documentação e gestão de infraestrutura existente.

Outra questão a ser considerada, é que as nuvens de pontos geradas para grandes áreas demandaram recursos computacionais locais extras, como computadores com alta capacidade para processamento e manuseio de modelos fotogramétricos, fato que deve ser considerado na operação de grandes volumes de dados.

Não somente a infraestrutura de hardware e software deve ser adequada, mas também as características e qualidade dos produtos, em termos de resolução espacial e margens de erro aceitáveis para variados usos. Assim, pode-se otimizar a quantidade de dados levantados e a resolução de produtos fotogramétricos em função de sua finalidade. Na prática, as nuvens de pontos podem ser menos densas (dependendo da finalidade) e/ou podem ser seccionadas e utilizadas parcialmente focando em áreas ou objetos de interesse específicos. Além disso, a utilização de softwares com processamento remoto (em nuvem) pode mitigar os altos investimentos para utilização da tecnologia em larga escala.

Três vídeos foram produzidos para apresentar dos modelos fotogramétricos do setor 1, 2 e 3. Abaixo, seguem os endereços web correspondentes.

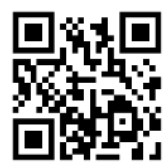

Setor 1: https://youtu. be/jDcbhHI9RvE

Setor 2: https://youtu. be/fzRR4EJ79H8

Setor 3: https://youtu.be/KGIZNoAPt2I 


\subsection{FASE 4 - MODELO BIM}

\subsubsection{CRIAÇÃO DO MODELO E IMPORTAÇÃO DE DADOS}

O modelo BIM foi gerado no software Autodesk InfraWorks cobrindo toda a área do Campus 2 da USP para que possam ser integrados modelos de outras partes futuramente. Em um primeiro momento, um modelo preliminar composto por uma superfície 3D do terreno foi gerado automaticamente pelo software utilizando o banco de dados de imagens de satélite disponível na plataforma. Esse modelo preliminar é a base para inserir as nuvens de pontos geradas nas fases anteriores e iniciar a modelagem. A Figura 55 apresenta uma vista do modelo preliminar com alguns arruamentos e volumetrias de edificações modelados.

Figura 55 - Vista do modelo preliminar do Campus 2 da USP gerada no Autodesk InfraWorks

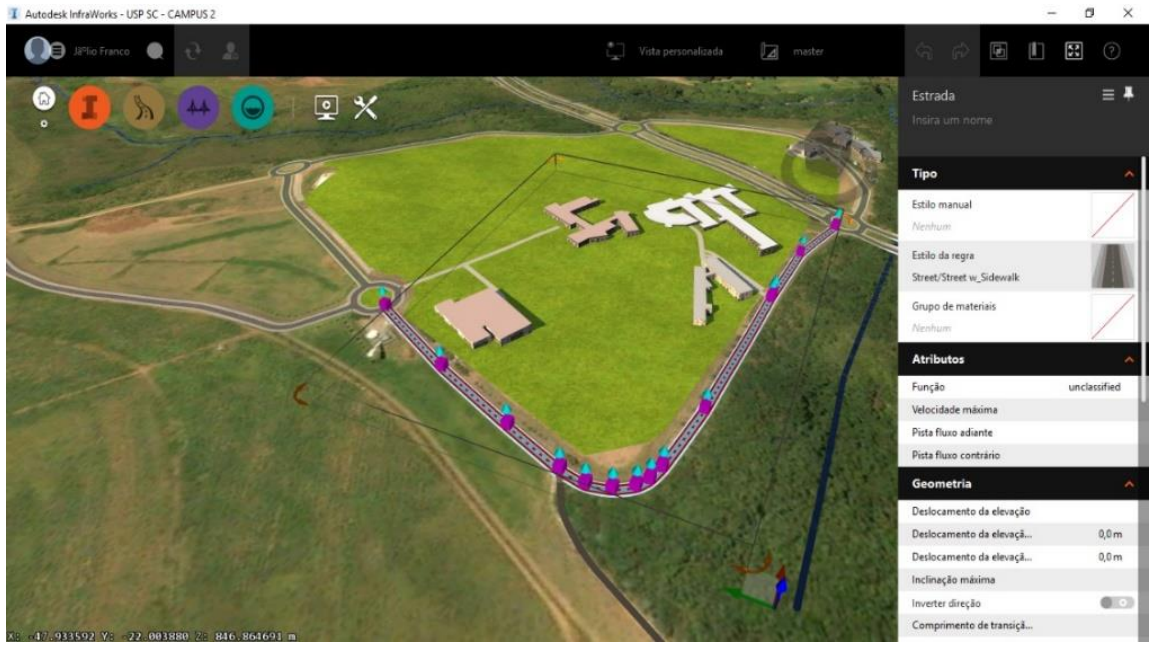

Fonte: Autor (2019)

Em seguida, foram incorporados os modelos digitais de superfície (DSM) resultantes do levantamento aéreo. No entanto a qualidade de visualização se mostrou insatisfatória pela baixa definição de elementos (Figura 56) e, em substituição, optou-se por importar as nuvens de pontos correspondentes. 
Figura 56 - Visão da nuvem importada na base de dados

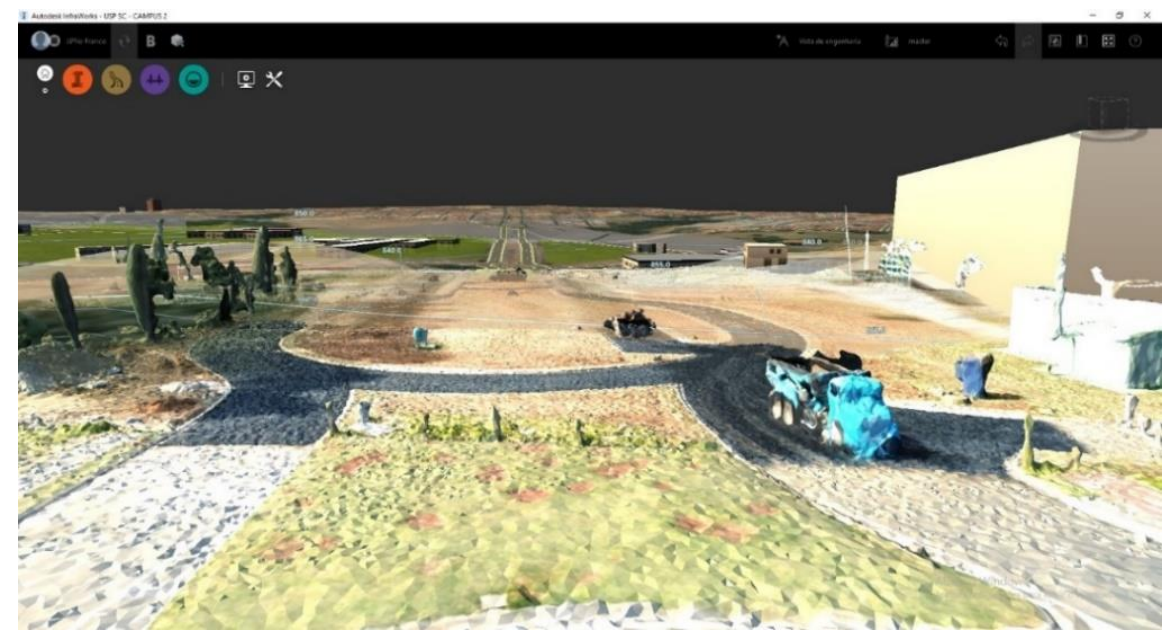

Fonte: Autor (2019).

Previamente à inserção no Autodesk InfraWorks, as nuvens de pontos foram pós processadas no Autodesk Recap para exclusão de ruídos e verificação do sistema de coordenadas adotado (SIRGAS2000, UTM 23S), conforme Figura 57. Nessa etapa, foram removidos pontos de superfícies visualmente falhas e outros ruídos de superfícies reflexivas. Como exemplo, o resultado para o acesso sul é apresentado na Figura 58. Por fim, os arquivos *.rcp foram gerados para importação no InfraWorks.

Figura 57 - Importação de nuvens de pontos no Autodesk Recap

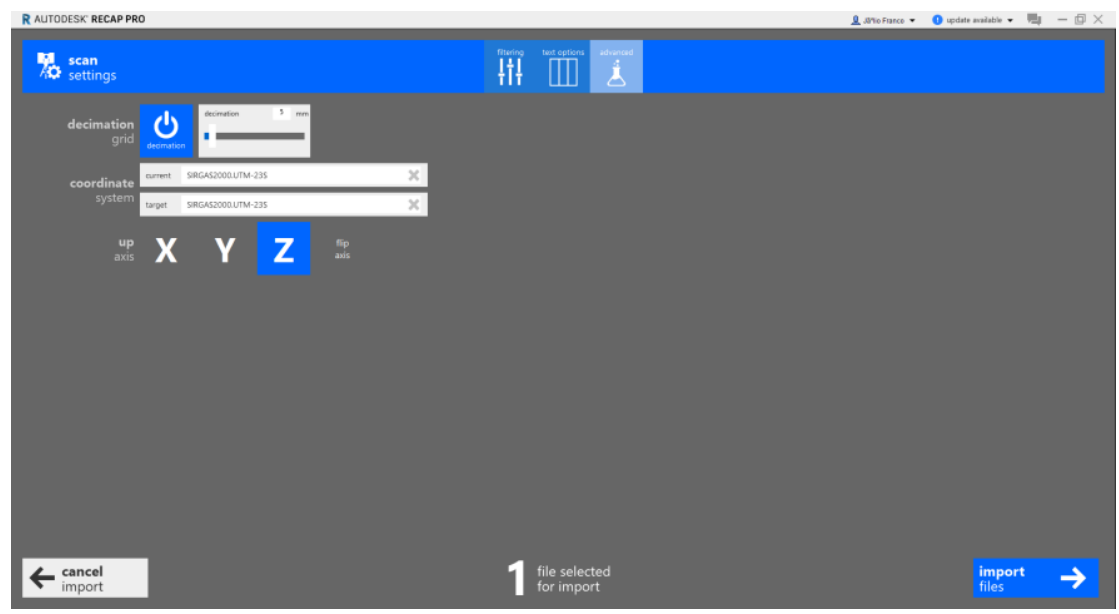

Fonte: Autor (2019). 
Figura 58 - Nuvem de pontos acesso sul pós-processada via Autodesk Recap

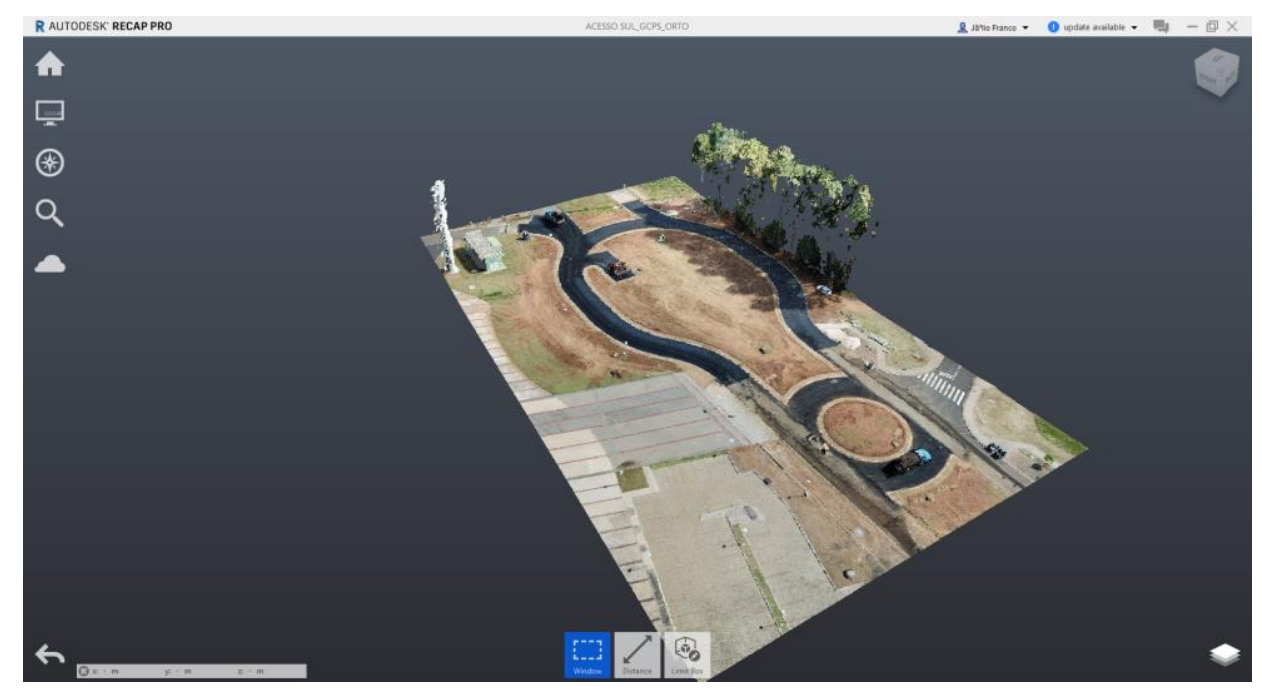

Fonte: Autor (2019)

As nuvens de pontos importadas compreenderam os seguintes locais: (i) Rua 11 e (ii) Acesso Sul - processadas na Fase 2 e, (iii) Setor 2-parcial - processada na Fase 3 (Figura 59). A nuvem de pontos do Setor 2 foi importada para abranger edificações próximas à Rua 11, especificamente, em torno da biblioteca. No entanto, a importação foi feita parcialmente para melhorar a operabilidade do modelo, conforme apontado na seção 4.3 4.3.2 Análise de resultados | Fase 3, página 172. 


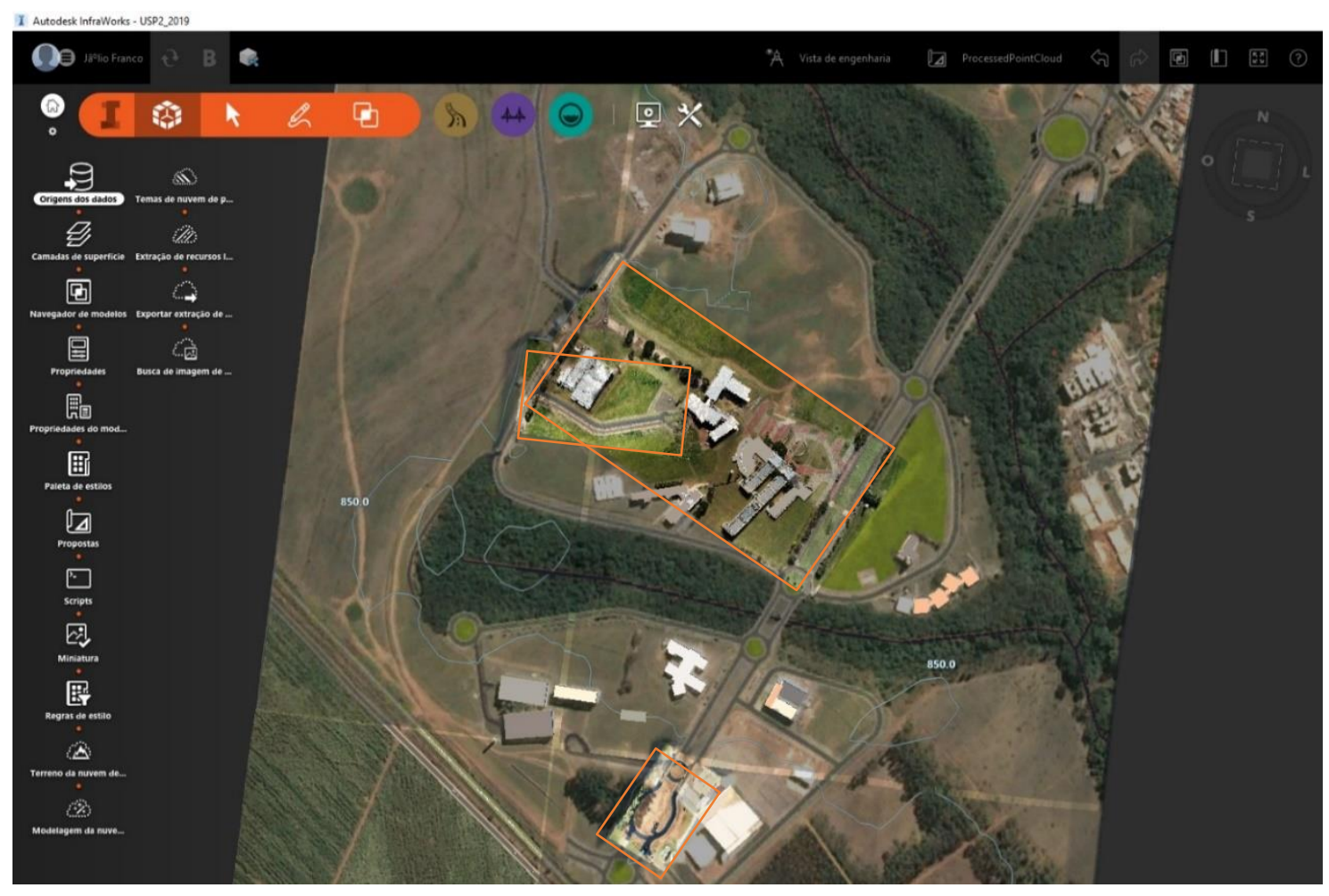

Fonte: Autor (2019).

Ressalta-se que a disposição espacial das nuvens de pontos durante a importação no InfraWorks se deu de forma automática e sem alteração de suas coordenadas, de forma a respeitar a orientação determinada a partir de pontos de controle processados na Fase 2 (Figura 60). À luz disso, foram observadas diferenças significativas entre as cotas das nuvens importadas e as do modelo preliminar gerado automaticamente pelo software a partir de imagens de satélite, vide a Figura 61, cuja grandeza ultrapassou 10 m (eixo z) em determinadas regiões. 
Figura 60 - Importação de nuvem de pontos no Autodesk InfraWorks

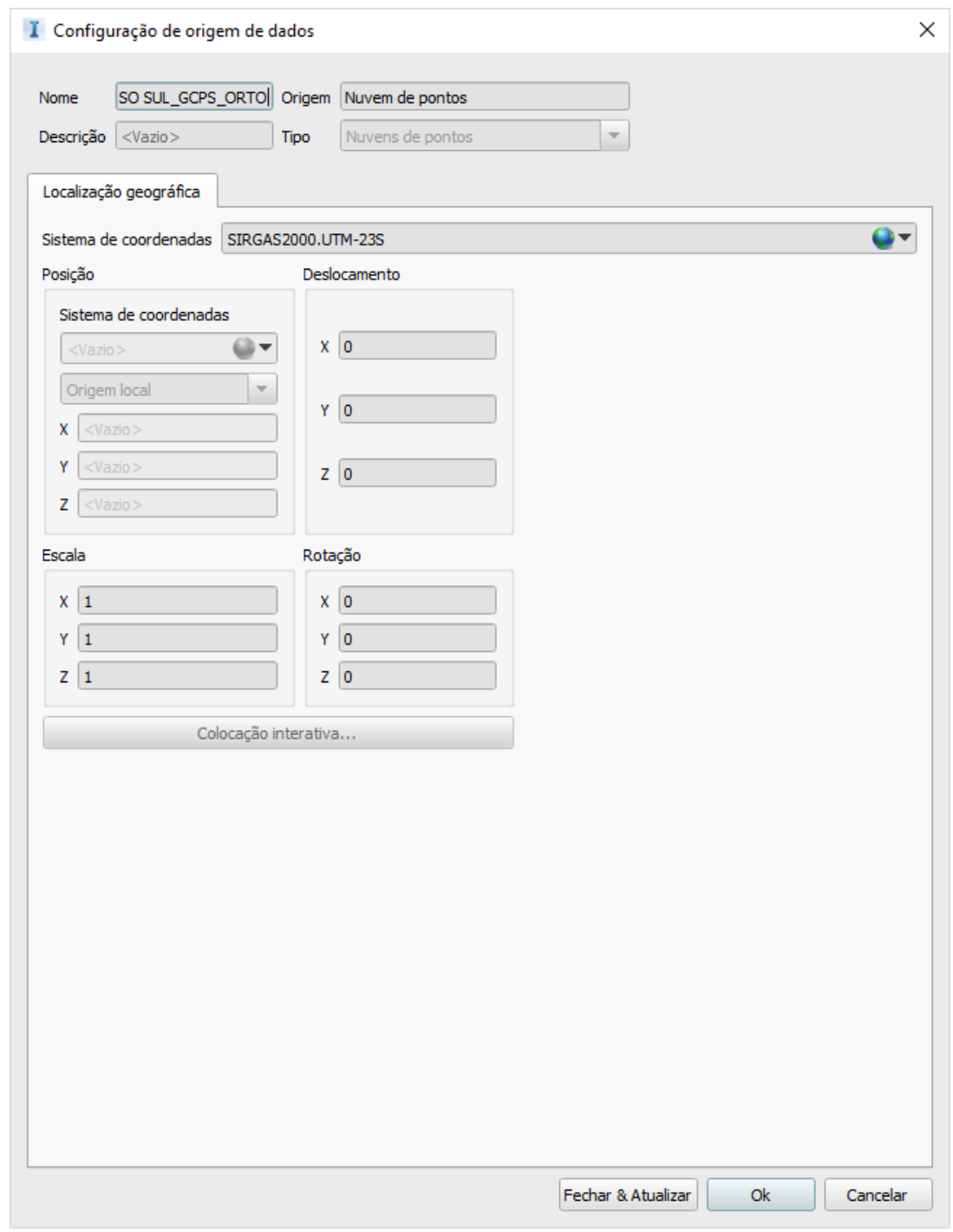

Fonte: Autor (2019). 
Figura 61 - Diferença de cotas entre nuvem de pontos e modelo preliminar de superfície (vista inferior)

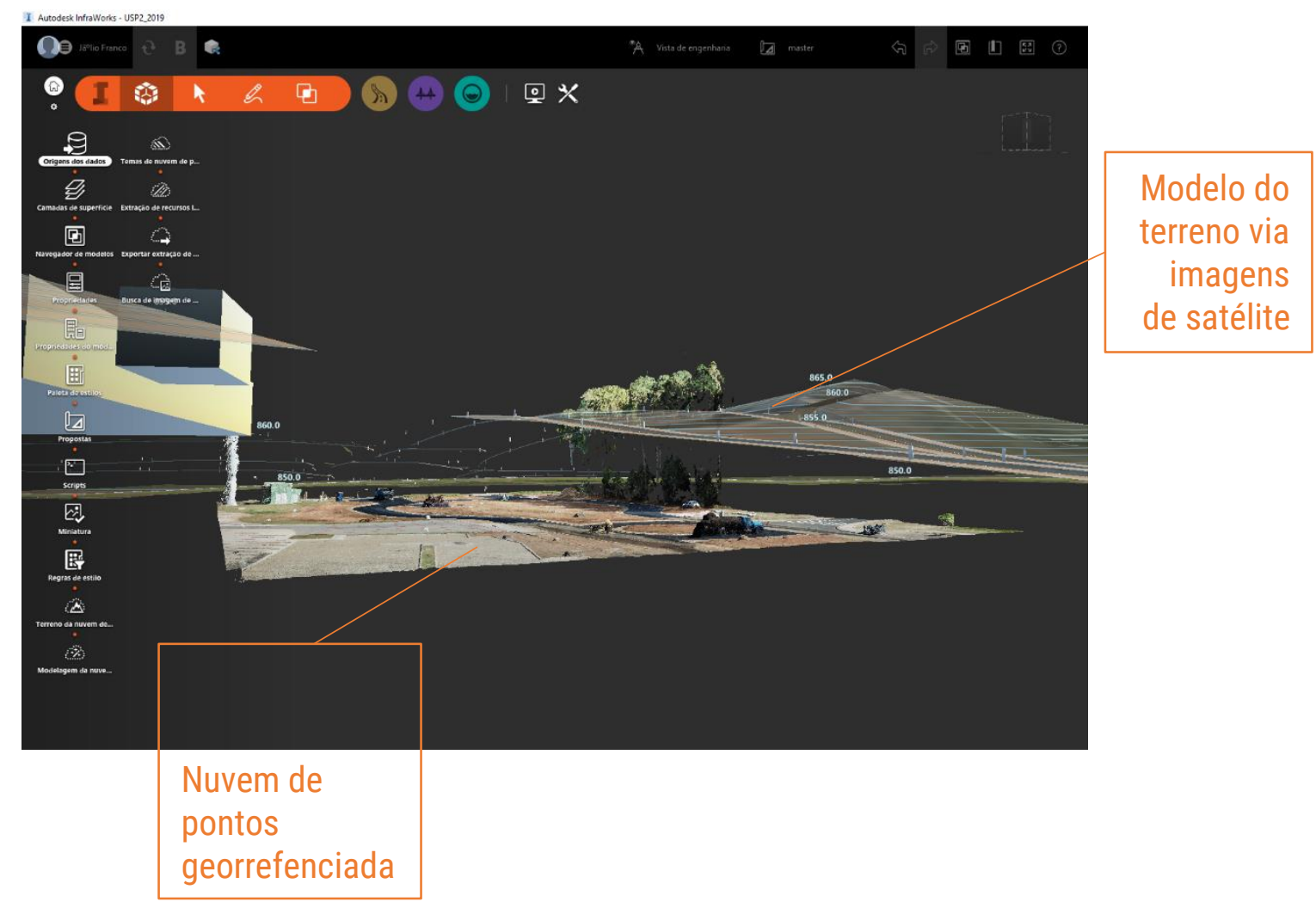

Fonte: Autor (2019).

Pontua-se que as coordenadas dos pontos de controle utilizadas no processamento possuem altitudes ortométricas, com devidas correções do sistema geodésico de referência para o local de estudo. E, mesmo considerando o desvio em z do levantamento (Tabela 6 e Tabela 9), a diferença é significativa e aponta baixa precisão de modelos baseados apenas em imagens de satélite pelo Autodesk InfraWorks.

\subsubsection{MODELAGEM DO TERRENO E VOLUMETRIAS DE EDIFICAÇÕES}

A partir das nuvens de pontos importadas, as superfícies do modelo foram remodeladas utilizando a ferramenta de geração de terreno e adotando a qualidade máxima selecionável, como indicado na Figura 62. 
Figura 62 - Geração de terreno a partir das nuvens de pontos importadas

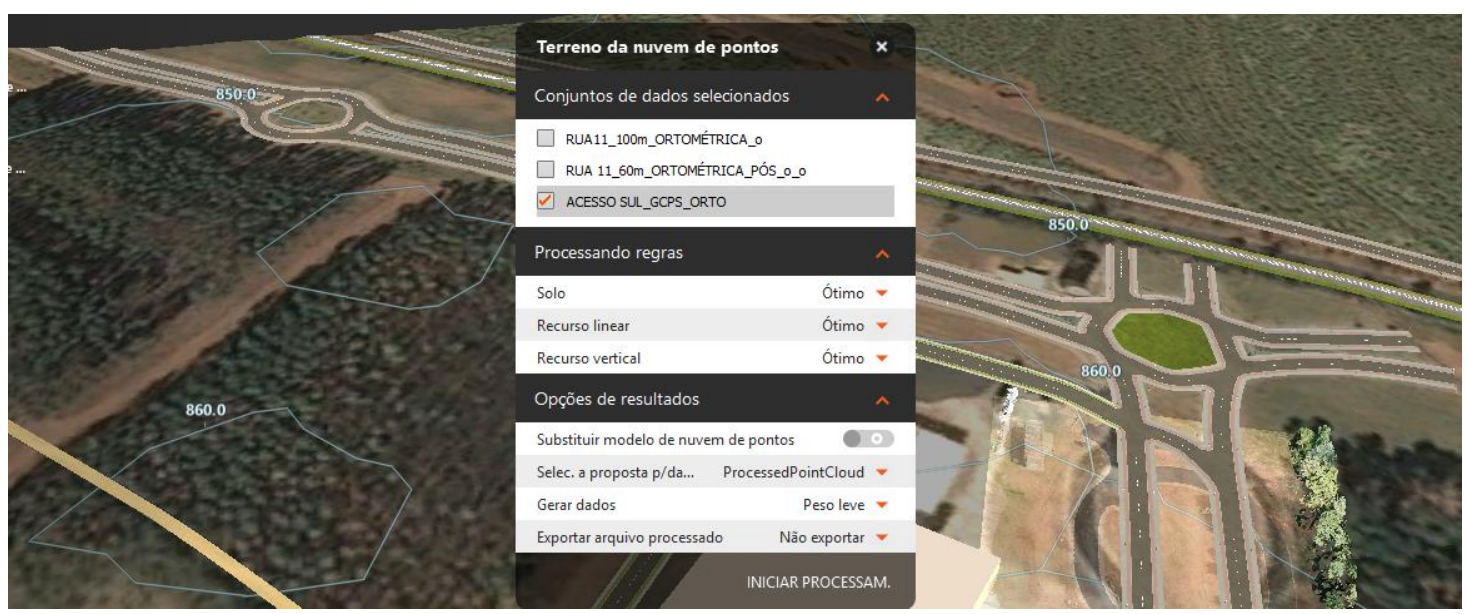

Fonte: Autor (2019).

Porém, as superfícies adjacentes às remodeladas mantiveram as características do modelo preliminar, resultando em terrenos irreais e com grandes inclinações (Figura 63). Para corrigir tal situação é necessário inserir nuvens de pontos que cubram toda a área e, em seguida, proceder com a modelagem novamente. No entanto, em função da da capacidade computacional disponível para operação do modelo de estudo, as nuvens de ponto foram limitadas as áreas de estudo e para as proximidades foram adotadas ferramentas manuais de terraplenagem para fazer concordâncias entre superfícies e diminuir as discrepâncias visuais do entorno às regiões de interesse. 
Figura 63 - Modelagem de terreno a partir da nuvem de pontos e adjacências

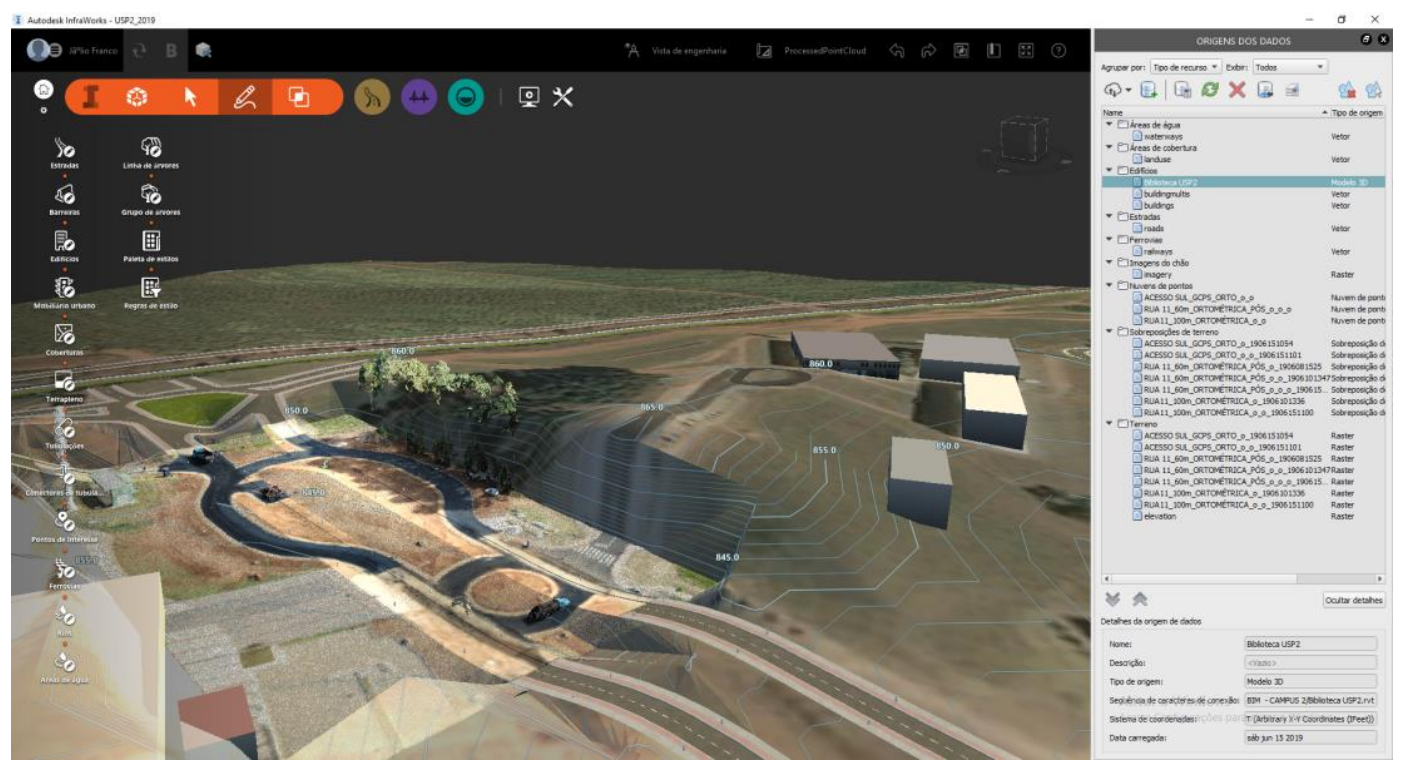

Fonte: Autor (2019).

Foram modeladas volumetrias de edificações existentes com ferramentas presentes no próprio software. Embora o grau de detalhamento seja baixo, a modelagem de volumes simples auxiliou a identificar construções e pontos de interesse, os quais podem ser detalhados e integrados em modelos futuros.

Para auxiliar nesse processo, foi inserido no modelo o arquivo (CAD) com informações da implantação do Campus e das obras da Rua 11 e Acesso Sul. Além disso, os pontos de controle (GCP) também foram indicados no modelo utilizando marcadores 3D, alimentados com as informações das coordenadas correspondentes. Na Figura 64, o marcador azul indica a posição de um GCP e as linhas coloridas na superfície das vias indicam o projeto geométrico contido no arquivo CAD inserido. 


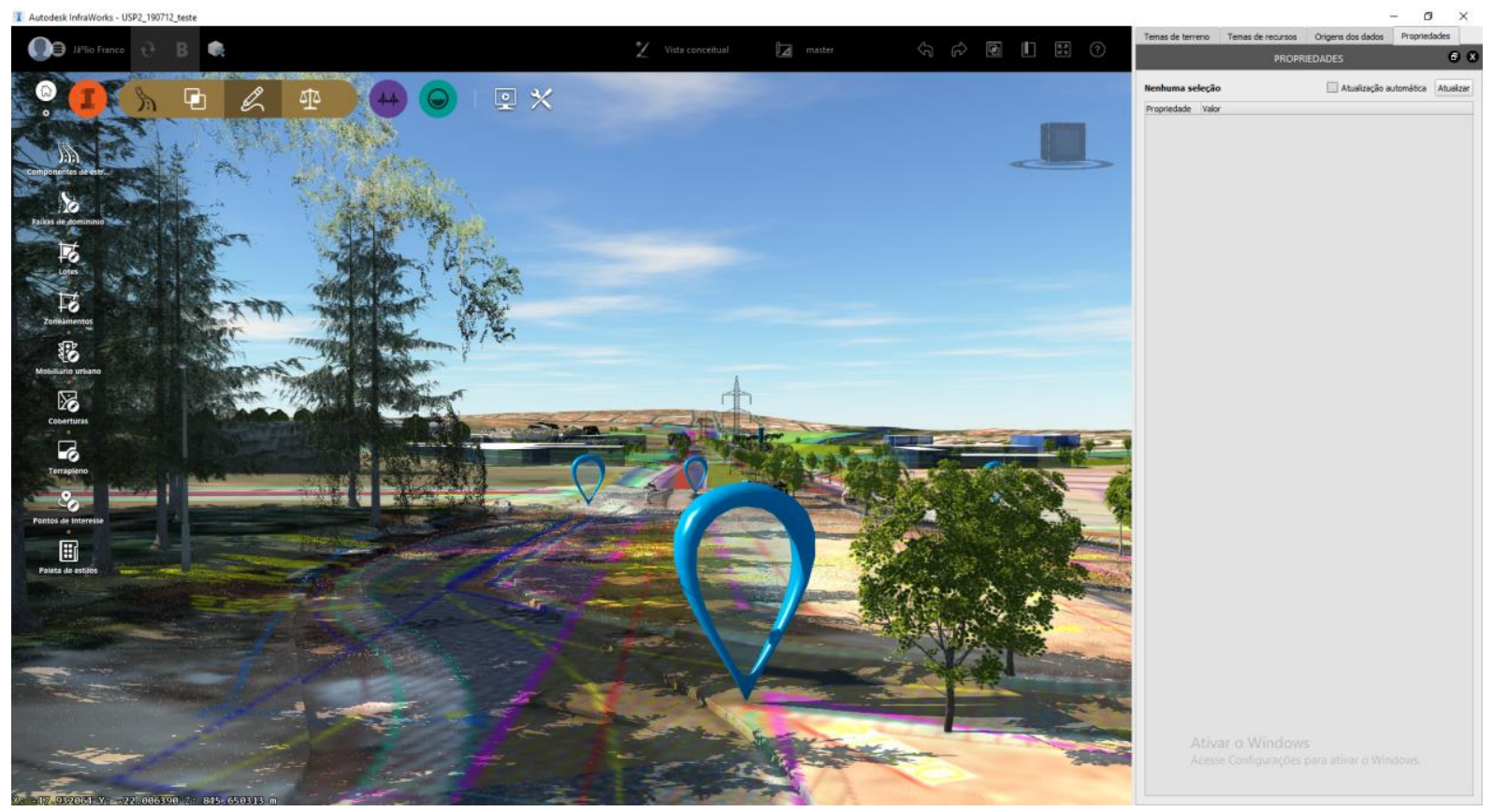

Fonte: Autor (2019).

\subsubsection{MODELAGEM DE VIAS}

As vias foram modeladas a partir das nuvens de ponto inseridas no modelo. Das nuvens de pontos, foram gerados modelos digitais do terreno de toda a área coberta utilizando a ferramenta do InfraWorks "modelagem de terreno a partir de nuvem de pontos". A partir do DSM gerado foram criados os arruamentos da área definindo traçados principais e curvas horizontais de vias com as ferramentas do próprio software.

As famílias de componentes utilizados na modelagem são advindas do Country Kit Brazil disponibilizado pela Autodesk e permitiram a adição e ajustes de larguras de faixas, sarjetas e elementos do entorno. Tais edições foram fundamentais para a adequação dos elementos disponíveis às características do objeto desse estudo. A Figura 65 ilustra a modelagem de curvas horizontais das vias do Campus. 
Figura 65 - Modelagem preliminar do traçado de curvas horizontais do acesso sul

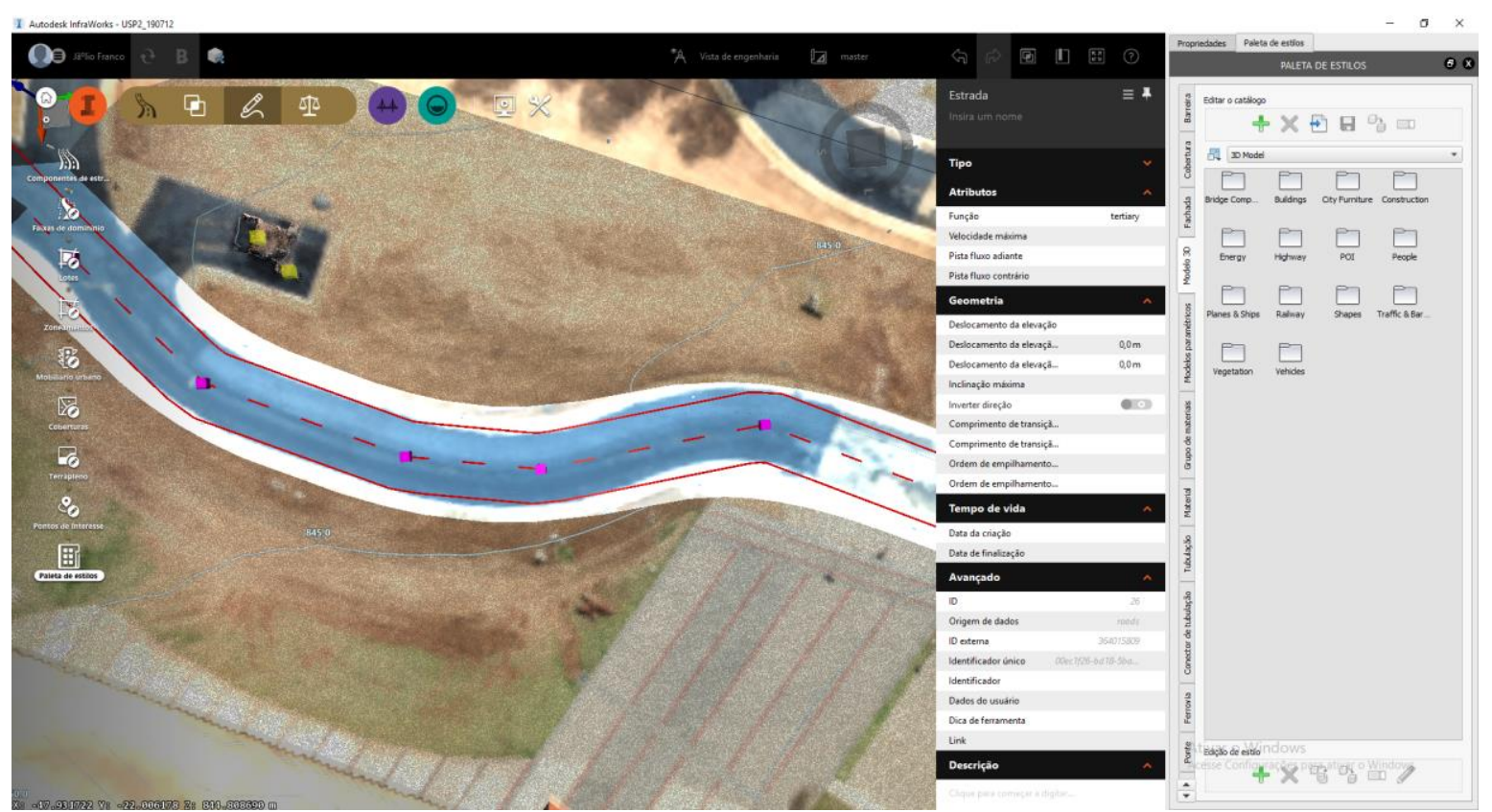

Fonte: Autor (2019).

Em seguida foram modeladas as curvas verticais de cada via através da criação e ajustes de cotas verticais de pontos de curvatura, também seguindo as superfícies geométricas decorrentes das nuvens de pontos. A Figura 66 apresenta uma das vias do acesso sul e a vista do perfil longitudinal durante a modelagem de curvas verticais. 
Figura 66 - Perspectiva do modelo do acesso sul
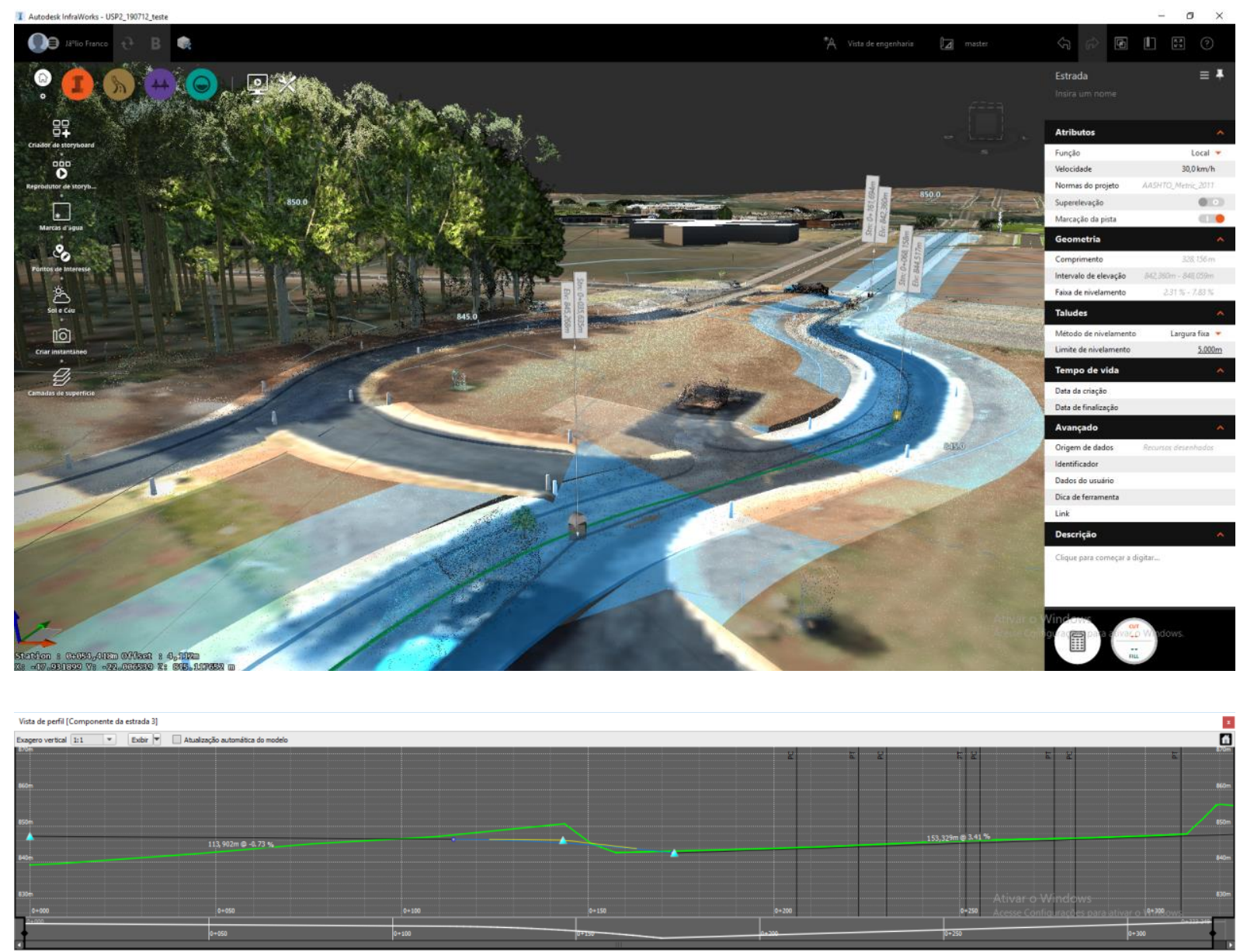

Fonte: Autor (2019)

Na Figura 67 são apresentados os resultados da modelagem de uma das vias do acesso sul. As etiquetas verticais em perspectiva na via apresentam informações do estaqueamento ao longo da via. Em destaque azulado, mostra-se o elemento selecionado do modelo e as adjacências do terreno. 
Figura 67 - Via do acesso sul modelada

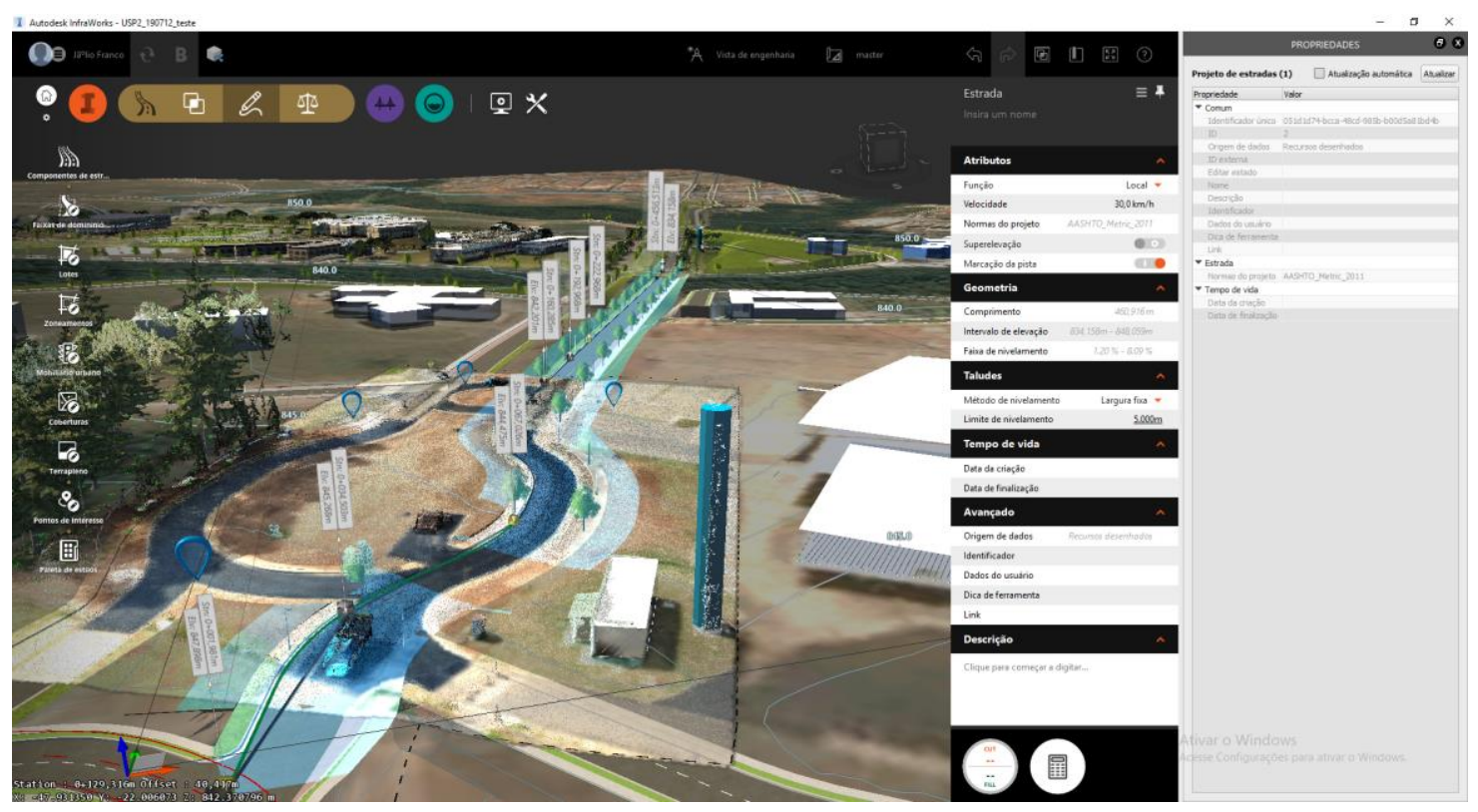

Fonte: Autor (2019).

Na rua 11 também foram aplicados os mesmos procedimentos e o resultado obtido é sintetizado na Figura 68.

Figura 68 - Vista em perspectiva da modelagem da Rua 11
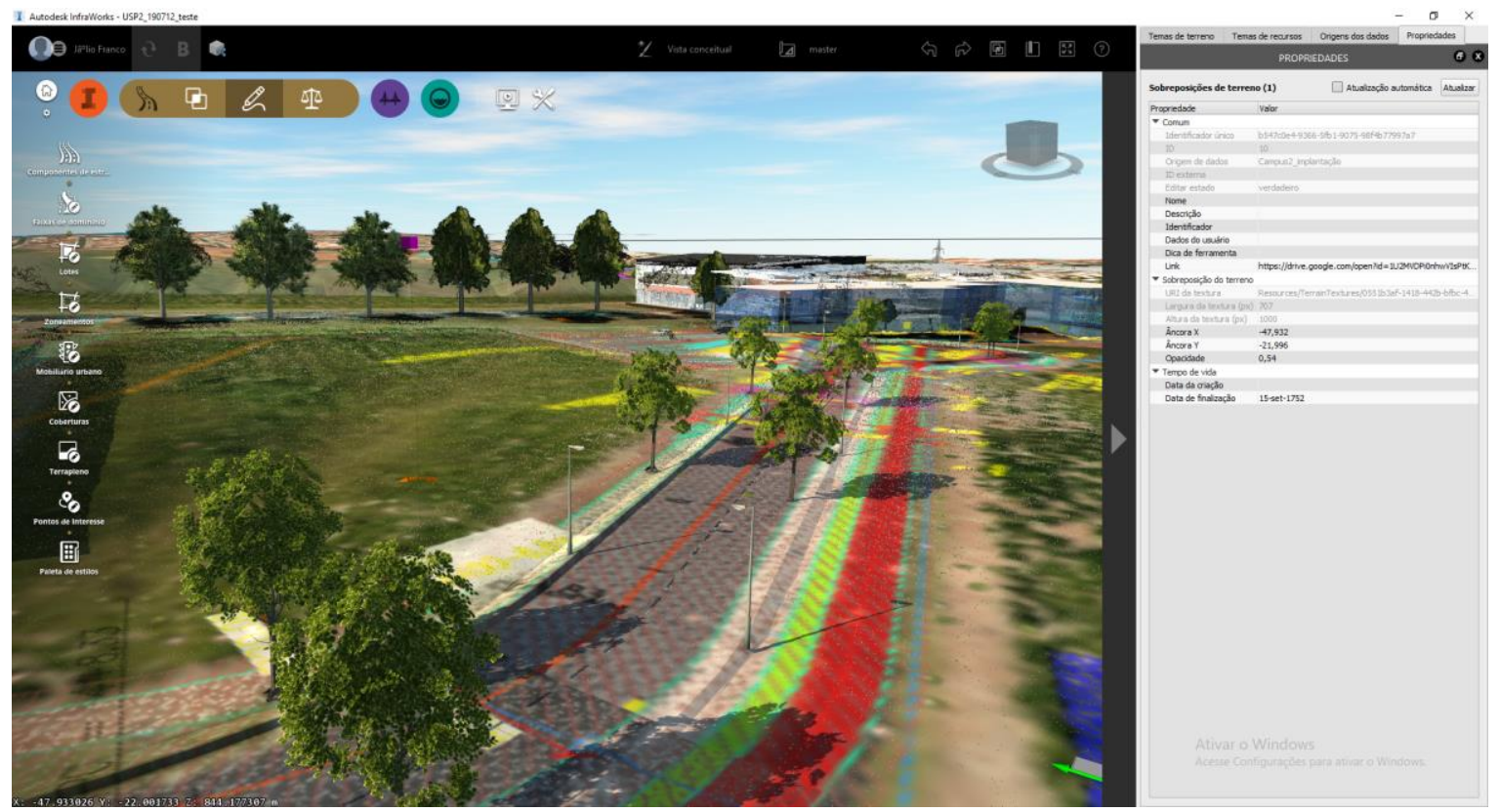

Fonte: Autor (2019). 
Por fim, apresenta-se na Figura 69 uma vista em perspectiva das vias modeladas do Campus.

Figura 69 - Vista geral da modelagem de vias do Campus 2 da USP

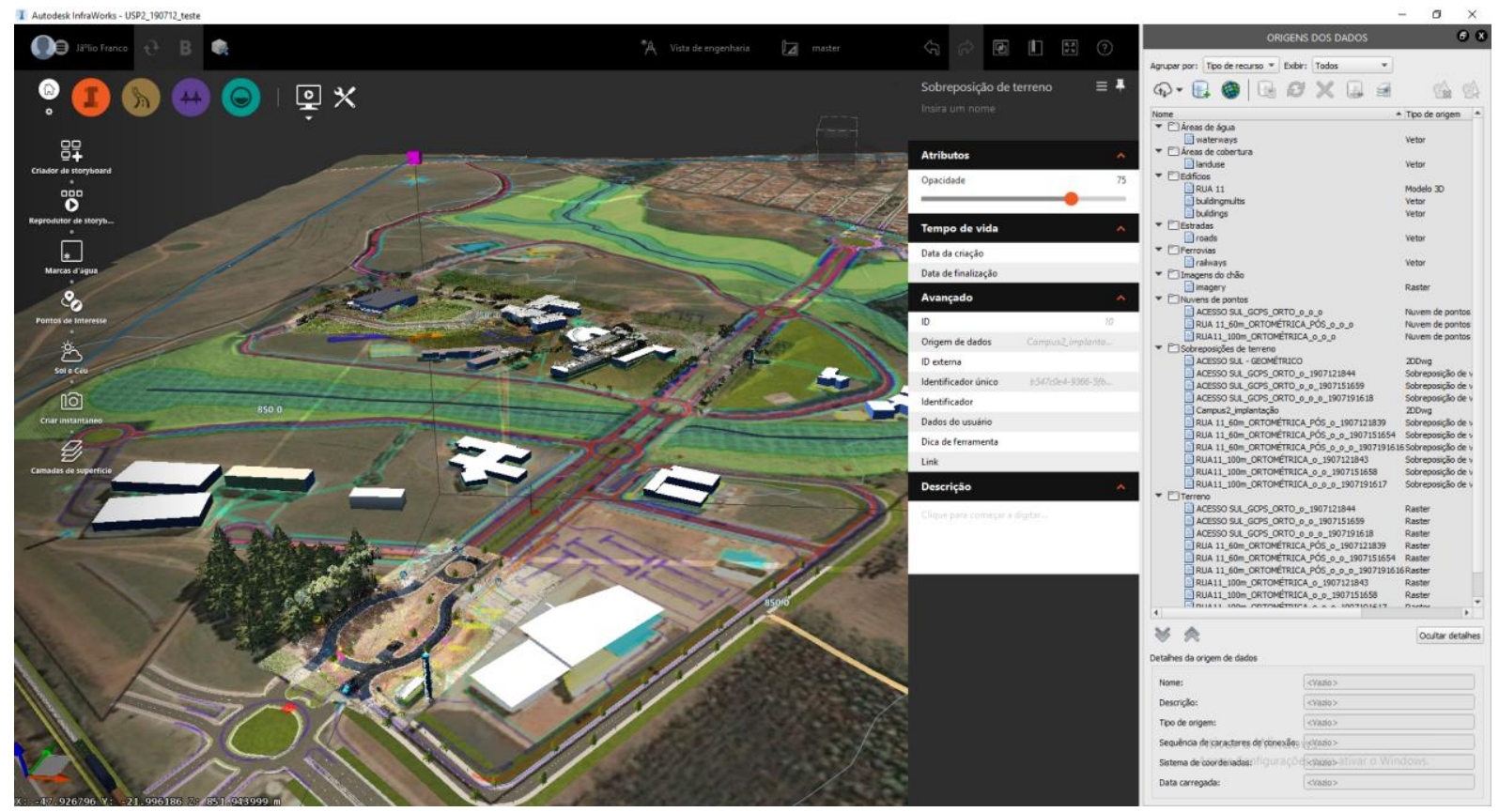

Fonte: Autor (2019).

\subsubsection{MODELAGEM DO ENTORNO}

Como pode ser visto nas figuras anteriores, as vias foram modeladas com elementos do seu entorno como calçadas, postes e árvores. Tais elementos foram inseridos no modelo utilizando biblioteca de famílias existente e incorporando de forma paramétrica às vias. No caso das árvores, a altura dos indivíduos foi ajustada de acordo com os respectivos pontos perceptíveis mais altos presentes na nuvem. Modelos indicativos das torres de energia, calçadas e sinalização viária também foram inseridos. Na Figura 70, exemplifica-se tais componentes a partir de uma vista da avenida central do Campus na região do setor 2 . 

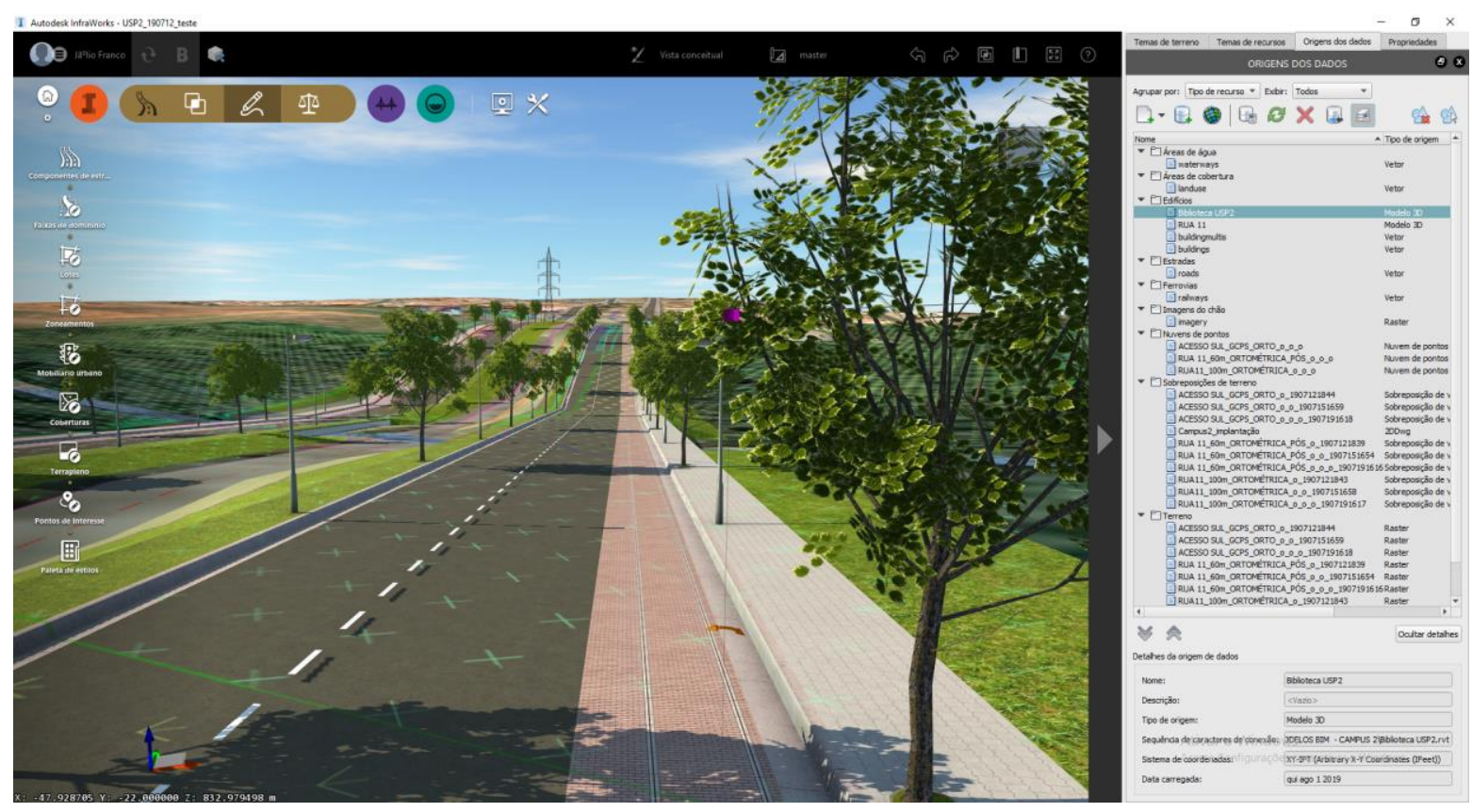

Fonte: Autor (2019).

\subsubsection{IMPORTAÇÃO DE MODELOS BIM EXISTENTES}

O modelo BIM de arquitetura da Biblioteca do Campus desenvolvido por Oliveira e Fabrício (2018) via Autodesk Revit foi inserido no desenvolvimento do modelo em questão. Esse modelo contempla os projetos de arquitetura da primeira fase de construção da biblioteca e foi sobreposto à nuvem de pontos na localização correspondente, conforme exposto na Figura 71. Na mesma figura, podem ser notados pontos brancos à esquerda do modelo inserido, referentes à segunda fase de construção da Biblioteca não contemplada no modelo BIM de arquitetura. 
Figura 71 - Modelo de arquitetura da Biblioteca
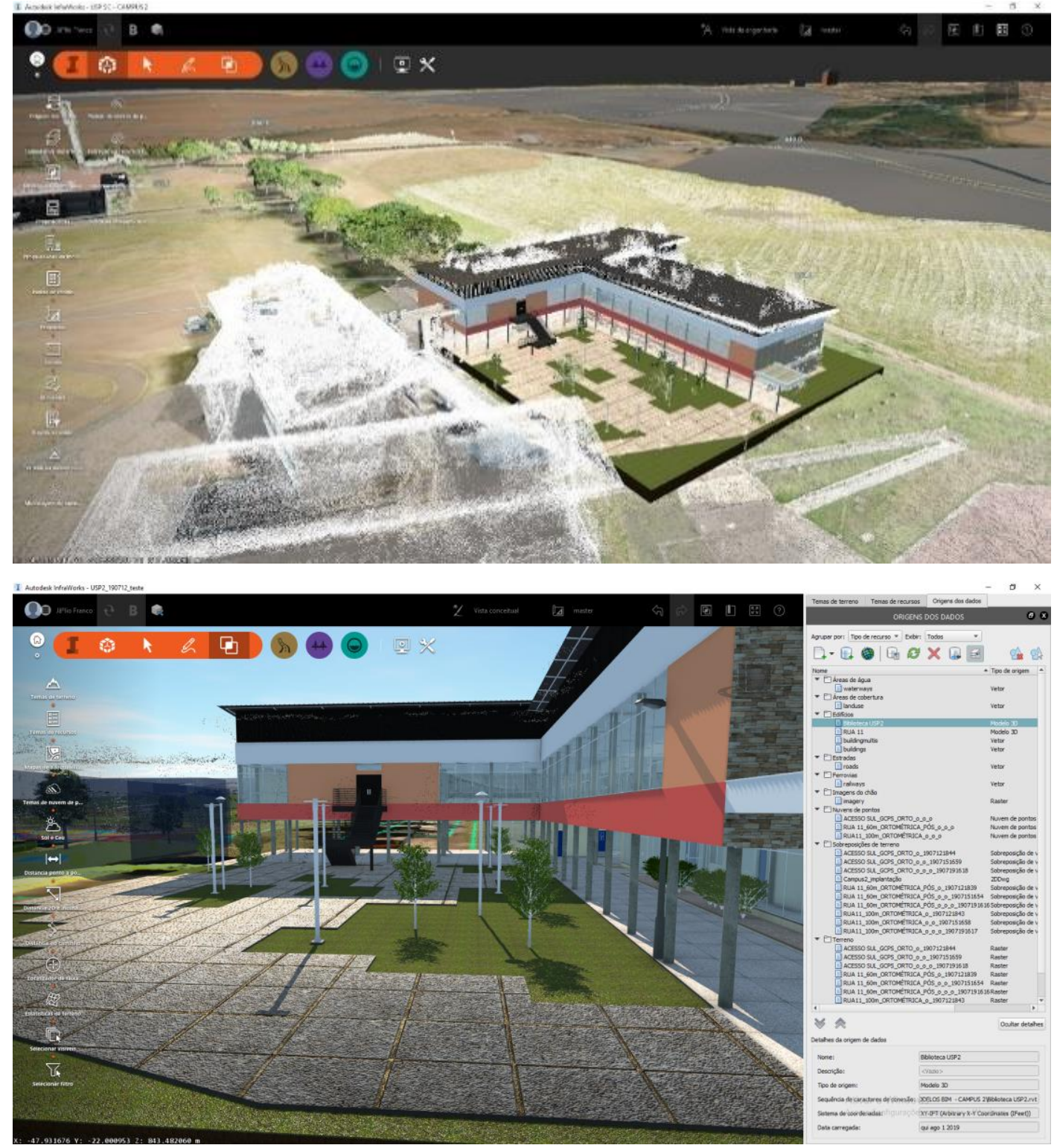

Fonte: Autor (2019).

Por fim, o modelo elaborado conjuga as nuvens de pontos dos levantamentos realizados na Rua 11, Acesso Sul e Setor 2 (parcial), com vias modeladas e superfície do terreno modeladas, arquivo CAD de implantação das obras e demais vias do Campus e o modelo BIM de arquitetura da Biblioteca. Na Figura 72 é apresentada uma vista com o modelo desenvolvido em perspectiva. 


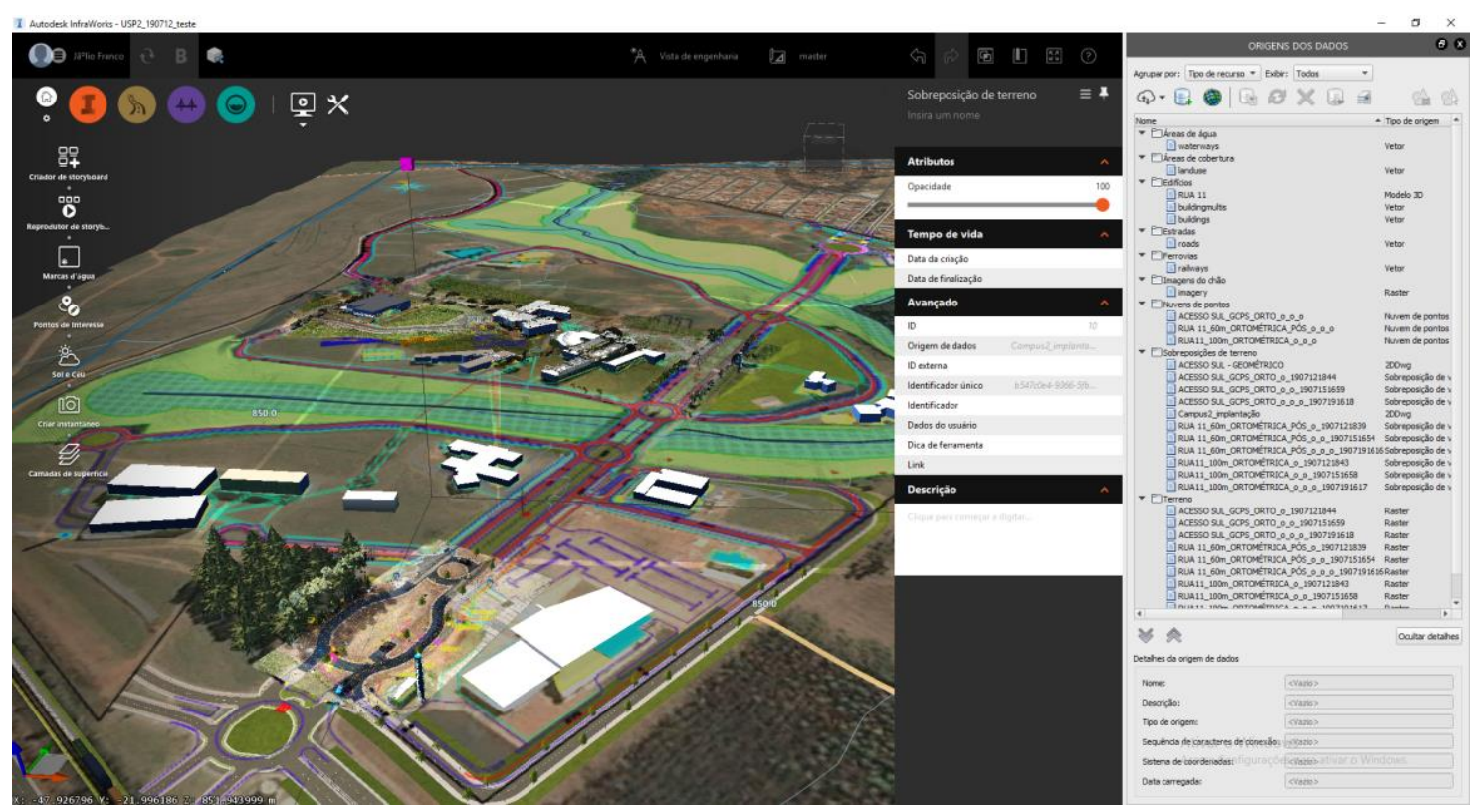

Fonte: Autor (2019).

\subsubsection{ANÁLISE DE RESULTADOS | FASE 4}

Os produtos importados obtiveram boa operabilidade, mas foi necessário restringir a área de estudo para isso. Como os produtos fotogramétricos foram georreferenciados, o posicionamento das nuvens se deu de forma facilitada e automática, o que possibilitou que levantamentos de grandes áreas fossem realizados e processados independentemente e depois inseridos um a um no modelo. Para malhas urbanas isso possibilita planejar diferentes levantamentos, segmentando áreas em função da autonomia da aeronave com confiabilidade na orientação geográfica de tais partições. Os segmentos podem ainda ser substituídos, atualizados e comparados para monitoramento e análises periódicas de modificações.

A dificuldade de modelagem de superfícies viárias por métodos tradicionais é superada frente a alta resolução de pontos obtida, o que permite registros e modelos de documentação mais precisos e com agilidade para cobrir grandes áreas (vide Fase 3). No entanto, fachadas de edifícios, ambientes internos, superfícies reflexivas ou vítreas e elementos fora da visada de captura necessitam 
de outros métodos de levantamento. No caso de fachadas, podem ser realizados levantamentos aéreos com rotas verticais de voo. Fotogrametria terrestre e escaneamento a laser também são métodos aplicáveis aos demais, sendo que os produtos obtidos por tais técnicas também podem ser integrados ao modelo desenvolvido.

A modelagem BIM a partir de modelos fotogramétricos ocorreu de forma ágil dessa maneira, principalmente pela modelagem de superfícies e identificação automática da localização de elementos verticais como árvores e placas. No entanto, todos os elementos precisaram de correções manuais, e famílias de elementos específicos podem ser desenvolvidas e mais bem customizadas.

A modelagem requer ferramentas mais robustas para que os elementos sejam melhor detalhados. Por exemplo, a edição de famílias é extremamente limitada no InfraWorks e depende de softwares adicionais, rotinas de programação ou a disponibilização pelo próprio fabricante. Tais tipos de restrições engessam os processos de modelagem e dificultam a utilização de softwares BIM no setor de infraestrutura, justamente por estes demostrarem imaturidade.

Quanto aos modelos BIM de edificações importados, as informações de parâmetros de família, folhas e vistas de impressão e demais parâmetros não são importados, e sim, somente a representação 3D do modelo é incorporada. Embora isso implique em não carregar todas as informações em um mesmo ambiente digital, otimiza a operabilidade dando mais leveza ao modelo e, em contrapartida, as atualizações se dão de forma automática no arquivo central, na ocorrência de edições nos arquivos conectados. Tais características auxiliam a manutenção do cadastro atualizado de documentos projetuais de ativos urbanos, criando interfaces entre diferentes arquivos de projeto e modelos digitais como um instrumento facilitador para associação de informações outrora desconexas. 
Um vídeo de apresentação do modelo BIM desenvolvido está armazenado para livre acesso no endereço web a seguir.

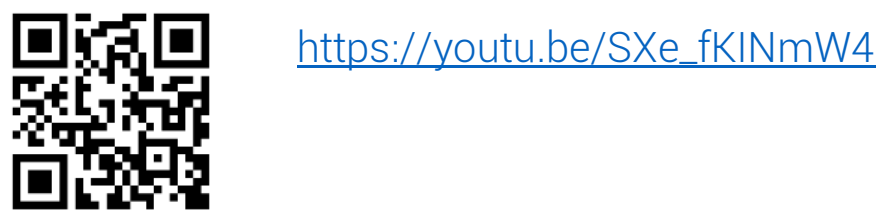

O modelo desenvolvido tem potencial para incorporação de documentações de outras edificações, servindo de base integrada de projetos do Campus. Além disso, possibilita a integração com sistemas de informações geográficas, como o ArcGis, nos quais outros dados urbanos podem ser convergidos e sobrepostos futuramente.

Em termos de documentação do Campus, o modelo desenvolvido permite que os gestores tenham acesso de forma mais ágil às informações do Campus para ações de manutenção. Isso permite que tomadas de decisão sejam mais bem embasadas, uma vez que o acesso à documentação é facilitado e lacunas decorrentes do espalhamento de informações podem ser minimizadas. Em outras palavras, os levantamentos aéreos realizados, as nuvens de ponto geradas e o modelo BIM constituem um as-is da implantação do Campus, permitindo que medições sejam aferidas para estudos técnicos preliminares por meios digitais, sem a necessidade estrita de novos levantamentos de campo.

Como mencionado, o modelo gerado tem potencial para ser utilizado em estudos preliminares de obras de novos projetos, permitindo o uso de ferramentas de modelagem ágeis para simulações de movimentação de terra e análises topográficas. Outro potencial visto está na geração de materiais de comunicação interna para apresentação e contextualização de intervenções, possibilitando melhor entendimento de intervenções e manutenções para leigos, promovendo o engajamento de agentes envolvidos.

Nas fases de uso e operação, o modelo tem potencial para ser utilizado na incorporação de documentação técnica de modernizações, informações relativas ao planejamento de manutenções prediais preventivas e corretivas através da utilização de parâmetros semânticos adicionais. 
Além disso, como replica virtual do Campus - ou digital twin -, o modelo pode servir de base digital para potenciais aplicações de conceitos de loT (Internet of Things), como sensores e tecnologias automatizadas para identificação de não conformidades, gestão inteligente de ativos, dispositivos de medição etc. Nesse sentido, os conceitos de loT e smartcities requerem bases de informações estruturadas para que possam ser aplicadas, e modelos BIM georreferenciados são potenciais meios para tal. 
O trabalho teve como objetivo principal estudar a geração de modelos fotogramétricos a partir de imagens áreas capturadas com RPAS para elaboração de modelos BIM de documentação. Tal propósito tem em vista a falta de informações estruturadas, dados obsoletos, incompatíveis e dispersos que provocam problemas de gestão da informação para a manutenção de infraestrutura existente. Além disso, há perda de informações sistemáticas ao longo do ciclo de vida dos ativos pelos processos em uso atualmente, o que pode gerar problemas operacionais ou, no mínimo, a necessidade de sempre se redescobrir parcialmente informações projetuais a cada nova intervenção.

Nesse cenário, a hipótese de otimizar processos de documentação com o uso integrado de técnicas de levantamento aéreo e modelagem BIM se demonstra válida para que melhores bases de dados de sistemas de infraestrutura sejam estabelecidas e que o levantamento de construções existentes seja abrangente e viável. Desse modo, o objetivo principal do trabalho é alcançado com a utilização dos métodos empregados, os quais possibilitaram a realização de levantamentos expeditos e demonstraram resultados consistentes para a digitalização de espaços urbanos e consequente sua melhor documentação.

A hipótese de que a modelagem BIM serve de base de informações estruturada é provada com a convergência de dados de múltiplas fontes com recursos paramétricos, o que permite gerar análises integradas para novas intervenções a partir dos resultados gerados, as quais seriam impossíveis com técnicas baseadas apenas em CAD.

Nesse aspecto, o dinamismo contemporâneo impulsionador de modificações funcionais de espaços urbanos reforça o risco de falhas na gestão de informações gerarem falhas operacionais. Justamente por isso, a utilização de modelos BIM para sistemas de infraestrutura pode ser peça fundamental para estruturar informações digitais existentes, dispondo-as de forma mais segura. O uso de BIM em infraestrutura tem potencial de impactar a forma como lidamos com alterações de uso ao longo do ciclo de vida de ativos, possibilitando simular o impacto de reconfigurações urbanas nos sistemas de infraestrutura correspondentes. 
Com relação ao primeiro objetivo específico dessa pesquisa, que foi aplicar métodos de levantamento aéreo estudando princípios e práticas de fotogrametria aérea para geração modelos digitais, observa-se que os resultados possibilitaram cobrir tópicos fundamentais ao contexto de infraestrutura urbana, uma vez que o emprego de RPAS tem-se viabilizado cada vez mais e abre novas oportunidades de uso, em especial, como um instrumento ágil de captura de dados geoespaciais para desenvolvimento de projetos urbanos.

O aprofundamento nos estudos das técnicas de levantamento, processamento e modelagem foi, é e será fundamental para adequada definição e afinamento de métodos de digitalização de infraestrutura urbana. É válido ressaltar que o detalhamento das técnicas de levantamento, processamento e modelagem é de grande importância para avaliar os resultados encontrados, de modo a maximizar as potencialidades dos equipamentos disponíveis, minimizar falhas e possibilitar resultados mais acurados.

Assim, a pesquisa se concentrou em revisar temas relevantes à área de estudo sob a visão particular e aplicada ao setor de AECO, o que se desdobrou teoricamente em fundamentar técnicas de levantamento aéreo e processamento digital e, praticamente, em preparar uma base de dados para estudos de documentação digital de infraestrutura urbana.

Quanto aos equipamentos utilizados, documentam-se problemas de interferência magnética nos levantamentos, supostamente em função das linhas de alta tensão que atravessam o Campus, a sensibilidade da aeronave a campos eletromagnéticos e/ou a defeitos na calibração dos seus sensores. Os problemas mais leves implicaram em dificuldades de configuração para início de voos, e os mais graves em panes do equipamento e necessidade de abortar o voo usando os procedimentos de segurança recomendados pelo fabricante.

Quanto a qualidade das imagens, os problemas recorrentes apresentam imagens desfocadas, tremulações e pequenas ondas em gravações de vídeo, possivelmente relacionados a vibrações dos motores durante o voo, problemas na absorção e estabilização de turbulências decorrentes do vento. No entanto, ressalta-se que as tais falhas não causaram nenhum acidente ou quaisquer 
danos, tanto ao patrimônio como a indivíduos. As falhas implicaram apenas em retrabalhos e necessidade de aprimoramento de técnicas empregadas.

Mesmo assim, a estabilidade da câmera se mostrou satisfatória tanto para fotografias quanto para registros de vídeo, o que atestou seu uso para fins de inspeções, documentação e monitoramento de áreas de difícil acesso. No caso de voos automáticos de mapeamento, atenta-se para a necessidade básica de utilizar métodos suplementares de georreferenciamento, o que pode ser feito por GCP ou sistemas RTK/PPK.

No que diz respeito ao segundo objetivo dessa pesquisa, a saber, aplicar ferramentas BIM para Infraestrutura estudando fundamentos teóricos e práticos de modelagem para integração com produtos de levantamentos aéreos, observamos que a integração de produtos se mostrou viável com a utilização do Autodesk InfraWorks, sendo possível o manuseio de nuvens de pontos, documentos CAD e modelos BIM de forma simplificada e ágil.

Para futuros trabalhos, tanto as nuvens de ponto quanto os modelos desenvolvidos devem ser georreferenciados corretamente, caso contrário o modelo não servirá de apoio tecnológico confiável de documentação. Desse modo, os produtos devem ser locados de forma acurada e georreferenciada para que o modelo final esteja coerente com o real e que suas partes estejam coesas. Pela mesma razão, as imagens de satélites e o relevo predisposto no InfraWorks devem ser aferidos e corrigidos de acordo com levantamentos topográficos de precisão que balizem a integração de todos os dados geoespaciais.

Ressalva-se que a integração dos produtos ainda é restrita a trocas superficiais de dados e análises preliminares de compatibilização de disciplinas. A análise de resultados dessa pesquisa aponta que há limitações significativas do emprego de BIM em infraestrutura em comparação com o que já é realizado em edificações. As limitações no InfraWorks incluem ferramentas de modelagem com recursos restritos de edição e instabilidades de processamento. O software por si só não tem recursos suficientes para modelagem com alto nível de detalhamento, sendo necessário, o desenvolvimento de outros modelos em softwares adicionais para, então, serem inseridos na base de dados. 
Complementarmente, é necessário estabelecer um plano de implantação BIM condizente com os processos locais de desenvolvimento de infraestrutura e compreender melhor as demandas que esse nicho requer, visto que são diferentes das abordagens atuais focadas em BIM para edificações.

Nesse sentido, Hijazi e Omar (2017) apontam que o primeiro passo é analisar os processos existentes, de forma a reconhecer o que acontece nos modos tradicionais de projetos de infraestrutura, seus critérios normativos e desafios. E, mais que protocolos de troca de informações, estabelecer planos de implementação BIM com diretriz, em nível de matriz, acerca das responsabilidades e deveres de todos os agentes.

Fica claro que as discussões do emprego de BIM em infraestrutura estão em um estágio anterior ao que vemos em edificações, supostamente pela adoção mais lenta do que no setor de edificações, embora haja exemplos bem-sucedidos do desenvolvimento de projetos de infraestrutura com a utilização de BIM (CHENG; LU e DENG, 2016; GOONETILLAKE; LARK e LI, 2018; SUCHOCKI, 2015).

Quando Hijazi e Omar (2017) compartilham estatísticas da distribuição temática de pesquisas de BIM para infraestrutura, eles revelam que parte significava dos trabalhos cobrem áreas únicas, enquanto os desafios podem estar centrados na integração de modelos de infraestrutura e edificações. Indicam também que os estudos focam na interface de modelos BIM, SIG e CityGml, contudo, uma abordagem mais focada no desenvolvimento de uma plataforma BIM única (de edificações e infraestrutura) poderia ser mais bem-sucedida em atender requisitos de ambos os nichos.

Adicionalmente, seu emprego depende não somente de condições tecnológicas (ferramentas disponíveis, por exemplo), mas também do desenvolvimento de um arcabouço de apoio ao emprego de BIM em infraestrutura urbana, vislumbrando toda cadeia de desenvolvimento associada.

Quanto ao uso futuro do modelo desenvolvido, a incorporação de novas informações e de outras disciplinas deve acontecer de forma sistemática para que se mantenha a fidelidade do modelo ao longo do tempo. Nesse sentido, há de se considerar que o trabalho em questão não abrangeu todas as disciplinas 
existentes nem incorporou toda a biblioteca de documentos do Campus por (i) capacidade produtiva limitada da equipe de pesquisa, (ii) necessidade de recursos computacionais adicionais e (iii) necessidade de mapeamento de demais processos organizacionais da gestão de ativos.

Assim, o trabalho não contemplou estudos organizacionais e processos "não técnicos" existentes, que também têm influência na gestão da informação de ativos. Porém, é sabida e ressaltada a importância dos mesmos para um melhor conhecimento acerca dos problemas no desenvolvimento de projetos de infraestrutura e como BIM pode ser incorporado nos processos existentes, e/ou alterá-los.

Outro limite desse trabalho diz respeito à condução de pesquisas essencialmente de cunho técnico, o que por si só não é suficiente para resolver os inúmeros problemas relacionados à infraestrutura urbana que nos assolam. Estudos em esferas sociais, econômicas e políticas são essenciais para melhor compreensão das dimensões que projetos de infraestrutura impactam e quais abordagens são mais cabíveis e mais bem arquitetadas. Nesse ponto, ressalta-se a natureza limitada em que BIM não é e não será uma panaceia capaz de resolver todas as nossas mazelas.

Em se tratando de ferramentas utilizadas nesse trabalho, ressalta-se que os softwares utilizados se limitaram aos apresentados no capítulo de métodos embora haja outras soluções de mercado. Nesse aspecto, uma análise comparativa com soluções de outros fabricantes não fez parte do escopo da pesquisa, mas vê-se como oportunidade para futuros trabalhos. Quanto aos levantamentos aéreos, empregou-se uma aeronave de relativo baixo custo e de amplo uso comercial. Isso, por um lado, ancora a pesquisa em ferramentas com forte apelo popular entre profissionais do setor, por outro, posiciona-a como primeiro passo para a utilização de equipamentos mais robustos no futuro em termos de qualidade de imagem, amplitude do espectro capturado e acurácia no geoposicionamento.

Assim, uma contribuição direta da pesquisa está em apresentar meios de integração entre tecnologias sem conexão clara de uso. Por parte de modelagem BIM, o emprego em infraestrutura urbana é recente, emergente e vislumbra atacar 
problemas de gestão de informação cuja amplitude é tal qual a magnitude dos projetos de infraestrutura, em outras palavras, BIM é oportunidade potencial de melhoria para o setor. Por parte de levantamentos aéreos com RPA, o emprego em infraestrutura urbana é essencial para viabilizar levantamentos de forma ágil e gerar dados de modelagem BIM para documentação. Assim, a pesquisa contribui para clarificar, de modo prático, o uso de aerofotogrametria e BIM para documentação de apoio à gestão de infraestrutura urbana.

Por fim, atenta-se que uma melhor gestão de informações possibilita a diminuição de erros (ou aumento de acertos) em projetos, construção e manutenção de infraestrutura urbana. Principalmente porque o dinamismo contemporâneo de espaços urbanos demanda agilidade assertiva em manutenções, reconfigurações funcionais e novas intervenções. Nesse cenário, são fundamentais abordagens interdisciplinares que considerem inclusive o emprego de novas tecnologias 4.0 (IOT, dispositivos inteligentes, inteligência artificial, machine learning, etc.). Para tanto, é inevitável o desenvolvimento de bases estruturadas de informação de sistemas de infraestrutura por meios de ferramentas de digitalização e integração de múltiplos dados, o que faz de BIM uma alavanca e instrumento facilitador da eficiência, flexibilidade e escalabilidade em sistemas de infraestrutura urbana. 


\section{REFERÊNCIAS BIBLIOGRÁFICAS}

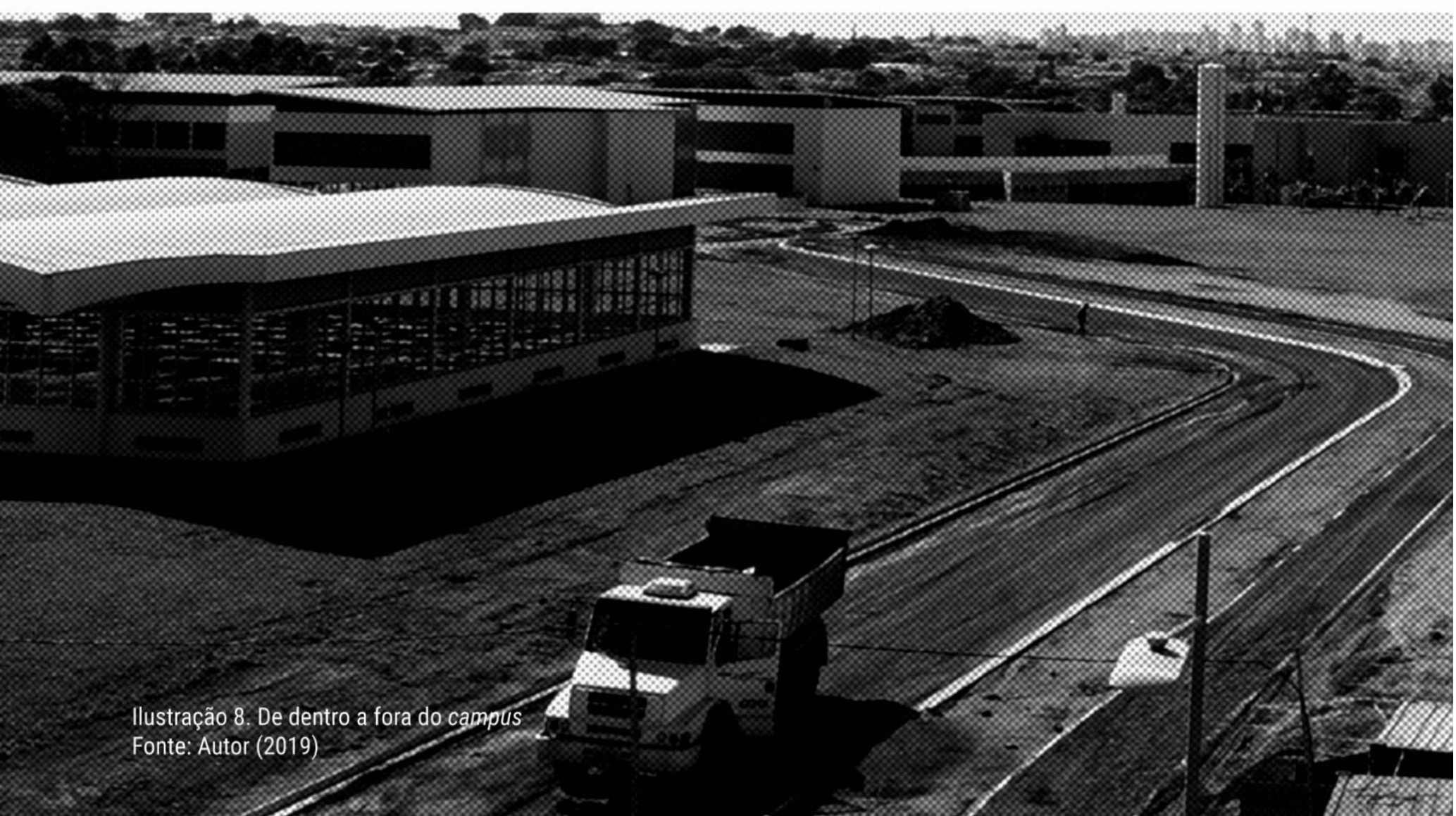


AGISOFT PHOTOSCAN. Manual do usuário. 2018.

Associação Brasileira de Normas Técnicas. NBR 10502 Informação e documentação - citações em documentação - Apresentação. Brasil, 2002.

Associação Brasileira de Normas Técnicas. NBR 6023 - Informação e documentação - Referências - Elaboração. Brasil, 2002.

ABDI. Guia 1: Processo de projeto BIM. Vol. 1. ed. Brasília, DF: Agência Brasileira de Desenvolvimento Industrial, 2017.

ABER, J. S.; MARZOLFF, I.; RIES, J. B. Platforms for Small-Format Aerial Photography. Small-Format Aerial Photography, p. 91-118, 2010a.

SFAP Survey Planning and Implementation. Small-Format Aerial Photography, n. 1958, p. 119-137, 2010b.

Basic Principles of Small-Format Aerial Photography. Small-Format Aerial Photography, p. 15-22, 2010c.

AGISOFT. Agisoft PhotoScan Features. Disponível em: https://www.agisoft.com/features/professional-edition/>. Acesso em: 10 ago. 2019.

AJAYI, O. G.; PALMER, M.; SALUBI, A. A. Modelling farmland topography for suitable site selection of dam construction using unmanned aerial vehicle (UAV) photogrammetry. Remote Sensing Applications: Society and Environment, v. 11, n. June, p. 220-230, 2018.

ALMEIDA, F.; ANDRADE, M. A integração entre BIM e GIS como ferramenta de gestão urbana. In: ENCONTRO BRASILEIRO DE TECNOLOGIA DE INFORMAÇÃO E COMUNICAÇÃO NA CONSTRUÇÃO, 7., 2015, Recife. Anais... Porto Alegre: ANTAC, 2015.

ALTUNTAS, C.; PEHLIVANLI, M. E.; KURBAN, S. Low-Cost 3D Imaging and Measurement Techniques for Documentation of Meram Masonry Arch Bridge in Turkey. International Journal of Sensors and Sensor Networks, v. 5, n. 5, p. 63, 2017.

ÁLVARES, J. S.; COSTA, D. B.; MELO, R. R. S. DE. Exploratory study of using unmanned aerial system imagery for construction site 3D mapping. Construction Innovation, v. 18, n. 3, p. 301-320, 2018.

AMANN, E.; BAER, W.; TREBAT, T.; LORA, J. V. Infrastructure and its role in Brazil's development process. Quarterly Review of Economics and Finance, v. 62, p. $66-73,2016$. 
AMORIM, A. L.. "Cidades Inteligentes e City Information Modeling", p. 481-488 In: XX Congreso de la Sociedad Iberoamericana de Gráfica Digital [=Blucher Design Proceedings, v.3 n. 1]. São Paulo: Blucher, 2016. ISSN 2318-6968, DOI 10.5151/despro-sigradi2016-440

DISCUTINDO CITY INFORMATION MODELING ( CIM ) Arivaldo Leão de Amorim Resumo. VII Encontro de Tecnologia de Informação e Comunicação na Construção - Edificações, Infra-estrutura e Cidade: Do BIM ao CIM, n. Cim, p. 103163, 2015.

ANAC. Orientações para usuários de Drones. p. 1-23, 2017 a.

Licença , Habilitação e Certificado Médico Aeronáutico. Disponível em: http://www.anac.gov.br/assuntos/paginas-tematicas/drones/licencahabilitacao-e-certificado-medico-aeronautico. Acesso em: 3 fev. 2019b.

Instrução suplementar IS No E94-003. Procedimentos para elaboração e utilização de avaliação de risco operacional para operadores de aeronaves não tripuladas. p. 10, 2017c.

Certificados de Drones. Disponível em:

http://www.anac.gov.br/assuntos/paginas-tematicas/drones/registros-ecertificados-de-drones. Acesso em: 3 abr. 2019.

ASBEA. Estruturação do Escritório de Projeto para a Implantação do BIM. Boas Práticas em BIM - Fascícuo I, 2013.

ASBEA. Fluxo de Projetos em BIM : Planejamento e Execução. Asbea, v. II, 2015.

AUTODESK. InfraWorks Overview. Disponível em:

https://www.autodesk.com/products/infraworks/overview. Acesso em: 20 jul. 2019a.

Recap Features. Disponível em:

https://www.autodesk.com/products/recap/features. Acesso em: 20 jul. 2019b.

Civil 3D Features. Disponível em: https://www.autodesk.com/products/civil3d/features. Acesso em: 21 jul. 2019c.

AZHAR, S. Building Information Modeling (BIM): Trends, Benefits, Risks, and Challenges for the AEC Industry. Leadership and Management in Engineering, $\mathrm{V}$. 11, n. 3, p. 241-252, 2011.

BAIK, A.; YAAGOUBI, R.; BOEHM, J. Integration of Jeddah Historical BIM and 3D GIS for Documentation and Restoration of Historical Monument. ISPRS International Archives of the Photogrammetry, Remote Sensing and Spatial Information Sciences, v. XL-5/W7, n. 5W7, p. 29-34, 2015.

BARAZZETTI, L. Integrated BIM-GIS model generation at the city scale using geospatial data. v. 1077308, n. August 2018, p. 18, 2018. 
BARBASIEWICZ, A.; WIDERSKI, T.; DALIGA, K. The analysis of the accuracy of spatial models using photogrammetric software: Agisoft Photoscan and Pix4D. E3S Web of Conferences, v. 26, p. 1-5, 2018.

BBC. Google Wing launches first home delivery drone service. Disponível em: https://www.bbc.com/news/technology-47880288. Acesso em: 10 abr. 2019.

BEW; RICHARDS. Modelo de Maturidade BIM, 2008.

BSI. PAS 1192-2-2013: Specification for information management for the capital/delivery phase of construction projects using building information modelling. BSI Standards Publication, n. 1, p. 1-68, 2013.

CANUTO, C. L. Modelo BIM e proposta de intervenção do Palácio Gustavo Capanema, Rio de Janeiro-RJ: pela preservação da arquitetura moderna. Rio de Janeiro-RJ: Universidade Federal do Rio de Janeiro, 2017.

CARBONIX. Drones Carbonix. Disponível em: https://carbonix.com.au/drones/. Acesso em: 2 jun. 2019.

CARTER, J. G.; CAVAN, G.; CONNELLY, A.; GUY, S.; HANDLEY, J.; KAZMIERCZAK, A. Climate change and the city: Building capacity for urban adaptation. Progress in Planning, v. 95, p. 1-66, 2015.

CBIC. Colaboração e integração BIM. In: Coletânea Implementação do BIM Para Construtoras e Incorporadoras. Brasília, DF. Volume 3, p. 132, $2016 a$.

_. Fundamentos BIM. In: Coletânea Implementação do BIM Para Construtoras e Incorporadoras. Brasília, DF. Volume 1, p. 124.

CHENG, J. C. P.; LU, Q.; DENG, Y. Analytical review and evaluation of civil information modeling. Automation in Construction, v. 67, p. 31-47, 2016.

CHONG, H. Y.; LOPEZ, R.; WANG, J.; WANG, X.; ZHAO, Z. Comparative Analysis on the Adoption and Use of BIM in Road Infrastructure Projects. Journal of Management in Engineering, v. 32, n. 6, p. 05016021, 2016.

CIRIBINI, A. Level of Detail and Level of Development: Commissioning processes and Information Modelling. TECHNE - Journal of Technology for Architecture and Environment, v. 0, n. 6, p. 90-99, 2013.

CIRIBINI, A. L. C.; MASTROLEMBO VENTURA, S.; PANERONI, M. Implementation of an interoperable process to optimise design and construction phases of a residential building: A BIM Pilot Project. Automation in Construction, v. 71, p. 6273, 2016.

CIVIL, C. Decreto 9.377-Estratégia Nacinal de disseminação de BIM Brasil, 2018. Disponível em: http://www. planalto.gov.br/ccivil_03/_ato20152018/2018/Decreto/D9377.htm 
COHN, P.; GREEN, A.; LANGSTAFF, M.; ROLLER, M. Commercial Drone are Here: The Future of Unmanned Aerial Systems. McKinsey\&Company, p. 1-11, 2017.

COLOMINA, I.; MOLINA, P. Unmanned aerial systems for photogrammetry and remote sensing: A review. ISPRS Journal of Photogrammetry and Remote Sensing, v. 92, p. 79-97, 2014.

COSTA, A. C. (org). BIM e a digitalização da construção e das infraestruturas. Instituto Superior Técnico, COTEC Portugal. 2018.

COSTIN, A.; ADIBFAR, A.; HU, H.; CHEN, S. S. Building Information Modeling (BIM) for transportation infrastructure - Literature review, applications, challenges, and recommendations. Automation in Construction, v. 94, n. June, p. 257-281, 2018.

CRAVEIRO, F.; DUARTE, J. P.; BARTOLO, H.; BARTOLO, P. J. Additive manufacturing as an enabling technology for digital construction: A perspective on Construction 4.0. Automation in Construction, v. 103, n. October 2018, p. $251-267,2019$.

DEBASIS SARKAR. Risk Based Building Information Modeling (BIM) for Urban Infrastructure Transportation Project. World Academy of Science, Engineering and Technology, v. 10, n. 8, p. 1022-1026, 2016.

DECEA. RBAC-E no 94. Regulamento Brasileiro da Aviação Civil Especial. p. 1-26, 2017.

Orientações e Legislação DRONE / RPAS. Disponível em:

www.decea.gov.br/drone. Acesso em: 2 nov. 2018.

DELOITTE. Managing the evolving skies Unmanned aircraft system traffic management (UTM), the key enabler. p. 1-16, 2018.

DERRIBLE, S. Urban infrastructure is not a tree: Integrating and decentralizing urban infrastructure systems. Environment and Planning B-Urban Analytics and City Science, v. 44, n. 3, p. 553-569, 2017.

DJI. Mavic Pro. Disponível em: https://www.dji.com/br/mavic. Acesso em: 2 fev. 2019.

Drone Camera Settings : All you Need to Know Drone Camera Settings Infographic. Disponível em: https://store.dji.com/guides/drone-camera-setting/. Acesso em: 13 maio. 2019a.

7 Camera Setting Mistakes Most Beginners Make. Disponível em: https://store.dji.com/guides/7-camera-setting-mistakes-most-beginnersmake/. Acesso em: 12 ago. 2019b.

DNER. Manual de projeto geometrico de rodovias rurais (706), 1999. 
DONG, L.; WANG, Y.; SCIPIONI, A.; PARK, H. S.; REN, J. Recent progress on innovative urban infrastructures system towards sustainable resource management. Resources, Conservation and Recycling, v. 128, p. 355-359, 2018.

DRONECODE. A visit to the "Drone Valley". Disponível em:

https://www.dronecode.org/a-visit-to-the-drone-valley/. Acesso em: 11 jun. 2019.

DRONEDEPLOY. How Do I Use Ground Control Points ? A guide to using ground control. Disponível em: https://www.dronedeploy.com/blog/what-are-groundcontrol-points-gcps-XDPDuxEAACMAzyeA/. Acesso em: 1 jun. 2019.

DUTT, F.; QUAN, S. J.; WOODWORTH, E.; CASTRO-LACOUTURE, D.; STUART, B. J.; YANG, P. P. J. Modeling algae powered neighborhood through GIS and BIM integration. Energy Procedia, v. 105, p. 3830-3836, 2017.

EASTMAN, C.; TEICHOLZ, P.; SACKS, R.; LISTON, K. BIM handbook: a guide to building information modeling for owners, managers, designers, engineers, and contractors. 2008. ed. Hoboken, New Jersey: John Wiley \& Sons, Inc., 2008.

EISENBEISS, H. UAV Photogrammetry. Zurich, Switzerland: Eidgenössische Technische Hochschule Zürich, 2009.

EL-DIRABY, T. E.; OSMAN, H. A domain ontology for construction concepts in urban infrastructure products. Automation in Construction, v. 20, n. 8, p. 11201132, 2011.

Fabricio, M. (2013). Industrialização das construções: revisão e atualização de conceitos. Pós. Revista Do Programa De Pós-Graduação Em Arquitetura $\mathrm{E}$ Urbanismo Da FAUUSP, 20(33), 228-248. https://doi.org/10.11606/issn.23172762.v20i33p228-248

FANNING, B.; CLEVENGER, C. M.; OZBEK, M. E.; MAHMOUD, H. Implementing BIM on Infrastructure: Comparison of Two Bridge Construction Projects. Practice Periodical on Structural Design and Construction, v. 20, n. 4, p. 04014044, 2014.

FIGUEIREDO, E. O.; FIGUEIREDO, S. M. M. Planos de Voo Semiautônomos para Fotogrametria com Aeronaves Remotamente Pilotadas de Classe 3. Circular Técnica Embrapa. ISSN 0100-9915. 2018.

FLOREANO, D.; WOOD, R. J. Science, technology and the future of small autonomous drones. Nature, v. 521, n. 7553, p. 460-466, 2015.

FREIMUTH, H.; KÖNIG, M. Planning and executing construction inspections with unmanned aerial vehicles. Automation in Construction, v. 96, n. October, p. 540553, 2018.

FRITSCH, D. Virtual cities and landscape models - what has photogrammetry to offer? Virtual Reality, p. 3-14, 1999. 
GAŠPAROVIĆ, M.; SELETKOVIĆ, A.; BERTA, A.; BALENOVIĆ, I. The evaluation of photogrammetry-based DSM from low-cost UAV by LiDAR-based DSM. SouthEast European Forestry, v. 8, n. 2, p. 117-125, 2017.

GERKE, M.; PRZYBILLA, H. J. Accuracy analysis of photogrammetric UAV image blocks: Influence of onboard RTK-GNSS and cross flight patterns.

Photogrammetrie, Fernerkundung, Geoinformation, v. 2016, n. 1, p. 17-30, 2016.

GIS GEOGRAPHY. Multispectral vs Hyperspectral Imagery. Disponível em: $<$ https://gisgeography.com/multispectral-vs-hyperspectral-imageryexplained/>. Acesso em: 10 jul. 2019.

GIUDICE, M. DEL; OSELLO, A. BIM for cultural heritage. In: International Archives of the Photogrammetry, Remote Sensing and Spatial Information Sciences ISPRS Archives. Anais. 2013.

GOONETILLAKE, J.; LARK, R.; LI, H. Advanced Computing Strategies for Engineering. [s.I.] Springer International Publishing, 2018. v. 10864

GRANDL, G.; CACHAY, J.; SALIB, J. The Future of Vertical Mobility Sizing the market for passenger, inspection, and goods services until 2035 A Porsche Consulting study. 2018.

GRIMSEY, D.; LEWIS, M. K. Evaluating the risks of public private partnerships for infrastructure projects. International Journal of Project Management, v. 20, n. 2, p. 107-118, 2002.

GROETELAARS, N. J. Criação de modelos BIM a partir de "nuvens de pontos": estudo de métodos e técnicas para documentação arquitetônica. p. 372, 2015 Tese (doutorado) - Universidade Federal da Bahia, Faculdade de Arquitetura, 2015

HEATON, J.; PARLIKAD, A. K. A conceptual framework for the alignment of infrastructure assets to citizen requirements within a Smart Cities framework. Cities, v. 90, n. January, p. 32-41, 2019.

HIJAZI, A. A.; OMAR, H. A. Level of detail specifications, standards and FileFormat challenges in infrastructure projects for BIM level three. WIT Transactions on the Built Environment, v. 169, p. 143-154, 2017.

HISTORIC ENGLAND. Photogrammetric Applications for Cultural Heritage. Guidance for Good Practice. p. 128, 2017.

HORUS. SISTEMA RTK/PPK: Economia na operação e precisão nos resultados. Disponível em: https://horusaeronaves.com/ebooks/. Acesso em 09 de fev. 2019. 
IBGE - INSTITUTO BRASILEIRO DE GEOGRAFIA E ESTATÍ́STICA. IBEG_Pergutas Frequentes. Disponível em:

https://ww2.ibge.gov.br/home/geociencias/geodesia/pmrg/faq.shtm. Acesso em: 10 abr. 2019.

MINISTÉRIO DA INFRAESTRUTURA. Drone Legal : Regras Vigentes. Disponível em: http://transportes.gov.br/component/content/article/108-paginastematicas-aviacao/6451-regras-vigentes.html. Acesso em: 1 maio. 2019.

INPE. Introdução ao Sensoriamento Remoto. Disponível em:

http://www3.inpe.br/unidades/cep/atividadescep/educasere/apostila.htm. Acesso em: 1 ago. 2019.

IPEA. Desafios da Nação. Brasília, DF: Ministério do Planejamento, Desenvolvimento e Gestão, 2018. v. 2

IZUMIDA, A.; UCHIYAMA, S.; SUGAI, T. Application of UAV-SfM photogrammetry and aerial lidar to a disastrous flood: Repeated topographic measurement of a newly formed crevasse splay of the Kinu River, central Japan. Natural Hazards and Earth System Sciences, v. 17, n. 9, p. 1505-1519, 2017.

KAEWUNRUEN, S.; LIAN, Q. Digital twin aided sustainability-based lifecycle management for railway turnout systems. Journal of Cleaner Production, v. 228, p. 1537-1551, 2019.

KANG, T. W.; HONG, C. H. A study on software architecture for effective BIM/GISbased facility management data integration. Automation in Construction, v. 54, p. 25-38, 2015.

KOEVA, M.; MUNEZA, M.; GEVAERT, C.; GERKE, M.; NEX, F. Using UAVs for map creation and updating. A case study in Rwanda. Survey Review, v. 50, n. 361, p. 312-325, 2018.

LINDER, W. Digital photogrammetry. A practical course. $1^{\text {a }}$ ed. Berlin. Germany: Springer-Verlag Berlin Heidelberg, 2006.

LIU, P.; CHEN, A. Y.; HUANG, Y.-N.; HAN, J.-Y.; LAI, J.-S.; KANG, S.-C.; WU, T.-H.; WEN, M.-C.; TSAI, M.-H. A review of rotorcraft Unmanned Aerial Vehicle (UAV) developments and applications in civil engineering. Smart Structures and Systems, v. 13, n. 6, p. 1065-1094, 2014.

LIU, X.; WANG, X.; WRIGHT, G.; CHENG, J.; LI, X.; LIU, R. A State-of-the-Art Review on the Integration of Building Information Modeling (BIM) and Geographic Information System (GIS). ISPRS International Journal of GeoInformation, v. 6, n. 2, p. 53, 2017.

LU, R.; BRILAKIS, I. Digital twinning of existing reinforced concrete bridges from labelled point clusters. Automation in Construction, v. 105, n. May, p. 102837, 2019. 
LUCIEN, M. Home of Drones. ETH Zurich, 2018. Disponível em:

https://www.ethz.ch/en/news-and-events/eth-news/news/2018/06/home-ofdrones.html. Acesso em: 11 jun. 2019.

MAINARDI NETO, A. I. Verificação de regras para aprovação de projetos de arquitetura em BIM para estações de metrô. A.I Mainardi Neto -- versão corr. -São Paulo, 2016. 124 p. Dissertação (Mestrado) - Escola Politécnica da Universidade de São Paulo. Departamento de Engenharia Civil, 2016.

MARTÍNEZ-CARRICONDO, P.; AGÜERA-VEGA, F.; CARVAJAL-RAMÍREZ, F.; MESAS-CARRASCOSA, F. J.; GARCÍA-FERRER, A.; PÉREZ-PORRAS, F. J. Assessment of UAV-photogrammetric mapping accuracy based on variation of ground control points. International Journal of Applied Earth Observation and Geoinformation, v. 72, n. February, p. 1-10, 2018.

MARZOUK, M.; ABDEL ATY, A.. Maintaining subways infrastructures using BIM. In: Construction Research Congress 2012: Construction Challenges in a Flat World, Proceedings of the 2012. https://doi.org/10.1061/9780784412329.233. Anais...2012.

MASCARÓ, J. L.; YOSHINAGA, M. Infra-Estrutura Urbana. Porto Alegre: Masquatro Editora, 2005.

MCGRAWHILL. The Business Value of BIM for Construction in Major Global Markets: How Contractors Around the World Are Driving Innovation With Building Information Modeling SmartMarket Report Executive Editor. Bedford, MA: Disponível em: www.construction.com. Acesso em: 15 nov 2018.

MCKINSEY GLOBAL INSTITUTE. Reinventing Construction: A Route To Higher Productivity. McKinsey \& Company, p. 20, 2017.

MDIC. BIM no Brasil e na União europeia. Diálogos setoriais para BIM Ministério da Indústria, Comércio Exterior e Serviços. 2015.

Estratégia Nacional de Disseminação do Building Information Modelling BIM. Brasília, DF. Ministério da Indústria, Comércio Exterior e Serviços, 2018 Disponível em: http://www.mdic.gov.br/images/REPOSITORIO/sdci/CGMO/2611-2018-estrategia-BIM-BR-2.pdf.

MELO, R. R. S. DE; COSTA, D. B.; ÁLVARES, J. S.; IRIZARRY, J. Applicability of unmanned aerial system (UAS) for safety inspection on construction sites. Safety Science, v. 98, p. 174-185, 2017.

NETO, M. S. Para que serve o GSD? Disponível em:

blog.droneng.com.br/fotogrametria-com-drones/. Acesso em: 1 set. 2019.

NEX, F.; REMONDINO, F. UAV for 3D mapping applications: A review. Applied Geomatics, v. 6, n. 1, p. 1-15, 2014. 
OLAYA, V. Sistemas de Información Geográfica. Journal of Chemical Information and Modeling, v. 53, n. 9, p. 1689-1699, 2014.

OLIVEIRA, R.; FABRÍCIO, M. Modelagem paramétrica de edifícios do campus da USP São Carlos: documentação e manutenção. 26 SEMINÁRIO

INTERNACIONAL DE INICIAÇÃO CIENTÍFICA E TECNOLÓGICA DA USP. Caderno de Resumos da Primeira Etapa do Instituto de Arquitetura e Urbanismo de São Carlos. Anais...São Carlos/SP: 2018

ONU. Transformando Nosso Mundo: A Agenda 2030 para o Desenvolvimento Sustentável(A/70/L.1)Rio de Janeiro-RJRio+20. Conferência das Nações Unidas sobre Desenvolvimento Sustentável, , 2015. Disponível em:

http://www.un.org/ga/search/view_doc.asp?symbol=A/RES/70/1\&Lang=E.

OSELLO, A.; RAPETTI, N.; SEMERARO, F. BIM Methodology Approach to Infrastructure Design: Case Study of Paniga Tunnel. IOP Conference Series:

Materials Science and Engineering, v. 245, n. 6, 2017.

PARANÁ, G. DO E. DO. Caderno BIM: coletânea de cadernos orientadores e caderno de especificações técnicas para contratação de projetos em BIM. Curitiba, 2018.

PARROTT, A.; WARSHAW, L. Industry 4.0 and the digital twin. Deloitte University Press, p. 1-17, 2017.

PIX4D. Getting GCPs on the field or through other sources (optional but recommended) - Support. Disponível em: https://support.pix4d.com/hc/enus/articles/202557489\#gsc.tab=0. Acesso em: 1 jun. 2019. 2019.

PIX 4D Features. Disponível em: <www.pix4d.com>. Acesso em: 10 ago.

RADÜNS, C. D. BIM APLICADO A OBRAS DE INFRAESTRUTURA (BiiM): MINI E PEQUENAS CENTRAIS HIDRELÉTRICAS. 119 p. Passo Fundo, 2013. Dissertação (Mestrado) - Faculdade de Engenharia e Arquitetura da Universidade Passo Fundo, 2013.

RAKHA, T.; GORODETSKY, A. Review of Unmanned Aerial System (UAS) applications in the built environment: Towards automated building inspection procedures using drones. Automation in Construction, v. 93, n. January, p. 252264, 2018a.

Review of Unmanned Aerial System (UAS) applications in the built environment: Towards automated building inspection procedures using drones. Automation in Construction, v. 93, n. March, p. 252-264, 2018 b.

REMONDINO, F.; BARAZZETTI, L.; NEX, F.; SCAIONI, M.; SARAZZI, D. Uav Photogrammetry for Mapping and 3D Modeling - Current Status and Future Perspectives -. International Archives of the Photogrammetry, v. XXXVIII, n. September, p. 14-16, 2011. 
RURAL, G. 40 \% das aeronaves não tripuladas no Brasil são usadas no agronegócio. Disponível em:

https://revistagloborural.globo.com/Noticias/Pesquisa-e-

Tecnologia/noticia/2018/09/40-das-aeronaves-nao-tripuladas-no-brasil-saousadas-no-agronegocio.html. Acesso em: 11 jun. 2019.

RUZGIENE, B.; BERTEŠKA, T.; GEČYTE, S.; JAKUBAUSKIENE, E.; AKSAMITAUSKAS, V. Č. The surface modelling based on UAV Photogrammetry and qualitative estimation. Measurement: Journal of the International Measurement Confederation, v. 73, n. 9+, p. 619-627, 2015.

SANDKUHL, K.; SHILOV, N. Facilitating Digital Transformation by Multi-Aspect Ontologies: Approach and Application Steps. Proceedings of 9th IFAC Conference on Manufacturing Modelling, Management and Control, v. 52, n. 13, p. 1701-1706, 2019.

SECRETARIA DE INFRAESTRUTURA E LOGÍSTICA DEPARTAMENTO DE GESTÃO DE PROJETOS E OBRAS. Caderno BIM. p. 136, 2018.

SEF. Projeto de execução de infraestrutura e pavimentação da rua 11 e do acesso sul do campus 2 - USP. São Carlos, SP. SEF - SUPERINTENDÊNCIA DO ESPAÇO FÍSICO DA UNIVERSIDADE DE SÃO PAULO, 2016.

SEO, J.; DUQUE, L.; WACKER, J. Drone-enabled bridge inspection methodology and application. Automation in Construction, v. 94, n. May, p. 112-126, 2018.

SHAHROUR, I.; ALILECHE, L.; ALFURJANI, A. Smart cities: System and tools used for the digital modelling of physical urban systems. 2017 Sensors Networks Smart and Emerging Technologies, SENSET 2017, v. 2017- Janeiro, p. 1-4, 2017.

SHOLARIN E.A., AWANGE J.L. (2015) Photogrammetry. In: Environmental Project Management. Environmental Science and Engineering. Springer, Cham. 2015.

SIEBERT, S.; TEIZER, J. Mobile 3D mapping for surveying earthwork projects using an Unmanned Aerial Vehicle (UAV) system. Automation in Construction, v. 41, p. 1-14, 2014.

SINDUSCON-GO. Brasil precisa investir 4,7\% do PIB em infraestrutura para atingir média global. Disponível em:

https://www.sinduscongoias.com.br/index.php/en/produtos-eservicos/noticias/1455-brasil-precisa-investir-4-7-do-pib-em-infraestruturapara-atingir-media-global. Acesso em: 20 ago. 2019.

SKYDRONES. Quantix. Disponível em: https://skydrones.com.br/quantix/. Acesso em: 3 abr. 2019.

STÖCKER, C.; NEX, F.; KOEVA, M.; GERKE, M. Quality assessment of combined IMU/GNSS data for direct georeferencing in the context of UAV-based mapping. International Archives of the Photogrammetry, Remote Sensing and Spatial Information Sciences - ISPRS Archives, v. 42, n. 2W6, p. 355-361, 2017. 
STOJANOVSKI, T. City information modeling (CIM) and urbanism: blocks, connections, territories, people and situations. In: SimAUD 2013, Symposium on Simulation for Architecture and Urban Design, San Diego. Anais [...]. Society for Computer Simulation International. 2013.

SUCCAR, B. Building information modelling framework: A research and delivery foundation for industry stakeholders. Automation in Construction, v. 18, n. 3, p. 357-375, 2009.

SUCCAR, B.; KASSEM, M. Macro-BIM adoption: Conceptual structures. Automation in Construction, v. 57, p. 64-79, 2015.

SUCHOCKI, M. BIM for Infrastructure: integrating spatial and model data for more efficient contextual planning, design, construction and operation. In: MAHDJOUBI, L.; BREBBIA, C.A.; LAING, R. (org). Building Information Modelling (BIM) in Design, Construction and Operations. Disponível em: http://library. witpress.com/viewpaper.asp?pcode=BIM15-026-1. p 305-315, 2015.

SWISS INFO. Welcome to the Drone Age. Disponível em: https://www.swissinfo.ch/eng/swiss-innovation_welcome-to-the-dronevalley/44375836. Acesso em: 11 jun. 2019.

TANG, L.; SHAO, G. Drone remote sensing for forestry research and practices. Journal of Forestry Research, v. 26, n. 4, p. 791-797, 2015.

THOMPSON, E. M.; GREENHALGH, P.; MULDOON-SMITH, K.; CHARLTON, J.; DOLNÍK, M. Planners in the Future City: Using City Information Modelling to Support Planners as Market Actors. Urban Planning, v. 1, n. 1, p. 79, 2016.

TOLMER, C. E.; CASTAING, C.; DIAB, Y.; MORAND, D. Adapting LOD definition to meet BIM uses requirements and data modeling for linear infrastructures projects: using system and requirement engineering. Visualization in Engineering, v. 5, n. 1, 2017.

TRATABRASIL, I. Principais estatísticas de Saneamento no Brasil. Disponível em: http://www.tratabrasil.org.br/saneamento/principais-estatisticas. Acesso em: 15 ago. 2019.

VOLK, R.; STENGEL, J.; SCHULTMANN, F. Building Information Modeling (BIM) for existing buildings - Literature review and future needs. Automation in Construction, v. 38, p. 109-127, 2014.

WANG, X.; JIANG, P.; LI, D.; SUN, T. Curvature continuous and bounded path planning for fixed-wing UAV. Sensors. Switzerland, 2017.

WAYNE, R. Image Processing and Analysis. Light and Video Microscopy, p. 255269, 2014. 
WILKE, J. A drone program taking flight Amazon Prime Air ' s New Delivery

Drone. Disponível em: https://blog.aboutamazon.com/transportation/a-droneprogram-taking-flight. Acesso em: 11 jun. 2019.

WING; GOOGLE. Wing: Transforming the Way Goods are Transported. Disponível em: https://x.company/projects/wing/.

WINGTRA. White Paper_Reaching $1 \mathrm{~cm}$ drone survey accuracy. Zurich, Switzerland: [s.n.]. Disponível em: https://wingtra.com. Acesso em: 1 jun. 2019.

WOETZEL, J.; RAJADHYAKSHA, V.; FREM, J. Thriving amid turbulence: Imagining the cities of the future. [s.l: s.n.]. Disponível em:

https://www.mckinsey.com/industries/public-sector/our-insights/thrivingamid-turbulence-imagining-the-cities-of-the-future.

ZEYBEK, M.; SANLIOĞLU, I. Point cloud filtering on UAV based point cloud.

Measurement: Journal of the International Measurement Confederation, v. 133, p. 99-111, 2019.

ZHANG, D. Guide to PPK and RTK. Disponível em:

https://www.identifiedtech.com/resources/download-ultimate-guide-rtkppk/?submissionGuid=bf1 ae07d-4ff1-493c-b95a-2c6ed92a1253. Acesso em: 12 abr. 2019.

ZHOU, S.; GHEISARI, M. Unmanned aerial system applications in construction: a systematic review. Construction Innovation, v. 18, n. 4, p. 453-468, 2018.

ZHU, J.; WRIGHT, G.; WANG, J.; WANG, X. A Critical Review of the Integration of Geographic Information System and Building Information Modelling at the Data Level. ISPRS International Journal of Geo-Information, v. 7, n. 2, p. 66, 2018.

ZIMMERMANN, A.; JUGEL, D.; SANDKUHL, K.; SCHMIDT, R.; SCHWEDA, C.; MÖHRING, M. Architectural Decision Management for Digital Transformation of Products and Services. Complex Systems Informatics and Modeling Quarterly, $\mathrm{n}$. 6, p. 31-53, 2016.

ZLATANOVA, S.; BEETZ, J. 3D spatial information infrastructure: The case of Port Rotterdam. 3U3D - Usage, Usability, and Utility of 3D City Models, 2012.

ZOU, P. X. W.; WANG, S.; FANG, D. A life-cycle risk management framework for PPP infrastructure projects. Journal of Financial Management of Property and Construction, v. 13, n. 2, p. 123-142, 2008. 


\section{ANEXO I - CHECKLIST DE V0O}
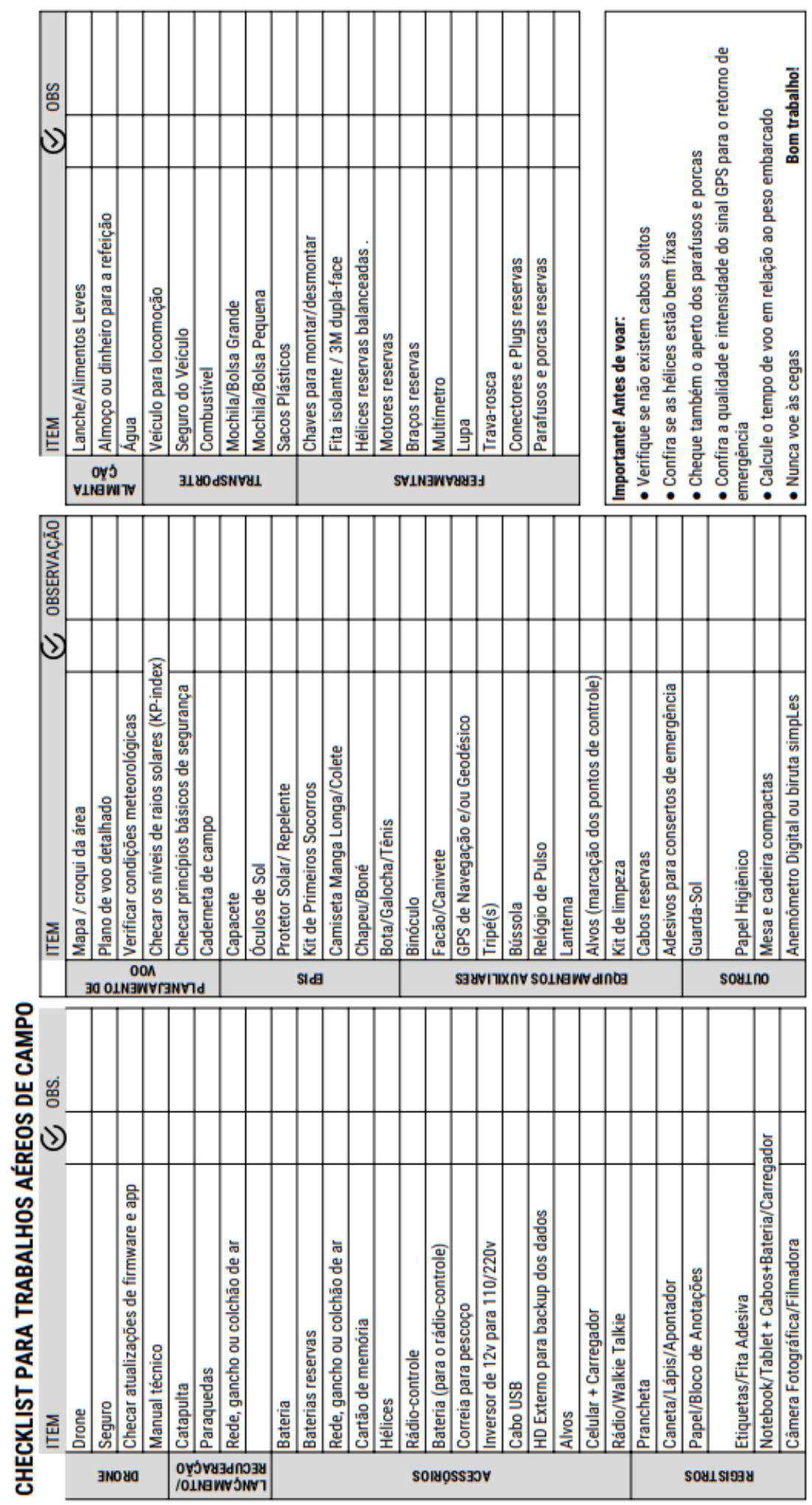


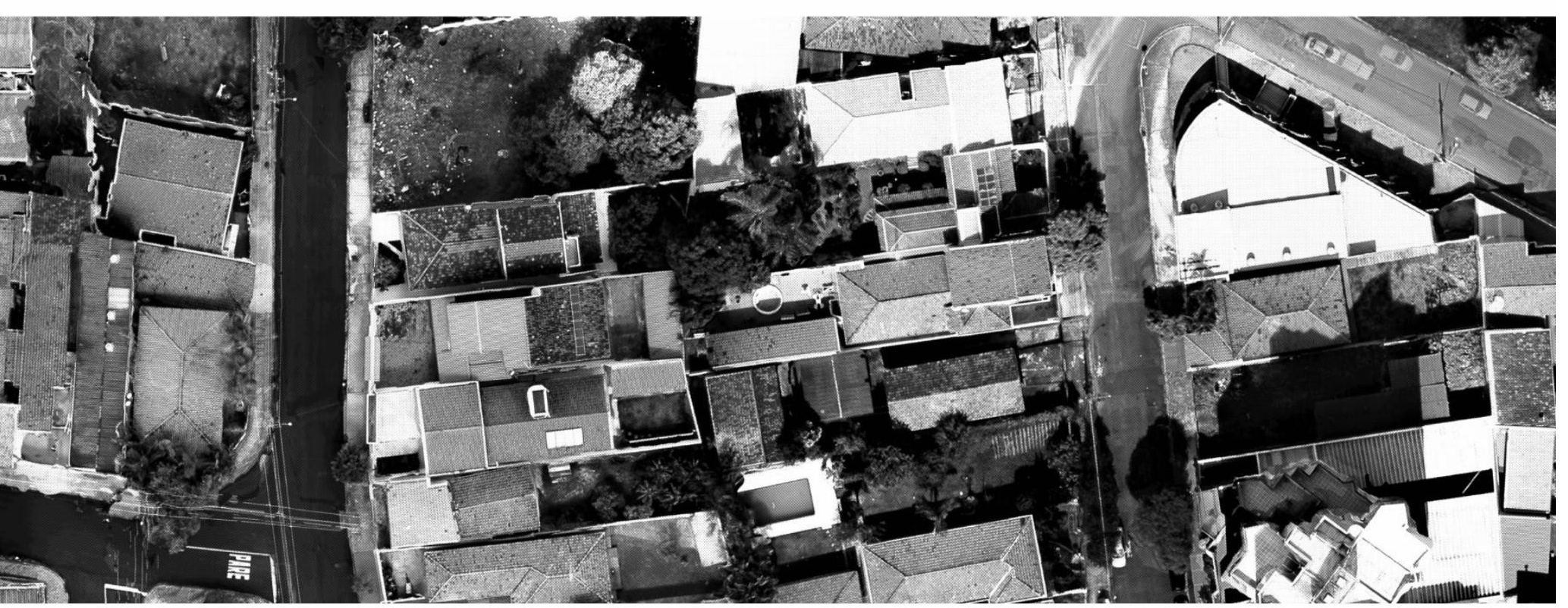

